\title{
AEROSOL-PRECIPITATION INTERACTIONS IN THE SOUTHERN APPALACHIAN MOUNTAINS
}

\author{
A Thesis \\ by \\ GINGER MARIE KELLY
}

\begin{abstract}
Submitted to the Graduate School
Appalachian State University

in partial fulfillment of the requirements for the degree of

MASTER OF ARTS
\end{abstract}

May 2011

Department of Geography and Planning 


\section{AEROSOL-PRECIPITATION INTERACTIONS IN THE SOUTHERN APPALACHIAN MOUNTAINS}

A Thesis

by

GINGER MARIE KELLY

May 2011

\section{APPROVED BY:}

L. Baker Perry

Chairperson, Thesis Committee

Brett F. Taubman

Member, Thesis Committee

Peter T. Soulé

Member, Thesis Committee

James E. Young

Chairperson, Department of Geography and Planning

Edelma D. Huntley

Dean, Research and Graduate Studies 
Copyright by Ginger Marie Kelly 2011

All Rights Reserved 


\begin{abstract}
AEROSOL-PRECIPITATION INTERACTIONS IN THE SOUTHERN APPALACHIAN MOUNTAINS. (May 2011)

Ginger Marie Kelly, B.S., University of North Carolina at Chapel Hill

$$
\begin{aligned}
& \text { M.A., Appalachian State University } \\
& \text { Chairperson: L. Baker Perry }
\end{aligned}
$$

Aerosols directly and indirectly influence the surface energy balance and therefore have an important impact on weather and climate. The indirect effects of aerosols, associated with changes in cloud properties and lifetimes, remain poorly understood. Likewise, there are many uncertainties associated with aerosol-precipitation interactions, particularly in mountain regions where a variety of processes at different spatial scales influence precipitation patterns. Aerosol-precipitation linkages were examined in the southern Appalachian Mountains, guided by the following research questions: 1) How do aerosol properties observed during precipitation events vary by season (e.g., summer vs. winter) and synoptic event type (e.g., frontal vs. orographic); 2) how do they compare between summer (June, July, August) 2009 and 2010, and 3) what influence does air mass source region have on aerosol properties? Precipitation events were identified based on data from the Boone Automated Weather Observing System Station, Boone Environmental and Climate Observing Network station, regional National Weather Service cooperative observer
\end{abstract}


stations, and observations from the Community Collaborative Rain, Hail, and Snow network. Events were classified using a synoptic classification scheme created for this thesis. Hourly aerosol data were collected by the Appalachian Atmospheric Interdisciplinary Research facility at Appalachian State University. Backward air trajectories provided information on upstream atmospheric characteristics and source regions.

Warm season precipitation events were characterized by much higher aerosol optical properties, including both natural and anthropogenic aerosols. The presence of larger, hygroscopic organic particles acting as effective cloud condensation nuclei enhanced warm season precipitation. Cool season precipitation events exhibited overall lower aerosol optical properties dominated my small organic particles. The change in aerosol values from event beginning to event maturation suggests that AppalAIR is impacted by hygroscopic particles from regional sources including local biogenic emissions and biomass burning.

The methodology employed in this thesis will be useful in aerosol-precipitation studies in other mountainous regions. The synoptic classification scheme created for this thesis characterized precipitation events in the southern Appalachian Mountains and will be important to climate researchers and weather forecasters in understanding orographic processes of precipitation. Aerosol properties associated with precipitation events were investigated and described in terms of seasonal and synoptic patterns. These findings will contribute to the parameterization of aerosols in weather and climate models and will enhance our understanding of future climate change in the southern Appalachian Mountains and other mountainous regions. 


\section{ACKNOWLEDGEMENTS}

Many thanks are due to a number of individuals whose assistance was instrumental in the completion of this thesis. Dr. L. Baker Perry, Dr. Brett F. Taubman, and Dr. Peter T. Soulé provided guidance in the design of this research project and valued advice and encouragement in its completion. Dr. James P. Sherman, Patrick Sheridan, and Dr. Charles Konrad provided technical advice and insight.

The Graduate Research Associate Mentor (GRAM) program was very supportive during my graduate career and in my research endeavors. I am very grateful for funding from the ASU Office of Student Research for equipment and travel expenses related to local and international research. Many thanks to the Cratis D. Williams Graduate School and Ronald and Kathie Zigli for a research award to pursue local atmospheric studies.

I would also like to gratefully acknowledge the following data sources: the NOAA Air Resources Laboratory (ARL) for the provision of the HYSPLIT transport and dispersion model used in this publication; the volunteer precipitation observers in the Community Collaborative Rain, Hail, and Snow network and the National Weather Service Cooperative Observer network for daily precipitation totals; Beech Mountain resort for supporting the BEECHTOP meteorological station; and the State Climate Office of North Carolina for supporting the Climate Retrieval and Observations Network of the Southeast database.

Lastly, I would like to acknowledge my dear family and many friends for their unwavering support and love during this process and always. 


\section{TABLE OF CONTENTS}

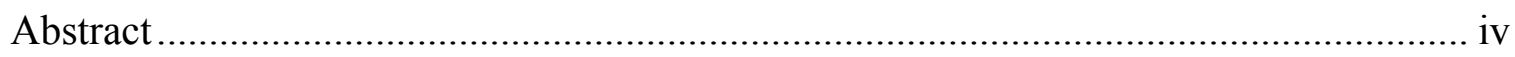

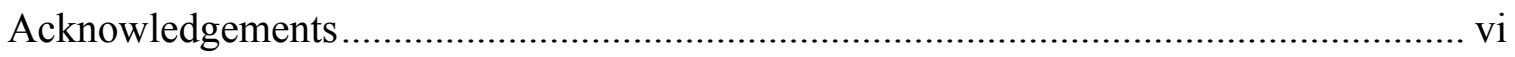

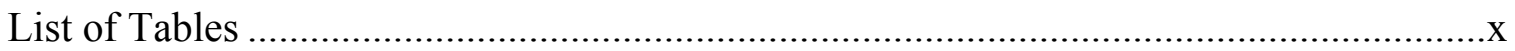

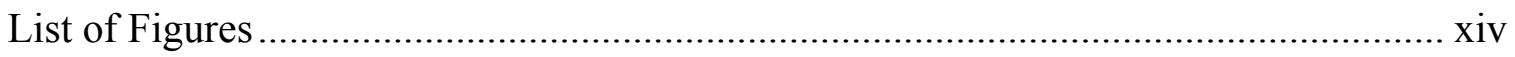

Chapter I: Introduction and Background .....................................................................

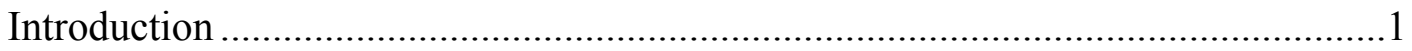

Surface Energy Balance..........................................................................

Climate Change in the Southeastern United States ...........................................

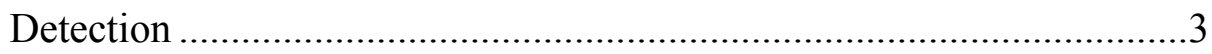

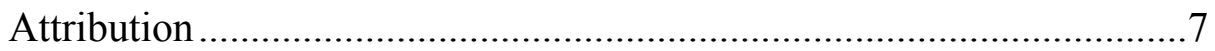

Uncertainties Related to Aerosols .................................................................10

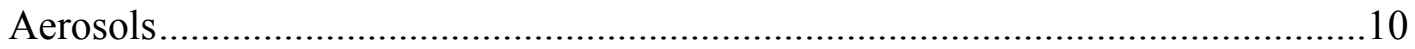

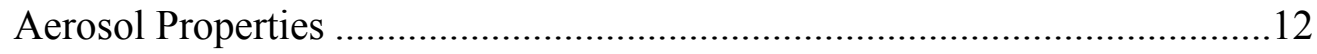

Synoptic Influences on Aerosols ................................................................17

Aerosol Loading and Source Apportionment ………………….............18

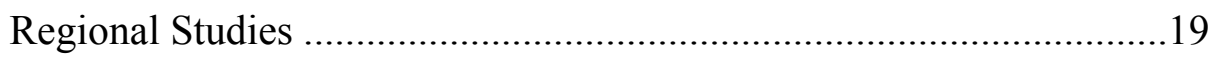

Atmospheric Processes of Precipitation Development …….....................................21

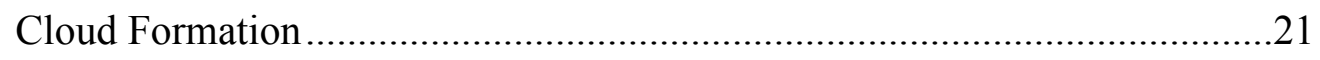

Precipitation Formation ………………....................................................2 
Collision and Coalescence

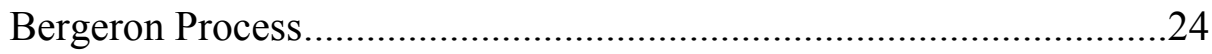

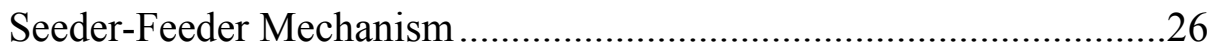

Orographic Precipitation.............................................................................2

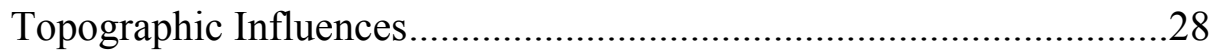

Atmospheric Influences .................................................................29

Synoptic Influences on Precipitation ............................................................31

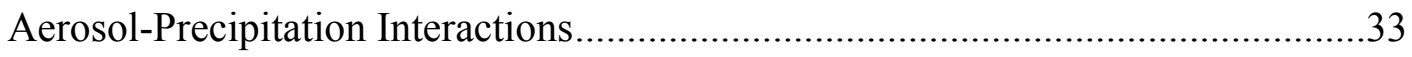

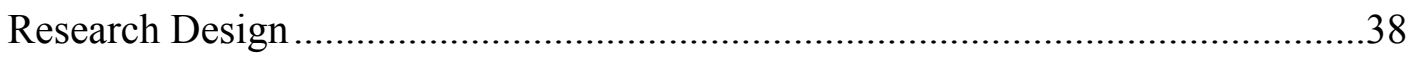

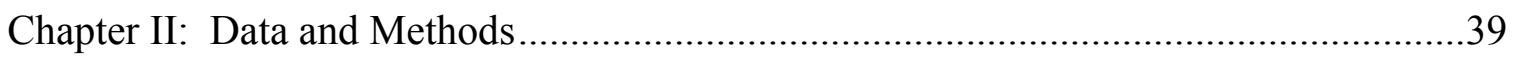

Precipitation Data and Event Identification ............................................................4

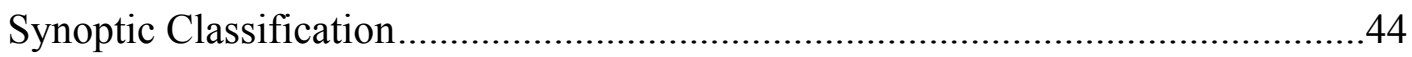

Meteorological Data ................................................................................................

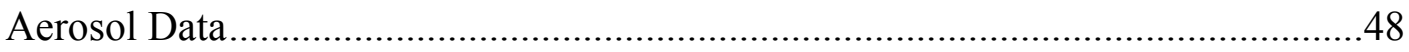

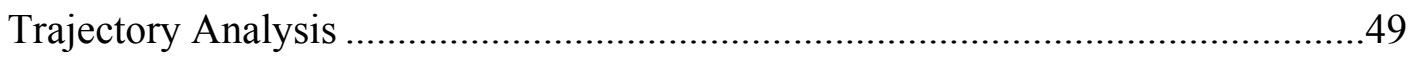

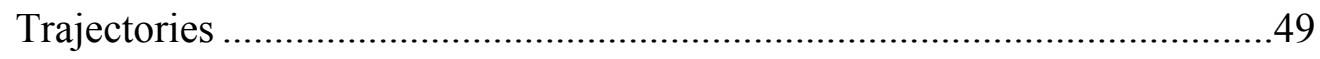

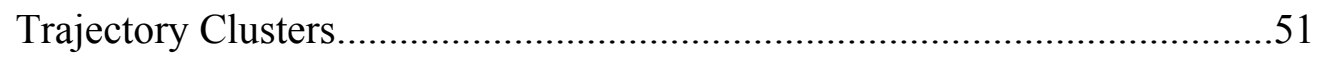

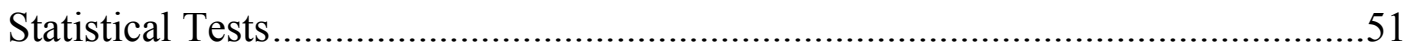

Chapter III: Results and Discussion...........................................................................53

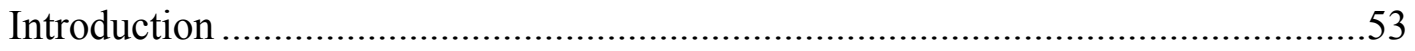

Anomalous Study Period in the SAM .................................................................54

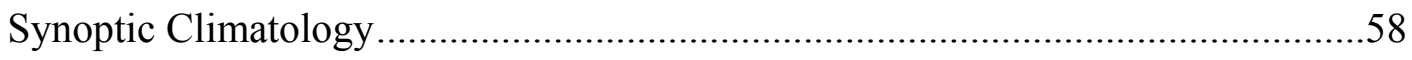

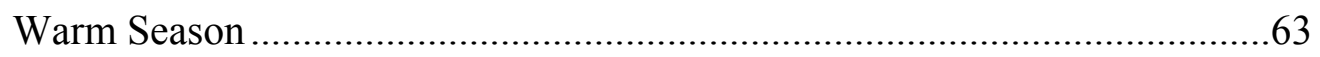

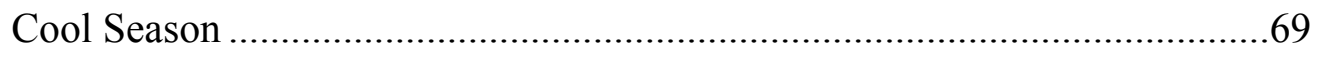

viii 
Aerosol Climatology

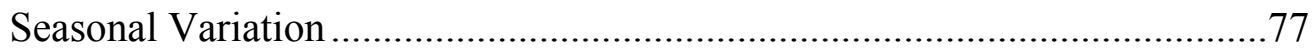

Warm Season vs. Cool Season: All Event Types .............................77

Warm Season vs. Cool Season: Frontal Precipitation Events..............90

Warm Season vs. Cool Season: Non-frontal Precipitation Events .....101

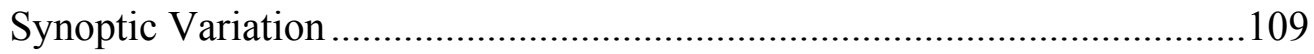

Warm Season: Frontal vs. Non-frontal ........................................109

Cool Season: Frontal vs. Non-frontal .........................................112

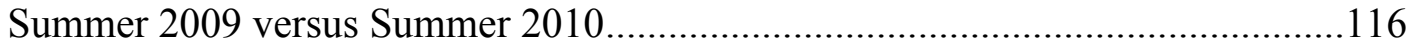

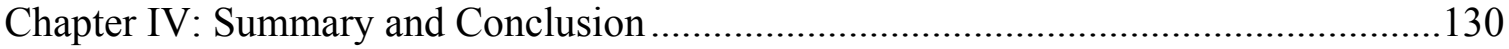

Precipitation Event Classification .................................................................... 131

Seasonal and Synoptic Variation in Aerosols ...............................................131

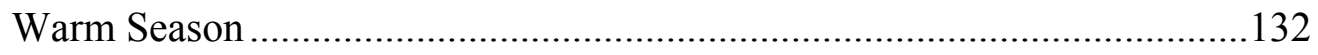

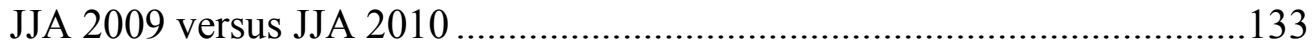

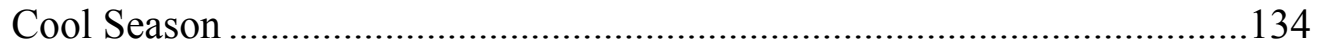

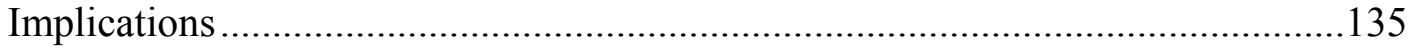

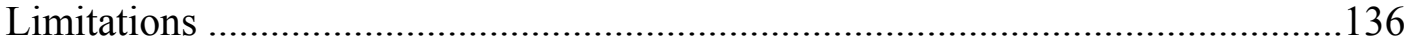

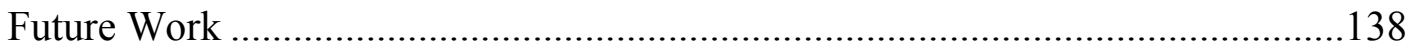

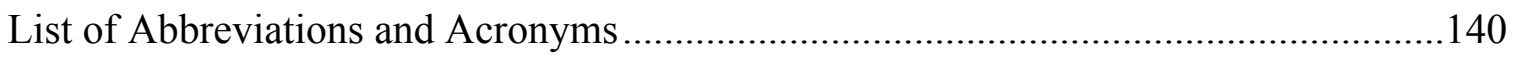

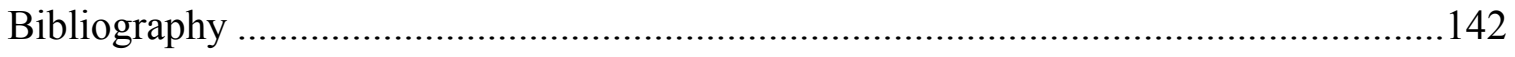

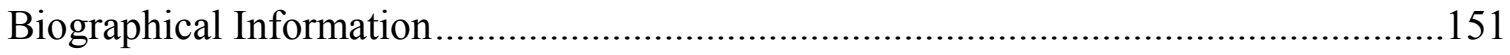




\section{LIST OF TABLES}

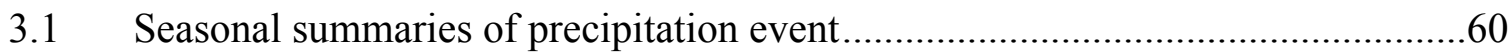

3.2 Summary of warm season precipitation event types...........................................67

3.3 Summary of cool season precipitation event types............................................74

3.4 Summaries of the meteorological characteristics and aerosol properties of each cluster representing all warm season events...

3.5 Summaries of the meteorological characteristics and aerosol properties of each cluster representing all cool season events

3.6 Mean meteorological and aerosol values and differences at beginning and maturation for all warm season events versus all cool season events

3.7 Differences from beginning to maturation for all warm season events versus all cool season events. . .86

3.8 Mean meteorological and aerosol values and differences at beginning and maturation between light versus heavy warm season events .87

3.9 Differences from beginning to maturation for all light versus heavy warm season events .88

3.10 Mean meteorological and aerosol values and differences at beginning and maturation between light versus heavy cool season events

3.11 Differences from beginning to maturation for all light versus heavy cool season events .90

3.12 Summaries of the meteorological characteristics and aerosol properties of each cluster representing all warm season frontal precipitation events 
3.13 Summaries of the meteorological characteristics and aerosol properties of each cluster representing all cool season frontal precipitation events .95

3.14 Mean meteorological and aerosol values and differences at beginning and maturation for all frontal precipitation events in the warm season versus the cool season .....96

3.15 Differences from beginning to maturation for warm season frontal versus cool season frontal precipitation events

3.16 Mean meteorological and aerosol values and differences at beginning and maturation between light versus heavy warm season frontal precipitation events .98

3.17 Differences from beginning and maturation in light versus heavy warm season frontal precipitation events

3.18 Mean meteorological and aerosol values and differences at beginning and maturation between light versus heavy cool season frontal precipitation events 100

3.19 Differences from beginning and maturation in light versus heavy cool season frontal precipitation events 101

3.20 Summaries of the meteorological characteristics and aerosol properties of each cluster representing all warm season non-frontal precipitation events. 104

3.21 Summaries of meteorological characteristics and aerosol properties of each backward air trajectory representing all cool season non-frontal precipitation events 104

3.22 Mean meteorological and aerosol values and differences at beginning and maturation for warm season versus cool season non-frontal precipitation events. 105

3.23 Differences from beginning to maturation for warm season non-frontal versus cool season non-frontal precipitation events 106 
3.24 Mean meteorological and aerosol values and differences at beginning and maturation between light versus heavy warm season non-frontal precipitation events 107

3.25 Differences from beginning and maturation in light versus heavy warm season nonfrontal precipitation events 108

3.26 Mean meteorological and aerosol values and differences at beginning and maturation for all warm season frontal and non-frontal precipitation events 110

3.27 Differences from beginning and maturation in warm season frontal versus non-frontal precipitation events

3.28 Mean precipitation $(\mathrm{mm})$ values associated with lower and upper quartile aerosol values during warm season frontal precipitation events

3.29 Mean precipitation $(\mathrm{mm})$ values associated with lower and upper quartile aerosol values during warm season non-frontal precipitation events

3.30 Mean meteorological and aerosol values and differences at beginning and maturation for all cool season frontal and non-frontal precipitation events 114

3.31 Differences from beginning and maturation in cool season frontal versus non-frontal precipitation events 115

3.32 Mean precipitation $(\mathrm{mm})$ values associated with lower and upper quartile aerosol values during cool season frontal precipitation events 115

3.33 Mean precipitation $(\mathrm{mm})$ values associated with lower and upper quartile aerosol values during cool season non-frontal precipitation events 116

3.34 Summary of JJA 2009 and JJA 2010 precipitation events 120

3.35 Summaries of the meteorological characteristics and aerosol properties of each cluster representing JJA 2009 precipitation events 122 
3.36 Summaries of the meteorological characteristics and aerosol properties of each cluster representing JJA 2010 precipitation events

3.37 Mean meteorological and aerosol values and differences at beginning and maturation for JJA 2009 vs. JJA 2010 123

3.38 Differences from event beginning and maturation during JJA 2009 vs. JJA 2010 events 124

3.39 Mean meteorological and aerosol values and differences at beginning and maturation for light versus heavy precipitation events during JJA 2009 125

3.40 Differences from event beginning to maturation during JJA 2009 light and heavy precipitation events 126

3.41 Mean meteorological and aerosol values and differences at beginning and maturation for light versus heavy precipitation events during JJA 2010

3.42 Differences from event beginning to maturation during JJA 2010 light and heavy precipitation events 128

3.43 Mean precipitation $(\mathrm{mm})$ values associated with lower and upper quartile aerosol values during JJA 2009 precipitation events 129

3.44 Mean precipitation $(\mathrm{mm})$ values associated with lower and upper quartile aerosol values during JJA 2010 precipitation events 129 


\section{LIST OF FIGURES}

1.1 Earth's surface energy balance ....................................................................

1.2 Annual global mean tempertures ................................................................4

1.3 Global annual temperatures from 1901 to 2005 and 1979 to 2005 .......................5

1.4 Observed changes in precipitation from 1901 to 2007 in the southeastern United

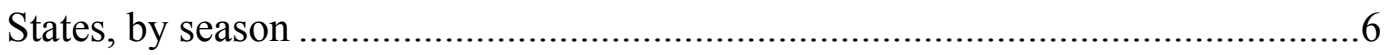

1.5 Annual snowfall trends for Boone, NC, 1929-2010 .........................................6

1.6 Ranges of estimated global average radiative forcing of anthropogenic mechanism, including spatial scale and level of scientific understanding ..............................

1.7 The direct and indirect effects of atmospheric aerosols...................................17

1.8 Seeder-Feeder mechanism of precipitation formation .................................27

1.9 Orographic uplift, cloud development, and the formation of a rain shadow ........28

1.10 The direct and indirect effects of aerosols on orographic precipitation.................37

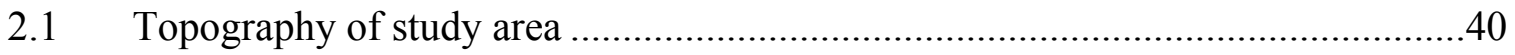

2.2 Top of sampling tower above trees at AppalAIR ..........................................40

2.3 Assignment of beginning, maturation, and ending hours during each precipitation

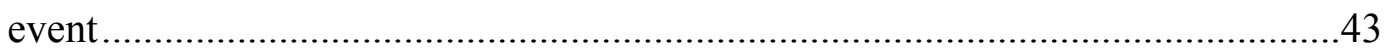

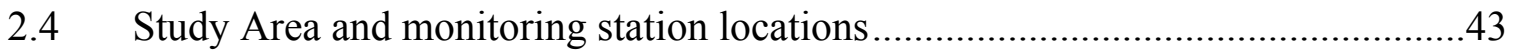

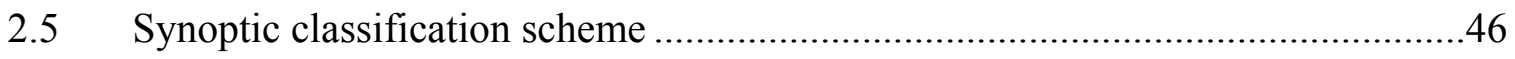

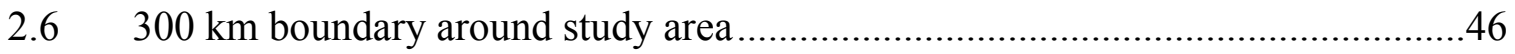

2.7 Meteorological instrumentation at BEECHTOP monitoring station ...................47

2.8 Location of BEECHTOP monitoring station ........................................... 48

2.9 Example of a 72-hr backward air trajectory created using HYSPLIT ..................50 
2.10 Example of a change in TSV plot for cluster analysis .....................................52

3.1 Temperature and precipitation departures during JJA 2009 ..............................56

3.2 $850 \mathrm{hPa}$ temperature and $500 \mathrm{hPa}$ height anomalies during JJA 2009 ................56

3.3 Observed daily high temperatures in Boone compared to climate normal for July 2009

3.4 Temperature and precipitation departures during DJF 2009-2010 _...................57

3.5 $850 \mathrm{hPa}$ temperature and $500 \mathrm{hPa}$ height anomalies during DJF 2009-2010 .......57

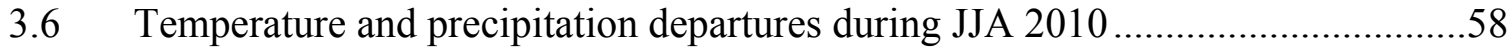

3.7 $850 \mathrm{hPa}$ temperature and $500 \mathrm{hPa}$ height anomalies during JJA $2010 \ldots \ldots \ldots \ldots \ldots . . . .58$

3.8 Composite plots of sea level pressure $(\mathrm{hPa})$ during maturation hour of each precipitation event during warm season and cool season .61

3.9 Composite plots of $500 \mathrm{hPa}$ pressure heights $(\mathrm{m})$ during maturation hour of each precipitation event during warm season and cool season .61

3.10 HYSPLIT cluster analysis of backward air trajectories representing maturation hour of each precipitation event during warm season and cool season

3.11 Example SRRS Analysis Charts representing warm season precipitation events, including cold front warm front, stationary front, and non-frontal event. .66

3.12 Composite plots of sea level pressure patterns and $500 \mathrm{hPa}$ geopotential heights during maturation hour of warm season precipitation event types .68

3.13 HYSPLIT cluster analysis of backward air trajectories representing maturation hour of each warm season precipitation event

3.14 Example SRRS Analysis Charts representing cool season events .73 
3.15 Surface and $500 \mathrm{hPa}$ geopotential height composite plots for cool season cold front, warm front, and occluded frontal precipitation events at maturation . .75

3.16 Surface and $500 \mathrm{hPa}$ geopotential height composite plots for cool season Gulf lows, Nor'easters, and non-frontal precipitation events at maturation 76

3.17 Backward air trajectories representing maturation hour of each cool season precipitation event.

3.18 HYSPLIT cluster analysis of backward air trajectories representing maturation hour of each precipitation event during warm season frontal and cool season frontal precipitation events

3.19 Composite plots of sea level pressure patterns during maturation hour of JJA 2009 and JJA 2010 precipitation events 120

3.20 Composite plots of $500 \mathrm{hPa}$ heights during maturation hour of JJA 2009 and JJA 2010 precipitation events 120

3.21 HYSPLIT cluster analysis of backward air trajectories representing maturation hour of each precipitation event during JJA 2009 and JJA 2010 events 


\section{Chapter I}

\section{INTRODUCTION AND BACKGROUND}

\section{Introduction}

Global climate is driven by natural and anthropogenic forces involving many complex interactions which limit the current scientific understanding of the climate system (Solomon et al. 2007). Among the greatest uncertainties in climate change research is the role of atmospheric aerosols. Aerosols directly and indirectly influence the surface energy balance and therefore have a large impact on weather and climate at different spatial scales. The indirect effects of aerosols, associated with changes in cloud properties and lifetimes, remain poorly understood. Likewise, there are many unknowns concerning aerosol-precipitation interactions. Long term climate trends in the southeastern United States (SEUS) and the southern Appalachian Mountains (SAM) have been modeled (Dai et al. 2004; Karoly and Wu 2005) and observed (Diem 2006; Konrad 1997; Bell et al. 2008; Wang et al. 2010) and can potentially be linked to changes in atmospheric circulation patterns and aerosol loading, with subsequent hydrological and ecological impacts.

\section{Surface Energy Balance}

Earth's climate variability is governed by the surface energy balance, in which incoming solar radiation (insolation) interacts with the atmosphere and surface features 
(Fig. 1.1). Roughly $30 \%$ of the insolation reaching the top of the atmosphere is scattered back into space by clouds and atmospheric particulate matter as well as by high-albedo surface features (Le Treut et al. 2007). Insolation that is not scattered is either absorbed or scattered by the atmosphere or the surface of the Earth. In order for the surface energy budget to stay balanced, the Earth must theoretically emit as much energy as it absorbs. Latent heat fluxes play an important role in this balance, as energy is exchanged from the surface to the atmosphere as water evaporates or is transpired and subsequently condenses to form clouds. Sensible heat fluxes also play an important role in which energy is emitted from the surface as long-wave thermal infrared (IR) radiation. This thermal IR radiation can become trapped by clouds or greenhouse gases (e.g., water vapor, carbon dioxide, methane, nitrous oxide, and ozone) and ultimately radiated back down to the surface resulting in a positive radiative forcing (RF), meaning there is more energy radiating down on the Earth over time (Le Treut et al. 2007). The greenhouse warming effect can be offset when aerosols inhibit insolation from reaching the surface of the earth by scattering or absorbing that energy (Goldstein et al. 2009). By influencing the surface energy balance, increased aerosol loading can influence atmospheric circulation, regional weather patterns, and ultimately result in changes in the local climate system (Twomey 1984; Albrecht 1989; Lohmann and Feichter 2005; Muhlbauer and Lohmann 2006). 


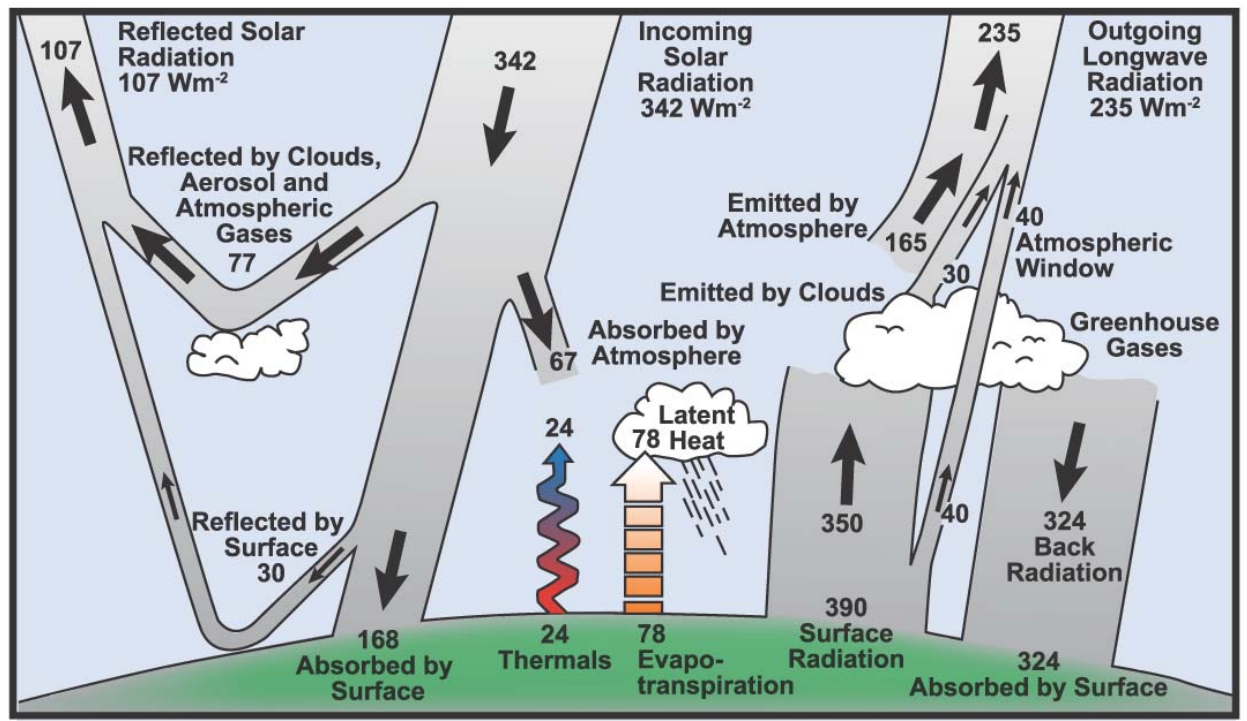

Figure 1.1. Earth's surface energy balance. Reprinted with permission. (Climate Change 2007: The Physical Science Basis. Working Group I Contribution to the Fourth Assessment Report of the Intergovernmental Panel on Climate Change, FAQ 1.1, Figure 1 (p. 96). Cambridge University Press.)

\section{Climate Change in the southeastern United States}

\section{Detection}

According to the Fourth Assessment Report (AR4) of the Intergovernmental Panel on Climate Change (IPCC), major regions of the globe have experienced significant overall warming within the past century and particularly within the last thirty years (Fig. 1.2). However, in the SEUS, an overall cooling trend was observed from 1901 to 2005, with a slight warming trend occurring since 1979 (Fig. 1.3) (Trenberth et al. 2007; Soulé 2011). Additionally, substantial increases in anomalously heavy precipitation events have been observed globally since 1950, including regions where overall average annual precipitation has decreased (Solomon et al. 2007). A similar effect has been observed in seasonal precipitation patterns in the SEUS within the last century (Fig. 1.4), wherein average fallseason precipitation has increased across the region by $30 \%$, while average precipitation in all other seasons has decreased by roughly 10\% (Karl et al. 2009). Wang et al. (2010) 
reported that within the last 30 years, annual summer rainfall in the SEUS has become characterized by highly variable periods of increased drought conditions and anomalous wetness strongly controlled by the westward extent of the Bermuda High.

In the SAM, changes in local weather patterns have been observed in recent decades as well. Winter precipitation totals have oscillated significantly in the SAM since 1929 (Fig. 1.5), with a slight decrease in past decades, potentially contributing to drought conditions in the region within the last decade. However, winter snowfall has increased in recent years. Under the influence of a warm-phase El Niño Southern Oscillation (ENSO) and highly anomalous negative phase of the Arctic Oscillation (AO), the 2009-2010 winter season was one of the coldest and wettest periods in the SAM on record and the most severe winter since the late 1970s.

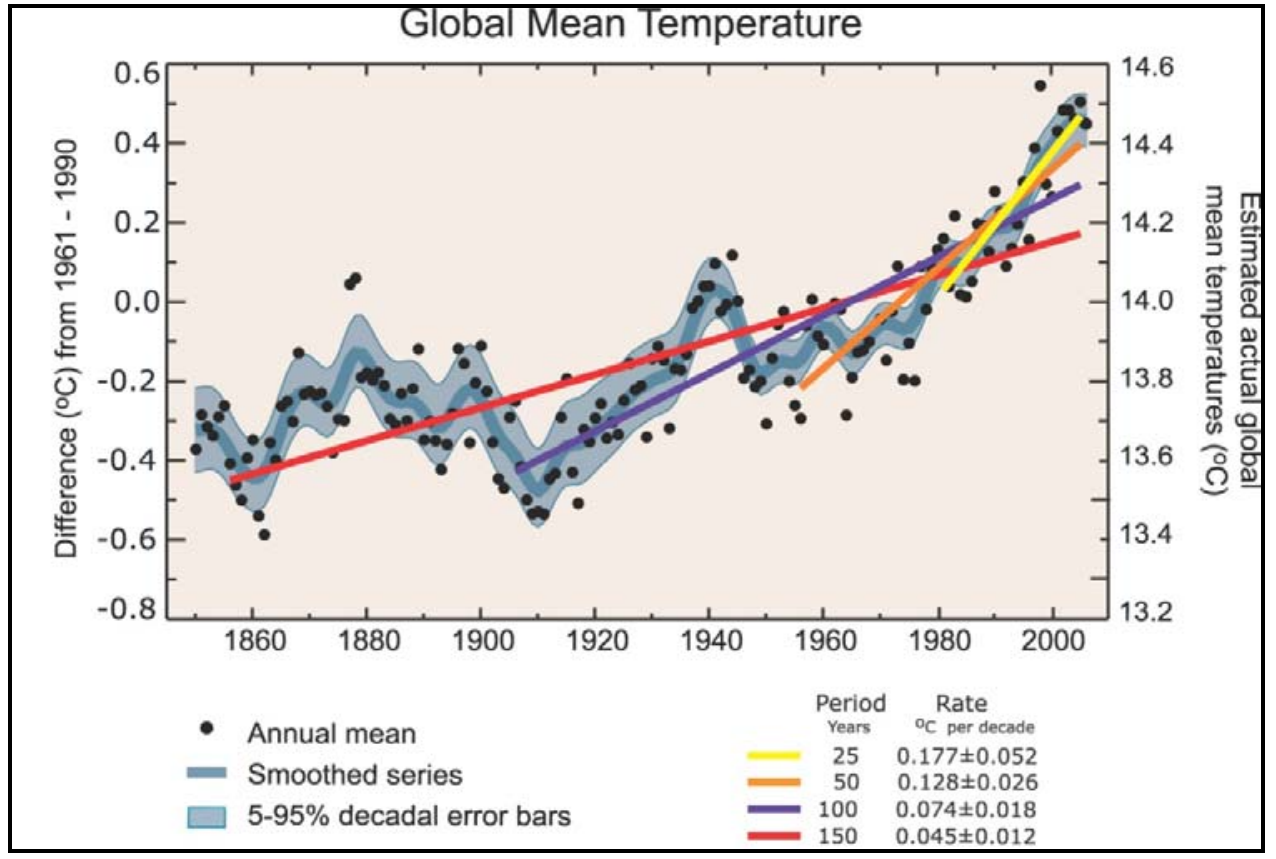

Figure 1.2. Annual global mean temperatures. Left axis shows temperature anomalies related to the 1961 to 1990 average and the right axis shows estimated actual temperatures $\left({ }^{\circ} \mathrm{C}\right)$. Linear trends are shown for the last 150 years (red), 100 years (purple), 50 years (orange), and 25 years (yellow). Decadal variations with $90 \%$ error range are in blue. Reprinted with permission. (Climate Change 2007: The Physical Science Basis. Working Group I Contribution to the Fourth Assessment Report of the Intergovernmental Panel on Climate Change, FAQ 3.1, Figure 1 (p. 253). Cambridge University Press.) 

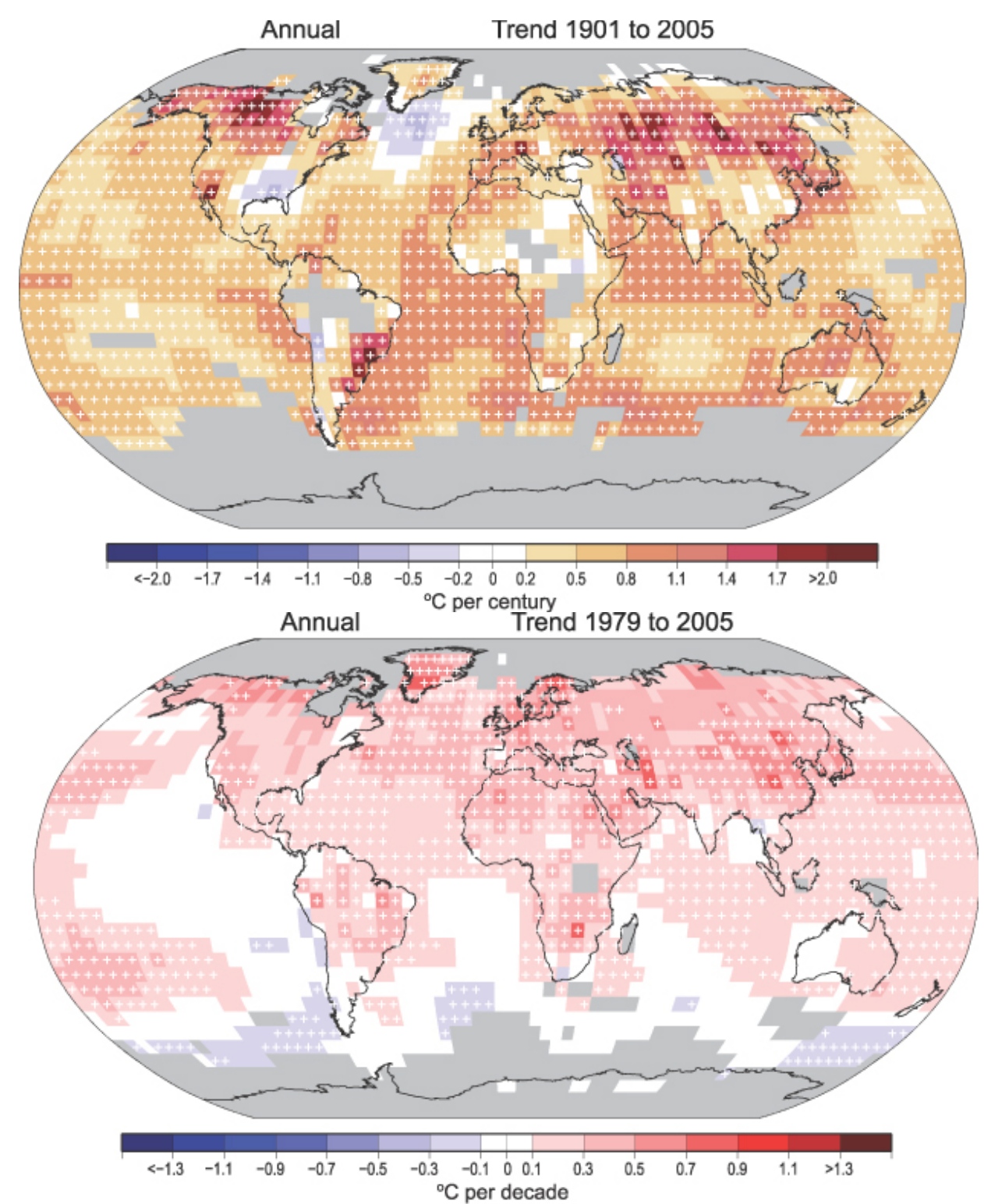

Figure 1.3. Global annual temperatures from 1901 to 2005 (top; ${ }^{\circ} \mathrm{C}$ per century) and 1979 to 2005 (bottom; ${ }^{\circ} \mathrm{C}$ per decade). Areas in grey have insufficient data to produce reliable trends. Reprinted with permission. (Climate Change 2007: The Physical Science Basis. Working Group I Contribution to the Fourth Assessment Report of the Intergovernmental Panel on Climate Change, Figure 3.9 (p. 250). Cambridge University Press.) 


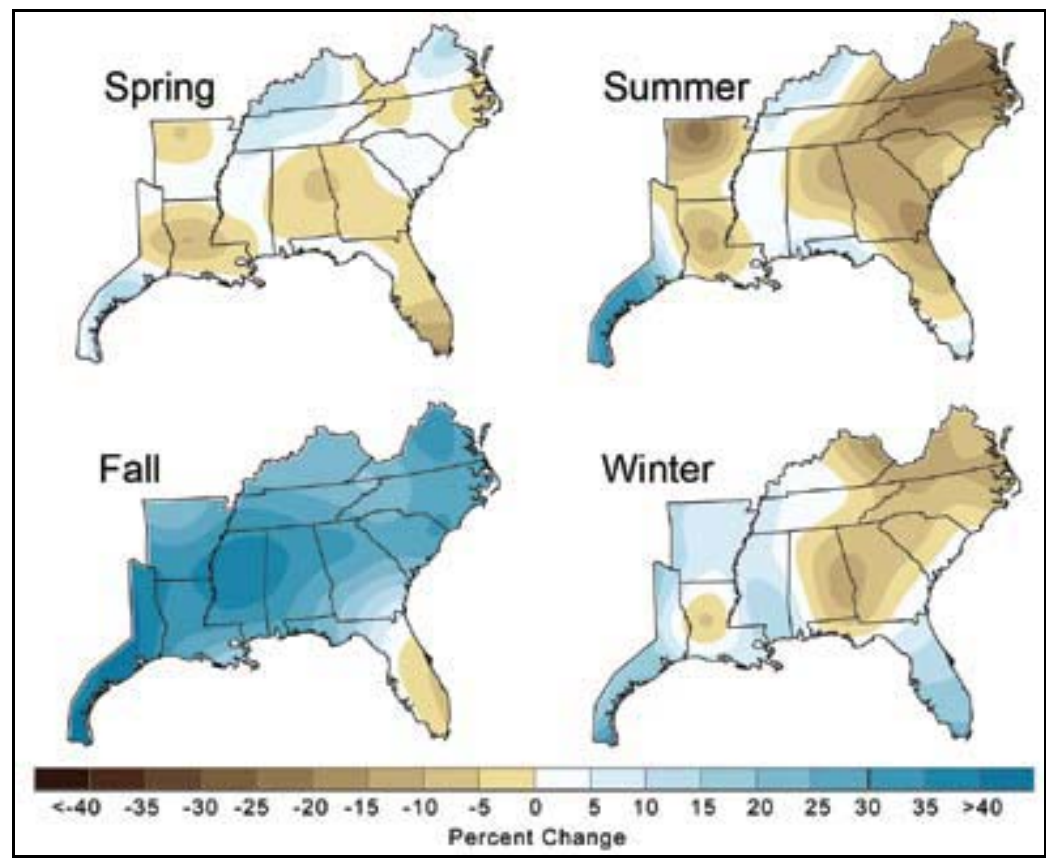

Figure 1.4. Observed changes in precipitation from 1901 to 2007 in the southeastern United States, by season (Karl et al. 2009).

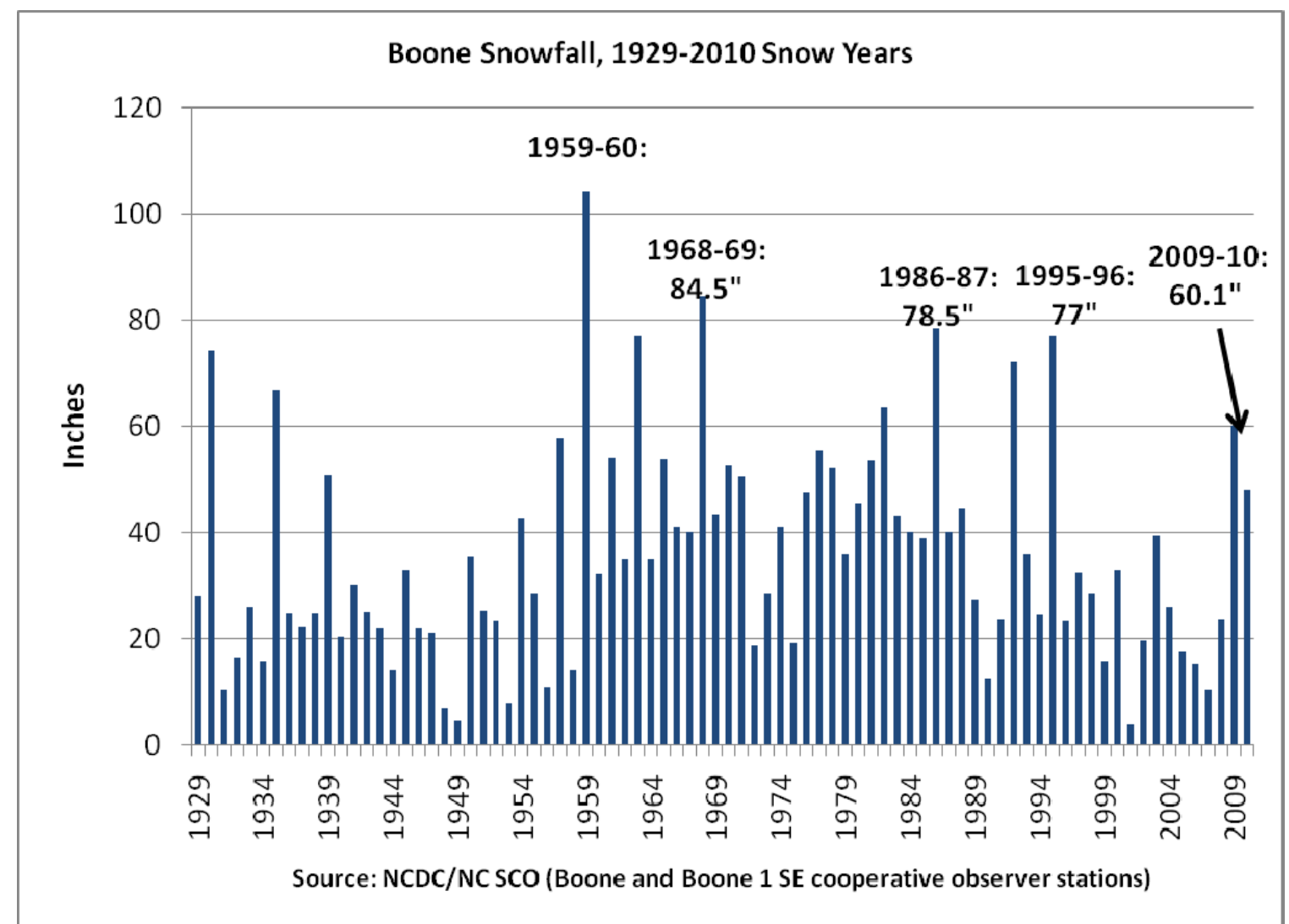

Figure 1.5. Annual snowfall trends for Boone, NC, 1929-2010. Data source: National Climatic Data Center. 


\section{Attribution}

Changes in atmospheric circulation may play a role in observed changes in climate in the SEUS. For example, the SAM has experienced a recent increase in snowfall associated with northwest flow, resulting in two consecutive years of above normal snowfall (Fig. 1.5). It is possible that changes in winter atmospheric circulation may be responsible for changes in seasonal precipitation in this region, such as the highly anomalous atmospheric circulation patterns responsible for the severe 2009-2010 winter (Cohen et al. 2010). Additionally, Li et al. (2010) suggested that anomalously wet or dry summers may occur with more frequency in the SEUS as a result of the intensifying North Atlantic Subtropical High (NASH) and that anthropogenic emissions are causing the intensification and spatial shift of the NASH. Simulations suggest that the westward extension of the NASH has a great impact on summer precipitation in the SEUS. As its western ridge moves to the north, weather patterns in the SEUS are dominated by subsidence and precipitation decreases. As the western ridge of the NASH moves south, warm moist air from the Gulf of Mexico is transported to the SEUS and precipitation increases. A strong connection was observed between the variation in the western ridge of the NASH and the variation in precipitation patterns in the SEUS within the last 30 years ( $\mathrm{Li}$ et al. 2010).

Atmospheric aerosols play an important role in the climate system and may exert a strong influence on observed climate changes in the SEUS and the SAM. Due to increased anthropogenic emissions, present day aerosol levels can reach concentrations of up to tens of

thousands $\mathrm{cm}^{-3}$ in polluted areas, compared to a few tens $\mathrm{cm}^{-3}$ in a pristine atmosphere devoid of human pollution (Andreae and Rosenfeld 2008). It has recently been suggested that the photosynthetic and carbon processes of the spruce-fir forests of the SAM may be impacted as 
a result of aerosol-induced increases in cloud ceiling heights (Reinhardt and Smith 2008). Additionally, in the SEUS, the long term cooling trend observed in the last century (Fig. 1.3) can potentially be attributed to the overall negative RF of the regionally high concentrations of atmospheric aerosols, compared to the RF of other mechanisms in the surface energy balance (Fig. 1.6). For instance, Twentieth Century increases in greenhouse gases caused increased surface warming by altering the $\mathrm{RF}$ of the atmosphere by $+2.4 \mathrm{~W} \mathrm{~m}^{-2}$ (Ramanathan et al. 2001). However, the warming effect of greenhouse gases may be partially offset by the presence of atmospheric aerosols, whereby these suspended particles scatter or absorb incoming solar radiation, inhibiting it from reaching Earth's surface (Andreae et al. 2004; Goldstein et al. 2009; Ramanathan et al. 2001). Aerosols have altered the RF by -0.5 to -2.5 $\mathrm{W} \mathrm{m}^{-2}$ (Ramanathan et al. 2001). Some of the recent warming in the SEUS may be tied to a reduction in emissions that previously resulted in the production of anthropogenic aerosols.

The interactions of aerosols, clouds, and precipitation are of particular concern in the SEUS where there is a high concentration of atmospheric aerosols of both natural and anthropogenic origin (Goldstein et al. 2009). While the major focus of this thesis is to address the influence of aerosols on precipitation formation in the SAM, it is important to acknowledge that there is a reciprocal relationship between aerosols and climate that remains poorly understood (Power et al. 2006). Atmospheric aerosols influence weather and climate patterns by altering Earth's surface energy balance and impacting the microphysical processes of cloud formation and precipitation development. However, weather and climate patterns influence aerosol loading and ultimately the chemical, optical, and microphysical properties of aerosols on a variety of scales. For example, areas located downwind from high urbanization near coastal areas of California and the Israeli Mountains have been impacted 
by anthropogenic emissions that influence the precipitation patterns in these downwind areas

(Givati and Rosenfeld 2004). This thesis aims to examine the synoptic controls of

precipitation patterns and aerosols in the SAM and devise a preliminary classification scheme

that characterizes aerosol-precipitation interactions in the region.

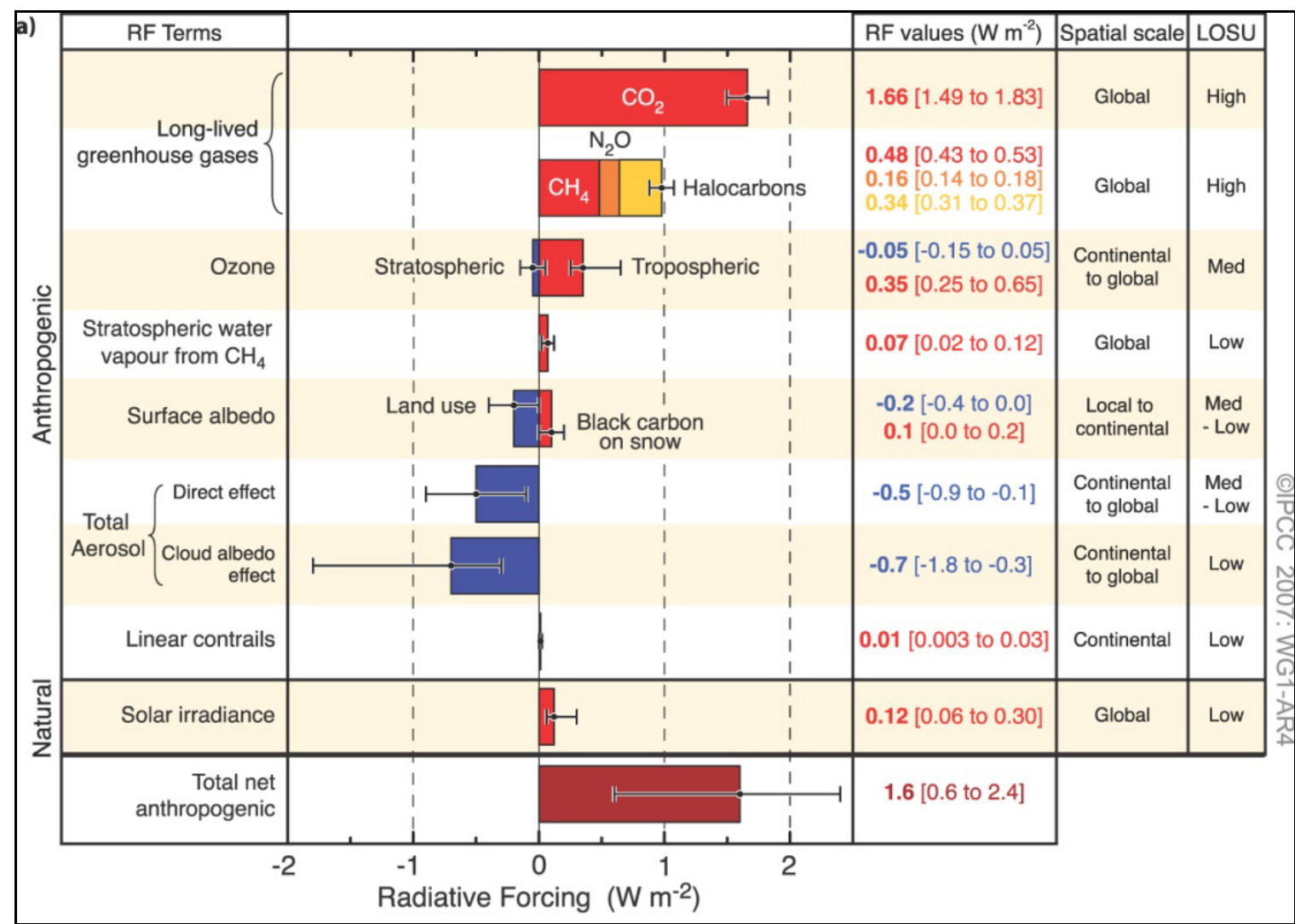

Figure 1.6. Ranges of estimated global average RF of anthropogenic mechanism, including spatial scale and level of scientific understanding (LOSU). Reprinted with permission. (Climate Change 2007: The Physical Science Basis. Working Group I Contribution to the Fourth Assessment Report of the Intergovernmental Panel on Climate Change, Figure TS.5 (p. 32). Cambridge University Press.) 


\section{$\underline{\text { Uncertainties related to aerosols }}$}

Research continues on the full range of climate-related impacts of atmospheric aerosols, and it is the aim of this thesis to begin to address the physical processes associated with some uncertainties surrounding these interactions in the SEUS and the SAM. The effects of aerosols on clouds and precipitation across the region may be evident by the occurrence of increased cloudiness, delayed or suppressed precipitation, or increased storminess. Periods of anomalously heavy rainfall, particularly during the warm season (June to September) may be associated with high aerosol mass concentration prior to event maturation, leading to increased storminess. Precipitation events associated with particular atmospheric circulation patterns, such as ENSO, may be strengthened by the presence of atmospheric aerosols. Additionally, atmospheric circulation patterns may have an impact on the spatial and temporal distribution of aerosols in the region, which may be more detectable in the warm season when a higher concentration of biogenic emissions impacts the SAM.

\section{Aerosols}

Particles in Earth's atmosphere are both natural and anthropogenic in origin. These particles, referred to as aerosols, are either emitted directly from a source (primary aerosols) or converted to particles from a gas through atmospheric reactions (secondary aerosols) (Seinfeld and Pandis 2006). With the exception of volcanic emissions, which can reside in the stratosphere for 1-2 years, most aerosols have a residence time in Earth's atmosphere ranging from minutes to weeks (Haywood and Boucher 2000) and are removed from the atmosphere either by gravitational fallout (dry deposition) or by coalescing water vapor to form cloud droplets and precipitation (wet deposition) (Seinfeld and Pandis 2006). Aerosols 
typically range in size from $0.001 \mu \mathrm{m}$ to roughly $10 \mu \mathrm{m}$ in diameter, with particles smaller than $0.1 \mu \mathrm{m}$ in diameter dominating the size distribution of aerosols in Earth's atmosphere. Generally, particles with diameters less than $2.5 \mu \mathrm{m}$ are considered "fine" and those with a diameter greater than $2.5 \mu \mathrm{m}$ "coarse." Particle size is significant in terms of the origination, transformation, transportation, composition, and optical properties of fine particles versus coarse particles (Seinfeld and Pandis 2006). Many fine particles are generated during combustion processes and tend to grow in size by accumulation with larger particles. These particles are typically removed from the atmosphere during precipitation. Particles in the accumulation phase tend to have a longer residence time in the atmosphere than finer or coarser particles. Coarse particles are primarily composed of dust and are typically removed from the atmosphere by dry deposition (Seinfeld and Pandis 2006).

Aerosols of a natural origin include terrestrial dust, volcanic eruptions, sea spray, biomass burning, and chemical reactions of atmospheric gases (Seinfeld and Pandis 2006). Naturally occurring primary aerosols include mineral dust, sea spray, volcanic dust, and biological debris. Secondary aerosols of natural origin include emissions of biogenic volatile organic compounds (VOCs) and the formation of sulfates. Sulfates can result from the oxidation of marine and volcanic emissions (Seinfeld and Pandis 2006).

Aerosols are also anthropogenically produced as a result of biomass burning, fossil fuel combustion, and dust from land use practices such as agriculture and urban development. Primary anthropogenic aerosols include industrial dust, black carbon (i.e., soot), and organic carbon. It is estimated that 20 to $50 \%$ of total mineral dust particles in the atmosphere are anthropogenic in origin (Haywood and Boucher 2000). The typical life span of mineral dust in the atmosphere is roughly two weeks, and particles can be transported thousands of 
kilometers from their source (Seinfeld and Pandis 2006). Secondary anthropogenic aerosols include sulfates and nitrates largely from fossil fuel combustion with a small contribution from biomass burning (Haywood and Boucher 2000).

In the past century anthropogenic emissions have increased, leading to a higher concentration of atmospheric aerosols. This is of great research interest not only in terms of air and water quality, but also in terms of the RF that these suspended particles exert in Earth's energy balance. Atmospheric aerosols interact with solar radiation and impact microphysical cloud formation processes, having direct and indirect effects on weather patterns and climate.

\section{Aerosol Properties}

The amount of solar radiation reflected back into space is referred to as global albedo. The fraction that is not reflected is absorbed by the atmosphere and the surface of the earth, which in turn drives atmospheric processes (Twomey 1974). Aerosols directly interact with light in the atmosphere by scattering or absorbing solar radiation (Fig. 1.7). They can also scatter, absorb, and emit thermal radiation (Lohmann and Feichter 2005). Often, aerosols are composed of a mixture of compounds that are both scattering and absorbing. The direct effects of aerosols are visually detectable in the haze often produced by the scattering of light. This radiative effect is also associated with a climatic response in which less solar radiation reaches the surface of the Earth, resulting in a net cooling effect. The direct effects

of aerosols, measured in $\mathrm{W} \mathrm{m}^{-2}$, essentially alter the energy budget of Earth's atmosphere and have the potential to drive changes in climate (Haywood and Boucher 2000). 
Measurements used to describe the radiative effects of aerosols include single scattering albedo (SSA), the asymmetry parameter, and aerosol optical depth (AOD). SSA is the ratio of aerosol scattering to the sum of aerosol scattering and aerosol absorption (Ramanathan et al. 2001). This value serves as an indication of how much light is being scattered versus extinguished, and it is an indicator of whether surface heating or cooling may be taking place. SSA depends on the size distribution and chemical composition of aerosols, and is wavelength-dependent (Seinfeld and Pandis 2006). Typical SSA values for black carbon aerosols in the visible light spectrum are around 0.2 , which is indicative of the lightabsorbing nature of this aerosol and its net warming effect. Typical SSA values for sulfate aerosols are around 1.0, indicative of the entirely light-scattering nature of this aerosol and its net cooling effect (Ramanathan et al. 2001).

Backscatter fraction is a measurement that indicates the ratio of the amount of light that is scattered in the backward direction to the total amount of scattered light. This value is a proxy for average aerosol particle size, and is inversely related to particle size, where the smaller the particles, the larger the backscatter fraction. Another value that is used to determine average particle size is scattering Ångström exponent (SAE), which determines the strength of the spectral dependence of total aerosols. When measuring scattering coefficients in multiple wavelengths, $\operatorname{SAE}(\alpha)$ can be derived from

$$
\alpha--\frac{\log \frac{\sigma_{\$ p} \lambda_{1}}{\sigma_{s p} \lambda_{2}}}{\log \frac{\lambda_{1}}{\lambda_{2}}}
$$


where $\sigma_{s p} \lambda_{1}$ and $\sigma_{s p} \lambda_{2}$ are the scattering coefficients measured at wavelengths $\lambda_{1}$ and $\lambda_{2}$, which in the case of this thesis are $450 \mathrm{~nm}$ and $700 \mathrm{~nm}$, respectively. SAE is inversely related to average particle size.

Additionally, absorption Ångström exponent (AAE) is a proxy for type of aerosol present, and is calculated in this thesis using equation (1), where $\sigma_{a p} \lambda_{1}$ and $\sigma_{a p} \lambda 2_{1}$ are the absorption coefficients measured at wavelengths $\lambda_{1}$ and $\lambda_{2}$, which are $467 \mathrm{~nm}$ and $660 \mathrm{~nm}$, respectively. Smaller AAE is indicative of the presence of black carbon, while larger AAE indicates the presence of more organic particles, also known as brown carbon.

AOD describes the amount of solar radiation between the source of radiation and the surface of the earth that is extinguished due to scattering and/or absorption by atmospheric aerosols. This value can be derived from

$$
\mathrm{I} / \mathrm{I}_{0}=\mathrm{e}^{-\tau}
$$

where the intensity of the radiation received at the surface is $I$, the intensity of the radiation at the source is $I_{o}$, and the amount of radiation transmitted through the layer of atmosphere is $e^{-\tau}$, where $\tau$ is the aerosol optical depth. This measurement depends on the concentration of aerosols in the atmospheric column. AOD serves as a proxy for the magnitude of heating or cooling taking place (Twomey 1974). Measured in the visible wavelength, typical AOD values on a clear day are 0.1 or less, while a hazy day may produce AOD values of 0.1 to 0.2 or greater.

Black carbon, a very small and dark-colored particle, is the most abundant visible lightabsorbing atmospheric aerosol, exerting a direct net warming effect on Earth's radiative balance (Seinfeld and Pandis 2006). Most other types of aerosols are lighter-colored particles that tend to scatter light more efficiently, causing a net cooling effect. The overall total RF of 
atmospheric aerosols is a net cooling effect. The IPCC reports a total direct aerosol RF of $0.5 \pm 0.4 \mathrm{~W} \mathrm{~m}^{-2}$ due to all aerosol types in the 2007 assessment report (Fig. 1.6) (Solomon et al. 2007). In the SEUS, sulfates and biogenic secondary organic aerosols are dominant at the surface, and this has led to a large AOD and a net cooling effect with a summer maximum across the region (Goldstein et al. 2009).

The indirect effects of aerosols consist of their influence on cloud properties, affecting both the microphysics of cloud formation and cloud lifetime (Fig. 1.7). The effects of aerosols serving as cloud condensation nuclei $(\mathrm{CCN})$ are described by two mechanisms: the cloud albedo effect (Twomey 1974, 1984) and the cloud lifetime effect (Albrecht 1989). The function of $\mathrm{CCN}$ in cloud formation is described in detail later in this thesis.

Cloud albedo is a measure of the amount of insolation reflected by clouds. Average cloud albedo depends on the scattering properties of the particles in the cloud, as well as the concentration and distribution of these particles (Twomey 1974). The cloud albedo effect describes the changes in radiative properties of clouds as a function of aerosols. An increase in concentration of aerosols results in an increase in available CCN (Twomey 1974). A cloud with an average concentration of $\mathrm{CCN}$ will promote the development of average size cloud droplets. Provided there is no change in the liquid water content of the cloud, an increase in available CCN will promote the development of a higher concentration of small cloud droplets. A cloud composed of a higher concentration of small droplets will have a higher albedo than a cloud with fewer but larger droplets (Brenguier et al. 2000). In this case, incoming solar radiation is inhibited from reaching Earth's surface, and more is reflected back into space. In some regions, climate warming driven by increased carbon dioxide emissions during the industrial era has been somewhat tempered by the RF of clouds 
(Brenguier et al. 2000). The IPCC reports an estimated indirect global cloud albedo effect of -0.3 to $-1.8 \mathrm{~W} \mathrm{~m}^{-2}$ (Solomon et al. 2007).

The second indirect effect of aerosols also results from the higher concentration of very small cloud droplets. An increase in available CCN leading to an increase in droplets of a very small size ultimately leads to increased general cloudiness (Albrecht 1989).

Additionally, the collision efficiency is very low in a cloud composed of small droplets, so an increase in aerosols leads to a decrease in cloud droplet coalescence in warm clouds (Muhlbauer and Lohmann 2006). The cloud lifetime effect describes the persistence of clouds that are composed of tiny cloud droplets that cannot grow large enough to precipitate. Andreae et al. (2004) compared mean cloud droplet radius and cloud lifetime among what were considered clean clouds to clouds formed by smoke from Amazonian forest fires. Clean clouds, having formed over the ocean and containing low concentrations of $\mathrm{CCN}$, grew quickly and precipitated early; smoke clouds, having formed over areas of forest fire or other highly polluted areas, exhibited a high concentration of CCN and tiny cloud droplets, suppressed or delayed precipitation, and in some cases violent storming (Andreae et al. 2004). The long-term results of the increased cloud lifetime effect may result in decreased surface warming and decreased precipitation. 


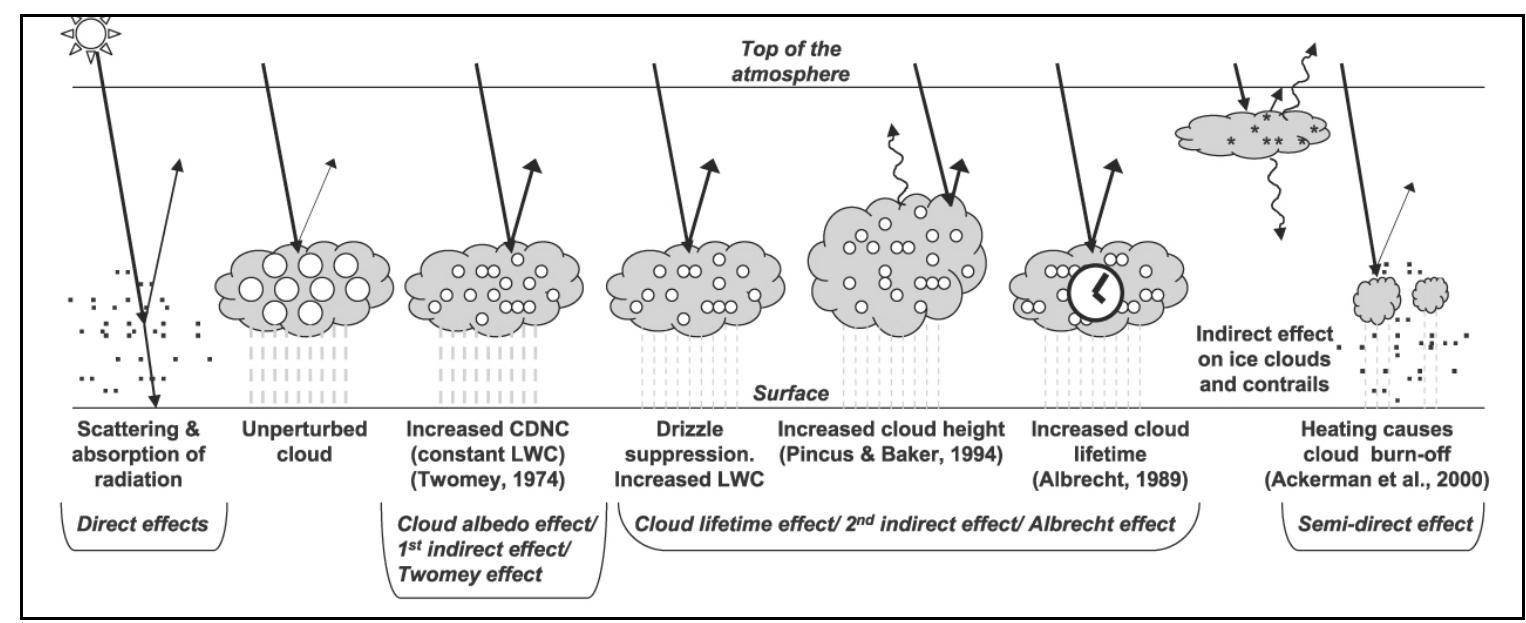

Figure 1.7. The direct and indirect effects of atmospheric aerosols. Reprinted with permission. (Climate Change 2007: The Physical Science Basis. Working Group I Contribution to the Fourth Assessment Report of the Intergovernmental Panel on Climate Change, Figure 2.10 (p. 154). Cambridge University Press.)

\section{Synoptic Influences on Aerosols}

Aerosol climatologies have been constructed based on the optical properties of aerosols produced by various sources of loading including biomass burning, desert dust, biogenic emissions, and anthropogenic sources (Holben et al. 2001). However, the transport of atmospheric particles from source regions to remote areas is an important component of global climate change research and incorporates processes of aerosol loading and synoptic climatology. Furthermore, a reciprocal relationship exists between aerosols and climate, wherein the RF of aerosols affects the surface energy balance and the development of meteorological patterns, while these patterns simultaneously exert great control over the spatial and temporal distribution of aerosols (Power et al. 2006). The climatological effects of large-scale aerosol loading have been observed in delayed precipitation during monsoon cycles in southern Asia (Bollasina et al. 2007). Additionally, aerosol behaviors are mitigated by climatic factors on a variety of scales: microscale climatic factors, such as humidity and insolation, can enhance conversion of gases into aerosols as well as growth of hygroscopic 
aerosols; atmospheric stability and convection at the mesoscale can often determine the concentration of aerosols in the atmosphere; and at synoptic levels, source region and variable flow patterns dictate the presence and concentration of atmospheric aerosols (Power et al. 2006).

\section{Aerosol Loading and Source Apportionment}

Natural and anthropogenic processes contribute to aerosol loading on a global scale. Soil and mineral dust aerosols have the highest atmospheric mass loading. These particles originate naturally from aeolian winds in desert areas and other arid regions, but also from human activities such as deforestation and agricultural practices (Cakmur et al. 2001; Tegen and Fung 1995). Increased desertification in arid regions can also increase the atmospheric loading of mineral and dust particles.

Sources of aerosols vary seasonally and inter-annually in many regions of the globe. For example, biomass burning practices typically take place on a seasonal basis during winter wood-burning or dry season agricultural practices, but can also occur naturally in the form of widespread wildfires (Holben et al. 2001). In highly industrialized areas, anthropogenic aerosol loading is largely controlled by regional climatology. For instance, aerosol loading in Asia is characterized by high desert dust in the pre-monsoon season and high anthropogenic urban-industrial aerosols during winter (Singh et al. 2004). In highly forested areas of the world, high warm-season aerosol loading is a result of the increased biogenic emissions of terpenes and other hydrocarbons during natural photosynthetic processes (Barr et al. 2003: Tunved et al. 2006). This effect is characteristic of the SAM during the summer, when biogenic emissions create a visible blue haze. Backward air trajectory analysis has been used 
to identify source regions of aerosols and to examine the synoptic meteorological regimes that drive the regional transport of aerosols (Dorling et al. 1992; Prados et al. 1999; Swap et al. 1992; Taubman et al. 2006). Source regions are often apportioned by performing a cluster analysis of backward air trajectories, and level of influence can be quantified for individual source regions based on percentage.

\section{Regional Studies}

A variety of methodologies have been used in evaluating the synoptic controls of atmospheric aerosols, including ground-based sampling schemes as well as backward air trajectory analyses. Focusing on the United States and Canada, Power et al. (2006) employed the Spatial Synoptic Classification (SSC) and determined significant differences in aerosol values associated with these weather types. Greater AOD was generally associated with moist weather types, while lower AOD was associated with drier weather types. AOD values associated with other weather types, such as Dry Tropical, exhibited much more seasonal variability, with high values in the summer and low values in the winter. While the SSC was an appropriate classification scheme for the spatial and temporal scale of the study conducted by Power et al. (2006), it would not have applied well to this study. This thesis takes a new approach to analyzing aerosol values according to a specialized classification scheme based on precipitation characteristics during the time period of study in the SAM.

A number of studies have used backward air trajectory analyses to investigate the synoptic influences on aerosols on global and regional scales. Dorling et al. (1992) examined seasonal clusters of three-day $1000 \mathrm{hPa}$ isobaric trajectories associated with precipitation and pollutant transport via wet deposition in southern Scotland. In this study, trajectories were 
determined from composite surface pressure patterns, which represented atmospheric transport patterns. Wet days exhibited a pattern of flow from the west and southwest, while dry days were associated with flow from the north and the east. Air trajectories represented the likelihood that aerosols would have traveled across a given region to the area of interest, while all other transformative processes of removal or oxidation during transport were ignored. Swap et al. (1992) also used isobaric trajectories at various pressure heights to illustrate the transport of Saharan dust to the Central Amazon Basin in association with large subtropical anticyclone wet season rain systems. As part of the Atmosphere/Ocean Chemistry Experiment (AEROCE) expedition in 1996, Prados et al. (1996) used a similar methodology in analyzing the transport of ozone and other aerosols to the North Atlantic Ocean.

The National Oceanic and Atmospheric Administration (NOAA) HYbrid Single Particle Lagrangian Integrated Trajectory (HYSPLIT) model is a tool used for computing simple air parcel trajectories (Draxler and Hess 1997, 1998; Draxler 1999), and is often used to determine source region information for weather systems or transported pollutants. Focusing on the northeastern United States, Brankov et al. (1998) used this model to create simulated backward air trajectory clusters to analyze the synoptic controls of the transport of pollutants to areas in New York, New Jersey, and Massachusetts. Taubman et al. (2006) used a similar backward air trajectory analysis technique to identify source region and transport patterns of aerosols during summer pollution events in the mid-Atlantic region of the U.S. Atmospheric properties were characterized by influence from source regions including the northern and southern Ohio River Valleys, periods of stagnant flow, and periods of north-northwest flow. 


\section{Atmospheric Processes of Precipitation Development}

\section{$\underline{\text { Cloud Formation }}$}

In a stable atmosphere, air typically resists vertical motion. Surface-atmosphere interactions give way to mechanisms that force air to rise, resulting in clouds. These lifting processes include localized convective lifting, convergence, frontal wedging, and orographic lifting (Lutgens and Tarbuck 2010). When an air mass is lifted and cooled, condensation of water vapor must take place in order for a cloud to develop. Water vapor condenses into liquid water under supersaturated conditions but will not survive and grow large enough to form cloud droplets, due to evaporation (Wallace and Hobbs 2006). In order for water vapor to condense into liquid water and form cloud droplets, a nucleation site is required.

Microscopic particles of dust, smoke, or other atmospheric aerosols (both naturally occurring and anthropogenically produced) serve as these nucleation sites or $\mathrm{CCN}$, as mentioned above. Some CCN promote condensation and allow the formation of cloud droplets at lower levels of saturation. This is because the particles are either hygroscopic ("water-seeking") or they are larger sized particles more readily wetted by the water vapor, giving them a higher solubility and allowing cloud droplets to form at a lower level of saturation. Other $\mathrm{CCN}$ do not promote cloud droplet formation because they are hydrophobic ("water-repelling") particles or they are smaller sized particles with lower solubility. Most $\mathrm{CCN}$ present in the atmosphere at any given time exhibit a combination of these characteristics (Ahrens 2000; Wallace and Hobbs 2006). As an air mass cools, molecules move about more slowly and collisions result in particles sticking together. Water vapor condenses or is deposited upon the $\mathrm{CCN}$ forming billions of liquid cloud droplets, causing the air mass to become visible as a cloud. 


\section{Precipitation Formation}

Cloud droplets are typically over one hundred times smaller than raindrops and are light weight enough that they remain suspended in the cloud by vertical air currents. A typical cloud droplet is roughly $20 \mu \mathrm{m}$ in diameter. For a cloud droplet to precipitate, it needs to grow in size to anywhere from $200 \mu \mathrm{m}$ to $5000 \mu \mathrm{m}$ in diameter (Ahrens 2000). In clouds containing water droplets, cloud droplets will continue to grow by condensation, but the rate of growth decreases as the droplets get larger. The process of growth by condensation alone is much too slow and that the droplets typically evaporate before they are large enough to precipitate as raindrops (Wallace and Hobbs 2006). The processes of collision and coalescence, the Bergeron or ice crystal process, and the seeder-feeder process provide three mechanisms of precipitation formation.

\section{Collision and Coalescence}

The process of collision and coalescence explains the growth of cloud droplets and the formation of precipitation in warm clouds, or clouds without significant concentrations of ice. During this process, larger droplets referred to as "collector drops" have a higher terminal fall speed than smaller droplets and initiate collisions as they are precipitated out of a cloud (Wallace and Hobbs 2006). Collisions occur when there is a large size distribution of cloud droplets present within a cloud and result in droplets coalescing, bouncing off of each other, or fragmenting.

Houghton (1950) conducted quantitative analyses on the efficiency of multiple mechanisms governing the growth of precipitation. It was determined that other precipitation processes are more efficient at the early stages of precipitation development, but collision- 
coalescence becomes much more rapid once larger droplets are present. The collection efficiency of larger collector drops depends on their size and relative fall velocity (Houghton 1950; Adam et al. 1968). Laboratory experiments conducted by Adam et al. (1968) revealed that droplets at $60 \mu \mathrm{m}$ in size will coalesce at an optimal fall speed of roughly $2.2 \mathrm{~m} \mathrm{~s}^{-1}$. Droplets sharing opposite electrical charges are likely to coalesce, but if surface tension on individual droplets is strong, collisions taking place at lower fall speeds may not result in coalescence. Collisions occurring at velocities greater than $2.2 \mathrm{~m} \mathrm{~s}^{-1}$ will not result in coalescence, and may result in droplets breaking apart. Collision-coalescence also depends on the residence time of a cloud droplet within a cloud. For example, strong vertical air currents in vertically thick clouds will keep droplets in suspension, increasing the potential for collisions (Ahrens 2000).

As described above, the process of collision and coalescence requires the presence of large cloud droplets initiating collisions with other cloud droplets. Various mechanisms have been suggested to explain the formation of these large cloud droplets (Wallace and Hobbs 2006). The presence of giant cloud condensation nuclei (GCCN) may explain the formation of large cloud droplets. Typical CCN have a radius of roughly $0.1 \mu \mathrm{m}$, while GCCN typically have a radius larger than $3 \mu \mathrm{m}$. In low concentrations, these GCCN can cause otherwise nonprecipitating clouds to precipitate. Also, turbulent fluctuations in a supersaturated cloud may cause large collector drops to form by condensational growth. Turbulence can affect fall speeds and horizontal movement among cloud droplets, thereby enhancing collisions and leading to droplet growth. A third mechanism of large droplet formation is described by the radiative broadening of cloud droplets. When water vapor condenses into a liquid droplet, heat is lost, causing the saturation vapor pressure around the droplet to be lower, and 
speeding up droplet growth by attracting more vapor molecules. A larger droplet will have a greater radiative effect and will subsequently experience enhanced growth. The last mechanism offered by Wallace and Hobbs (2006) is stochastic collection, which describes the increased likelihood that larger drops will initiate collisions during the formation process. As collision and coalescence happens, some droplets grow larger and the size distribution of total cloud droplets broadens. The larger droplets within that distribution are more likely to collide with smaller droplets, due to their rapid fall speeds and larger cross-section (Houghton 1950).

\section{Bergeron Process}

Bergeron (1935) proposed the mechanism of precipitation formation in cold clouds based on the difference in vapor pressure between ice and water. The Bergeron process has been shown to be a much more efficient development mechanism in the early stages of precipitation formation than other processes (Houghton 1950). Much of the precipitation that falls in middle and high latitudes forms as a result of the Bergeron process (Ahrens 2000). In the SAM, most precipitation (except for some shallow orographic precipitation) is a result of the Bergeron process. During summer months, cumulonimbus clouds typically extend to an altitude well above the freezing line, causing these clouds to be composed of a mix of ice crystals and liquid water.

Cloud droplets remain in a supercooled liquid phase even when cloud temperatures are below freezing. Clouds at $-20{ }^{\circ} \mathrm{C}$ are typically composed of a mixture of water and ice crystals, and at $-40{ }^{\circ} \mathrm{C}$, clouds are composed entirely of ice crystals (Ahrens 2000). In saturated clouds at sub-freezing temperatures, homogenous freezing of pure water will occur 
without the presence of a nucleus, thereby forming ice embryos. At temperatures just below freezing, thermal agitations can shatter these ice embryos, but temperatures as low as $-40{ }^{\circ} \mathrm{C}$ allow these ice embryos to remain intact and serve as ice nuclei (IN). In cold clouds, clay minerals and bacteria can also be present and act as IN, upon which ice crystals will form just as cloud droplets form on $\mathrm{CCN}$.

Sub-freezing clouds are typically composed of both supercooled liquid droplets and ice crystals. At equilibrium, the number of molecules leaving the surface of both the liquid droplet and the ice crystal is equal to the number returning to each. Since vapor molecules can move about more freely from a liquid than from a solid, there are more vapor molecules surrounding the liquid droplet than there are surrounding the ice crystal. This causes the liquid droplet to have a higher vapor pressure than the ice crystal. This difference in vapor pressure causes vapor molecules to diffuse away from the liquid droplet to the ice crystal, leading to the evaporation of the liquid molecule and the growth of the ice crystal.

In order for an ice crystal to grow large enough to precipitate out of the cloud, there must be an abundance of water droplets to feed this growth. Ahrens (2000) suggested a ratio of ice crystals to water droplets on the order of 1:100,000 to 1:1,000,000. As the ice crystals grow, they become heavy enough to precipitate as snow. Falling through the cloud, the collisioncoalescence process occurs as the ice crystals collide with other supercooled droplets creating rimed crystals, which may in turn fracture upon colliding with other droplets. Ice crystals colliding with other ice crystals may accumulate to form snowflakes or graupel. Precipitation may fall to earth in a frozen state or melt into rainfall. 


\section{Seeder-Feeder Mechanism}

The seeder-feeder mechanism of precipitation formation is common in mountainous areas (Bergeron 1965), including the Appalachian region (Barros and Kuligowski 1998). In this process, low-lying "feeder" clouds containing cloud droplets too small to precipitate on their own are washed out by higher level "seeder" clouds precipitating from above. The seederfeeder couplet can form when cold air builds up on the windward side of a mountain, causing a density gradient where the cold air is trapped near the surface (Barros and Kuligowski 1998). Warm, moist winds ascend the cool surface air, forming seeder clouds above the lowlying feeder cloud (Fig. 1.8). This forced orographic lift induces precipitation of the seeder cloud (as described in the following section on orographic precipitation), and causes scavenging of moisture within feeder clouds. If the overlying seeder cloud is above the -10 ${ }^{\circ} \mathrm{C}$ isotherm, it may contain ice crystals which can precipitate into the feeder clouds, scavenging moisture and enhancing precipitation development by vapor diffusion, as described by the Bergeron process. If both the seeder and the feeder clouds are above the -10 ${ }^{\circ} \mathrm{C}$ isotherm, then precipitating ice crystals from the seeder cloud my collide and coalesce with ice crystals in the feeder cloud, causing riming and enhancing precipitation (Choularton and Perry 1986).

The seeder-feeder mechanism of precipitation development helps to explain the greater precipitation rates occurring over mountains versus the surrounding low-level areas (Reinking et al. 2000). Choularton and Perry (1986) report that the seeder-feeder mechanism can enhance orographic precipitation by up to three times the normal amount of precipitation from the seeder cloud alone. Additionally, Dore et al. (1992) reported that low-lying feeder clouds can often contain higher concentrations of anthropogenic air pollution, which can 
result in pollutant deposition in mountainous regions. The higher concentration of pollutants contained in feeder clouds may help to explain the aerosol-induced suppression of precipitation in such clouds, as discussed further in the atmospheric aerosols section.

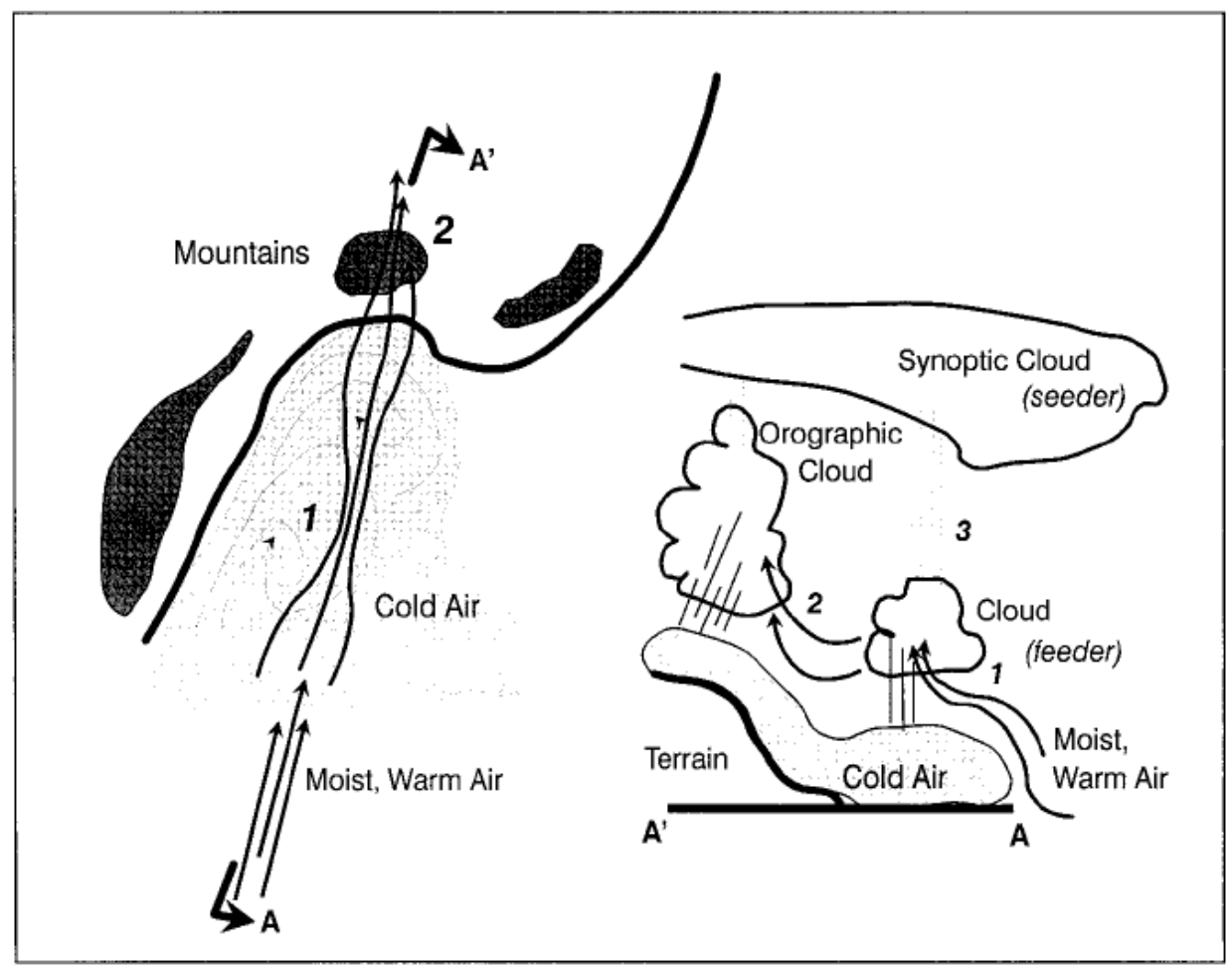

Figure 1.8. Seeder-Feeder mechanism of precipitation formation (Barros, A. P. and R. J. Kuligowski. 1998. Orographic effects during a severe winter rainstorm in the Appalachian Mountains. Monthly Weather Review 126:2648-2672). (C) American Meteorological Society. Reprinted with permission.

\section{Orographic Precipitation}

Mountains present obstacles to atmospheric flow, upsetting atmospheric equilibrium and ultimately leading to precipitation (Barros and Lettenmaier 1994). Mountain precipitation is often orographically enhanced, whereby the amount of precipitation falling on an area is composed of that which would have fallen in the absence of mountains and as a result of air mass characteristics and convective potential, in addition to the orographically enhanced portion resulting from the forced uplift and intensification of precipitation processes (Barry 1992). Pure orographic precipitation would occur when topography provides the only forcing 
and no other mechanisms (e.g., the seeder-feeder process) are relevant to the formation of precipitation (Fig. 1.9).

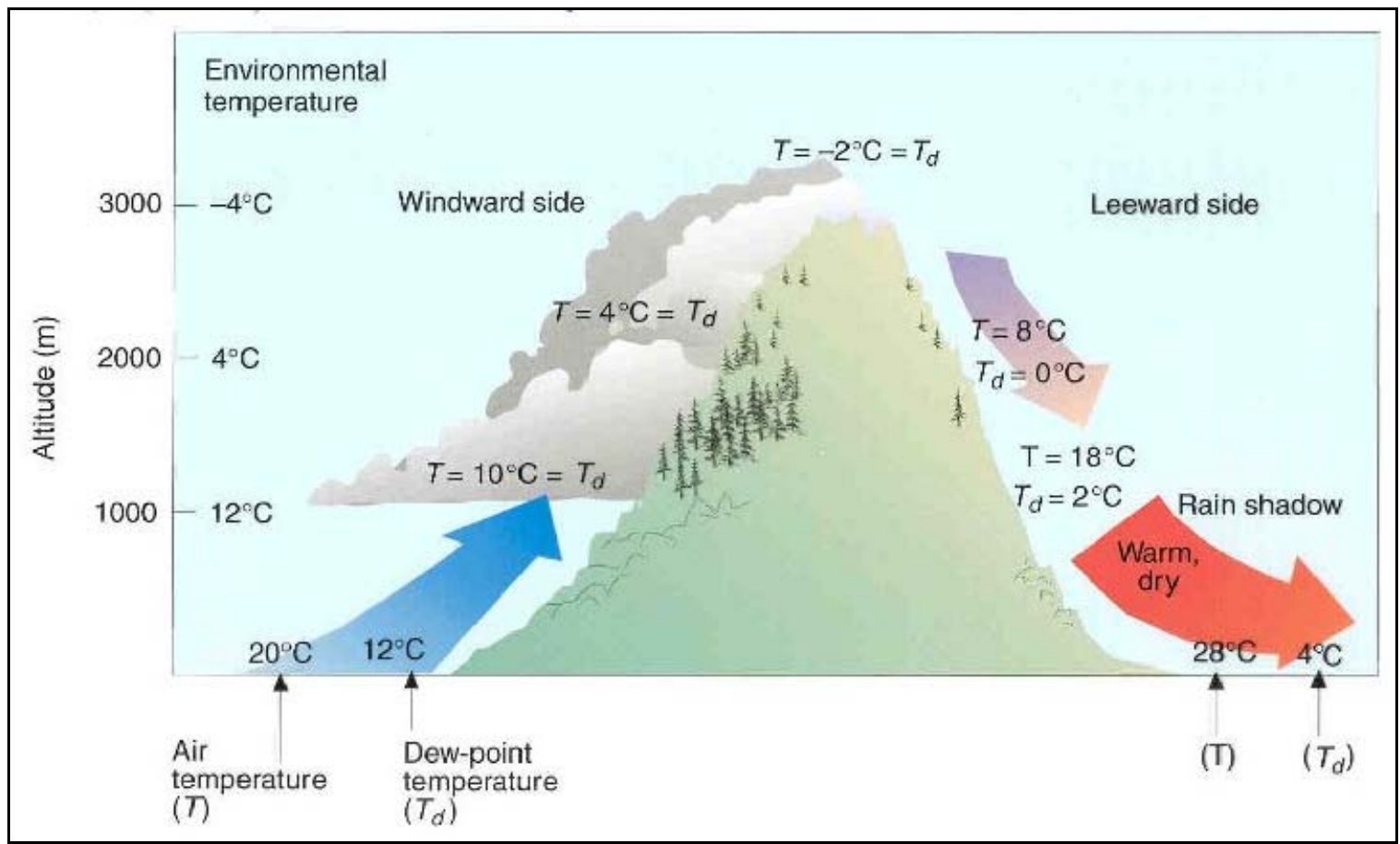

Figure 1.9. Orographic uplift, cloud development, and the formation of a rain shadow. Reprinted with permission. (From AHRENS. Meteorology Today, 6E, p. 171, (C) 2000 Brooks/Cole, a part of Cengage Learning, Inc. Reproduced by permission. www.cengage.com/permissions)

\section{Topographic Influences}

The orographic controls of precipitation have been examined in terms of various topographic and geographic characteristics exerting influence on the intensity and distribution of rainfall in mountainous regions. These variables include elevation, exposure, aspect/orientation, slope, and latitude/longitude. The mountainous island of La Réunion in the Southwest Indian Ocean, known as one of the wettest places in the world, has been the focus of extreme orographic rainfall studies in which world record rainfall maximums were reported for this location (Barcelo et al. 1997; Quetelard et al. 1999). 
The SAM is characterized by significant topographic variability, exerting a considerable influence on the distribution and intensity of precipitation across the region (Perry and Konrad 2006; Barros and Kuligowski 1998). This region has a temperate and moist climate and is subject to both maritime and continental influences (Whiteman 2000). West-northwest winds dominate in the cool season, while warm, moist air is carried to the region from the Gulf of Mexico in the warm season. The northeast-southwest orientation of the Southern Appalachian Mountains lends this region to experience orographically enhanced northwest flow snowfall (NWFS) with a periodic Great Lakes connection (Perry et al. 2007), as well as southeast upslope flow precipitation during the warm season (Lee and Goodge 1984; Johnstone and Burrus 1998). In the Appalachian region, the majority of heavy rainfall events, defined as those producing at least $50 \mathrm{~mm}$ of measurable precipitation, occur during the warm season (Konrad and Meentemeyer 1994). In the cool season, NWFS accounts for nearly $50 \%$ of annual average snowfall (Perry et al. 2007).

\section{Atmospheric Influences}

Orographic precipitation events are often a function of the velocity of wind encountering the mountain range, stability of the air mass, and the height of the mountainous barrier (Lin et al. 2001). Orographic barriers influence these atmospheric circulation features on multiple scales. Planetary-scale effects include large scale friction, deflection of airflow, and modified energy fluxes through cloud and precipitation formation (Barry 1992). Synoptic-scale effects include the influence of orography on weather systems such as frontal cyclones and the development of lee cyclogenesis. And on the local scale, orographic influences affect airflow 
regimes and directly influence local weather patterns. For the purpose of this thesis, the synoptic and local-scale effects of orographic processes are described.

On the synoptic-scale, fronts approaching mountainous areas may experience a masking effect when encountering and ascending cool shallow air, which leads to the reduction of the temperature gradient in cold fronts and an enhancement of this contrast in warm fronts. Frontal deformation can also occur as lower air becomes trapped by the mountainous barrier as upper air continues over the barrier, leading to increased clouds and precipitation on windward slopes. Additionally, synoptic wind fields are modified by mountain barriers due to pressure differentials between the windward and leeward slopes and the deflection of airflow (Barry 1992). Lifted airflow creates a deeper layer of cool dense air on windward slopes, while hydrostatic pressure corrections cause warm air to descend the lee slopes to replace deflected air, sometimes producing fall winds. Weather patterns on lee slopes can also be affected by lee cyclogenesis. Cold air advection leads to upper level divergence associated with conditional instability, encouraging lower level convergence and the possible formation of rain bands (Barry 1992). Many heavy rainfall events associated with orographic processes take place when upslope rain is coupled with a conditionally unstable atmosphere (Lin et al. 2001). In an atmosphere of convective instability, orographic influences can lead to the lifting of an entire layer of the atmosphere. In this scenario, the atmospheric column is stratified by moisture content and a dry inversion layer caps a moist layer. As these layers are lifted, the bottom of the inversion layer will reach its lifting condensation level much more quickly than the top of the inversion layer, leading to destabilized cooling rates within the layer of the capping inversion (Barros and Lettenmaier 1994; Wallace and Hobbs 2006). 
On a local scale, the deformation of airflow over a mountain range depends on the vertical wind profile, stability structure, and shape of the obstacle. Three airflow scenarios explain the behavior of airflow encountering a mountain barrier: light winds encountering a mountain flow smoothly across the obstacle in a shallow wave; stronger wind speeds can lead to an eddy pattern on lee side slopes; and very high wind speeds with an increasing vertical wind speed gradient encountering windward slopes can lead to lee waves and wave clouds persisting for multiple kilometers downwind of the range, sometimes producing lenticular clouds. When airflow separates from the surface, turbulent zones of airflow can occur, posing a hazard to aircraft and impacting local weather patterns (Barry 1992).

Thermal patterns associated with mountain topography can affect airflow by the development of thermal mountain-valley winds. These winds are a result of small-scale baroclinicity related to differential heating and cooling of slopes (Barry 1992). Anabatic flow describes the upslope movement of warm air as a result of daytime heating, leading to upvalley winds; katabatic flow describes the down-slope movement of cold air at night as a result of nocturnal cooling, feeding down-valley winds and causing valleys to be considerably colder than adjacent ridges at night. This effect is common in the SAM, particularly during clear and calm conditions. These thermal flow regimes can lead to regional circulations that affect weather patterns in surrounding lowland areas.

\section{Synoptic Influences on Precipitation}

Synoptic climatologies have been created to classify precipitation processes of the SEUS and the SAM. Focusing on the interior SEUS, Konrad (1997) determined that heavy precipitation events are tied to high moisture warm air advection and identified five synoptic 
patterns. These patterns included descriptions of boundary layer and low level convergence scenarios within the synoptic scale (100-1,000 km) vicinity of heavy rainfall. Keim (1996) also analyzed the synoptic properties associated with seasonal heavy rainfall events in the SEUS based on a scheme adopted from Muller (1977) wherein events are classified as either frontal, tropical disturbance, or air mass. It was determined that most seasonal heavy rainfall across the region is associated with frontal systems. Diem (2006) examined the synoptic controls of both wet and dry periods in the Atlanta, Georgia, metropolitan area, identifying the impact of varying synoptic-scale circulation patterns on precipitation. Wet periods were identified in association with upper-level troughs in the interior SEUS coupled with high pressure along the eastern coast with wet periods; dry periods were associated with interior anticyclones coupled with low pressure along the SEUS coast.

In the SAM, synoptic classification schemes have been created to classify seasonal precipitation patterns. Konrad and Meentemeyer (1994) examined synoptic controls of warm season heavy rainfall focusing on the Appalachian region. Synoptic classification was based on the orientation and location of lower tropospheric warm air advection, with which $60 \%$ of study events were associated. Focusing on the Great Smoky Mountains in the SAM, Perry et al. (2007) manually classified snowfall events that took place over a 14-year time period, based on surface and 500-hPa synoptic patterns. This resulted in thirteen synoptic classes similar to those described by Miller (1946), including Miller A cyclones which account for the greatest contribution of annual snowfall across the region and are associated with northwest flow at their heaviest. To further address significant cold season precipitation patterns, Perry et al. (2007) used backward air trajectory analyses to create a synoptic classification of NWFS events impacting the SAM. NWFS events can account for roughly 
$50 \%$ of annual snowfall along windward slopes in the SAM, and are often associated with a Great Lakes connection. Trajectory cluster analysis results were classified based on a grid created specifically for the study, which included five distinct regions of origin associated with specific synoptic characteristics.

\section{Aerosol-Precipitation Interactions}

Numerous studies have addressed aerosol-induced precipitation enhancement (Rosenfeld et al. 2002; Rudich and Khersonsky 2002; Givati and Rosenfeld 2004; Khain et al. 2005; Bell et al. 2008; Lohmann and Hoose 2009) and precipitation suppression as a function of aerosols (Rosenfeld 2000; Borys et al. 2003; Andreae et al. 2004; Rosenfeld and Givati 2006). The effects of aerosols on precipitation, from micro- to synoptic scale, remain a poorly understood dimension of the indirect effects of aerosols. On the microscale, aerosols acting as $\mathrm{CCN}$ affect precipitation formation processes. Typically, larger, more hydrophilic particles such as sea spray serve as more efficient $\mathrm{CCN}$, while smaller, more hydrophobic particles such as soot do not enhance the condensation of water vapor and therefore are poor CCN (Rudich et al. 2002; Givati and Rosenfeld 2005). Most atmospheric aerosols are an amalgam of many chemical species due to oxidation and other alteration processes taking place in the atmosphere. Silver iodide and dry ice particles, both used in cloud seeding operations, are larger high-solubility particles and enhance the development of precipitation on the microscale by enhancing the growth of ice crystals (Bruintjes 1999). Rudich et al. (2002) reported on the natural enhancement of precipitation as a result of salt-dust particles aerosolized from the Aral Sea. The gradual drying-up of this sea has caused it to be reduced in size by $40 \%$ since the 1960 's, thereby increasing the salinity of its waters by a factor of 
three and exposing dried salt beds at its shores. Subsequent salt-dust storms, containing particles ranging from $3.8-6 \mu \mathrm{m}$, altered cloud microphysics and enhanced precipitationformation processes. Rosenfeld et al. (2002) observed a similar effect of sea salt aerosols inducing precipitation in polluted clouds over the ocean. Sea salt particles acted as large, hygroscopic $\mathrm{CCN}$ and enhanced the development of raindrops in clouds previously composed of anthropogenic aerosols serving as inefficient CCN.

In contrast, aerosols produced by the smoke from biomass burning serve as small $\mathrm{CCN}$ and inhibit or suppress precipitation by producing very small cloud droplets (Diehl et al. 2007; Rosenfeld et al. 2002). Petzold et al. (2005) described the coating effect of aerosols, in which insoluble black carbon particles can become coated with soluble or inorganic particles thereby enhancing their $\mathrm{CCN}$ potential. It was shown that carbonaceous particles emitted from a gas turbine combustor serve as poor $\mathrm{CCN}$, similar to insoluble particles. As these particles aged and became coated in soluble sulfuric acid, their $\mathrm{CCN}$ activation potential increased. Conversely, Abbatt et al. (2005) conducted laboratory experiments revealing that thick coats of stearic acid led to the complete $\mathrm{CCN}$ deactivation of typically soluble ammonium sulfate even as particles grew larger in diameter.

On the synoptic scale, aerosols can affect precipitating air masses by either enhancing or suppressing precipitation. Bell et al. (2008) have reported on a weekend effect resulting from changes in urban pollution levels during the work week being tied to weekly variations in cloud cover and summer precipitation patterns in the United States. Aerosol-induced delayed precipitation can affect convective air masses resulting in vertical cloud development reaching heights above the $-10{ }^{\circ} \mathrm{C}$ isotherm where the tiny cloud droplets freeze, release latent heat, and initiate more cloud updrafts which further promotes convective cloud growth. 
In a moist, unstable environment, initial delayed precipitation can lead to increased violent storms and heavy rainfall (Givati and Rosenfeld 2004; Khain et al. 2005; Bell et al. 2008). Lohmann and Feichter (2005) refer to this indirect aerosol effect as the thermodynamic effect and cite model simulations which have shown this effect in deep convective clouds (Khain et al. 2004, 2005; Zhang et al. 2005). A similar effect, referred to as the glaciation indirect effect, takes place in cold clouds where aerosols, including black carbon, can act as ice nuclei and lead to an increase in cloud freezing and snowfall rate (Lohmann and Feichter 2005; Lohmann and Hoose 2009).

Conversely, it has been shown that the addition of anthropogenic air pollution, typically composed of fine aerosol particles, leads to suppressed precipitation (Rosenfeld 2000; Borys et al. 2003; Andreae et al. 2004; Givati and Rosenfeld 2004; Jirak and Cotton 2005; Rosenfeld and Givati 2006; Muhlbauer and Lohmann 2006; Rosenfeld et al. 2007; Lohmann and Hoose 2009). An increase in black carbon and sulfate aerosols since preindustrial times has led to a de-activation effect, since these particles act as poor condensation nuclei (Lohmann and Hoose 2009). This effect has also been observed in snowfall studies, wherein it was determined that an increase in anthropogenic sulfate particles by $1 \mu \mathrm{g} \mathrm{m}^{-3}$ can lead to a $50 \%$ decrease in snowfall rate in the Rocky Mountains (Borys et al. 2003). In some regions of the world, particularly in areas located downwind from highly urbanized areas, research has shown that the anthropogenic influence on aerosol loading has affected cloud lifetime and precipitation patterns within the last fifty years (Givati and Rosenfeld 2004). This same effect was not observed in regions that were not located downwind from industrialized areas. Rosenfeld et al. (2007) observed the cloud lifetime effect in the mountains of central China where hazy conditions led to a $50 \%$ decrease in rainfall. 
Typically, the suppression of precipitation caused by aerosols affects shallow stratiform clouds which occur below (i.e., under) the $-10{ }^{\circ} \mathrm{C}$ isotherm (Rosenfeld 1999, 2000). It has been observed that orographic clouds are particularly sensitive to the indirect effects of anthropogenic aerosols, due to their shallow vertical structure and downwind termination (Borys et al. 2003; Givati and Rosenfeld 2004, 2005; Rosenfeld and Givati 2006). Givati and Rosenfeld (2004) indicated a 15 to $20 \%$ decrease in upslope orographic precipitation downwind of pollution sources in the mountains of California and Israel. Jirak and Cotton (2005) determined a similar trend in the Rocky Mountains, where areas downwind from the metropolitan areas of Denver and Colorado Springs have experienced a decrease in the orographic enhancement of precipitation within the last half century. Higher concentrations of anthropogenic aerosols also inhibit the seeder-feeder process of snowfall development in orographic clouds by affecting the microphysics of the low-lying feeder cloud. Borys et al. (2003) observed that higher concentrations of anthropogenic sulfate and other pollutants reduced ice particle growth, snow particle concentration, and precipitation rate at the Storm Peak Laboratory on Mt. Werner in Colorado.

Aerosol-induced suppression of upslope orographic precipitation can lead to enhanced down slope precipitation as a result of the moisture that remains in the air mass as it passes a ridge (Fig. 1.10). Rosenfeld and Givati (2006) report a decrease in orographic precipitation in the last two decades as a result of increased fine-particle loading in the coastal mountain ranges of the western United States. This decrease in upslope precipitation was accompanied by an increase in downslope precipitation, as corroborated by measurements from precipitation gauges on both sides of the ridge. Muhlbauer and Lohmann (2006) hypothesized that the indirect effects of aerosols on orographic precipitation could have 
implications for climate change by altering the hydrological cycle on either side of a mountain range.

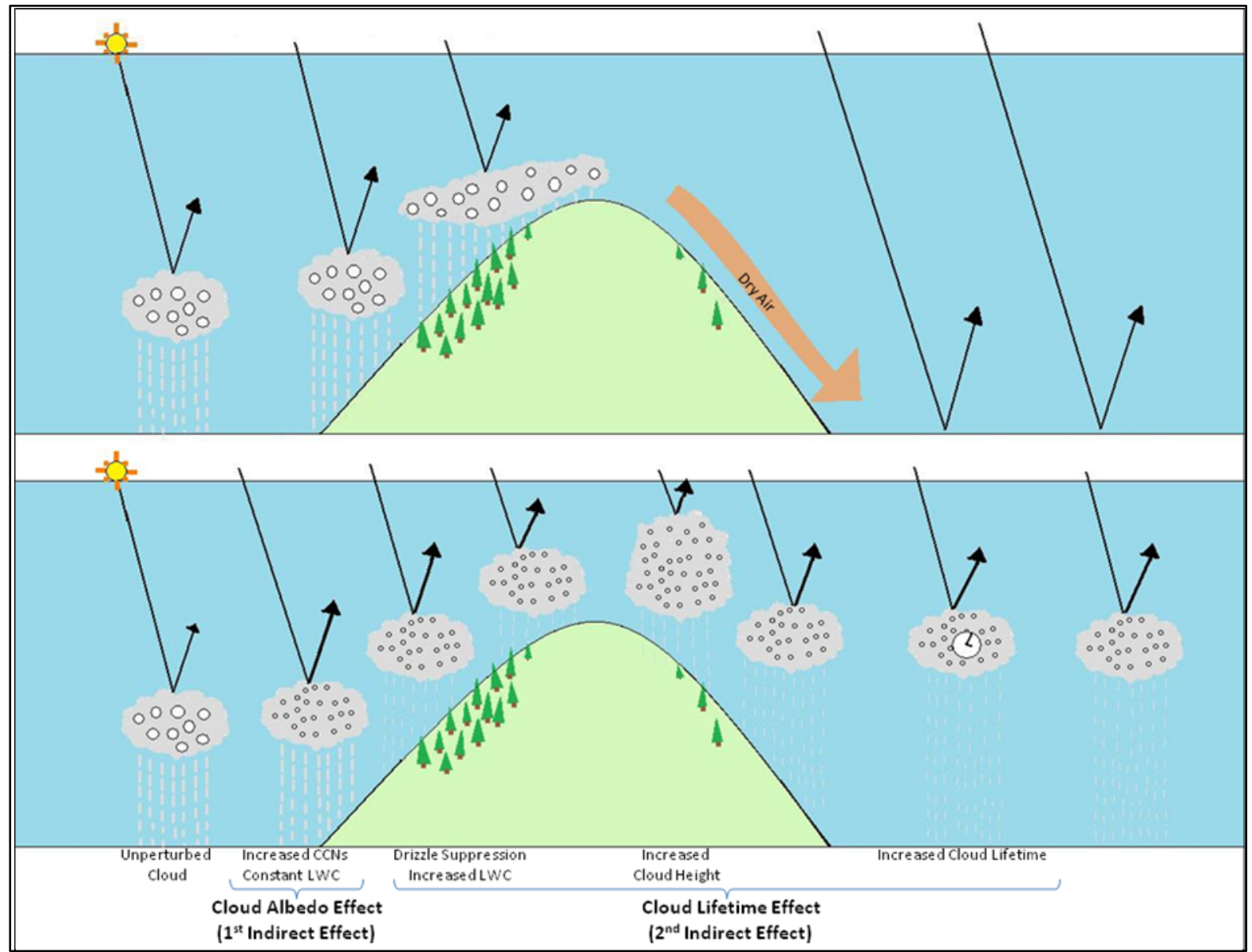

Figure 1.10. The direct and indirect effects of aerosols on orographic precipitation. (Adapted from Ahrens (2000) and Forster et al. (2007)) 


\section{Research Design}

\section{$\underline{\text { Research Questions }}$}

This thesis is guided by three main research questions:

1) How do aerosol properties observed during precipitation events vary by season (e.g., summer vs. winter) and synoptic event type (e.g., frontal vs. non-frontal),

2) How do they compare between the summer of 2009 and 2010, and

3) What influence does air mass source region have on aerosol properties?

These research questions are addressed by three main objectives, which include:

1) Creating a synoptic classification scheme for this project to classify events,

2) Summarizing precipitation events by synoptic influences and aerosol values, and

3) Evaluating event case examples for evidence of the indirect effects of aerosols (delayed or suppressed precipitation). 


\section{Chapter II}

\section{DATA AND METHODS}

This thesis offers a new approach to analyzing aerosol-precipitation interactions by developing a specialized synoptic classification scheme for precipitation events affecting the SAM and analyzing aerosol patterns and properties associated with these events. Weather patterns in the SAM are strongly influenced by topography and proximity to coastal regions, while the area is characterized by very high concentrations of both anthropogenic and biogenic aerosols, particularly in the warm season. The study area encompassed roughly $14,000 \mathrm{~km}^{2}$ of mountainous terrains in northwestern North Carolina, eastern Tennessee, and southwestern Virginia (Fig. 2.1). Serving as the central location of this study, the Appalachian Atmospheric Interdisciplinary Research (AppalAIR) facility $\left(36.213^{\circ},-81.691^{\circ}\right.$; $1076 \mathrm{~m}$ ) on campus at Appalachian State University (ASU) is an air quality and climate research station that has been in operation since June 2009 (Fig. 2.2) (www.appalair.appstate.edu). As a member of NOAA Earth System Research Laboratory (ESRL) Global Aerosol Monitoring Network, AppalAIR is the only participating site east of the Mississippi River and is the source of all aerosol data used in this thesis.

Precipitation events taking place from June 2009 through September 2010 were analyzed in conjunction with hourly aerosol optical and microphysical values recorded during each event. Backward air trajectory cluster analyses provided information on source region 
influences and all precipitation events were classified according to an aerosol-precipitation synoptic classification scheme developed for this thesis.

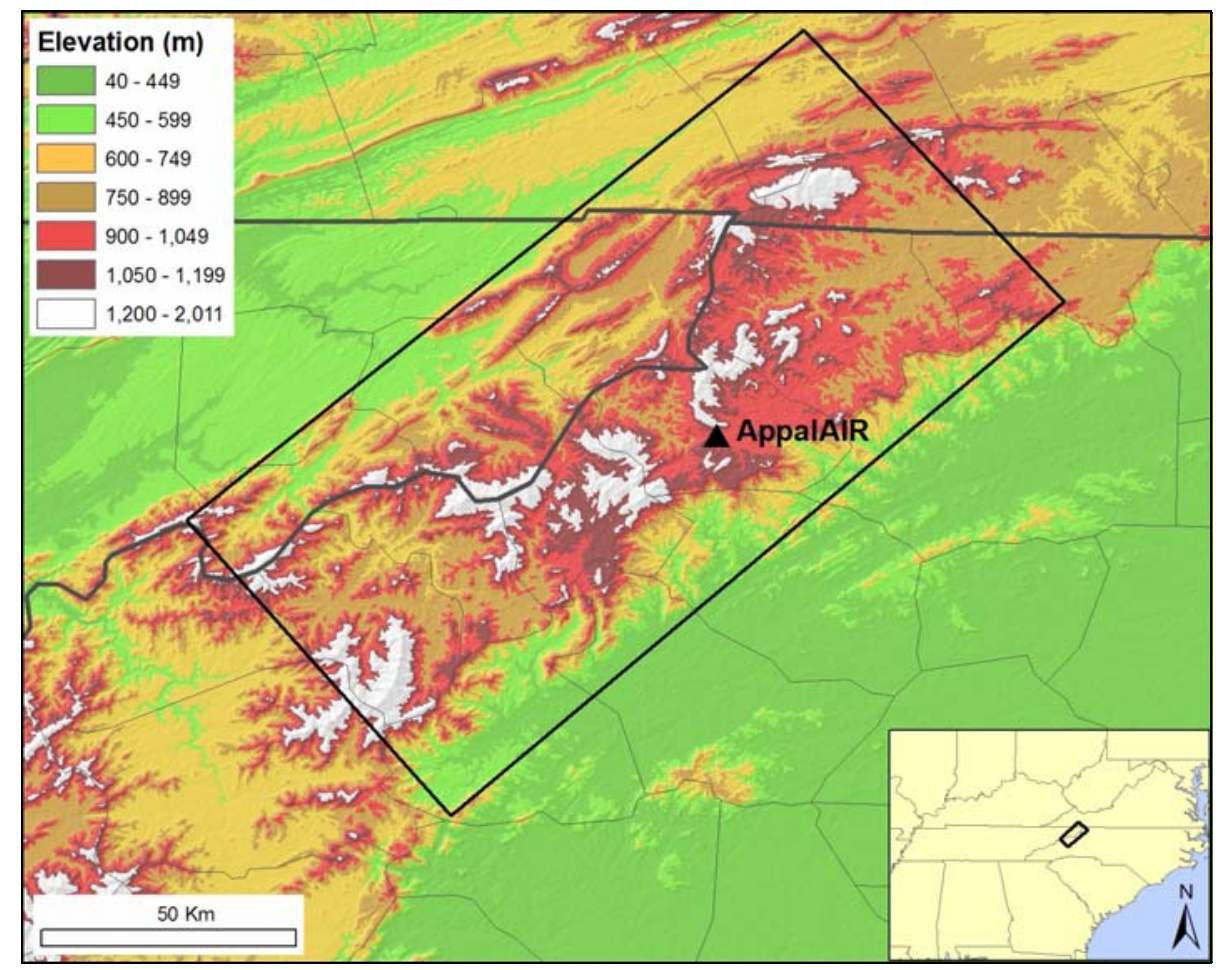

Figure 2.1. Topography of study area.

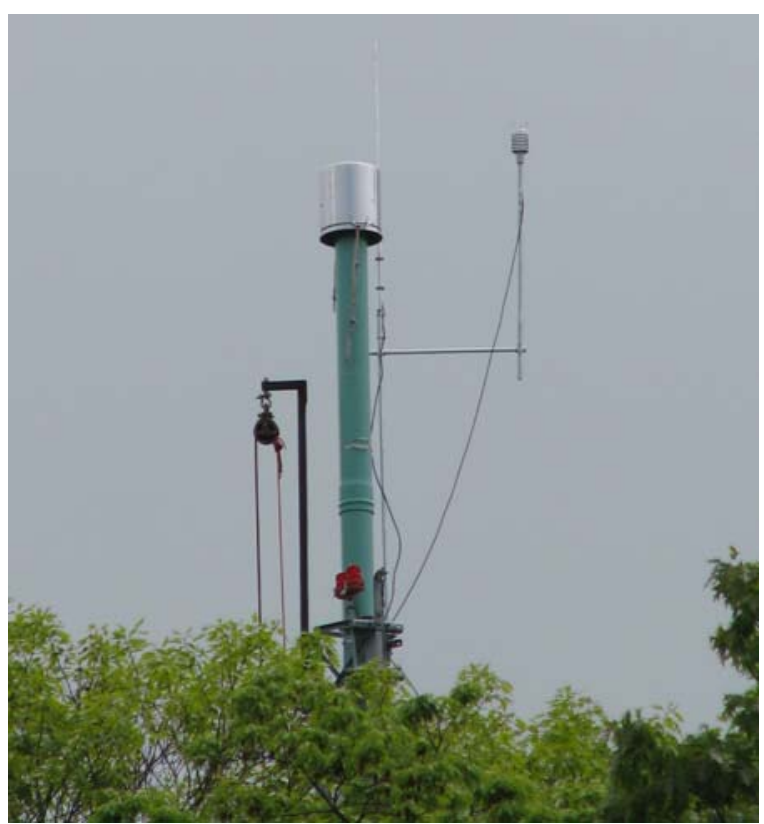

Figure 2.2. Top of sampling tower above trees at AppalAIR. Steel canister prevents water from entering air sampling tube. 


\section{Precipitation Data and Event Identification}

Daily precipitation totals at monitoring stations within the study area were analyzed during the period 01 June 2009 - 30 September 2009 (i.e., warm season) and 01 November 2009 - 30 April 2010 (i.e., cool season). Warm season and cool season events were separated due to the spatial and temporal variability in the stability, precipitation development, and biogenic and anthropogenic aerosol emissions that characterize each season (Konrad 1997). The warm season in the SAM is typically characterized by greater atmospheric instability. Increased surface heating, high rates of evapotranspiration, and a greater influx of Gulf and Atlantic moisture lead to a higher mixing ratio, often resulting in short periods of heavy rainfall. Biogenic aerosol emissions associated with photosynthetically active vegetation in the region are also higher during the warm season. Conversely, the cool season in the SAM is characterized by greater atmospheric stability and periods of both rainfall and snowfall. Biogenic aerosol emissions are lower during this season associated with the disappearance of vegetation during the cool season, while anthropogenic aerosol emissions dominate as a result of winter wood burning and fossil fuel combustion sources. The shoulder months of May and October were omitted from this study because they do not fit cleanly into either warm or cool season and exhibit characteristics of both. These transitional months encompass the change in weather systems and phenological cycles that accompany the change of seasons in the SAM.

Periods of precipitation were identified from the Boone Automated Weather Observing System (AWOS) hourly weather-type data and corroborated with hourly precipitation data from the Boone Environmental and Climate Observing Network (ECONet) station, daily precipitation totals from the Boone cooperative observer (COOP) station, and daily 
precipitation totals from the Community Collaborative Rain, Hail, and Snow (CoCoRaHS) network stations (Cifelli et al. 2005) in the town of Boone. Events that qualified for this study had measurable precipitation $(\geq 0.25 \mathrm{~mm})$ reported by at least one of the aforementioned daily precipitation data sources. Events were distinguished from one another by a six-hour time period of no precipitation, and the timing of each event was characterized in terms of starting, ending, and maturation times based on Boone AWOS hourly weather-type data (Fig. 2.3). The beginning of an event was defined as the hour corresponding with the first report of precipitation of any kind, with a minimum of six hours of no precipitation beforehand; the maturation of an event was defined as the hour corresponding with the heaviest precipitation reports; and the ending of an event was defined as the hour corresponding with the last report of precipitation of any kind. This approach was consistent with that of Perry et al. (2007 and 2010) in their investigations of snowfall in the SAM. Regional precipitation data were obtained and compiled for analysis from 59 monitoring stations in the CoCoRaHS network and from 16 monitoring stations in the COOP network, all of which were located above 305 m elevation (Fig. 2.4). 


\begin{tabular}{|c|c|c|}
\hline Date/Time (EST) & Boone AWOS Weather Type & \multirow[b]{5}{*}{ Beginning $=$} \\
\hline $10 / 14 / 20092: 42$ & & \\
\hline $10 / 14 / 20093: 42$ & & \\
\hline $10 / 14 / 20094: 42$ & & \\
\hline $10 / 14 / 20095: 42$ & & \\
\hline $10 / 14 / 20096: 42$ & Rain $\longleftarrow$ & \multirow[t]{4}{*}{ hour of first report of precipitation } \\
\hline $10 / 14 / 20097: 42$ & Light rain & \\
\hline $10 / 14 / 20098: 42$ & Rain & \\
\hline $10 / 14 / 20099: 42$ & Heavy rain & \\
\hline $10 / 14 / 2009$ 10:42 & Light rain & \multirow[t]{4}{*}{ hour of heaviest precipitation } \\
\hline $10 / 14 / 200911: 42$ & Rain & \\
\hline $10 / 14 / 200912: 45$ & Rain & \\
\hline $10 / 14 / 200913: 42$ & Heavy drizzle & \\
\hline $10 / 14 / 200914: 43$ & & Ending $=$ \\
\hline $10 / 14 / 200915: 42$ & Rain $\longleftarrow$ & \multirow[t]{8}{*}{ hour of last report of precipitation } \\
\hline $10 / 14 / 200916: 42$ & & \\
\hline $10 / 14 / 2009$ 17:42 & & \\
\hline $10 / 14 / 2009$ 18:42 & & \\
\hline $10 / 14 / 2009$ 19:43 & & \\
\hline $10 / 14 / 200920: 43$ & & \\
\hline $10 / 14 / 200921: 42$ & & \\
\hline $10 / 14 / 200922: 42$ & & \\
\hline
\end{tabular}

Figure 2.3. Assignment of beginning, maturation, and ending hours during each precipitation event.

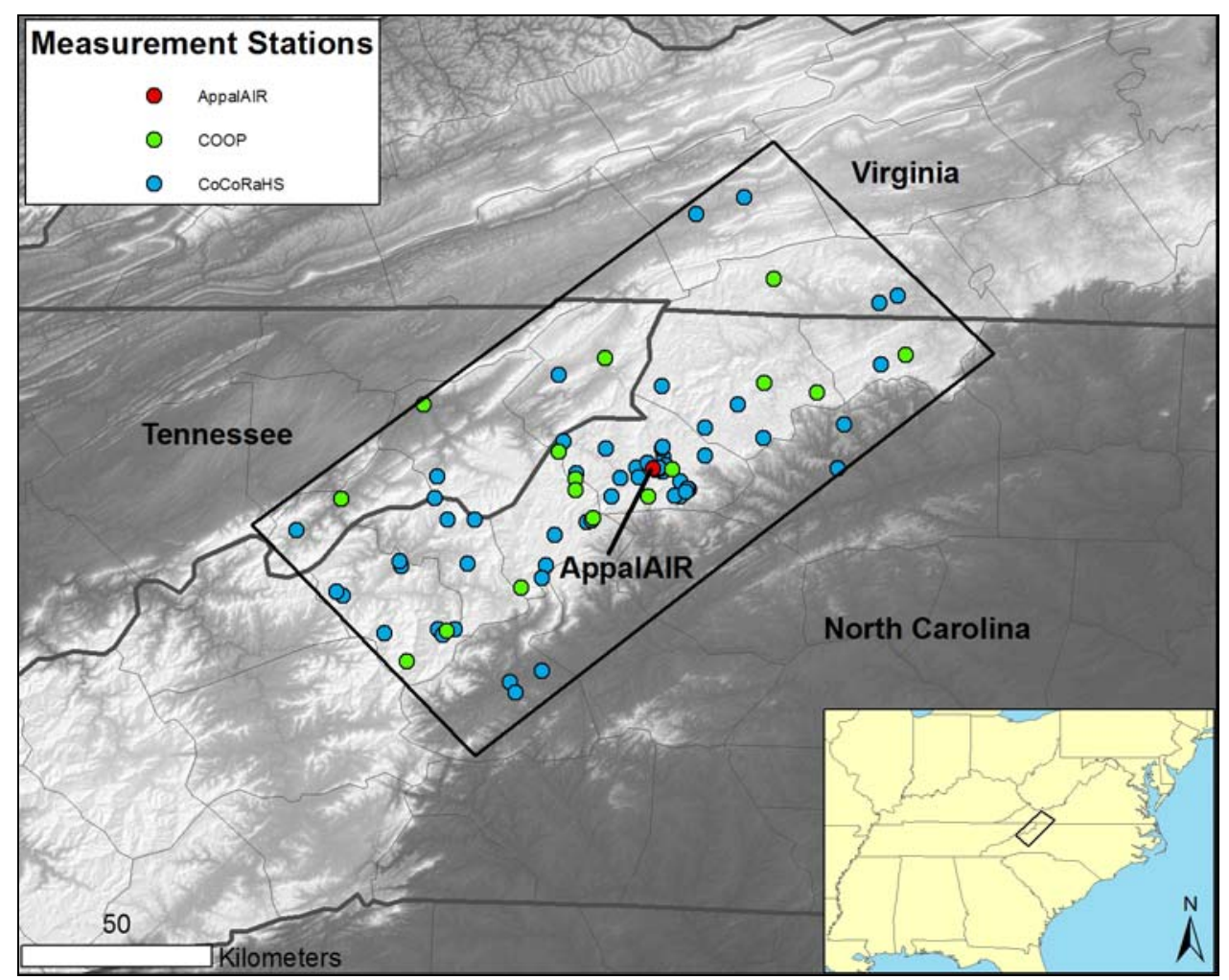

Figure 2.4. Study Area and monitoring station locations. 


\section{$\underline{\text { Synoptic Classification }}$}

Events were classified using a synoptic classification scheme developed for this project, adapted from the classification used by Keim (1996) (Figure 2.5). As discussed above, events taking place between 01 June and 30 September were defined as warm season events, and events taking place between 01 November and 30 April were defined as cool season events. Events were further classified as frontal or non-frontal events, based on archived three-hourly National Centers for Environmental Prediction (NCEP) Service Records Retention System (SRRS) Analysis and Forecast Charts (NCEP 2010a) and NCEP daily weather maps (NCEP 2010b). It was important to differentiate between frontal and non-frontal events based on the synoptic influences driving these events, particularly in terms of source region information for moisture and aerosols. Frontal events were identified in conjunction with the approach or passage of a frontal boundary or surface low pressure, while non-frontal events included convective processes or systems that showed no frontal mechanisms, such as orographic processes.

Previous studies have employed distance criteria ranging from 100 to $2500 \mathrm{~km}$ from the area of interest in order to classify various frontal events taking place in lowland areas (Muller 1977; Harnack et al. 2001) and also in mountainous terrain (Konrad 1997; Konrad and Meentemeyer 1994; Lin et al. 2001; Maddox et al. 1979). In this thesis, frontal events were defined as having occurred if a frontal boundary was within $300 \mathrm{~km}$ of the study area at the time of event maturation (Fig. 2.6). This distance accounts for the moistening and strengthening of upslope flow that can begin to generate light precipitation in the study area well ahead of a front. Based on the SRRS and NCEP weather charts, frontal events were further identified as cold, warm, stationary, or occluded, and whether the study area was 
located in the cold or warm sector. Two exceptions to this rule included the classification of Gulf Lows and Nor'easters. In the absence of a clear frontal boundary within $300 \mathrm{~km}$ of the study area, events were classified as Gulf Lows when precipitation was associated with a low pressure center in the Gulf of Mexico. Additionally, events were classified as Nor'easters if there was a surface cyclone tracking to the northeast along the East Coast. Nor'easters were also sometimes associated with a $500 \mathrm{hPa}$ low pressure center passing nearby the study area. Non-frontal events were defined as any precipitation event during which frontal activity was $>300 \mathrm{~km}$ from the study area and precipitation was not associated with the presence of a Gulf low or Nor'easter at event maturation.

Events were further characterized based on spatial coverage, described as either scattered or widespread. As a general rule, scattered events were defined as having measurable precipitation at $<75 \%$ of reporting stations, and widespread events were those with measurable precipitation at $\geq 75 \%$ of reporting stations. Additionally, event types were analyzed according to upper and lower quartile precipitation values, creating subcategories of events representing light and heavy precipitation, respectively. Daily mean composite plots were created for individual events/groups of similar events illustrating atmospheric variables including geopotential height at $500 \mathrm{hPa}$ and sea level pressure (NCEP 2010c). Composite plots were created using the NCEP/National Center for Atmospheric Research (NCAR) reanalysis dataset, which is a global dataset composed of daily meteorological values from 1948 to the present (Kalnay et al. 1996). 


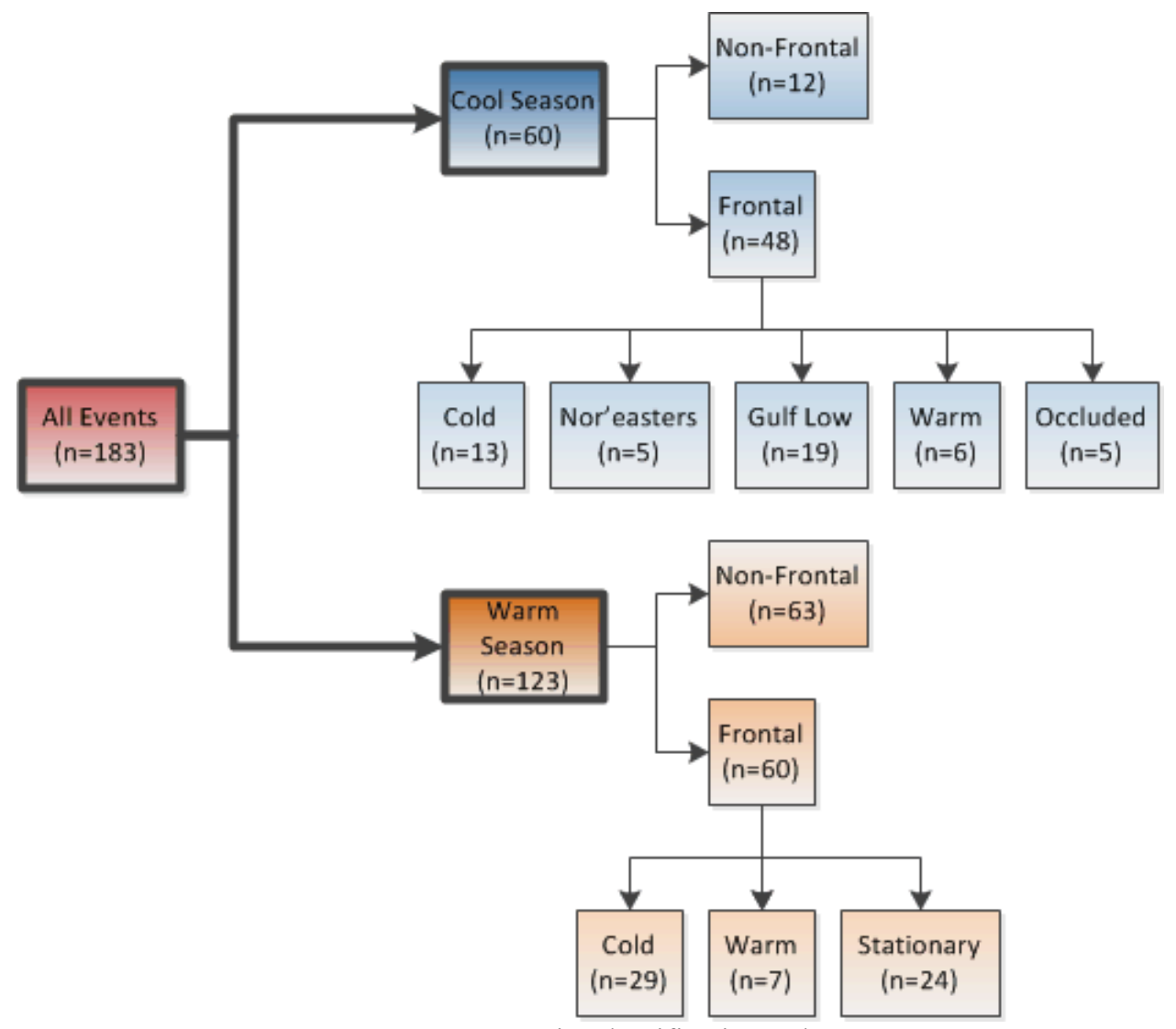

Figure 2.5. Synoptic Classification Scheme

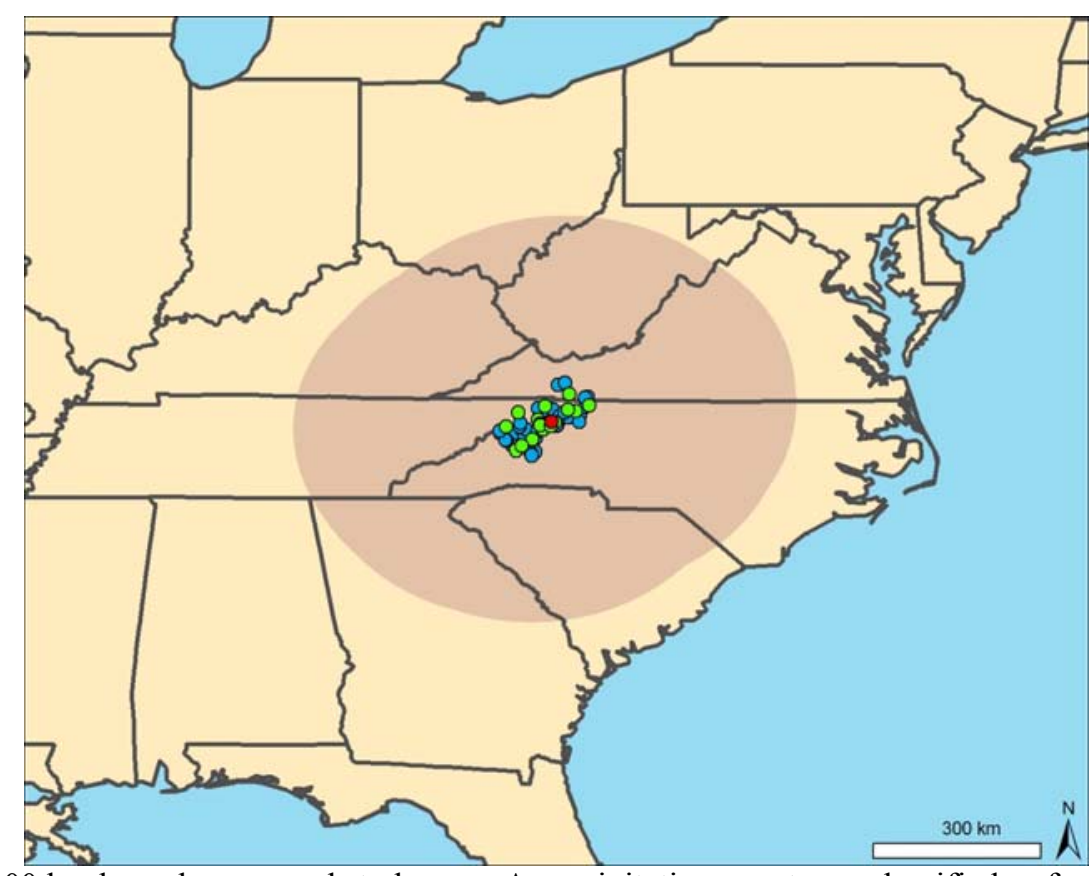

Figure 2.6. $300 \mathrm{~km}$ boundary around study area. A precipitation event was classified as frontal if a frontal boundary was located within the shaded area at or near the time of event maturation. 


\section{Meteorological Data}

Meteorological data were collected from the Beech Mountain monitoring station (Fig. 2.7) (BEECHTOP, $36.18^{\circ},-81.88^{\circ} ; 1,678 \mathrm{~m}$ ), located approximately $17.4 \mathrm{~km}$ west of AppalAIR (Fig. 2.8). Variables of temperature, relative humidity, wind speed, and wind direction were compiled for the beginning and maturation hour of each event and summarized by event type. Data were collected from the State Climate Office of North Carolina Climate Retrieval and Observations Network of the Southeast (CRONOS) database. Data were not available from 26 December 2009 through 10 January 2010 due to severe ice and wind causing the tower to collapse. In contrast to Boone and other valley or ridge-top locations, wind direction at Beech Mountain is not significantly controlled by local topography. Data from the BEECHTOP monitoring station represented atmospheric conditions at the approximately $825 \mathrm{hPa}$ height throughout the region and therefore were representative of lower tropospheric conditions across the study area.

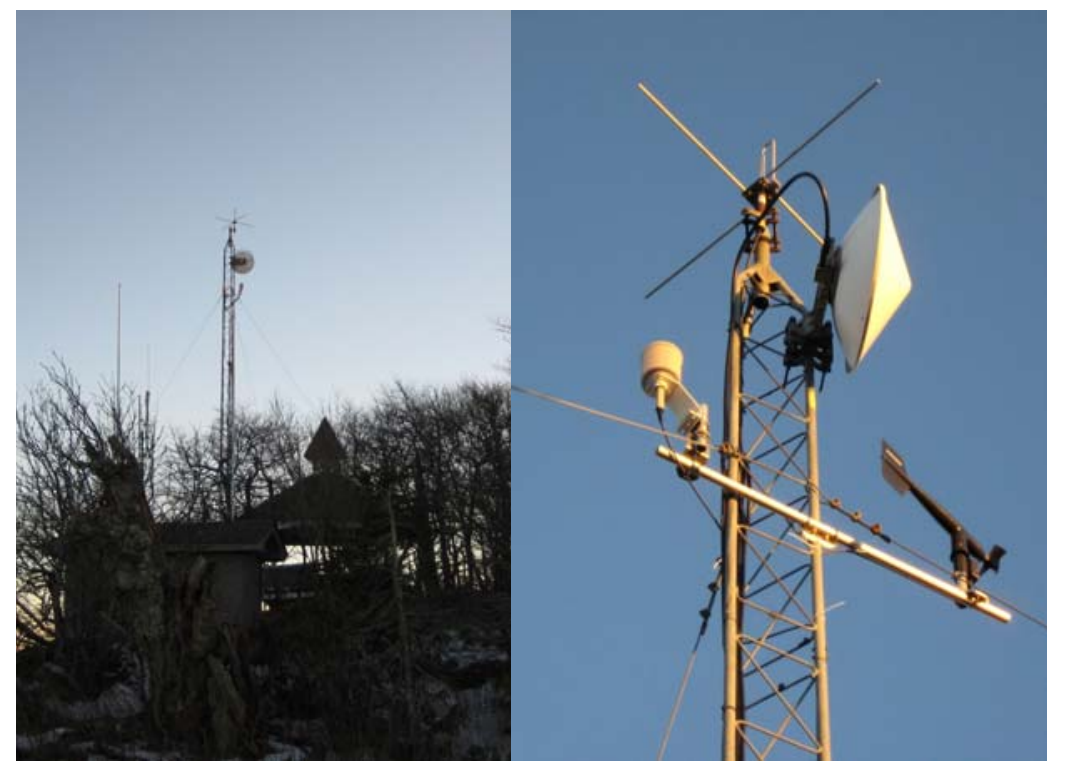

Figure 2.7. Meteorological instrumentation at BEECHTOP monitoring station. 


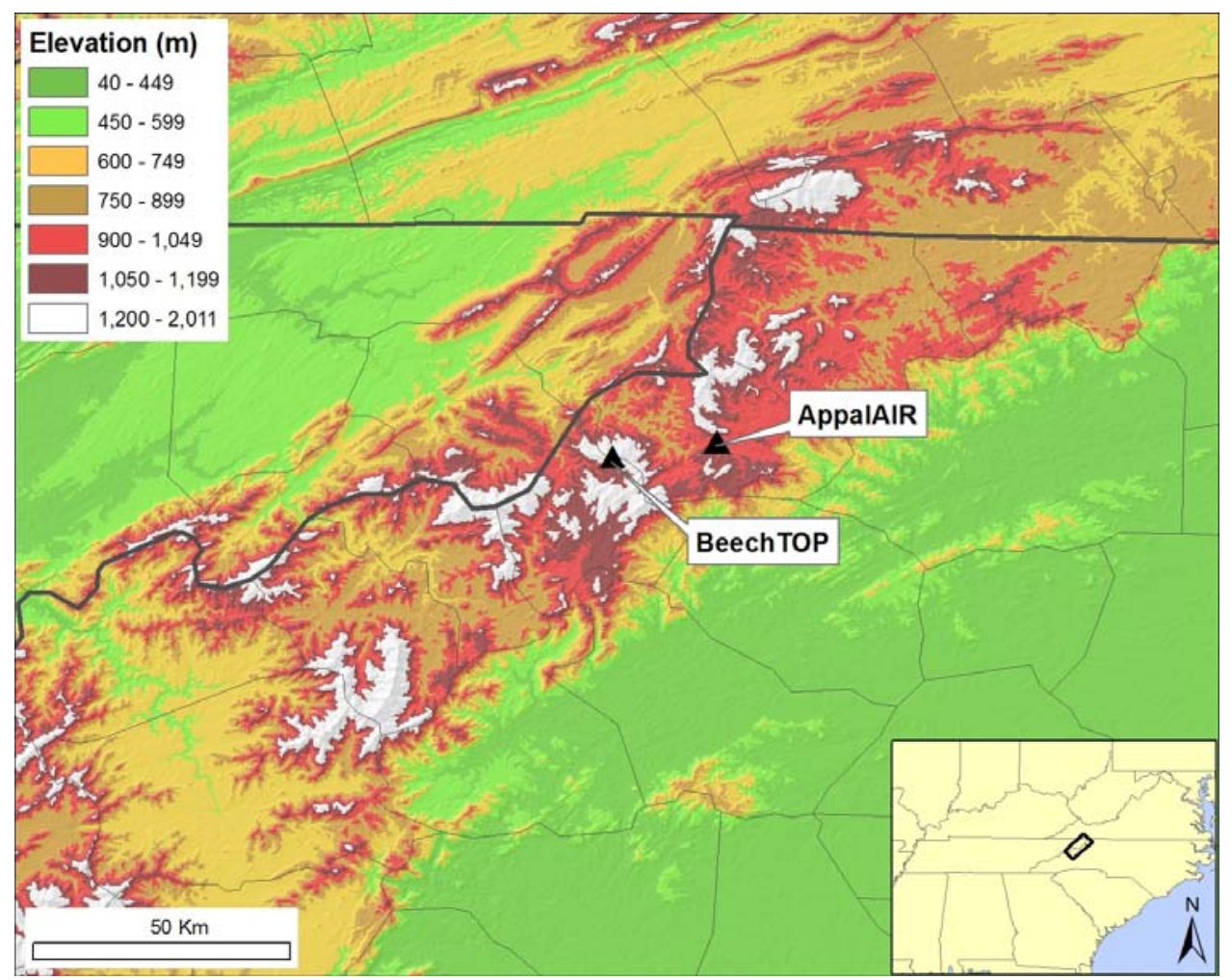

Figure 2.8. Location of BEECHTOP monitoring station.

\section{$\underline{\text { Aerosol Data }}$}

Hourly aerosol values collected at AppalAIR dated back to 01 June 2009. Properties including aerosol absorption, scattering, backscatter fraction, SSA, SAE, and AAE (Table 2) were analyzed for the duration of each event (i.e., during the beginning, maturation, and ending times).SAE and AAE were calculated using Equation (1). SAE values were obtained from a 3-wavelength integrating nephelometer (TSI, Inc.), while AAE values were obtained from a Particle Soot Absorption Photometer (PSAP, Radiance Research, Inc.) housed at AppalAIR. All values were analyzed for aerosol particles $10 \mu \mathrm{m}$ in diameter or less, as this size limit accounted for the optical properties of virtually all aerosols measured at AppalAIR. 


\section{$\underline{\text { Trajectory Analysis }}$}

\section{Trajectories}

The NOAA HYSPLIT model is a tool for computing simple air parcel trajectories (Draxler and Hess 1997, 1998; Draxler 1999). This model was used to create 72-hr backward air trajectories ending at the maturation time of each event (Fig. 2.9). The coordinate location of AppalAIR was used as the ending location of each trajectory. Different ending heights were used for warm season versus cool season trajectories. In the SAM, the higher sun angle in the warm season leads to increased surface warming causing a thicker lower troposphere (i.e., higher $500 \mathrm{hPa}$ geopotential height and greater 1000-500 hPa thickness) than in the cool season. The atmospheric boundary layer is also generally thicker in the warm season (Whiteman 2000). Therefore, the warm season trajectories were run at $2000 \mathrm{~m}$ above sea level (asl) to simulate conditions at the $800 \mathrm{hPa}$ pressure height; ending heights for the cool season trajectories were run at $1500 \mathrm{~m}$ asl to simulate conditions at the $850 \mathrm{hPa}$ pressure height. This approach accounted for surface-atmosphere interactions in the lower troposphere and was most illustrative of the low-level flow patterns associated with seasonal precipitation in the region.

HYSPLIT trajectories were simulated using four-dimensional $(\mathrm{x}, \mathrm{y}, \mathrm{z}, \mathrm{t})$ meteorological fields from the HYSPLIT-compatible meteorological model dataset archives. The National Weather Service (NWS) 40-km spatial resolution and 3-hr temporal resolution Eta Data Assimilation System (EDAS) meteorological dataset was downloaded in semi-monthly increments to include 01 June 2009 through 30 September 2010. EDAS was produced by NOAA NCEP and combined radar and aircraft data to create eight three-hourly initial states 
during a 24-hr period to contribute to the NCEP North American Mesoscale (NAM) forecast model (NCEP 2010d).

NOAA HYSPLIT MODEL

\section{Backward trajectory ending at 0700 UTC 30 Jan 10} EDAS Meteorological Data

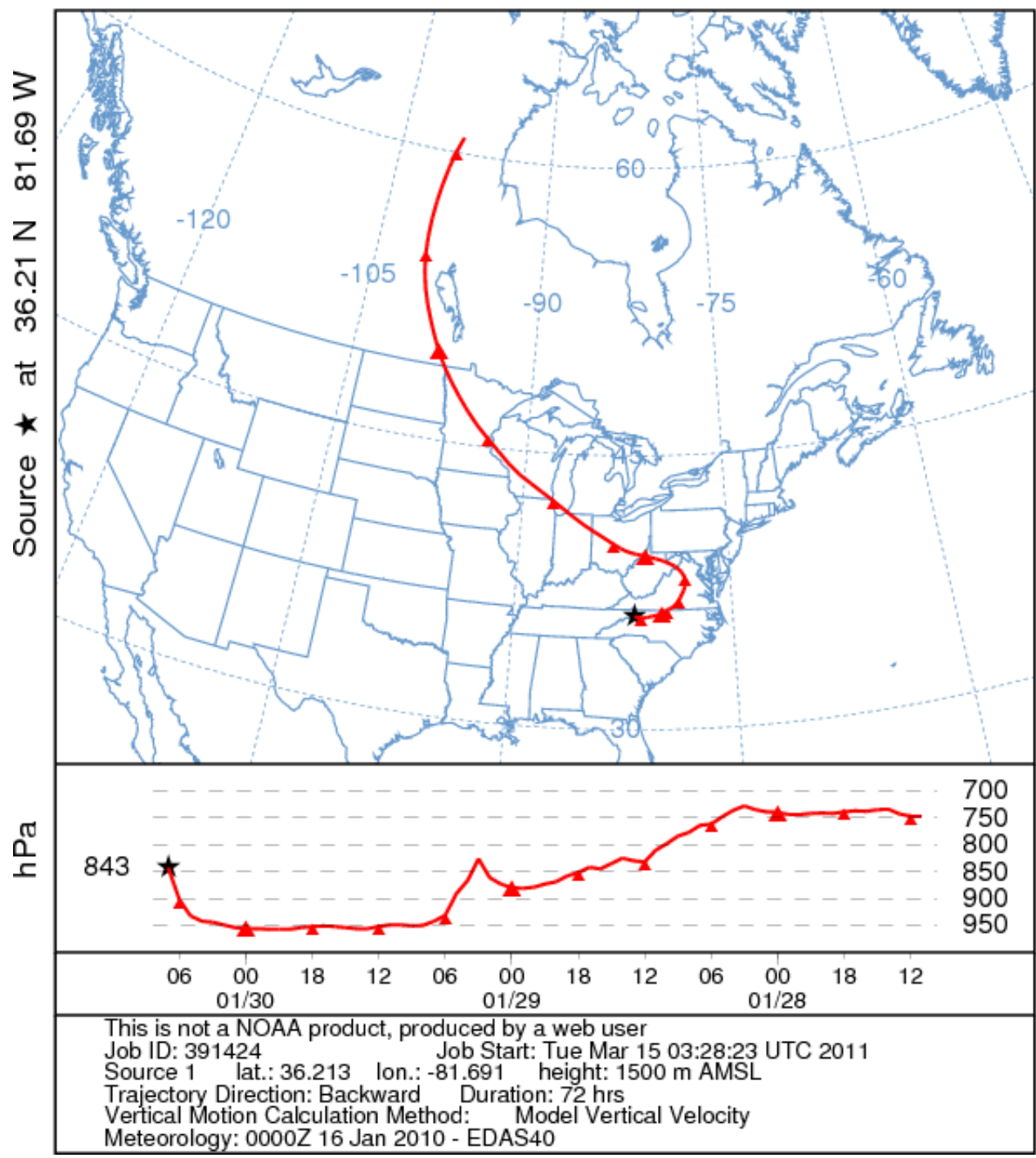

Figure 2.9. Example of a 72-hr backward air trajectory created using HYSPLIT. Trajectory ends at the coordinate location of AppalAIR. 


\section{Trajectory Clusters}

The HYSPLIT statistical cluster analysis combined similar trajectories into groups or clusters. This process maximized the differences among individual clusters of trajectories, and each cluster represented different synoptic regimes and source regions influencing the entire sample of trajectories. A cluster analysis was performed on backward air trajectories based on the event groups outlined in the synoptic classification scheme (Fig. 2.5). Resulting cluster options often omit one or more trajectories if they are considered severe outliers.

HYSPLIT provided a variety of cluster numbers from which to choose based on total spatial variance (TSV), which accounted for the variance within each cluster relative to the average trajectory, or trajectory center, of each cluster. Change in TSV was plotted against number of clusters (Fig. 2.10). A large increase in the change in TSV indicated significantly different trajectories being merged into the same cluster. Therefore, the appropriate number of clusters was the number directly preceding the large change in TSV. The choice of final number of clusters for analysis can be somewhat subjective, but was not arbitrary.

\section{$\underline{\text { Statistical Tests }}$}

All datasets including aerosol properties, precipitation data, and other meteorological values were tested for normality $(\alpha=0.05)$ using the Kolmogorov-Smirnov test. For data that were not normally distributed, differences of means were tested $(\alpha=0.05)$ using the MannWhitney U two-sample rank sums test (non-parametric). When normally distributed, an independent samples T-test (parametric) was used. Differences of means of meteorological and aerosol values were tested for each event type, and comparisons were made between seasons, and also among different event types within the same season. Precipitation events 
also were analyzed in terms of upper and lower quartile precipitation values (i.e., heavy and light precipitation events) and the corresponding aerosol values in order to assess the pattern of aerosols associated with light precipitation versus heavy precipitation. Aerosol values at the beginning and maturation hour of each event were analyzed separately. Aerosol values at the beginning hour of each event indicated the properties of aerosols before heavy precipitation set in, giving information about aerosol loading and the potential for impacting precipitation. Values at maturation indicated the interaction of aerosols with precipitation in terms of a possible raining out effect. As a result, the differences in values from beginning to maturation were analyzed.

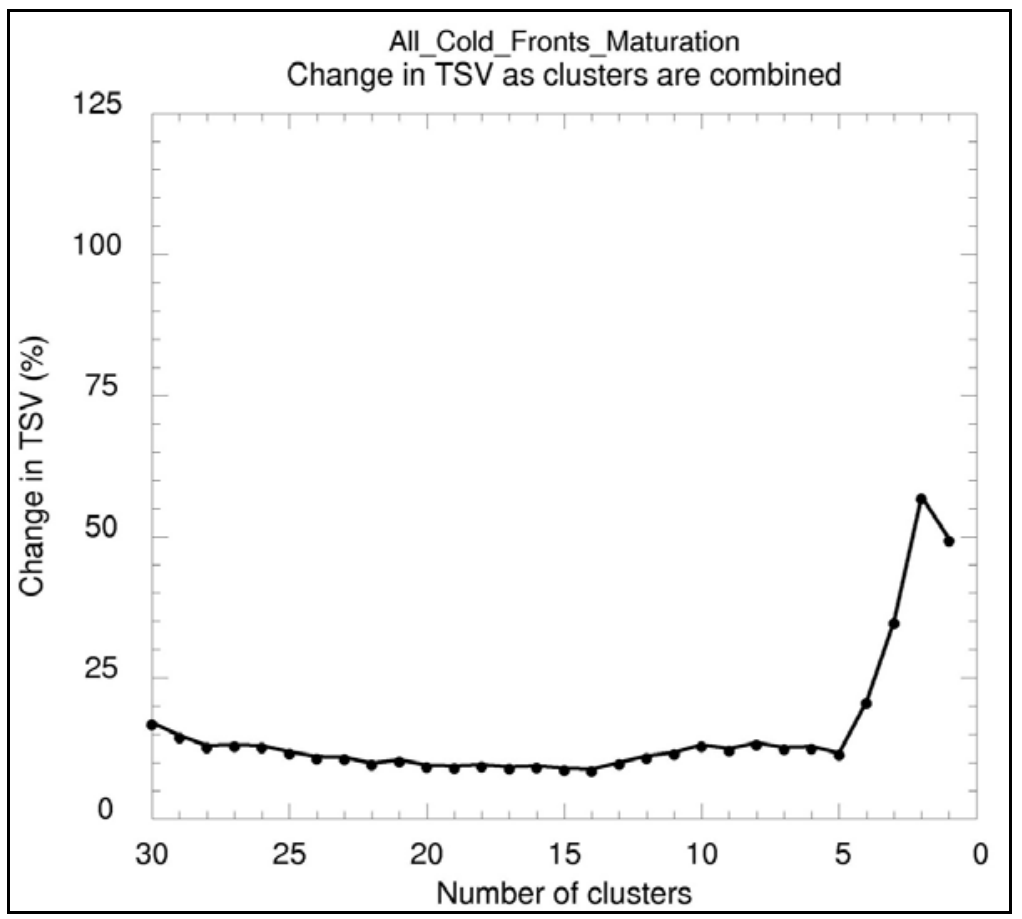

Figure 2.10. Example of a change in TSV plot for cluster analysis. Five was determined to be the optimal number of clusters in this example because of the large change in TSV. 
Chapter III

\section{RESULTS AND DISCUSSION}

\section{Introduction}

The purpose of this thesis is to assess aerosol-precipitation interactions in the SAM from

June 2009 to September 2010 by analyzing 1) variations in aerosol properties by season and by synoptic event type, 2) differences in aerosol properties between the 2009 and 2010 warm seasons, and 3) the effects of air mass source region on aerosol properties. This chapter begins with a discussion of the anomalous weather patterns that impacted the SAM during the study period. The second section focuses on the synoptic classification scheme created specifically for this thesis, highlighting differences between precipitation events taking place during warm and cool season events. The third section addresses the aerosol climatologies of the study period focusing on seasonal and synoptic variation in aerosol properties affecting the SAM using HYSPLIT backward air trajectory analysis to determine air mass source region information. The fourth section presents a comparison of the synoptic and aerosol properties of the climatological summers of June, July, and August (JJA) of 2009 and 2010. These summers were characterized by different and highly anomalous weather patterns, resulting in interesting differences in the synoptic and aerosol climatologies of each season. 


\section{Anomalous Study Period in the SAM}

Highly anomalous weather patterns impacted the SAM during the study period of this thesis, resulting from various phases of ENSO and associated with a highly negative AO. While ENSO is most instrumental in the climatic variability of the tropics, impacts are seen in the northern hemisphere as well. El Niño is associated with warmer than normal eastern tropical Pacific waters causing a strong low pressure pattern in the eastern South Pacific, referred to as the Southern Oscillation. Warm-phase ENSO typically occurs every two to five years and has a large impact on global weather. This pattern can lead to wetter summer conditions and both colder and wetter winter conditions across the southeastern United States. Conversely, cool-phase ENSO, or La Niña, is associated with cooler water temperatures in the tropical Pacific, leading to a high pressure pattern at the surface near the equator. This pattern can lead to warmer, drier conditions in the SEUS (Gershunov and Barnett 1998). The AO is an index used to describe the differences in cool season sea level pressure values between the Arctic and mid-latitude regions of the northern hemisphere (Thompson and Wallace 2000). The AO strongly influences climatic variability in extratropical regions of the northern hemisphere (Cohen et al. 2010).

JJA 2009 was characterized by anomalously cool temperatures and higher precipitation than normal (Fig. 3.1) as a result of a persistent $500 \mathrm{hPa}$ trough over the eastern US. Temperature anomalies at $850 \mathrm{hPa}$ illustrated the abnormally cool temperatures affecting much of the Midwest and SEUS, and $500 \mathrm{hPa}$ height anomalies indicated negative geopotential height departures consistent with a cooler lower troposphere (Fig. 3.2). Observed daily high temperatures in Boone during July 2009 were particularly anomalous, 
with 14 days exhibiting maximum high temperatures below the normal monthly maximum temperature (Fig. 3.3)

The climatological winter of 2009-2010, including December, January, and February (DJF), was characterized by anomalously low temperatures and increased precipitation (Fig.

3.4). Temperature anomalies at $850 \mathrm{hPa}$ illustrated the abnormally cool temperatures affecting the region, and $500 \mathrm{hPa}$ height anomalies indicated a cooler lower troposphere (Fig. 3.5). This winter season was considered the most severe winter in the SAM since the late 1970's with many stations across the region setting new records for total snowfall and days of snow cover. In addition to the effects of the warm-phase ENSO, a negative Arctic Oscillation (AO) led to a pattern of high pressure at high latitudes and low pressure at midlatitudes. Warming in the polar vortex pushed the jet stream to the south, resulting in anomalously low temperatures and high moisture content in the SEUS (Cohen et al. 2010).

Under the influence of cool-phase ENSO conditions, JJA 2010 was characterized by anomalously warm temperatures and drier conditions than normal (Fig. 3.6). Temperature anomalies at $850 \mathrm{hPa}$ illustrated the abnormally warm temperatures across the region, and positive $500 \mathrm{hPa}$ height anomalies were consistent with a warmer lower troposphere (Fig. 3.7). 


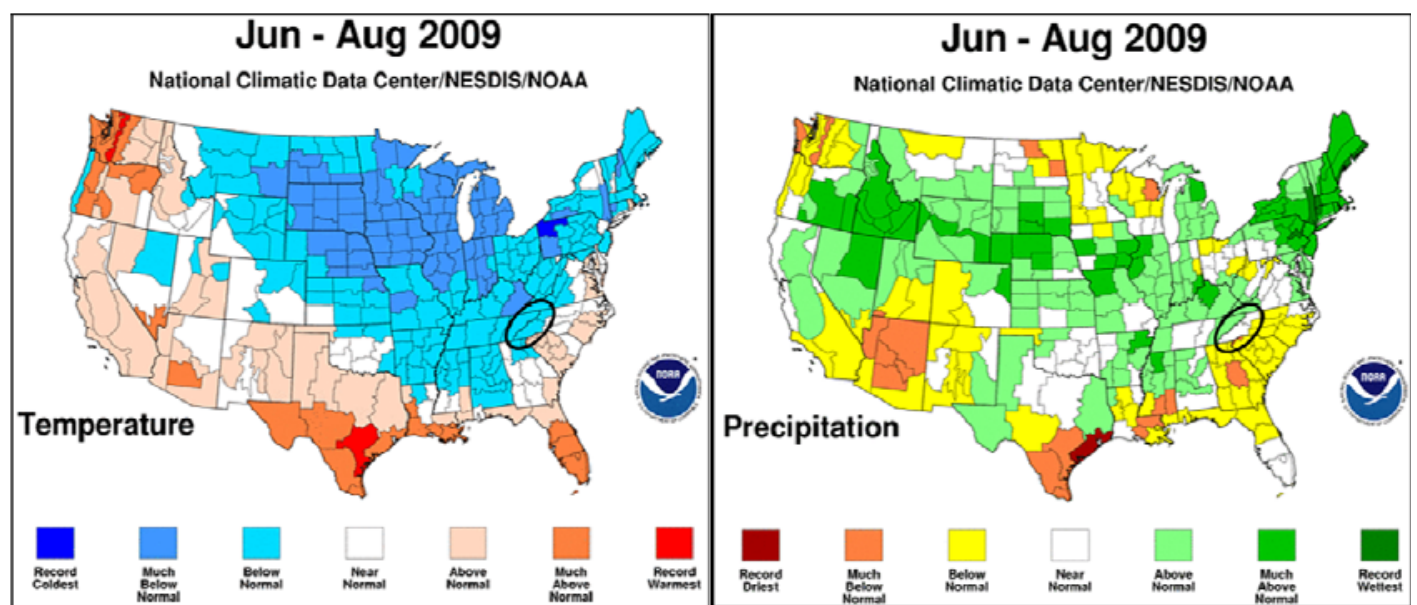

Figure 3.1. Temperature and precipitation departures during JJA 2009. (Images provided by the NOAA/ESRL Physical Sciences Division, Boulder Colorado, USA, from their Web site at http://www.esrl.noaa.gov/psd/).
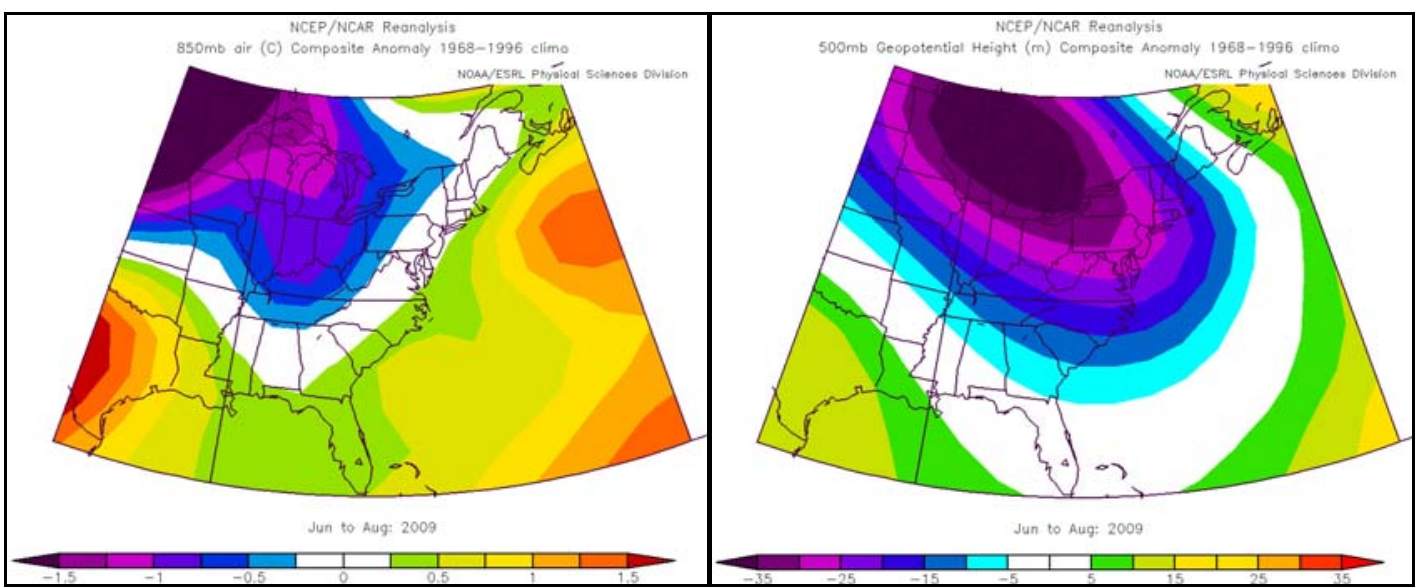

Figure 3.2. $850 \mathrm{hPa}$ temperature (left) and $500 \mathrm{hPa}$ height anomalies (right) during JJA 2009. (Images provided by the NOAA/ESRL Physical Sciences Division, Boulder Colorado, USA, from their Web site at http://www.esrl.noaa.gov/psd/).

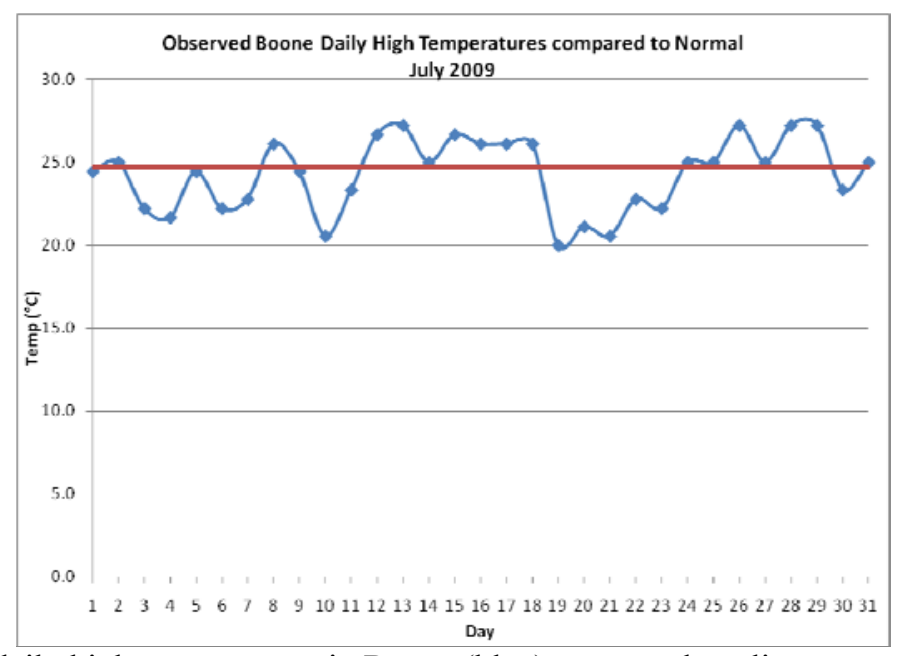

Figure 3.3. Observed daily high temperatures in Boone (blue) compared to climate normal (red) for July 2009.

Data provided by the State Climate Office of NC CRONOS database. 


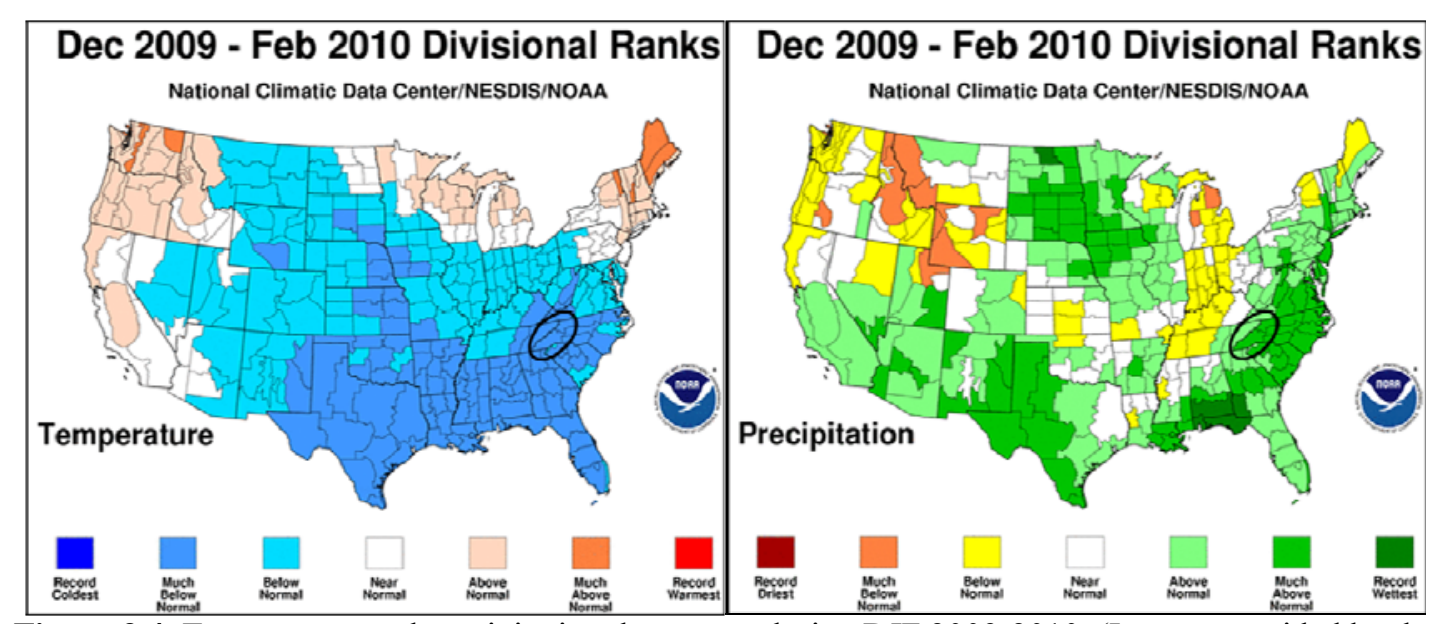

Figure 3.4. Temperature and precipitation departures during DJF 2009-2010. (Images provided by the NOAA/ESRL Physical Sciences Division, Boulder Colorado, USA, from their Web site at http://www.esrl.noaa.gov/psd/).

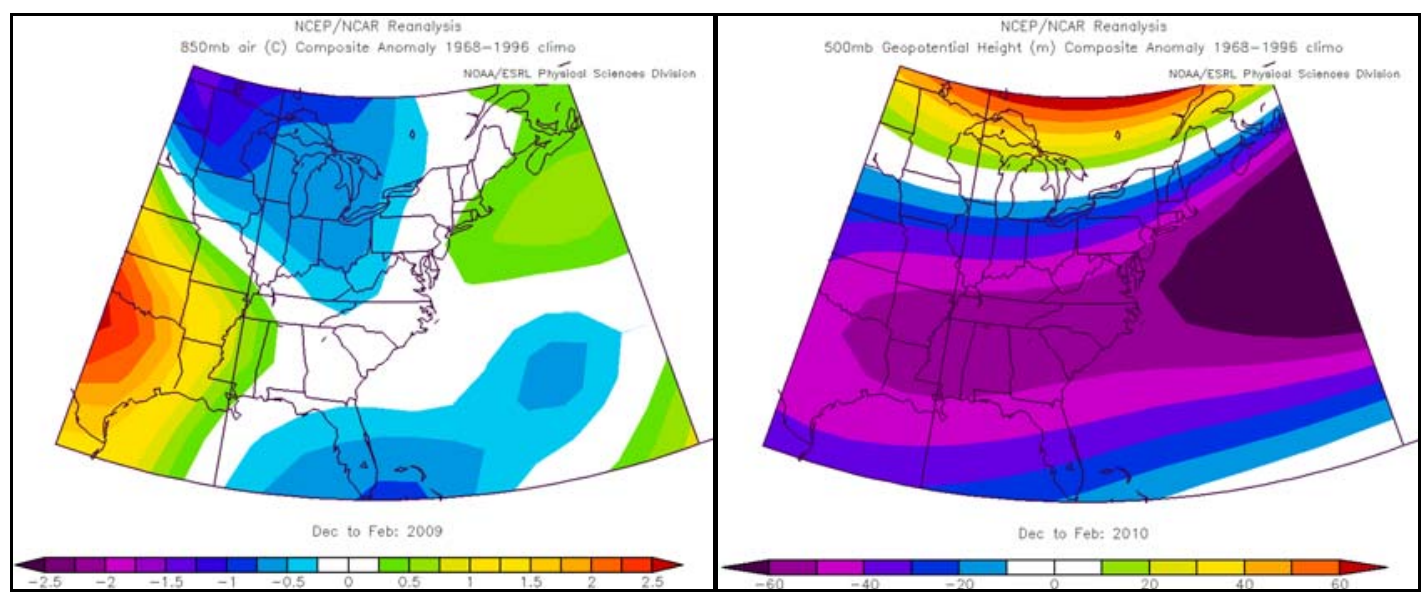

Figure 3.5. $850 \mathrm{hPa}$ temperature (left) and $500 \mathrm{hPa}$ height anomalies (right) during DJF 2009-2010. (Images provided by the NOAA/ESRL Physical Sciences Division, Boulder Colorado, USA, from their Web site at http://www.esrl.noaa.gov/psd/). 


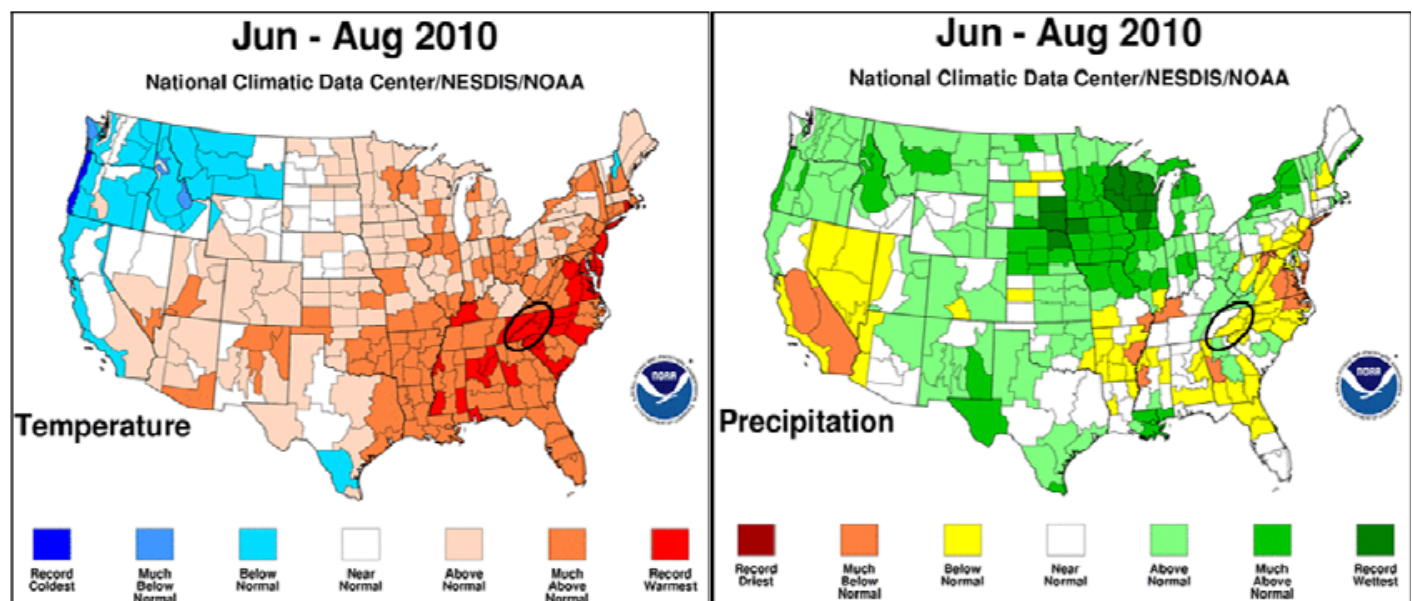

Figure 3.6. Temperature and precipitation departures during JJA 2010. (Images provided by the NOAA/ESRL Physical Sciences Division, Boulder Colorado, USA, from their Web site at http://www.esrl.noaa.gov/psd/).
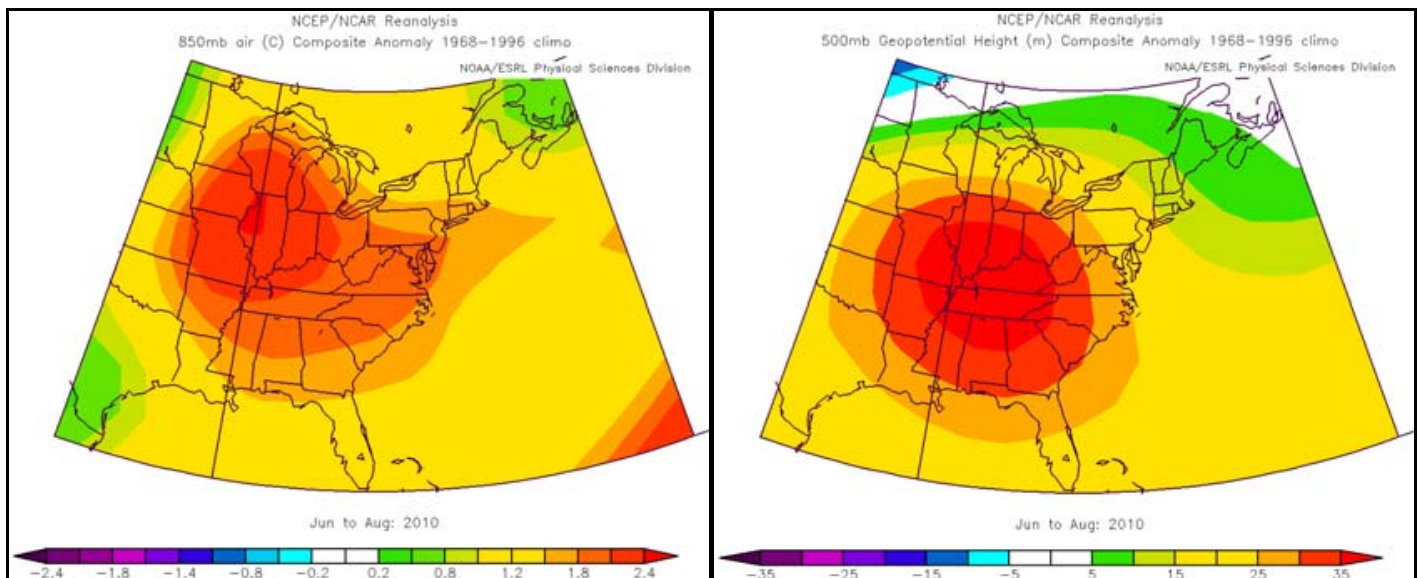

Figure 3.7. $850 \mathrm{hPa}$ temperature (left) and $500 \mathrm{hPa}$ height anomalies (right) during JJA 2010. (Images provided by the NOAA/ESRL Physical Sciences Division, Boulder Colorado, USA, from their Web site at http://www.esrl.noaa.gov/psd/).

\section{Synoptic Climatology}

Stark contrasts existed between warm season and cool season precipitation events (Table

3.1). The study period included two warm seasons (2009 and 2010), resulting in 123 warm season precipitation events, of which $21 \%$ of events took place during June, $28 \%$ during July, $32 \%$ during August, and 20\% during September. Warm season events included precipitation associated with cold, warm, and stationary fronts, as well as non-frontal mechanisms involving shallow upslope flow and terrain-induced convection. Warm season precipitation 
events lasted an average of 5 hours, ranging in duration from 1 to 29 hours, and producing an average of $8.9 \mathrm{~mm}$ of precipitation.

Overall, warm season events were characterized by the presence of the NASH (or Bermuda High) to the east (Fig. 3.8) (e.g., Li et al. 2010). The presence of this high pressure system favors precipitation in the SEUS by the advection of moisture from the Atlantic and the Gulf of Mexico, resulting in an average wind direction from the southwest for warm season precipitation events (Table 3.1). Events were also characterized by slight long-wave troughing at the $500 \mathrm{hPa}$ level, suggesting a slightly cooler lower troposphere compared to areas east and west of the study area (Fig. 3.9). This characteristic was consistent with the presence of cooler air masses or precipitation. Air mass source regions during the warm season included a strong southerly component, with roughly $43 \%$ originating either in the Gulf of Mexico or off the Atlantic coast with inferred high mixing ratios (Fig. 3.10). Additionally, $38 \%$ of events originated west or northwest of the study area, while $20 \%$ originated in the northeast and exhibited a southeasterly approach to the study area.

This thesis included only one cool season, resulting in 60 precipitation events. Of these events, roughly $7 \%$ took place in November, $13 \%$ in December, $27 \%$ in January, $22 \%$ in February, 20\% in March, and 13\% in April. Cool season events included frontal precipitation associated with cold, warm, and occluded fronts, as well as Gulf lows and Nor'easters. Nonfrontal mechanisms, such as northwest upslope flow (e.g., Perry et al. 2007) were also responsible for some events. Cool season precipitation events exhibited an overall longer duration than warm season events, lasting an average of 16 hours and ranging in duration from 1 to 66 hours, and producing an average of $13.4 \mathrm{~mm}$ of precipitation. 
Cool season precipitation events were associated with lower pressures over the study area and to the northeast, with higher pressures to the west (Fig. 3.8). This pattern would suggest the advection of air from inland areas and much less moisture originating in the Gulf of Mexico or the Atlantic. Slight troughing of 500hPa heights near the study area was consistent with the presence of cool air masses and precipitation (Fig. 3.9). Most air masses associated with cool season precipitation events originated southwest of the study area or in the Midwest and approached the study area from the west and southeast (Fig. 3.10).

Table 3.1. Seasonal summaries of precipitation events. Average total precipitation values from COOP and CoCoRaHS stations in study area. Temperature, relative humidity, wind speed, and wind direction are from the BEECHTOP meteorological station.

\begin{tabular}{|c|c|c|c|c|c|c|c|}
\hline Season & $\mathbf{n}$ & $\begin{array}{c}\text { Coverage } \\
(\%)\end{array}$ & $\begin{array}{c}\text { Avg. Total Precip } \\
(\mathbf{m m})\end{array}$ & $\begin{array}{c}\text { Temperature } \\
\left({ }^{\circ} \mathbf{C}\right)\end{array}$ & $\begin{array}{c}\text { Relative } \\
\text { Humidity (\%) }\end{array}$ & $\begin{array}{c}\text { Wind Speed } \\
(\mathbf{m} / \mathbf{s})\end{array}$ & $\begin{array}{c}\text { Wind Direction } \\
(\mathbf{d e g r e e s})\end{array}$ \\
\hline Warm & 123 & 80 & 8.9 & 15.8 & 95.6 & $244(\mathrm{SW})$ \\
\hline Cool & 60 & 69 & 13.4 & -1.6 & 98.0 & \\
\hline
\end{tabular}




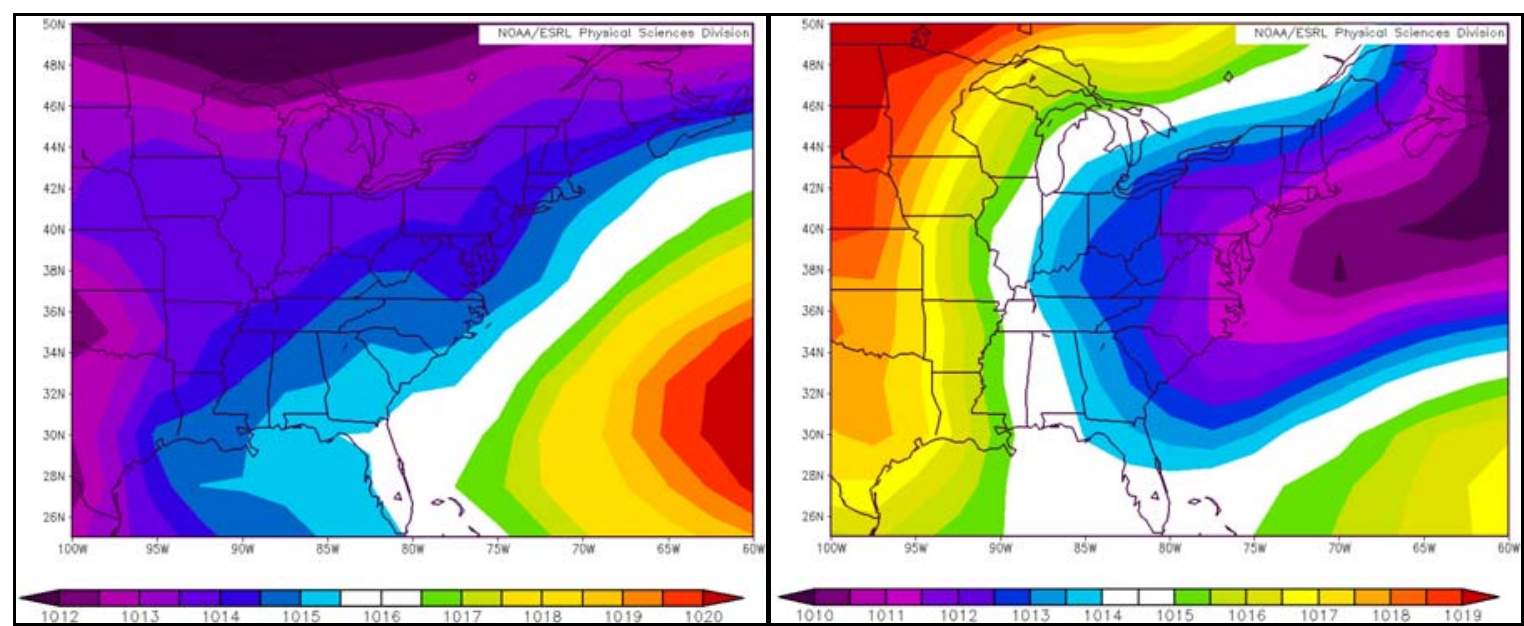

Figure 3.8. Composite plots of sea level pressure (hPa) during maturation hour of each precipitation event during warm season (left) and cool season (right). (Images provided by the NOAA/ESRL Physical Sciences

Division, Boulder Colorado, USA, from their Web site at http://www.esrl.noaa.gov/psd/).

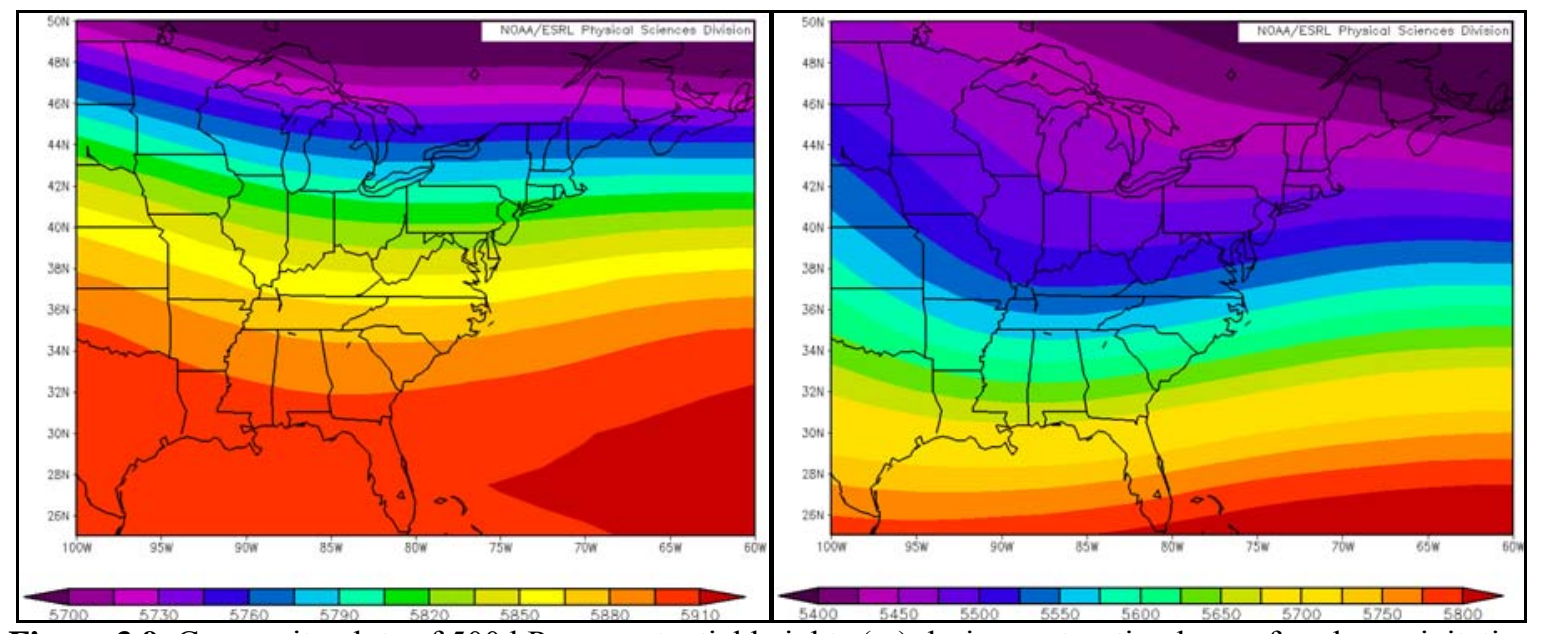

Figure 3.9. Composite plots of $500 \mathrm{hPa}$ geopotential heights $(\mathrm{m})$ during maturation hour of each precipitation event during warm season (left) and cool season (right). (Images provided by the NOAA/ESRL Physical Sciences Division, Boulder Colorado, USA, from their Web site at http://www.esrl.noaa.gov/psd/). 


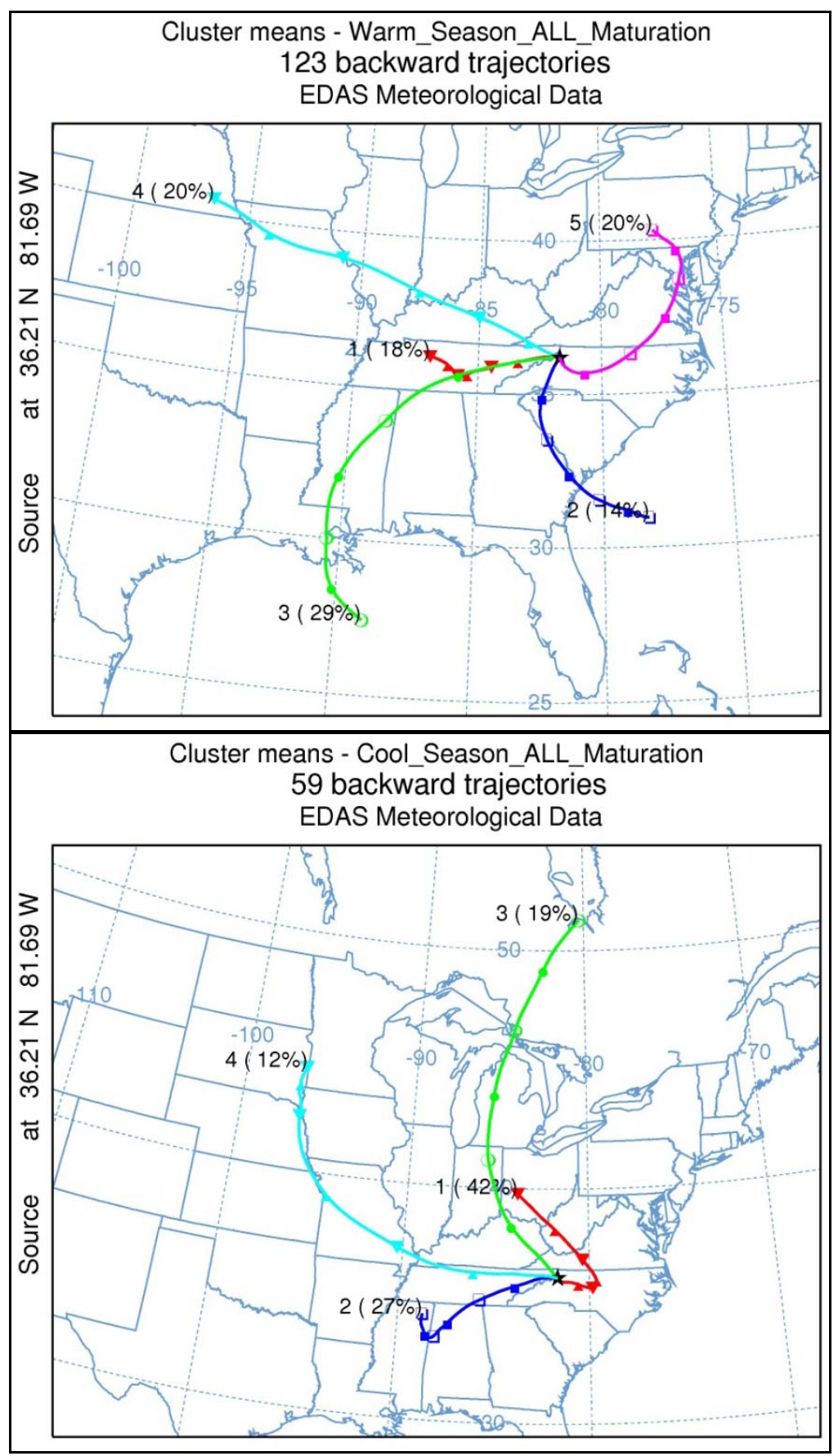

Figure 3.10. HYSPLIT cluster analysis of backward air trajectories representing maturation hour of each precipitation event during warm season (left) and cool season (right). Clusters are numbered and values in parentheses represent the percentage of backward air trajectories included in each cluster. Outliers were omitted from cluster analysis. 


\section{$\underline{\text { Warm Season }}$}

Due to the time period of this study, two vastly different warm seasons were analyzed together. As described above, the 2009 warm season was largely characterized by cooler wetter conditions, while the 2010 warm season was largely characterized by warmer, drier conditions. Overall, warm season frontal events constituted $49 \%$ of warm season precipitation events and were characterized by short, intense precipitation (Table 3.2). The synoptic differences among these event types are illustrated by SRRS analysis charts (Fig. 3.11) and meteorological summaries (Table 3.2). Warm season frontal events were typically characterized by lower pressures in the study region and the presence of the NASH offshore to the east of the study area, consistent with moist air advection from the Atlantic and the Gulf of Mexico (Fig. 3.12). The Atlantic and the Gulf of Mexico were a common source of origin for air masses associated with warm season frontal precipitation, as were areas to the west and northwest of the study area (Fig. 3.13).

Cold fronts accounted for $48 \%$ of warm season frontal precipitation events (Table 3.2). Precipitation events associated with warm season cold fronts were largely associated with low pressure in Canada north of the study area with a trailing cold front (Fig. 3.12). Troughing of $500 \mathrm{hPa}$ heights near the study area suggested the presence of a cool air mass and precipitation (Fig. 3.12). Events in this category exhibited an average wind direction from the west-northwest (Table 3.2), with the majority of air masses originating to the west (Fig. 3.13) and presumably associated with high moisture content from the Gulf of Mexico. Air masses also originated in the Midwest, as well as more locally in southern West Virginia, roughly $120 \mathrm{~km}$ north of the study area. Wind speeds at maturation ranged from $1.3-8.4 \mathrm{~m} / \mathrm{s}$ with an average of $3.9 \mathrm{~m} / \mathrm{s}$ (Table 3.2$)$. 
Warm fronts accounted for $12 \%$ of warm season frontal precipitation events (Table 3.2). Events were characterized by the presence of a large area of low pressure just west of the study area likely causing advection of warmer air from the southeast (Fig. 3.12). Ridging of $500 \mathrm{hPa}$ heights near the study area indicated warmer air and drier conditions at the study area (Fig. 3.12). These events were typically widespread across the study area, and approached from the west, with a few air masses originating from coastal areas (Fig. 3.13). These events are also typically warmer at BEECHTOP during maturation. Wind speeds ranged from $1.2-7.4 \mathrm{~m} / \mathrm{s}$ with an average of $3.5 \mathrm{~m} / \mathrm{s}$ from the southwest (Table 3.2).

Stationary fronts accounted for $40 \%$ of warm season frontal precipitation events and were the highest precipitation producers (Table 3.2). These events were generally widespread and originated either northwest of the study area or from the Gulf of Mexico, with a few cases that originated northeast of the study area and approached from the southeast (Fig. 3.13). These events were characterized by widespread low pressure west and north of the study area, and slight troughing of $500 \mathrm{hPa}$ heights (Fig. 3.12). The study area was most often in the cold sector of the frontal boundary at maturation, resulting in higher precipitation totals possibly tied to isentropic lift associated with lower-tropospheric warm air advection or elevated convection over a stable surface layer. Wind speeds at maturation ranged from $1.5-$ $8.8 \mathrm{~m} / \mathrm{s}$ with an average of $3.8 \mathrm{~m} / \mathrm{s}$ from the southwest (Table 3.2).

Non-frontal events constituted approximately $51 \%$ of warm season frontal precipitation events in this study (Table 3.2). These event types took place in the absence of a clear frontal boundary within $300 \mathrm{~km}$ of the study area (Fig. 3.11). In very few cases (n=3), precipitation was tied to a $500 \mathrm{hPa}$ low pressure passing directly over the study area. If more common, this type of pattern may have warranted individual analysis as a separate class of warm season 
frontal precipitation events, but was grouped with the non-frontal events in this thesis. Warm season non-frontal events most likely occurred in association with local convective and orographic processes, such as described by Barros and Kuligowski (1998). Conditions for the development of precipitation can be enhanced through orographic processes such as forced lifting and differential advection of moist air. A large percentage (59\%) of events exhibited westerly flow at the study area, half of which were associated with moisture that likely originated in the Gulf of Mexico (Fig. 3.13). Additionally, a few events originated at the Atlantic coast, either from the southeast off the coast of Georgia or in the northeast passing by the coast of Virginia (Fig. 3.13). Approximately $67 \%$ of warm season non-frontal precipitation events were widespread across the study area, while the remaining 33\% were scattered. Overall, precipitation events in this category were associated with strong areas of low pressure to the west and north of the study area and the presence of the NASH offshore to the east (Fig. 3.12), causing the advection of warm, moist air from the Atlantic and the Gulf of Mexico. These events were also characterized by the presence of a slight trough in $500 \mathrm{hPa}$ heights near the study area, indicative of the presence of cool, moist air (Fig. 3.12). Average temperature of these events at BEECHTOP was $15.7^{\circ} \mathrm{C}$ and wind speeds at maturation ranged from $0.8-10.8 \mathrm{~m} / \mathrm{s}$ with an average of $3.5 \mathrm{~m} / \mathrm{s}$ from the southeast (Table $3.2)$. 


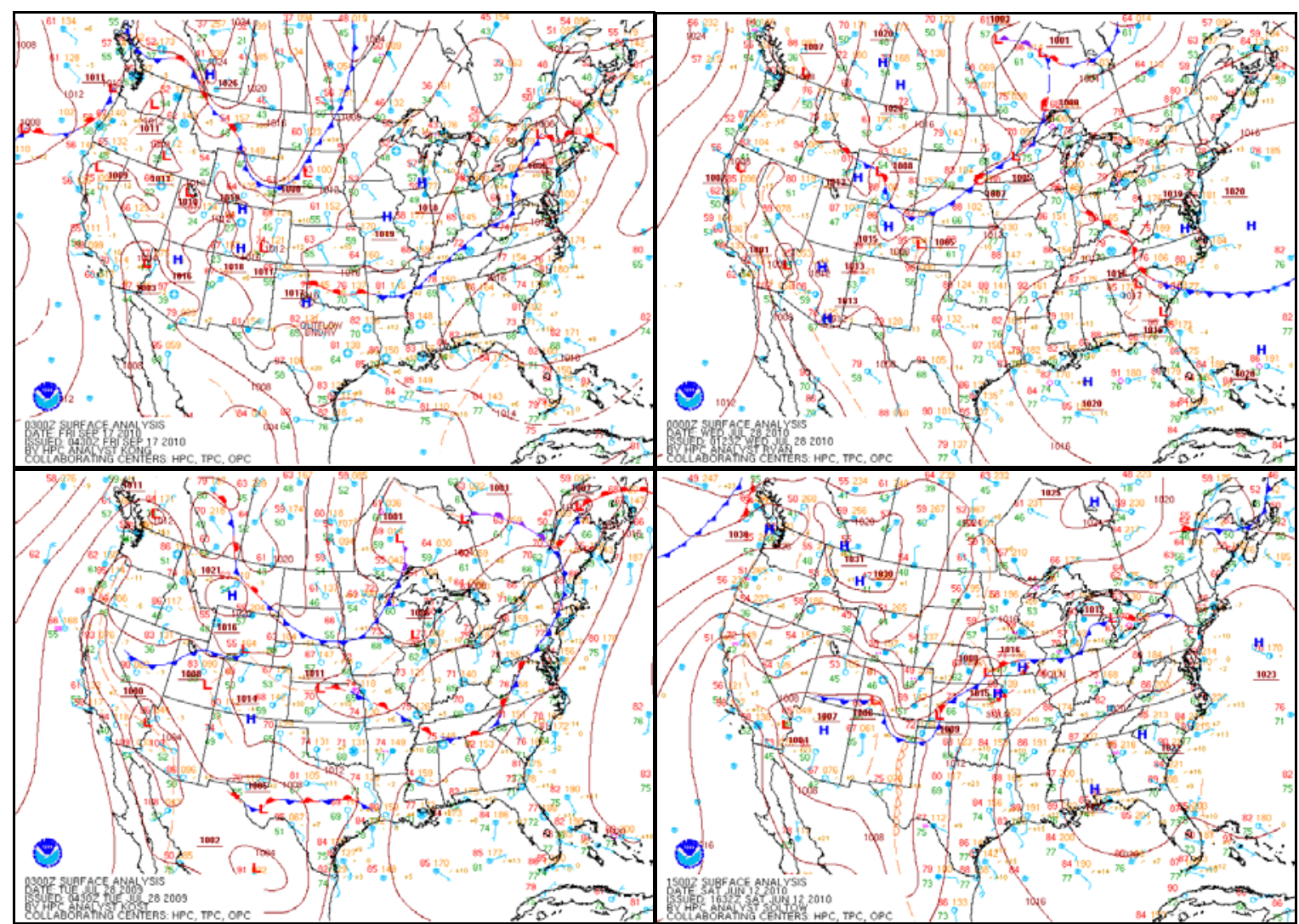

Figure 3.11. Example SRRS Analysis Charts representing warm season precipitation events, including cold front (top left), warm front (top right), stationary front (bottom left), and non-frontal event (bottom right). (Images provided by NOAA/National Climatic Data Center, U.S. Department of Commerce, from their Web site at http://nomads.ncdc.noaa.gov/index.php). 


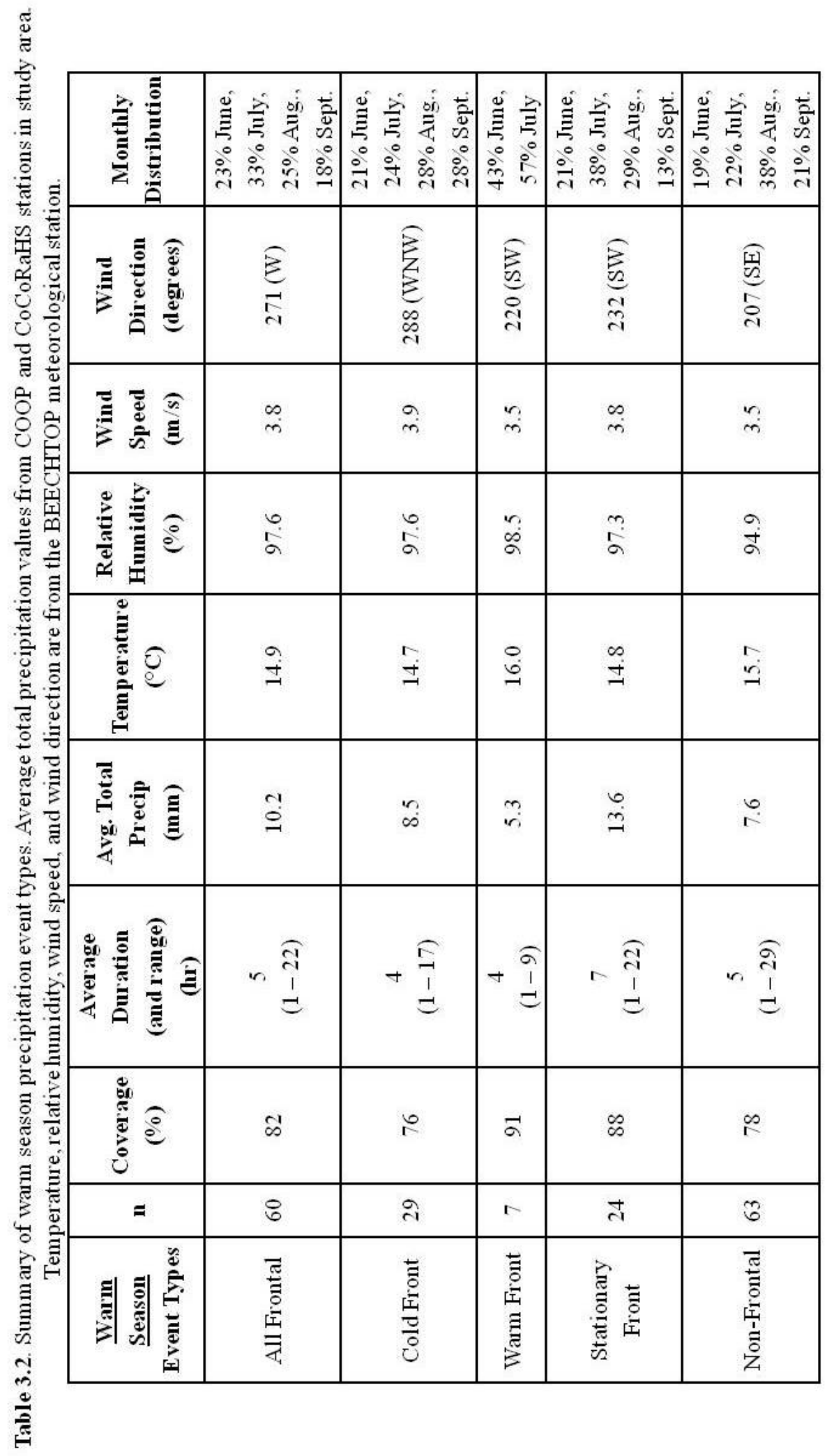



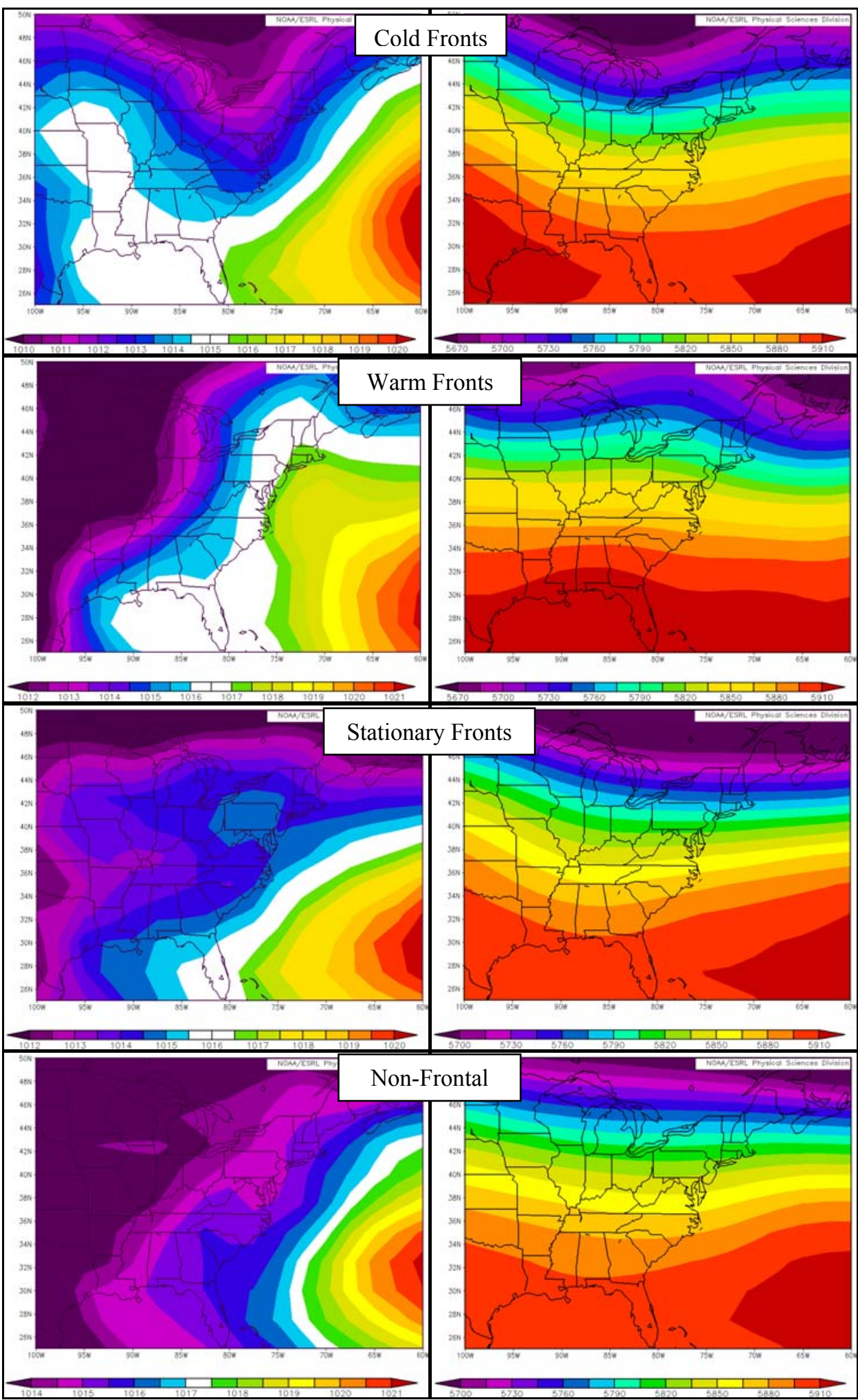

Figure 3.12. Composite plots of sea level pressure patterns (left) and $500 \mathrm{hPa}$ geopotential heights (right) during maturation hour of warm season precipitation event types from top to bottom: cold fronts, warm fronts, stationary fronts, and non-frontal precipitation events. (Images provided by the NOAA/ESRL Physical Sciences Division, Boulder Colorado, USA, from their Web site at http://www.esrl.noaa.gov/psd/). 


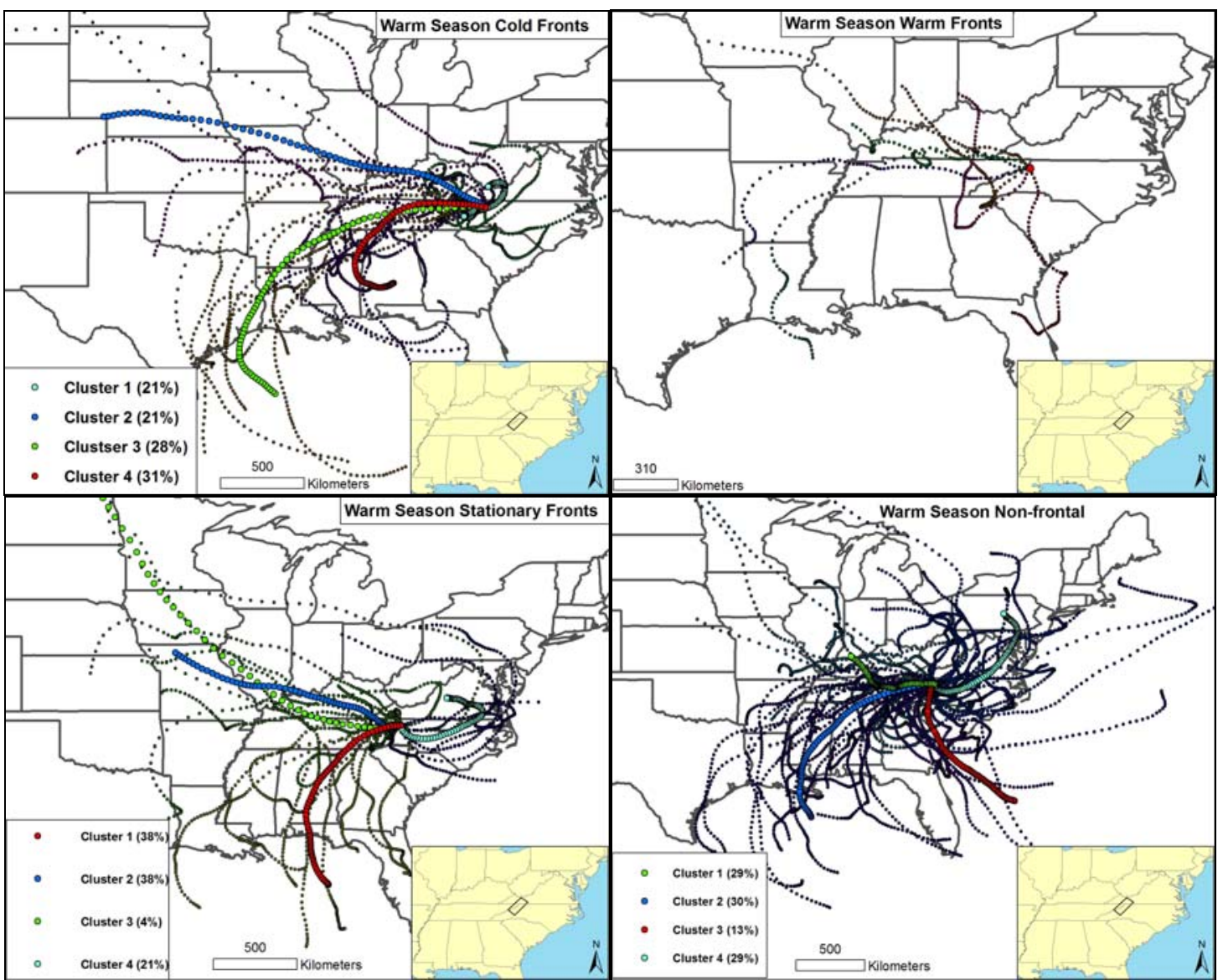

Figure 3.13. Backward air trajectories representing maturation hour of each warm season precipitation event. Plots represent precipitation associated with cold fronts (top left); warm fronts (top right), stationary fronts (bottom left), and non-frontal events (bottom right). HYSPLIT Clusters are shown in color where applicable. Clusters are numbered; values in parentheses represent percentage of backward air trajectories in each cluster.

Trajectories considered extreme outliers were omitted from cluster analysis. An insufficient number of backward air trajectories prevented HYSPLIT cluster analysis; plots of individual trajectories are shown.

\section{$\underline{\text { Cool Season }}$}

Approximately 52\% of all cool season precipitation events were snow events. Cool season frontal events constituted approximately $80 \%$ of cool season precipitation, and were long in duration (Table 3.3). Synoptic differences among these event types are illustrated by SRRS analysis charts (Fig. 3.14) and meteorological summaries (Table 3.3), while backward air trajectory analyses depicted source region information (Fig. 3.17). Precipitation events associated with cool season fronts were typically characterized by a strong center of low pressure to the northeast of the study area, coupled with troughing of $500 \mathrm{hPa}$ heights, 
indicating the presence of cool moist air (Fig. 3.15 and 3.16). These events were also sometimes associated with a pattern of low pressure to the west of the study area coupled with some ridging of $500 \mathrm{hPa}$ heights near the study area, indicative of the presence of warmer and drier air (Fig. 3.15 and 3.16). Precipitation associated with cool season fronts typically exhibited greater wind speeds and higher precipitation totals than precipitation events associated with warm season fronts.

Cold fronts accounted for approximately $27 \%$ of cool season frontal precipitation events (Table 3.3). These events were associated with an area of low pressure to the northeast of the study area coupled with a trough in $500 \mathrm{hPa}$ heights, indicating the presence of cool moist air likely advected from the Gulf of Mexico (Fig. 3.15). Air masses associated with these events typically approached the study area from the west and originated in the Midwest and the Gulf of Mexico (Fig. 3.17). BEECHTOP temperatures averaged $0.1{ }^{\circ} \mathrm{C}$ and wind speeds ranged from $3.6-7.8 \mathrm{~m} / \mathrm{s}$ with an average of $5.4 \mathrm{~m} / \mathrm{s}$ at maturation from the west (Table 3.3).

Warm fronts accounted for roughly $13 \%$ of cool season frontal precipitation events (Table 3.3). Precipitation events associated with cool season warm fronts were characterized by an area of low pressure to the west of the study area coupled with an area of high pressure offshore to the east of the study area (Fig. 3.15). Additionally, ridging of $500 \mathrm{hPa}$ heights near the study area indicated the presence of warmer drier air at the study area (Fig. 3.15). Precipitation events associated with cool season warm fronts were often influenced by air masses originating in the southeast or northwest (Fig. 3.17) with moisture likely advected from the Atlantic. BEECHTOP wind speeds averaged $13.1 \mathrm{~m} / \mathrm{s}$ from the south-southeast during these events, which were relatively warm compared to other cool season precipitation events, with average temperatures of $4.1{ }^{\circ} \mathrm{C}$ (Table 3.3). 
Occluded fronts accounted for $10 \%$ of cool season frontal precipitation events, and were the highest precipitation producers in this category (Table 3.3). These events were characterized by an area of low pressure directly over and to the west of the study region with an area of high pressure in Canada to the north-northeast of the study area (Fig. 3.15). At $500 \mathrm{hPa}$, a trough to the southwest and a ridge to the northeast of the study area was possibly indicative of cool moist air from the west wedging below warmer and drier air from the east directly over the study area (Fig. 3.15) resulting in isentropic lifting and enhanced precipitation. Air masses typically originated off the Atlantic coast or to the northeast and approached the study area from the south (Fig. 17). These events were the warmest of the cool season frontal precipitation events, at an average of $4.5^{\circ} \mathrm{C}$ at BEECHTOP and average wind speeds of $6.4 \mathrm{~m} / \mathrm{s}$ from the south-southeast (Table 3.3).

Gulf Lows accounted for $40 \%$ of cool season frontal precipitation events and were relatively long in duration (Table 3.3). These events were identified based on the absence of a clear frontal boundary within $300 \mathrm{~km}$ of the study area during maturation, while precipitation at the study area was connected to an area of low pressure in the Gulf of Mexico. These events were characterized by an area of high pressure to the north in Canada, with the study area located between a trough in $500 \mathrm{hPa}$ heights to the west and a ridge in $500 \mathrm{hPa}$ heights to the east (Fig. 3.16). This pattern suggests that seasonably cool and moist air from the Gulf of Mexico was encountering warmer and drier air from the east, perhaps inducing isentropic lifting and enhancing precipitation at the study area. Cluster analysis exhibited low-level airflow associated with these events originating in the Gulf of Mexico and also to the west and northwest of the study area (Fig. 3.17). During precipitation events associated with cool season Gulf lows, temperatures averaged $-1.4^{\circ} \mathrm{C}$, while wind speeds 
averaged $5.3 \mathrm{~m} / \mathrm{s}$ from the east-southeast at the BEECHTOP meteorological station (Table $3.3)$.

Nor'eastsers accounted for $10 \%$ of cool season frontal precipitation events (Table 3.3) and were identified by precipitation occurring in association with a well-defined $500 \mathrm{hPa}$ low pressure passing near or to the northeast of the study area and in the absence of a clear frontal boundary within $300 \mathrm{~km}$ of the study area at event maturation. These events were characterized by an area of low pressure to the northeast with an area of high pressure to the northwest in Canada (Fig. 3.16). Troughing and highly negative $500 \mathrm{hPa}$ anomalies near the study area suggested the presence of cooler conditions and enhanced lift (Fig. 3.16). Air masses associated with these events typically originiated to the west-northwest of the study area (Fig. 3.17). Additionally, precipitation events associated with Nor'easters were the coldest of the cool season frontal precipitation events, with an average temperature of -10.6 ${ }^{\circ} \mathrm{C}$ at BEECHTOP and average winds at $6.1 \mathrm{~m} / \mathrm{s}$ from the west-northwest (Table 3.3).

Non-frontal events constituted approximately $20 \%$ of cool season precipitation events in this study (Table 3.3). These event types took place in the absence of a clear frontal boundary within $300 \mathrm{~km}$ of the study area (Fig. 3.14), and precipitation likely occurred as a result of upslope flow and orographic enhancement. This category is almost entirely characterized by low-level northwest upslope flow, $75 \%$ of which were snow events at the Boone AWOS (e.g., Perry et al. 2007). Precipitation events associated with cool season non-frontal conditions were characterized by an area of low pressure offshore to the east-northeast of the study area, with an area of high pressure to the west (Fig. 3.16). Troughing and highly negative $500 \mathrm{hPa}$ heights near the study area suggested the presence of cooler conditions and enhanced lift (Fig. 3.16). Almost all air masses associated with cool season non-frontal 
precipitation originated northwest of the study area, except for one air mass that originated to the northeast and exhibited southeasterly flow at the study area (Fig. 3.17). These events were also among the coldest of the cool season precipitation events, with an average temperature of $-8.0 \mathrm{C}$ at BEECHTOP and an average wind speed of $5.4 \mathrm{~m} / \mathrm{s}$ from the westnorthwest (Table 3.3).

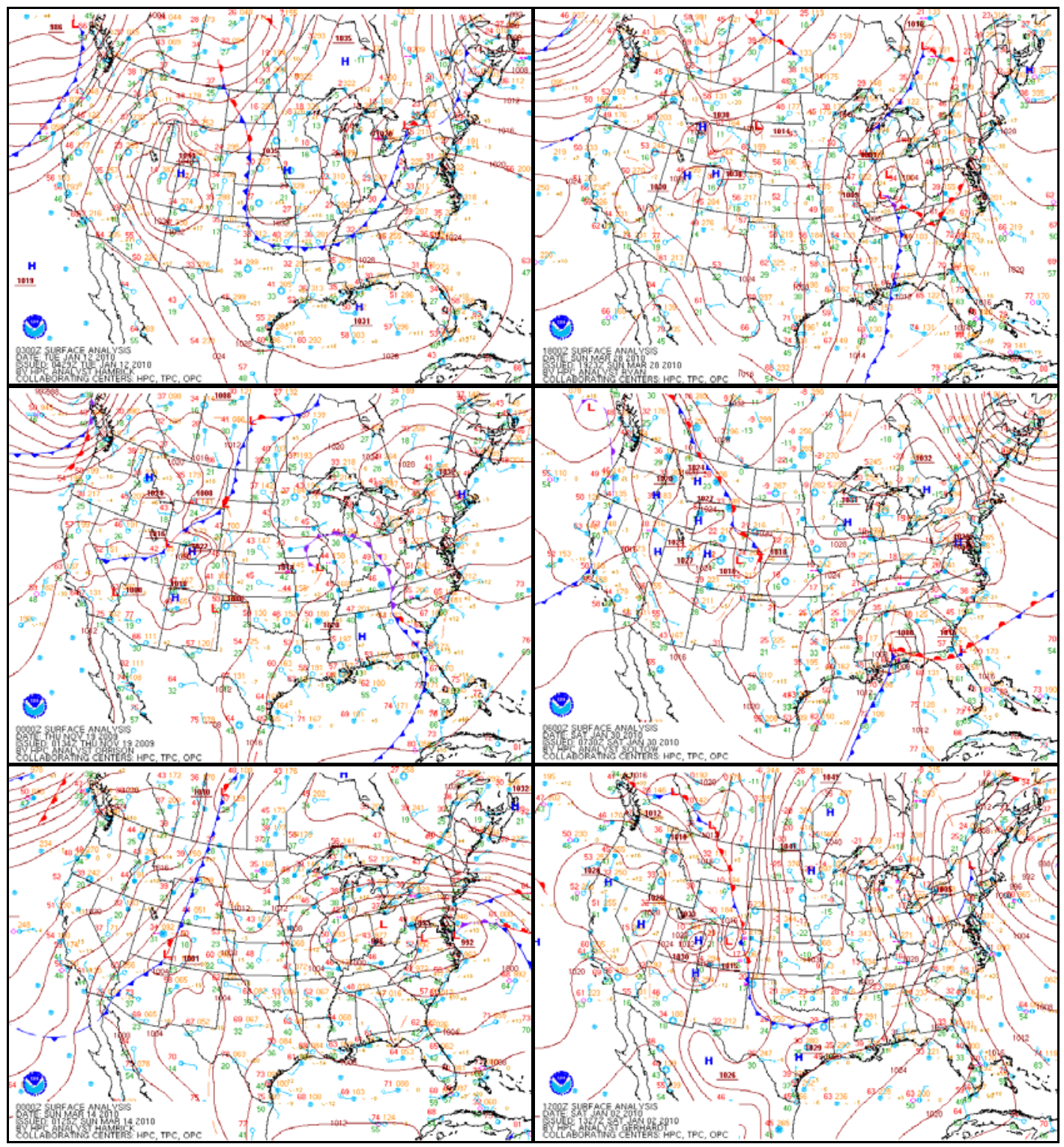

Figure 3.14. Example SRRS Analysis Charts representing cool season events, including (from left to right, starting at top left): cold front, warm front, occluded front, Gulf Low, Nor'easter, and non-frontal mechanisms. (Images provided by NOAA/National Climatic Data Center, U.S. Department of Commerce, from their Web site at http://nomads.ncdc.noaa.gov/index.php). 


\begin{tabular}{|c|c|c|c|c|c|c|c|}
\hline 党高 & 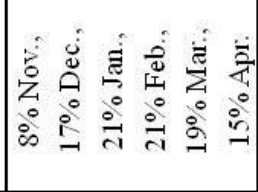 & 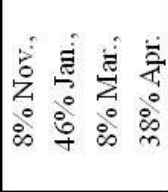 & 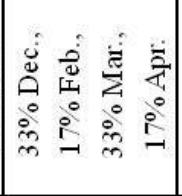 & 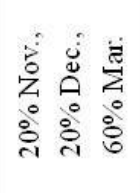 & 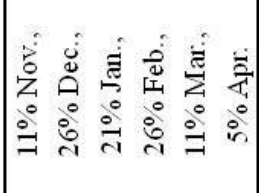 & 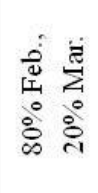 & 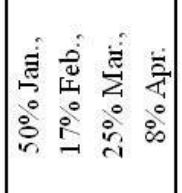 \\
\hline 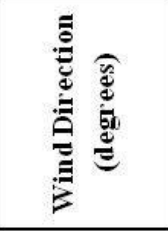 & $\underset{2}{0}$ & $\underset{E}{E}$ & 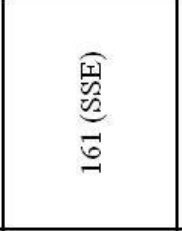 & 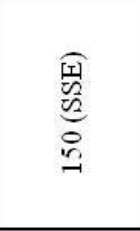 & 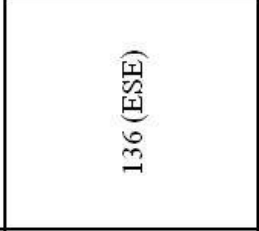 & 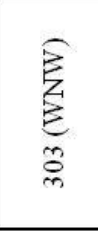 & 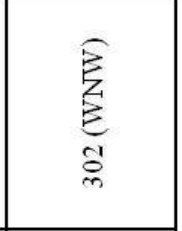 \\
\hline 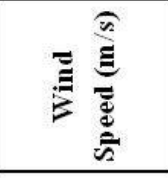 & $\overrightarrow{6}$ & $\exists$ & $\vec{g}$ & ఫै & mis & $\overrightarrow{6}$ & $\vec{r}$ \\
\hline 跑 & $\stackrel{1}{\stackrel{1}{\alpha}}$ & $\vec{\sigma}$ & $\stackrel{\circ}{\stackrel{8}{8}}$ & $\stackrel{\circ}{\stackrel{8}{8}}$ & $\ddot{\alpha}$ & ڤू & $\stackrel{\circ}{\check{a}}$ \\
\hline 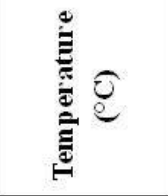 & $\begin{array}{l}0 \\
\stackrel{0}{i}\end{array}$ & $\overrightarrow{0}$ & 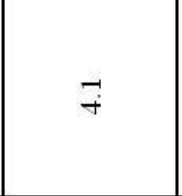 & 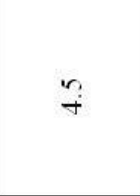 & $\stackrel{+}{-}$ & \begin{tabular}{l}
$\stackrel{0}{\circ}$ \\
\hdashline
\end{tabular} & $\stackrel{\circ}{\phi}$ \\
\hline 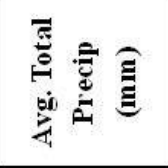 & $\vec{\sigma}$ & $\stackrel{\circ}{\stackrel{-}{\circ}}$ & $\begin{array}{l}0 \\
\square \\
\square\end{array}$ & ڤ̊) & $\vec{a}$ & $\stackrel{\infty}{+}$ & $\stackrel{0}{\ddot{m}}$ \\
\hline 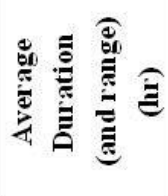 & 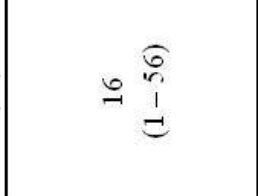 & $\begin{array}{l}0 \\
\infty \\
\infty \\
1 \\
1 \\
=\end{array}$ & $\therefore \begin{array}{c}0 \\
0 \\
1 \\
1 \\
c\end{array}$ & $2 \begin{array}{c}\vec{m} \\
1 \\
0\end{array}$ & 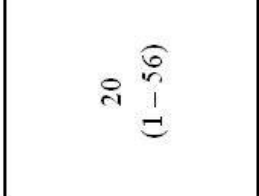 & $\stackrel{\widehat{F}}{\stackrel{\widehat{F}}{=}}$ & $\begin{aligned} & 6 \\
& 0 \\
& 1 \\
& 1\end{aligned}$ \\
\hline 这 & 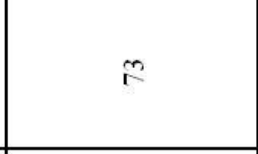 & ㅇ & $\stackrel{0}{1}$ & $\infty$ & $\vec{I}$ & in & in \\
\hline$=$ & $\stackrel{\infty}{+}$ & 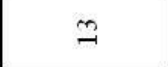 & 0 & $n$ & 2 & n & $\Im$ \\
\hline 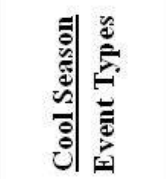 & 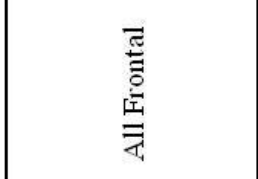 & 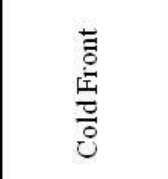 & 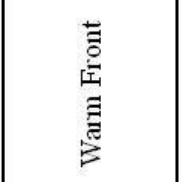 & 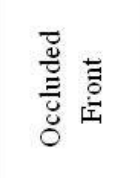 & 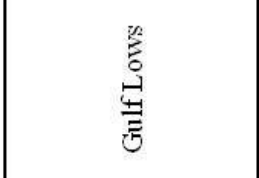 & 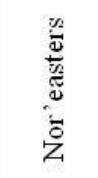 & 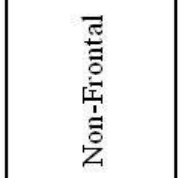 \\
\hline
\end{tabular}




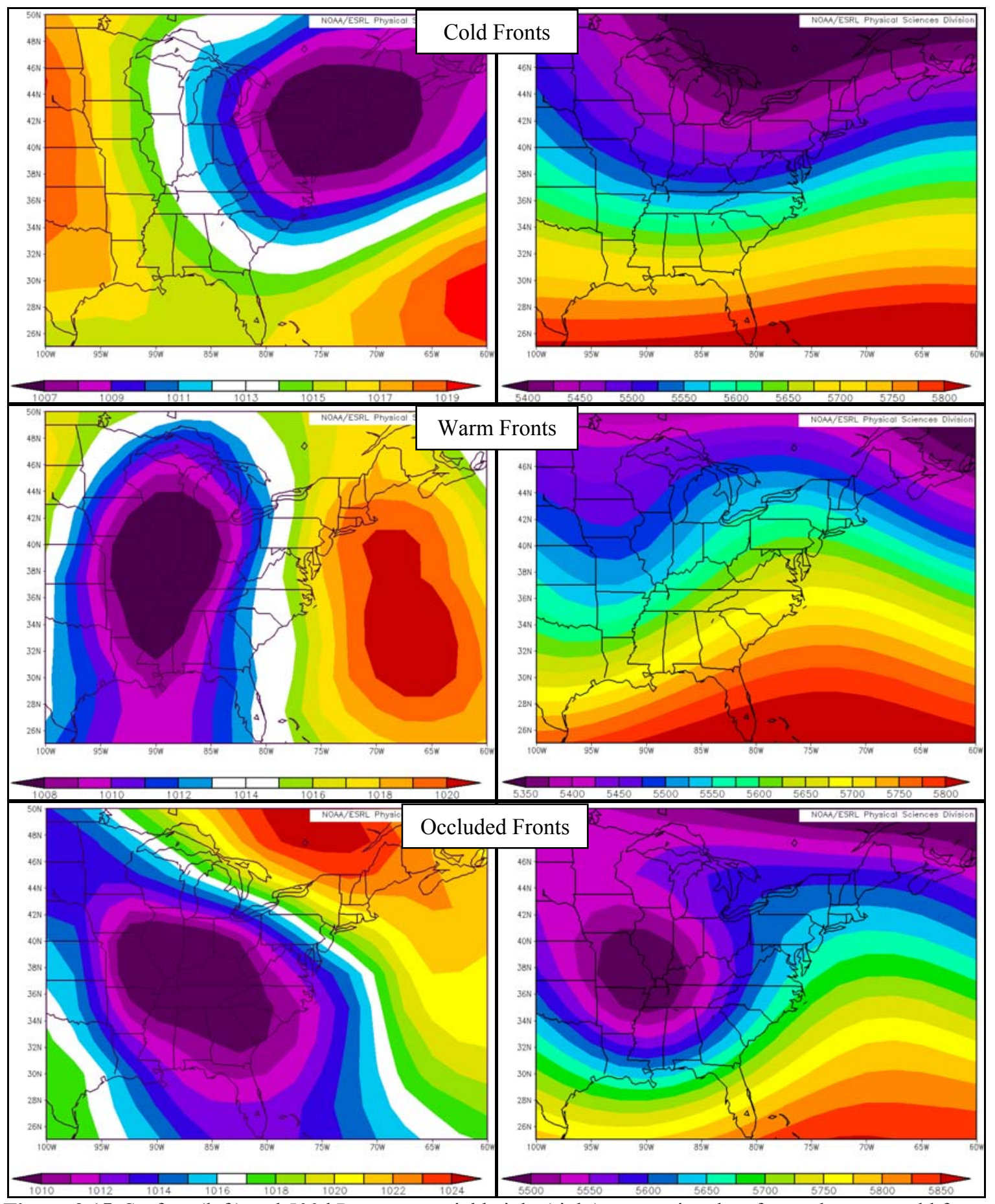

Figure 3.15. Surface (left) and $500 \mathrm{hPa}$ geopotential height (right) composite plots for cool season cold front, warm front, and occluded frontal precipitation events at maturation. (Images provided by the NOAA/ESRL Physical Sciences Division, Boulder Colorado, USA, from their Web site at http://www.esrl.noaa.gov/psd/). 


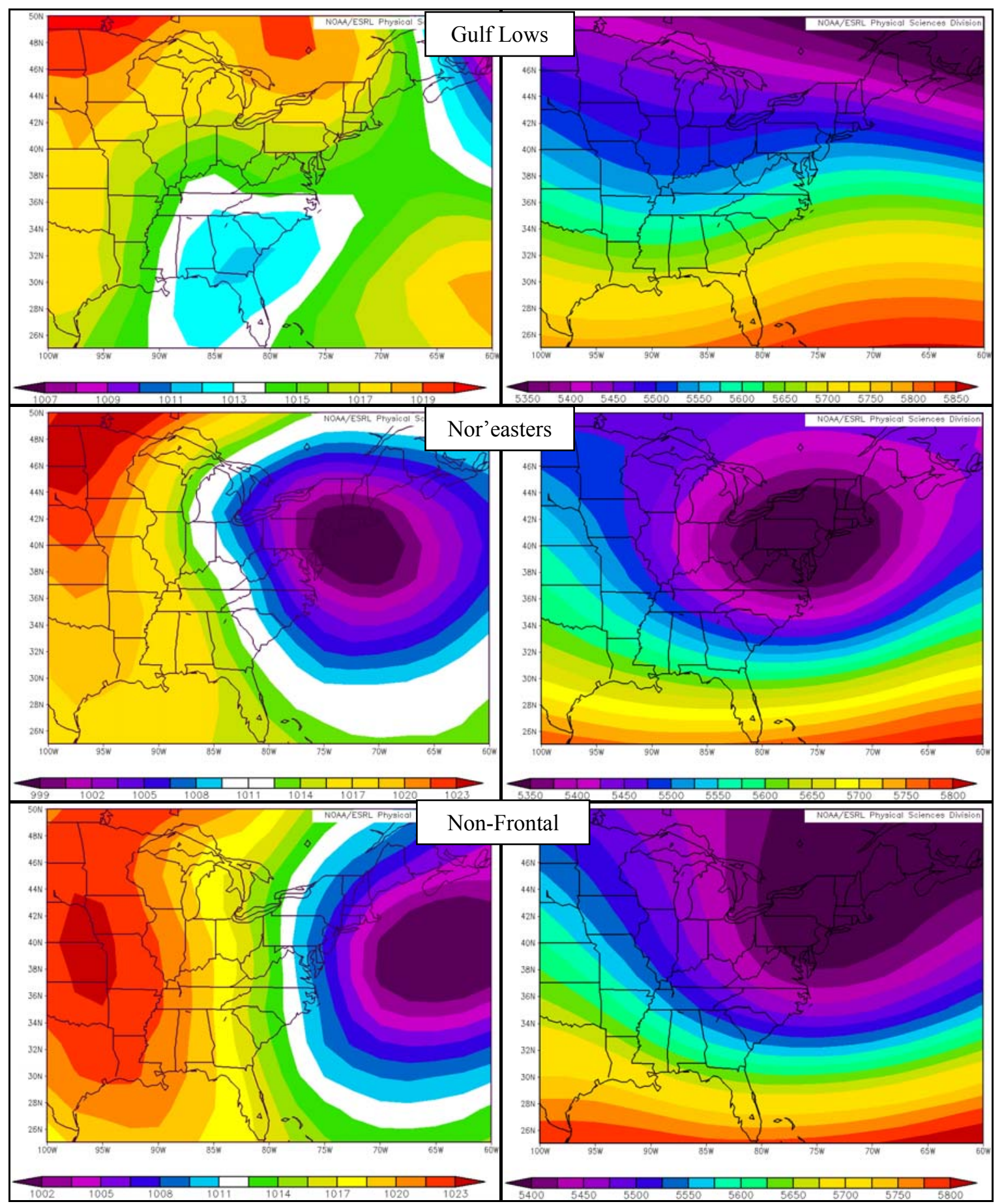

Figure 3.16. Surface (left) and $500 \mathrm{hPa}$ geopotential height (right) composite plots for cool season Gulf lows, Nor'easters, and non-frontal precipitation events at maturation. (Images provided by the NOAA/ESRL Physical Sciences Division, Boulder Colorado, USA, from their Web site at http://www.esrl.noaa.gov/psd/). 


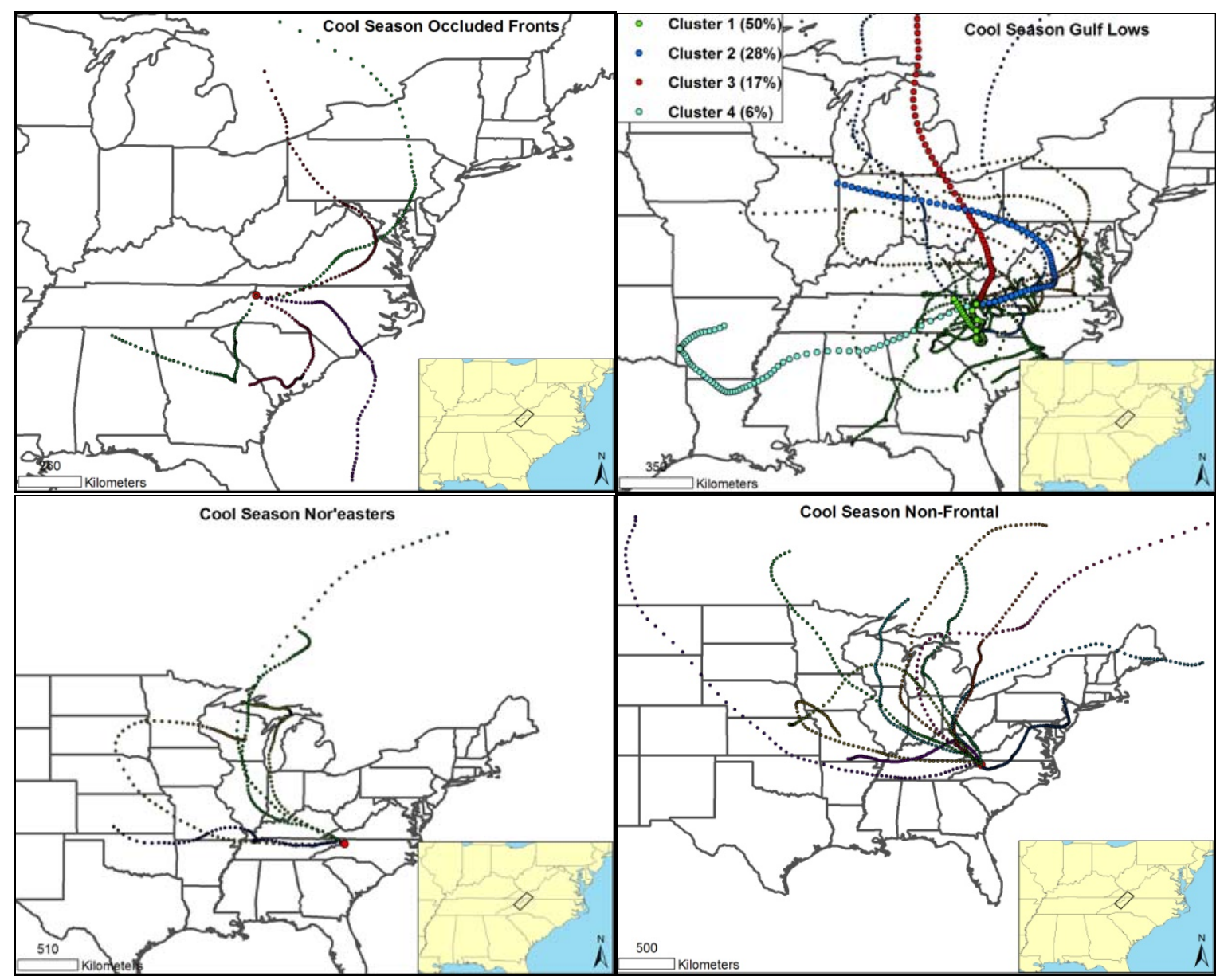

Figure 3.17. Backward air trajectories representing maturation hour of each cool season precipitation event. Plots represent cool season precipitation events associated with (left to right, top to bottom): cold fronts, warm fronts, occluded fronts, Gulf lows, Nor'easters, and non-frontal events. There were an insufficient number of backward air trajectories for most event types to perform HYSPLIT cluster analysis; individual trajectory plots are shown instead. For cool season Gulf lows, HYSPLIT clusters are shown in color. Trajectories that were considered extreme outliers were omitted from cluster analysis.

\section{Aerosol Climatology}

\section{$\underline{\text { Seasonal Variation }}$}

Warm Season versus Cool Season: All Event Types

Analyses were performed on the aerosol properties associated with all event types, including frontal and non-frontal precipitation events in the warm season versus cool season. Analyses resulted in strongly significant seasonal differences. Seasonal cluster analyses revealed varying source regions driving precipitation events impacting the SAM, with a 
stronger influence from the southeast during the warm season and from the northwest during the cool season (Fig. 3.10). Comparisons of meteorological variables and aerosol properties at beginning and maturation for each cluster reveal distinct differences in source region influences during warm season (Table 3.4) and cool season precipitation events (Table 3.5). Scattering values were much higher during warm season precipitation events, which was consistent with the overall regional increase in secondary organic aerosols during this season. Cool season events were characterized by higher backscatter fraction, SAE, and AAE values, indicating the presence of smaller biomass burning particles from local wood-burning stoves.

Warm season Clusters 2 and 5 represented air masses associated with events that produced the largest amount of precipitation (Fig. 3.10). These air masses originated at the Atlantic Coast and approached the study area from the southeast, providing low-level moisture during precipitation events. These clusters were composed largely of non-frontal precipitation events and were associated with southeast upslope flow precipitation. Cluster 5 exhibited higher scattering and absorption values than Cluster 2, indicating anthropogenic emissions from fossil fuel combustion along the I-81 corridor (Table 3.4). Cluster 3, which represented air masses that originated in the Gulf of Mexico and approached the study area from the west-southwest, contained the greatest number of events. This cluster was composed of mostly non-frontal and cold-frontal precipitation events associated with some of the highest AAE values among the warm season precipitation events (Table 3.4). Higher AAE values indicated the presence of more organic particles, originating near the Gulf of Mexico.

Cool season Cluster 1 represented air masses associated with events that produced the largest amount of precipitation (Fig. 3.10). These air masses originated north-northwest of 
the study area near the Ohio River Valley region, and eventually approached the study area from the southeast. This cluster was largely composed of Gulf low precipitation events (Table 3.5), which indicated the advection of low-level air from north of the study area toward the Gulf of Mexico, where moisture was likely added and precipitation intensified through southeast upslope flow near the study region. Cluster 1 also exhibited the highest wind speeds of all cool season precipitation events, at an average of $7.2 \mathrm{~m} / \mathrm{s}$ from the eastsoutheast at maturation (Table 3.5). This cluster displayed the highest scattering and absorption values at event beginning, as well as the highest AAE values at maturation, evident of a large fraction of organics.

Statistical analyses of aerosol values at event beginning and maturation display highly significant differences between warm season and cool season precipitation (Table 3.6). These differences are explained not only by differences in the climatology of each season, but also by increased aerosol optical properties during the warm season. Higher warm season scattering values are driven by hygroscopic growth and coagulation during this time of year (Barr et al. 2003). Significantly smaller backscatter fraction and SAE values during the warm season were indicative of overall larger particle sizes present at event beginning and maturation. The larger warm season SSA values indicated the presence of more scattering particles as a result of increased biogenic emissions. Smaller warm season AAE values indicate the presence of relatively more soot-like particles during this time of year and less biomass burning particles. An increase in soot particles was related to more local input related to fossil fuel combustion during the summer tourist season in the SAM and surrounding regions (e.g., I-81 corridor), as well as greater regional transport. Larger AAE 
values during the cool season were consistent with the presence of biomass burning aerosols, which were emitted locally as a result of winter wood burning in the SAM.

There were significant differences in aerosol values from event beginning to event maturation during both seasons (Table 3.7). Both scattering and absorption values decreased significantly from beginning to maturation during cool season precipitation events, which was consistent with a raining out effect that removed particles from the air during precipitation. The fact that absorption did not decrease from beginning to maturation in the warm season was further evidence that there was a greater relative fraction of hydrophobic soot particles. The lack of a significant decrease in scattering may have resulted from the fact that warm season scattering was driven by secondary organic aerosols, which were less hydroscopic than sulfate aerosols. Also, as relative humidity increased from beginning to maturation, low vapor pressure water soluble organic carbon compounds were getting taken into the existing particles (coalescence), an effect that increased scattering while particles being rained out were simultaneously decreasing scattering. Additionally, a significant increase in AAE from beginning to maturation was displayed in both seasons as well, indicating the aging and mixing of black carbon as well as the uptake of water soluble organic carbon compounds as moisture increases.

Analysis of light and heavy warm season precipitation revealed a significant difference in temperature and wind speed at event beginning between the two sets (Table 3.8). At maturation, heavy and light events exhibited nearly equal relative humidity values, while heavy events were warmer. This indicated higher mixing ratios (i.e., more water vapor) associated with heavy events. Also, lighter winds associated with heavy events were tied to slower storm movement. Additionally, there was a significant difference in SAE values 
between light and heavy warm season precipitation, wherein SAE values were significantly higher during beginning and maturation of light events indicating smaller particle sizes during these events (Table 3.8). Smaller particles typically serve as poor CCN, which may have inhibited precipitation intensity. Heavy warm season precipitation events displayed significantly higher AAE values during maturation than light events, suggesting the presence of more organics during periods of heaviest rainfall. The difference in AAE values during heavy warm season precipitation was also significant between beginning and maturation (Table 3.9). The higher fraction of organic aerosols, which serve as effective CCN, relative to soot particles, which do not make effective $\mathrm{CCN}$, may have enhanced the precipitation intensity in the SAM.

Analysis of light and heavy cool season precipitation revealed a significant difference in temperature and wind speed between light and heavy events, wherein heavy events were overall warmer and windier during event beginning and maturation (Table 3.10). Again, warmer heavy events indicated higher mixing ratios when heavy and light events had nearly equal relative humidity values. Heavy cool season events were associated with significantly higher winds than light events, as opposed to heavy warm season events which exhibited significantly lower winds that light events (Table 3.10). During heavy cool season precipitation, strong winds were from the southeast and were presumably transporting high moisture, creating ideal conditions for orographic enhancement. There were some significant differences in aerosol values between light and heavy cool season precipitation, but only during event beginning. Scattering and absorption values were significantly higher during heavy cool season precipitation, while SAE values were significantly lower (Table 3.10). This is indicative of greater aerosol mass loading during these heavy events, due to larger 
particle size during heavy events. The presence of larger particles in the beginning of heavy precipitation events indicated these particles served as effective $\mathrm{CCN}$, while smaller particles present in the beginning of light precipitation events did not serve as effective CCN. Scattering and absorption values were significantly different between the beginning and maturation of heavy cool season precipitation, wherein both values significantly decreased at maturation (Table 3.11). This suggested that particles were rained out during the period of heaviest precipitation. A significant increase in AAE values was displayed by both light and heavy cool season precipitation (Table 3.11), further indicating that absorption was largely driven by biomass burning aerosols in the cool season. During the warm season when there was a relatively larger fraction of soot, differences in the amount of hygroscopic secondary organic aerosols serving as effective $\mathrm{CCN}$ impacted precipitation intensity. The fact that there was a greater fraction of biomass burning aerosols relative to soot in the cool season decreased the importance of variability in these aerosols to precipitation intensity. 


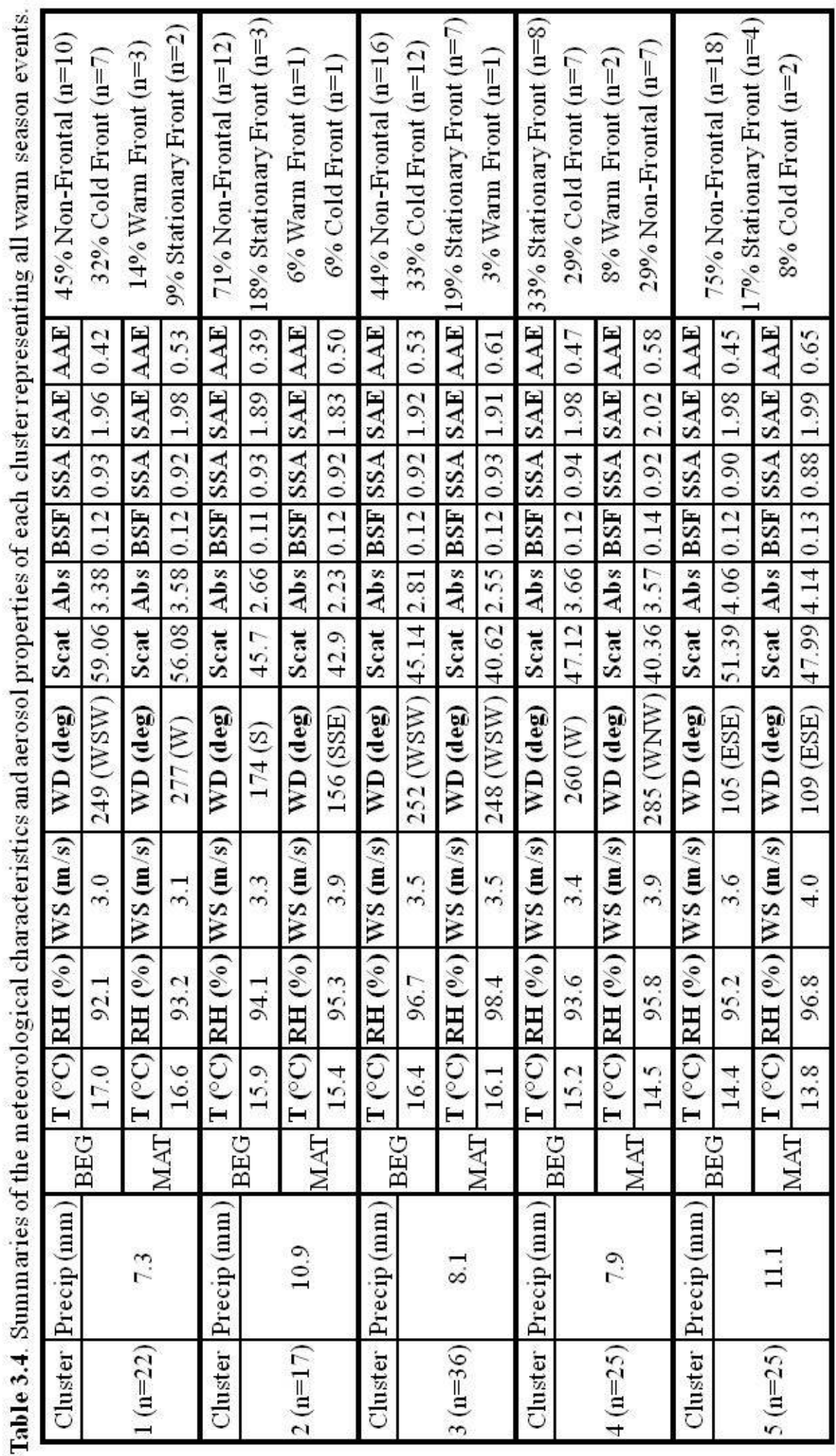




\begin{tabular}{|c|c|c|c|c|c|c|c|c|c|c|c|c|c|c|c|}
\hline 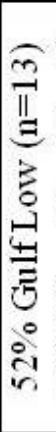 & 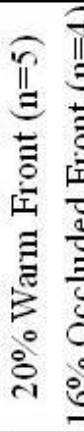 & 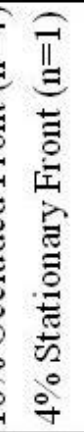 & 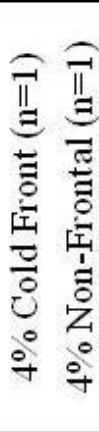 & 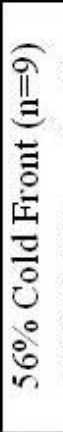 & 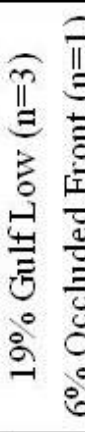 & 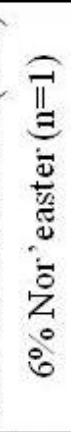 & 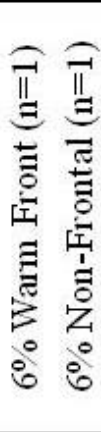 & & 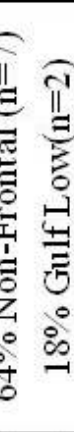 & : & & & 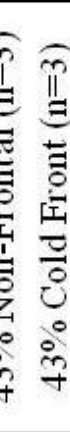 & 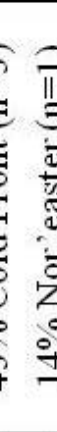 & \\
\hline 舆 & $\stackrel{8}{\circ}$ & 岳 & $\stackrel{8}{i}$ & 署 & @ & \begin{tabular}{|l|} 
\\
\end{tabular} & 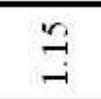 & 界 & \begin{tabular}{|l|}
1 \\
0 \\
0 \\
\end{tabular} & 舆 & $\stackrel{?}{=}$ & 空 & \begin{tabular}{|l|} 
\\
$\vdots$ \\
0
\end{tabular} & 䰹 & $\stackrel{\text { I }}{=}$ \\
\hline 媱 & $\stackrel{8}{8}$ & 空 & $\underset{c i}{c}$ & 鲟 & $\underset{c}{\stackrel{\circ}{c}}$ & 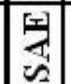 & $\frac{m}{r i}$ & 鱼 & \begin{tabular}{c|}
-1 \\
$r i$
\end{tabular} & 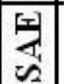 & $\frac{9}{i}$ & 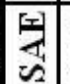 & \begin{tabular}{l|}
$\vec{y}$ \\
$\vec{r}$ \\
$\vec{c}$
\end{tabular} & 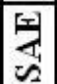 & $\stackrel{n}{\sim}$ \\
\hline $\begin{array}{l}\mathbb{4} \\
\approx \\
\approx\end{array}$ & $\begin{array}{l}3 \\
\infty \\
0\end{array}$ & 朵 & $\begin{array}{l}0 \\
\infty \\
0\end{array}$ & \begin{tabular}{l}
$\overrightarrow{4}$ \\
\multirow{2}{*}{}
\end{tabular} & $\begin{array}{l}\infty \\
\infty \\
0\end{array}$ & $\begin{array}{l}\overline{4} \\
\approx \\
\approx\end{array}$ & $\begin{array}{c}3 \\
0 \\
0\end{array}$ & $\begin{array}{l}\overrightarrow{4} \\
\sqrt[2]{2} \\
\approx\end{array}$ & $\begin{array}{l} \\
\vdots \\
0\end{array}$ & $\begin{array}{l}4 \\
\approx \\
\approx\end{array}$ & $\begin{array}{l}\circ \\
\vdots \\
0\end{array}$ & $\begin{array}{l}\sqrt{1} \\
\therefore \\
\approx\end{array}$ & \begin{tabular}{|l|} 
\\
$\infty$ \\
0
\end{tabular} & $\begin{array}{l}\sqrt{1} \\
\sqrt{2}\end{array}$ & $\hat{0}$ \\
\hline 采 & $\frac{17}{0}$ & 岺 & $\frac{5}{0}$ & 梥 & $\begin{array}{l}6 \\
-1 \\
0\end{array}$ & \begin{tabular}{|l|}
\multicolumn{1}{|c|}{} \\
苗
\end{tabular} & $\frac{5}{0}$ & 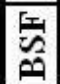 & $\frac{ \pm}{ \pm}$ & 㝑 & $\frac{12}{0}$ & 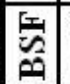 & \begin{tabular}{|c|}
0 \\
-1 \\
0
\end{tabular} & 岺 & $\frac{ \pm}{0}$ \\
\hline$\stackrel{\sim}{=}$ & 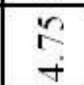 & $\hat{\epsilon}$ & î & 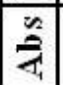 & $\underset{m}{\stackrel{y}{y}}$ & $\begin{array}{l}n \\
\overline{4}\end{array}$ & i & 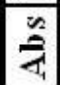 & $\frac{i}{i}$ & $\hat{=}$ & $\vec{i}$ & $\begin{array}{ll}n \\
\hat{z}\end{array}$ & 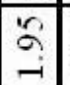 & $\stackrel{\sim}{4}$ & $\stackrel{+}{-}$ \\
\hline 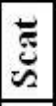 & $\begin{array}{l}m \\
\stackrel{3}{0} \\
\stackrel{1}{c}\end{array}$ & 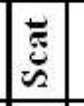 & ำ & 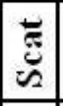 & $\begin{array}{l}\vec{m} \\
\dot{d}\end{array}$ & 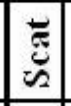 & $\stackrel{n}{2}$ & 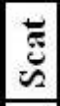 & $\begin{array}{l}m \\
\ddot{n} \\
\tilde{a}\end{array}$ & \begin{tabular}{|l|}
\multirow{2}{*}{} \\
\end{tabular} & \begin{tabular}{|l|} 
\\
$\infty$ \\
-1 \\
-1
\end{tabular} & 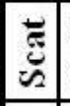 & $\begin{array}{l}\hat{\sigma} \\
m \\
m\end{array}$ & 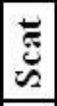 & $\begin{array}{l}\mathbf{I} \\
\stackrel{2}{-}\end{array}$ \\
\hline 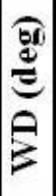 & 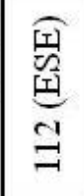 & 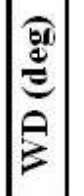 & 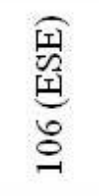 & 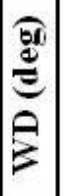 & 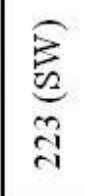 & 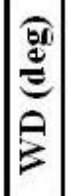 & $\underset{\substack{1 \\
\text { i }}}{\mid}$ & 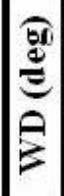 & 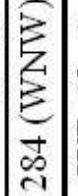 & 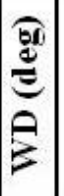 & 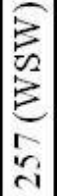 & 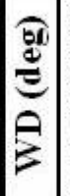 & 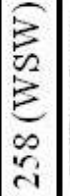 & 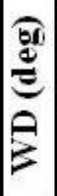 & $\mid \begin{array}{l}\vec{z} \\
\hat{\beta} \\
\infty \\
\infty \\
\infty\end{array}$ \\
\hline 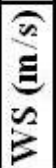 & ţ & 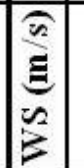 & $\stackrel{?}{n}$ & 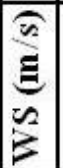 & $\stackrel{6}{+}$ & 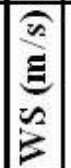 & m & 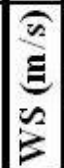 & in & 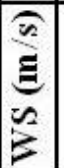 & $\begin{array}{l}\infty \\
+\end{array}$ & 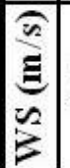 & $\stackrel{m}{+}$ & 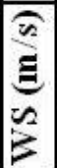 & in \\
\hline 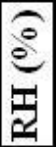 & $\stackrel{3}{\circ}$ & $\stackrel{8}{8}$ & $\stackrel{0}{8}$ & 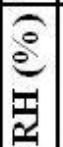 & $\begin{array}{l}\grave{a} \\
\stackrel{\circ}{ }\end{array}$ & 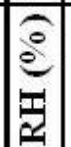 & $\stackrel{\circ}{\alpha}$ & 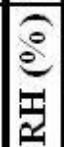 & ¿্ণ & 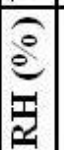 & $\begin{array}{l}0 \\
2\end{array}$ & 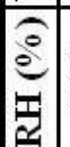 & $\begin{array}{l}+ \\
\stackrel{\sigma}{2}\end{array}$ & $\frac{\hat{e}}{2}$ & $\vec{\sigma}$ \\
\hline 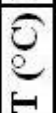 & r & $\begin{array}{l}0 \\
0 \\
0\end{array}$ & " & 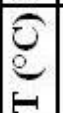 & $\stackrel{m}{i}$ & 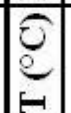 & $\stackrel{\circ}{i}$ & $\begin{array}{l}0 \\
0 \\
0 \\
1=1\end{array}$ & $\begin{array}{l}\infty \\
0 \\
0 \\
\end{array}$ & $\begin{array}{l}0 \\
0 \\
0 \\
-1\end{array}$ & $\frac{9}{0}$ & $\begin{array}{l}0 \\
e \\
e\end{array}$ & $\begin{array}{l}9 \\
i \\
i\end{array}$ & 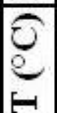 & $\begin{array}{l}0 \\
\infty \\
1\end{array}$ \\
\hline & $\begin{array}{l}\text { प } \\
\text { III } \\
9\end{array}$ & & 案 & & T) & & 恶 & & & 2 & & D & & & \\
\hline 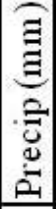 & & ầ & & 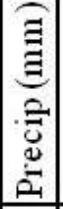 & & $\begin{array}{l}0 \\
\infty\end{array}$ & & $\mid \begin{array}{c}0 \\
\vdots \\
0 \\
0 \\
0 \\
0 \\
0 \\
0\end{array}$ & & $\stackrel{9}{f}$ & & 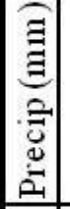 & & $m$ & \\
\hline 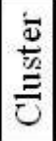 & & $\underset{-1}{\stackrel{\Omega}{\Omega}}$ & & $\stackrel{\bar{s}}{\frac{5}{2}}$ & & $\underset{d}{\stackrel{6}{\pi}}$ & & 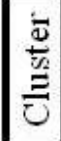 & & $\underset{m}{\stackrel{\exists}{\exists}}$ & & 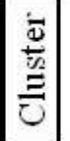 & & + & \\
\hline
\end{tabular}


Table 3.6. Mean meteorological and aerosol values and differences at beginning and maturation for all warm season events versus all cool season events. $P$-values (2-tailed) italicized in bold indicate significance at the $95 \%$ confidence interval or greater. An asterisk $(*)$ indicates values obtained using a parametric test.

\section{BEGINNING \\ Meteorological Values}

Avg. Total Precip (mm)

Beech $\mathrm{T}\left({ }^{\circ} \mathrm{C}\right)$

Beech RH (\%)

Beech WS (m/s)

Beech WD (degrees)

Aerosol Values

Scattering

Absorption

Backscatter Fraction

SSA

SAE

AAE

MATURATION

Meteorological Values

Beech $\mathrm{T}\left({ }^{\circ} \mathrm{C}\right)$

Beech RH (\%)

Beech WS (m/s)

Beech WD (degrees)

Aerosol Values

Scattering

Absorption

Backscatter Fraction

SSA

SAE

AAE

\begin{tabular}{|c|c|c|c|}
\hline$\underline{\text { All Warm }}$ & All Cool & $\underline{\text { Abs Diff }}$ & $\underline{p \text {-value }}$ \\
\hline$n=123$ & $n=60$ & & \\
\hline 8.9 & 13.4 & 4.5 & .919 \\
\hline 15.8 & -1.6 & 17.4 & $.000 *$ \\
\hline 94.6 & 98.0 & 3.4 & .055 \\
\hline 3.4 & 5.0 & 1.6 & .016 \\
\hline 244 (WSW) & $172(\mathrm{~S})$ & 72 & NA \\
\hline 49.33 & 24.93 & 24.40 & .000 \\
\hline 3.30 & 3.68 & 0.38 & .890 \\
\hline 0.12 & 0.15 & 0.03 & .000 \\
\hline 0.92 & 0.86 & 0.07 & .000 \\
\hline 1.95 & 2.12 & 0.17 & .000 \\
\hline 0.47 & 0.96 & 0.49 & $.000 *$ \\
\hline
\end{tabular}

\begin{tabular}{|c|c|c|c|}
\hline$\underline{\text { All Warm }}$ & $\underline{\text { All Cool }}$ & $\underline{\text { Abs Diff }}$ & $p$-value \\
\hline$n=123$ & $n=60$ & & \\
\hline 15.3 & -2.2 & 17.49 & $.000 *$ \\
\hline 96.2 & 98.8 & 2.6 & .205 \\
\hline 3.7 & 5.7 & 2.1 & .004 \\
\hline 244 (WSW) & $176(\mathrm{~S})$ & 68 & NA \\
\hline 45.08 & 16.58 & 28.50 & .000 \\
\hline 3.20 & 2.40 & 0.80 & .002 \\
\hline 0.13 & 0.16 & 0.04 & .000 \\
\hline 0.92 & 0.84 & 0.07 & .000 \\
\hline 1.95 & 2.16 & 0.21 & .000 \\
\hline 0.58 & 1.20 & 0.62 & $.000 *$ \\
\hline
\end{tabular}


Table 3.7. Differences from beginning to maturation for all warm season events versus all cool season events. $P$-values (2-tailed) italicized in bold indicate significance at the $95 \%$ confidence interval or greater. An asterisk

$(*)$ indicates values obtained using a parametric test.

Meteorological Values

Beech $\mathrm{T}\left({ }^{\circ} \mathrm{C}\right)$

Beech RH (\%)

Beech WS (m/s)

Beech WD (degrees)

Aerosol Values

Scattering

Absorption

Backscatter Fraction

SSA

SAE

AAE

$\begin{array}{rr}\frac{\text { All Warm }}{p \text {-value }} & \frac{\text { All Cool }}{p \text {-value }} \\ -0.182 * & -0.772 \\ +0.209 & +0.486 \\ +0.100 & +0.450 \\ \text { NA } & \text { NA } \\ & \\ -0.217 & \mathbf{- 0 . 0 0 6} \\ -0.192 & \mathbf{- 0 . 0 0 2} \\ +0.408 & +0.188 \\ 0.602 & -0.449 \\ 0.974 & +0.062 \\ +\boldsymbol{0 . 0 0 4 *} & +\boldsymbol{0 . 0 0 0 *}\end{array}$


Table 3.8. Mean meteorological and aerosol values and differences at beginning and maturation between light versus heavy warm season events. $P$-values (2-tailed) italicized in bold indicate significance at the $95 \%$ confidence interval or greater. An asterisk $(*)$ indicates values obtained using a parametric test.

\begin{tabular}{|c|c|c|c|c|}
\hline BEGINNING & Light & Heavy & Abs Diff & $p$-value \\
\hline Meteorological Values & $n=31$ & $n=31$ & & \\
\hline Avg. Total Precip (mm) & 2.0 & 20.1 & 18.1 & 0.000 \\
\hline Beech $\mathrm{T}\left({ }^{\circ} \mathrm{C}\right)$ & 14.4 & 16.4 & 2.0 & $0.012 *$ \\
\hline Beech RH (\%) & 96.3 & 92.7 & 3.6 & 0.122 \\
\hline Beech WS (m/s) & 4.0 & 3.3 & 0.7 & $0.084 *$ \\
\hline Beech WD (degrees) & $259(\mathrm{~W})$ & $201(\mathrm{SSW})$ & 58 & NA \\
\hline \multicolumn{5}{|l|}{ Aerosol Values } \\
\hline Scattering & 51.14 & 49.18 & 1.96 & $0.819^{*}$ \\
\hline Absorption & 3.51 & 3.30 & 0.21 & 0.816 \\
\hline Backscatter Fraction & 0.13 & 0.12 & 0.01 & 0.129 \\
\hline SSA & 0.93 & 0.90 & 0.03 & 0.882 \\
\hline SAE & 2.05 & 1.93 & 0.12 & 0.026 \\
\hline AAE & 0.41 & 0.47 & 0.06 & $0.414 *$ \\
\hline MATURATION & Light & Heavy & Abs Diff & $p$-value \\
\hline Meteorological Values & $n=31$ & $n=31$ & & \\
\hline Beech T $\left({ }^{\circ} \mathrm{C}\right)$ & 14.4 & 15.4 & 1.0 & $0.187 *$ \\
\hline Beech RH (\%) & 96.0 & 95.7 & 0.3 & 0.844 \\
\hline Beech WS (m/s) & 4.1 & 3.8 & 0.3 & $0.563^{*}$ \\
\hline Beech WD (degrees) & 254 (WSW) & $184(\mathrm{~S})$ & 70 & NA \\
\hline \multicolumn{5}{|l|}{ Aerosol Values } \\
\hline Scattering & 48.87 & 47.25 & 1.62 & $0.841 *$ \\
\hline Absorption & 3.12 & 3.23 & 0.11 & 0.647 \\
\hline Backscatter Fraction & 0.12 & 0.13 & 0.01 & 0.547 \\
\hline SSA & 0.94 & 0.91 & 0.03 & 0.159 \\
\hline SAE & 2.05 & 1.92 & 0.13 & 0.016 \\
\hline AAE & 0.48 & 0.70 & 0.22 & 0.016* \\
\hline
\end{tabular}


Table 3.9. Differences from beginning to maturation for all light versus heavy warm season events. $P$-values (2-tailed) italicized in bold indicate significance at the $95 \%$ confidence interval or greater. An asterisk $\left(^{*}\right)$ indicates values obtained using a parametric test.

\begin{tabular}{|c|c|c|}
\hline Meteorological Values & $\underset{\text { p-value }}{\underline{\text { Light }}}$ & $\frac{\text { Heavy }}{\text { p-value }}$ \\
\hline Beech T $\left({ }^{\circ} \mathrm{C}\right)$ & $0.983 *$ & $+0.213^{*}$ \\
\hline Beech RH (\%) & -0.993 & +0.092 \\
\hline Beech WS (m/s) & $+0.993^{*}$ & $+0.281^{*}$ \\
\hline Beech WD (degrees) & NA & NA \\
\hline \multicolumn{3}{|l|}{ Aerosol Values } \\
\hline Scattering & $-0.758^{*}$ & $-0.832 *$ \\
\hline Absorption & -0.420 & $-0.898 *$ \\
\hline Backscatter Fraction & -0.473 & +0.919 \\
\hline SSA & $+0.237^{*}$ & +0.646 \\
\hline SAE & 0.978 & -0.505 \\
\hline AAE & $+0.334 *$ & $+0.012 *$ \\
\hline
\end{tabular}


Table 3.10. Mean meteorological and aerosol values and differences at beginning and maturation between light versus heavy cool season events. $P$-values (2-tailed) italicized in bold indicate significance at the $95 \%$ confidence interval or greater. An asterisk $(*)$ indicates values obtained using a parametric test.

\begin{tabular}{|c|c|c|c|c|}
\hline BEGINNING & Light & Heavy & Abs Diff & $p$-value \\
\hline Meteorological Values & $n=15$ & $n=15$ & & \\
\hline Avg. Total Precip (mm) & 1.27 & 39.37 & 38.1 & $0.000 *$ \\
\hline Beech $\mathbf{T}\left({ }^{\circ} \mathrm{C}\right)$ & -4.9 & 2.7 & 7.67 & $0.000 *$ \\
\hline Beech RH (\%) & 98.7 & 99.9 & 1.14 & 0.088 \\
\hline Beech WS (m/s) & 3.9 & 7.8 & 3.91 & $0.010 *$ \\
\hline Beech WD (degrees) & $267(\mathrm{~W})$ & 151 (SSE) & 116 & NA \\
\hline \multicolumn{5}{|l|}{ Aerosol Values } \\
\hline Scattering & 17.86 & 33.46 & 15.6 & $0.024 *$ \\
\hline Absorption & 2.54 & 5.20 & 2.66 & $0.002 *$ \\
\hline Backscatter Fraction & 0.15 & 0.15 & 0.00 & $0.500^{*}$ \\
\hline SSA & 0.87 & 0.85 & 0.02 & 0.237 \\
\hline SAE & 2.18 & 2.04 & 0.14 & $0.067^{*}$ \\
\hline AAE & 0.95 & 1.00 & 0.05 & $0.315^{*}$ \\
\hline MATURATION & Light & Heavy & Abs Diff & $p$-value \\
\hline Meteorological Values & $n=15$ & $n=15$ & & \\
\hline Beech $\mathrm{T}\left({ }^{\circ} \mathrm{C}\right)$ & -4.8 & 2.6 & 7.44 & $0.001 *$ \\
\hline Beech RH (\%) & 99.1 & 99.9 & 0.88 & 0.062 \\
\hline Beech WS (m/s) & 3.4 & 9.5 & 6.1 & $0.001 *$ \\
\hline Beech WD (degrees) & 256 (WSW) & $142(\mathrm{SE})$ & 114 & NA \\
\hline \multicolumn{5}{|l|}{ Aerosol Values } \\
\hline Scattering & 14.28 & 15.95 & 1.67 & 0.835 \\
\hline Absorption & 2.75 & 2.36 & 0.39 & 0.297 \\
\hline Backscatter Fraction & 0.17 & 0.16 & 0.01 & 0.531 \\
\hline SSA & 0.82 & 0.83 & 0.01 & 0.531 \\
\hline SAE & 2.19 & 1.97 & 0.22 & $0.192 *$ \\
\hline AAE & 1.24 & 1.28 & 0.04 & $0.669^{*}$ \\
\hline
\end{tabular}


Table 3.11. Differences from beginning to maturation for all light versus heavy cool season events. $P$-values (2tailed) italicized in bold indicate significance at the $95 \%$ confidence interval or greater. An asterisk $(*)$ indicates values obtained using a parametric test.

$\begin{array}{lrr}\text { Meteorological Values } & \begin{array}{c}\text { Light } \\ \text { p-value }\end{array} & \frac{\underline{\text { Heavy }}}{\text { p-value }} \\ \text { Beech T }\left({ }^{\circ} \mathbf{C}\right) & +0.953^{*} & -0.955^{*} \\ \text { Beech RH (\%) } & +0.737 & 0.550 \\ \text { Beech WS (m/s) } & -0.678^{*} & +0.364^{*} \\ \text { Beech WD (degrees) } & \mathrm{NA} & \mathrm{NA} \\ \quad \text { Aerosol Values } & & \\ \text { Scattering } & -0.499^{*} & \mathbf{- 0 . 0 1 1} \\ \text { Absorption } & +0.929 & \mathbf{- 0 . 0 0 3} \\ \text { Backscatter Fraction } & +0.144 & +0.255^{*} \\ \text { SSA } & -0.089 & -0.950 \\ \text { SAE } & +0.844^{*} & -0.673^{*} \\ \text { AAE } & +\mathbf{0 . 0 0 0}^{*} & +\mathbf{0 . 0 0 5 *}\end{array}$

Warm Season versus Cool Season: Frontal Precipitation Events

Cluster analysis of frontal precipitation events in the warm season and the cool season revealed varying source regions associated with events (Fig. 3.18). Warm season frontal precipitation was strongly influenced by air masses originating in the Gulf of Mexico, while cool season frontal precipitation was strongly tied to air masses originating in the northwest. A visual assessment of the summaries of meteorological variables and aerosol properties at beginning and maturation for each cluster revealed some distinct differences in source region influences during warm season frontal precipitation (Table 3.12) and cool season frontal precipitation (Table 3.13).

It both seasons, air masses associated with the heaviest frontal precipitation events originated locally. During the warm season, the heaviest frontal precipitation events were associated with air masses represented by Cluster 3, which originated in eastern Kentucky and eventually approached the study area from the southwest (Fig. 3.18). Events associated with air masses represented by Cluster 3 consisted of warm season cold fronts and stationary 
fronts. This cluster was also associated with the highest overall scattering values and greatest growth in AAE values from event beginning to maturation, consistent with the fact that organic aerosols served as effective $\mathrm{CCN}$.

During the cool season, the heaviest frontal precipitation events were associated with Cluster 1 . These air masses approached the study area from the southeast and were likely associated with an influx of moisture from the Atlantic or the Gulf of Mexico (Fig. 3.18). This cluster represented air masses largely associated with Gulf low precipitation events (Table 3.13). Cluster 1 exhibited relatively high absorption values, overall low SSA values, some of the highest AAE values overall, and the greatest decrease in absorption from event beginning to maturation, indicating the presence of high concentrations of biomass burning particles during these periods.

Statistical analysis of aerosol properties associated with frontal precipitation events in both seasons revealed strongly significant differences between warm season and cool season frontal precipitation events (Table 3.14). There were significant differences in scattering, absorption, and backscatter values from event beginning to event maturation during cool season frontal precipitation (Table 3.15). Both scattering and absorption values decreased significantly, coupled with an increase in AAE values from beginning to maturation during cool season frontal precipitation events. These changes indicated a raining out effect of biomass burning particles coupled with coalescence of low-vapor pressure organic compounds as moisture increased.

Analysis of light and heavy warm season frontal precipitation revealed a significant difference in temperature and wind speed between the two sets (Table 3.16). Heavy events were warmer and calmer than light events, which suggested slower storm movement during 
these events and a higher mixing ratio during maturation. However, there were no significant differences in aerosol values between the two sets (Table 3.16), nor were there any significant differences in values from beginning to maturation (Table 3.17). This was a result of the snowplow effect, in which passing fronts accumulated aerosols ahead of the front as they moved across a region.

Analysis of light and heavy cool season frontal precipitation revealed a significant difference in temperature and wind speed between the two sets (Table 3.18). Overall, heavy events were significantly warmer than light events, indicating the presence of less ice and less scavenging of water vapor due to riming during heavy events. With nearly equal relative humidity values between light and heavy events, warmer heavy events indicated higher moisture content. Also, there was a significant difference in scattering values between light and heavy cool season frontal precipitation. Scattering values were significantly higher during maturation of light events, which showed a higher concentration of particles present during maturation as a result of not being rained out. Conversely, there was a significant decrease in scattering and absorption values from beginning to maturation during heavy cool season frontal precipitation, which indicated that heavy events were influenced by particles acting as $\mathrm{CCN}$ while light events were not (Table 3.19). There was also a significant increase in AAE values from beginning to maturation during both light and heavy cool season frontal precipitation events. 


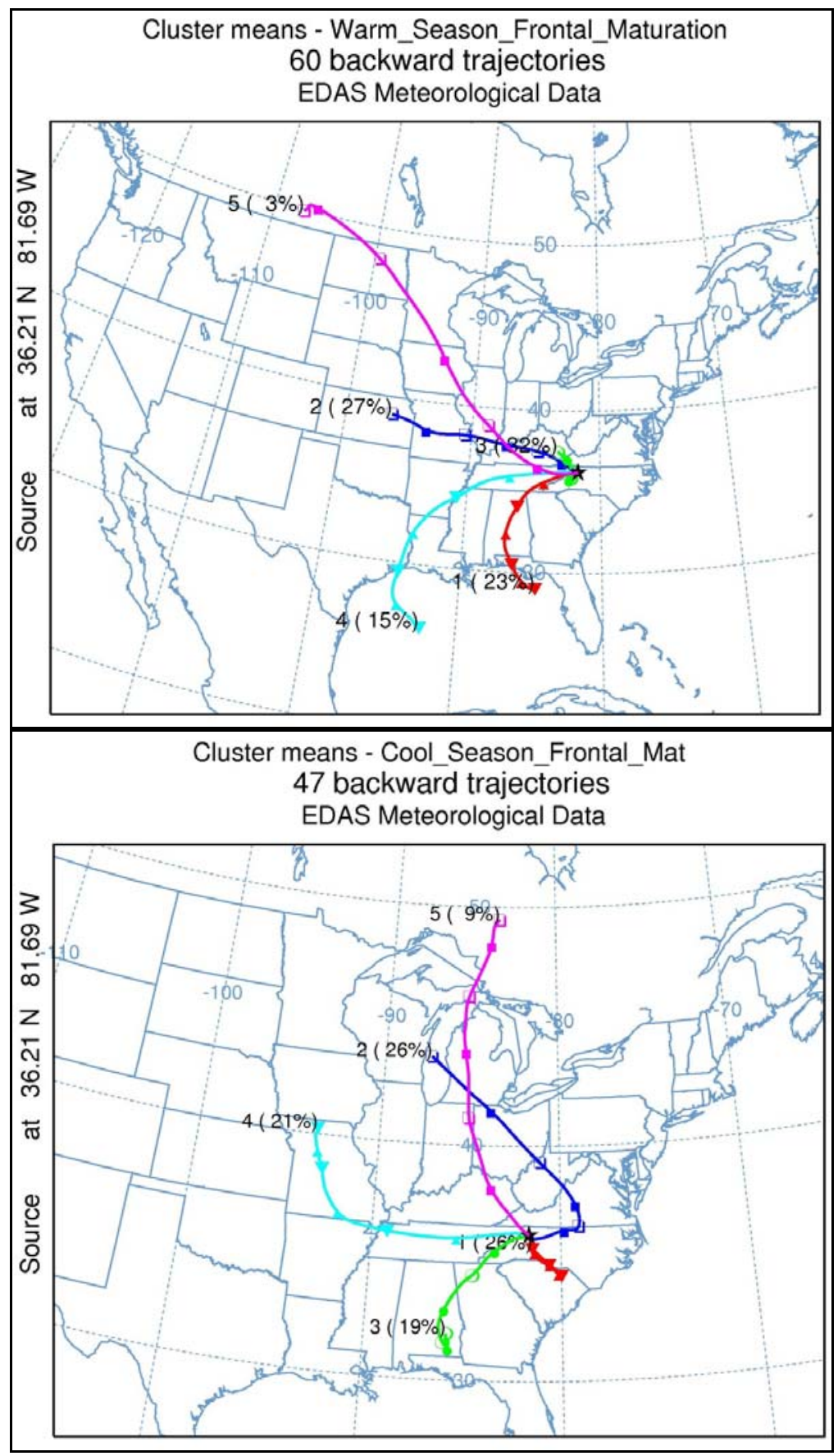

Figure 3.18. HYSPLIT cluster analysis of backward air trajectories representing maturation hour of each precipitation event during warm season frontal (top) and cool season frontal (bottom) precipitation events. Clusters are numbered and values in parentheses represent the percentage of backward air trajectories included in each cluster. Outliers were omitted from cluster analysis. 


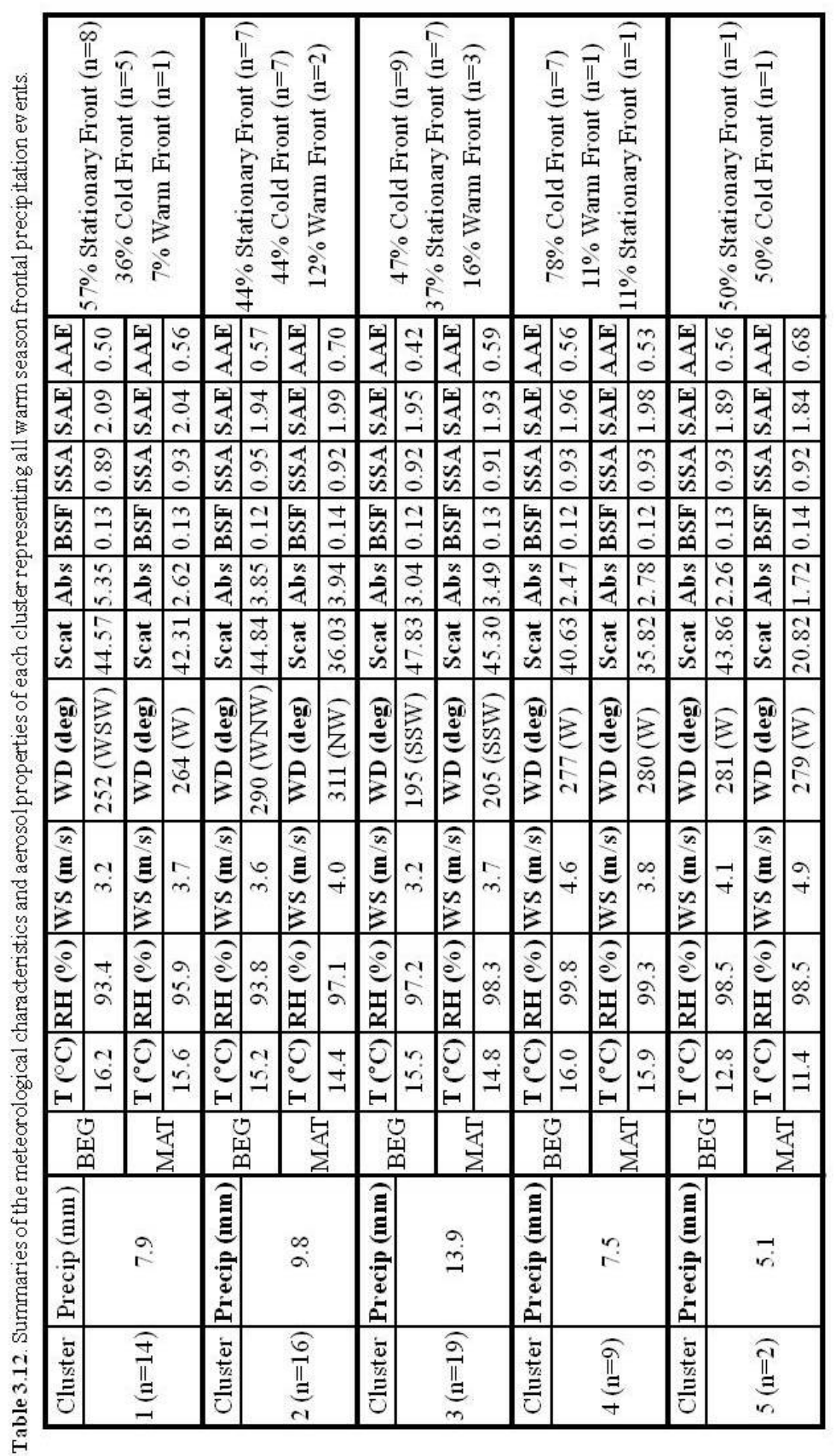




\begin{tabular}{|c|c|c|c|c|c|c|c|c|c|c|c|c|c|c|c|c|}
\hline 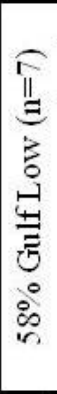 & 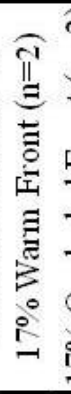 & 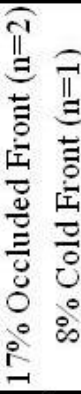 & & 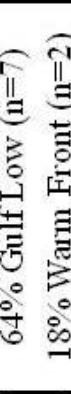 & 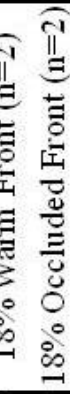 & & 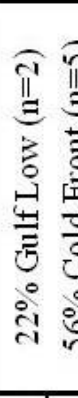 & 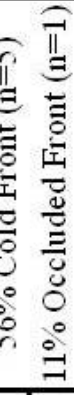 & 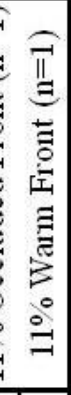 & & 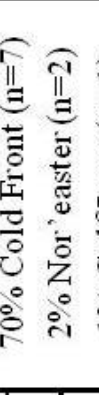 & & & & & \\
\hline 委 & \begin{tabular}{|l|l|}
8 & 5 \\
& \\
\end{tabular} & 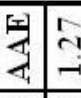 & \begin{tabular}{|l|} 
\\
\\
\end{tabular} & \begin{tabular}{|l|} 
\\
\\
-
\end{tabular} & 空妾 & 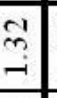 & 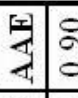 & \begin{tabular}{l|l}
2 \\
0
\end{tabular} & $=$ & 囷 & 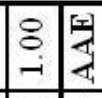 & $\begin{array}{l}0 \\
\text { in } \\
-1\end{array}$ & \begin{tabular}{l|} 
\\
\end{tabular} & \begin{tabular}{l|l} 
& \\
$\infty$ & \\
0 &
\end{tabular} & 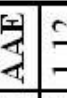 & $\begin{array}{l}3 \\
= \\
\end{array}$ \\
\hline 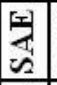 & 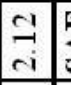 & \begin{tabular}{l|l} 
空 & 8 \\
出 & i \\
\end{tabular} & 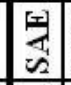 & \begin{tabular}{|c|} 
\\
0 \\
$-i$
\end{tabular} & 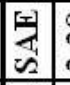 & \begin{tabular}{l|}
$\infty$ \\
$i$ \\
$i$ \\
$c$
\end{tabular} & 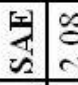 & 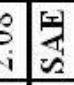 & $\begin{array}{l}3 \\
-i \\
\end{array}$ & 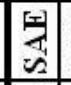 & \begin{tabular}{|c|c|} 
î & \multicolumn{1}{|r}{} \\
in & \multicolumn{1}{|c|}{} \\
\end{tabular} & \begin{tabular}{|l|}
$\vec{i}$ \\
$i$ \\
$i$
\end{tabular} & \begin{tabular}{l|} 
\\
国 \\
至 \\
\end{tabular} & \begin{tabular}{l|l} 
\pm & $E$ \\
$i$ & \\
$C$
\end{tabular} & 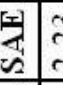 & $\begin{array}{l}3 \\
\text { in } \\
c 1\end{array}$ \\
\hline 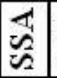 & \begin{tabular}{|l|l} 
& \\
0 & \\
0
\end{tabular} & \begin{tabular}{l|l}
$\pi$ & 0 \\
0 & $\infty$ \\
$v$ & 0
\end{tabular} & $\begin{array}{l}\overrightarrow{1} \\
\hat{\sim}\end{array}$ & \begin{tabular}{|l|} 
\\
$\infty$ \\
0 \\
0
\end{tabular} & 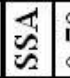 & $\begin{array}{l}2 \\
\vdots \\
0\end{array}$ & \begin{tabular}{l|l}
$\pi$ & $=$ \\
$\approx$ & $=$
\end{tabular} & \begin{tabular}{l|l}
0 \\
0 \\
0
\end{tabular} & $\begin{array}{l}\circ \\
\infty \\
0\end{array}$ & 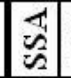 & 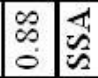 & $\begin{array}{l}\dot{\infty} \\
\dot{0} \\
0\end{array}$ & 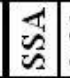 & $\overrightarrow{\hat{\theta}}$ & $\begin{array}{l}4 \\
\hat{v} \\
\approx\end{array}$ & \% \\
\hline 䆝 & \begin{tabular}{c|c} 
& \\
-1 & 5 \\
0 & \\
\end{tabular} & 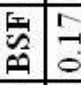 & 萓 & \begin{tabular}{l|} 
\pm \\
0 \\
\end{tabular} & 岺: & $\frac{1}{0}$ & 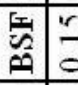 & \begin{tabular}{l|l}
0 \\
0
\end{tabular} & $\stackrel{\infty}{-\infty}$ & 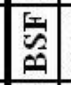 & \begin{tabular}{|c|c|c|}
0 & \multicolumn{1}{|c|}{} \\
& & \\
\end{tabular} & $\begin{array}{l}0 \\
0 \\
0\end{array}$ & 岺 & \begin{tabular}{|l|l|}
$\rightarrow$ & 5 \\
0 & 6 \\
\end{tabular} & 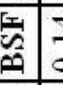 & I \\
\hline 望 & 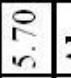 & 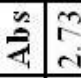 & 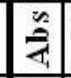 & \begin{tabular}{l}
$m$ \\
\hdashline \\
+
\end{tabular} & 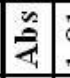 & 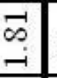 & 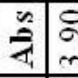 & 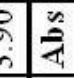 & ने & 望 & 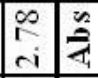 & $\begin{array}{c}m \\
\text { i } \\
\end{array}$ & 先 & \begin{tabular}{|l|l}
0 & \\
$\dot{m}$ & \\
\end{tabular} & 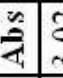 & $\begin{array}{l}\hat{O} \\
\dot{m} \\
\dot{n}\end{array}$ \\
\hline \begin{tabular}{|l|}
\multirow{2}{*}{} \\
$\tilde{n}$ \\
\end{tabular} & \begin{tabular}{|l|} 
\\
2 \\
\end{tabular} & 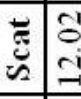 & 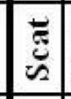 & \begin{tabular}{l|}
\multirow{2}{*}{} \\
$\dot{m}$ \\
\end{tabular} & 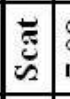 & 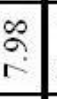 & 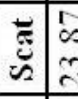 & 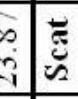 & $\begin{array}{l}n \\
2 \\
-1 \\
\end{array}$ & \begin{tabular}{|l|}
$\overrightarrow{\tilde{s}}$ \\
$\tilde{n}$
\end{tabular} & 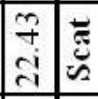 & $\begin{array}{l}0 \\
2 \\
i \\
i \\
\end{array}$ & \begin{tabular}{|l|}
$\overrightarrow{\tilde{V}}$ \\
$\tilde{v}$
\end{tabular} & \begin{tabular}{|l|l} 
& \\
& \\
0 & \\
0 & \\
\end{tabular} & 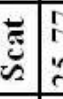 & $\begin{array}{l}\text { E } \\
\text { ci }\end{array}$ \\
\hline 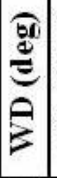 & 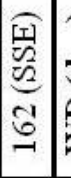 & 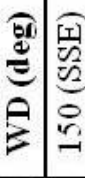 & 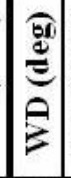 & 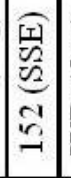 & : & 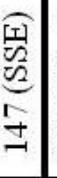 & 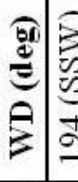 & 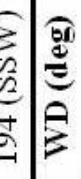 & $\begin{array}{l}3 \\
\overrightarrow{5} \\
2 \\
2 \\
2\end{array}$ & 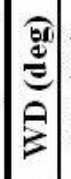 & 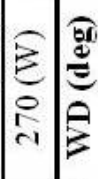 & 产 & 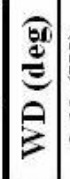 & $\begin{array}{l}\hat{Z} \\
8 \\
0\end{array}$ & 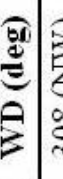 & $\sum_{\substack{\infty \\
\infty \\
\infty}}$ \\
\hline 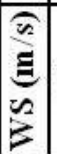 & 垈 & 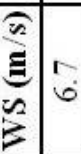 & 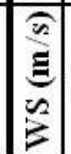 & $\begin{array}{l}0 \\
1\end{array}$ & 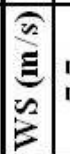 & $\underline{r}$ & 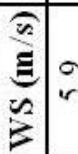 & 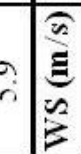 & ชै & 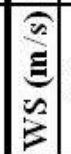 & 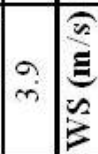 & 品 & 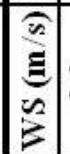 & $\begin{array}{cc} \\
m \\
m\end{array}$ & 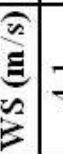 & $\exists$ \\
\hline 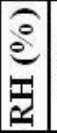 & $\begin{array}{ll}1 \\
2 \\
2\end{array}$ & 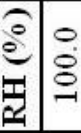 & 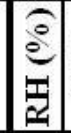 & $\begin{array}{l}n \\
\infty \\
\infty\end{array}$ & \begin{tabular}{|c|} 
\\
\\
0 \\
0
\end{tabular} & $\begin{array}{l}\stackrel{0}{8} \\
\stackrel{-}{-}\end{array}$ & 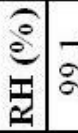 & $\frac{\hat{e}}{8}$ & $\stackrel{\circ}{\circ}$ & 量 & 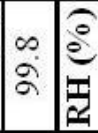 & $\vec{\alpha}$ & 官 & $\begin{array}{cc}3 \\
2 \\
2 & 0 \\
0 & 0\end{array}$ & $\frac{0}{0}$ & $\frac{1}{2}$ \\
\hline \begin{tabular}{|c|} 
\\
0 \\
0 \\
-1
\end{tabular} \mid & $+\vec{m}$ & 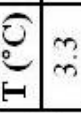 & $\begin{array}{l}\begin{array}{l}0 \\
0 \\
0 \\
-1\end{array} \\
\end{array}$ & \begin{tabular}{|l|} 
\\
\\
\end{tabular} & \begin{tabular}{|c|} 
\\
0 \\
0 \\
-1
\end{tabular} & $\overrightarrow{0}$ & \begin{tabular}{l|l}
0 & \\
0 & -1
\end{tabular} & 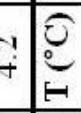 & $m$ & \begin{tabular}{|l|}
0 \\
0 \\
0 \\
-1
\end{tabular} & \begin{tabular}{|c|c} 
& 0 \\
i & 0 \\
\end{tabular} & 9 & \begin{tabular}{|l|} 
\\
0 \\
0 \\
-1
\end{tabular} & \begin{tabular}{|l|l|l}
+ & $f$ \\
$\infty$ & 0 \\
$i$ & 0 \\
\end{tabular} & & i \\
\hline & & 孚 & $\begin{array}{l}5 \\
15 \\
p\end{array}$ & If & 案 & & $\begin{array}{l}\text { I) } \\
\text { 되 } \\
\text { | }\end{array}$ & & 畜 & $\begin{array}{l}5 \\
15 \\
09\end{array}$ & q & & & & 䔔 & \\
\hline 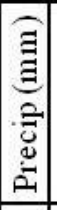 & & $\begin{array}{l}6 \\
\dot{a} \\
i\end{array}$ & 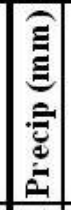 & & $\overrightarrow{d i}$ & & 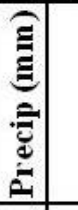 & $\mathcal{I}$ & & 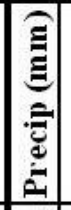 & $m$ & & 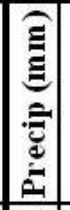 & & + & \\
\hline $\begin{array}{l}\overline{\bar{s}} \\
\bar{z} \\
\Xi\end{array}$ & & $\underset{-1}{\stackrel{\partial}{a}}$ & 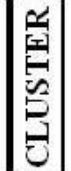 & & $\underset{\sim}{\stackrel{\overparen{I}}{\Xi}}$ & & 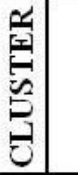 & $\underset{m}{\mathbb{1}}$ & & 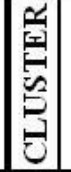 & & & 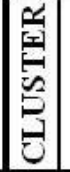 & & & \\
\hline
\end{tabular}


Table 3.14. Mean meteorological and aerosol values and differences at beginning and maturation for all frontal precipitation events in the warm season versus the cool season. $P$-values (2-tailed) italicized in bold indicate significance at the $95 \%$ confidence interval or greater. Asterisks $\left(^{*}\right)$ indicate values obtained using parametric test.

\begin{tabular}{|c|c|c|c|c|}
\hline$\frac{\text { BEGINNING }}{\text { Meteorological Value }}$ & $\frac{\text { Warm Frontal }}{(n=60)}$ & $\frac{\text { Cool Frontal }}{(n=48)}$ & $\underline{\text { Abs Diff }}$ & $\underline{p \text {-value }}$ \\
\hline Avg. Total Precip (mm) & 10.2 & 15.8 & 5.6 & .579 \\
\hline Beech T $\left({ }^{\circ} \mathrm{C}\right)$ & 15.6 & 0.1 & 15.5 & $.000 *$ \\
\hline Beech RH (\%) & 95.8 & 98.3 & 2.5 & .100 \\
\hline Beech WS (m/s) & 3.5 & 5.2 & 1.7 & .040 \\
\hline $\begin{array}{c}\text { Beech WD (degrees) } \\
\text { Aerosol Value }\end{array}$ & $262(\mathrm{~W})$ & $172(\mathrm{~S})$ & 90 & NA \\
\hline Scattering & 44.93 & 27.15 & 17.77 & .000 \\
\hline Absorption & 3.21 & 4.14 & 0.93 & .113 \\
\hline Backscatter Fraction & 0.12 & 0.15 & 0.03 & .000 \\
\hline SSA & 0.92 & 0.85 & 0.07 & .000 \\
\hline SAE & 1.98 & 2.11 & 0.13 & $.002 *$ \\
\hline AAE & 0.50 & 0.99 & 0.48 & $.000 *$ \\
\hline$\frac{\text { MATURATION }}{\text { Meteorological Value }}$ & $\frac{\text { Warm Frontal }}{(n=60)}$ & $\frac{\text { Cool Frontal }}{(n=48)}$ & $\underline{\text { Abs Diff }}$ & $p$-value \\
\hline Beech T $\left({ }^{\circ} \mathbf{C}\right)$ & 14.9 & -0.7 & 15.64 & .000 \\
\hline Beech RH (\%) & 97.6 & 99.3 & 1.7 & .391 \\
\hline Beech WS (m/s) & 3.8 & 6.2 & 2.4 & $.002 *$ \\
\hline $\begin{array}{c}\text { Beech WD (degrees) } \\
\text { Aerosol Value }\end{array}$ & $271(\mathrm{~W})$ & $176(S)$ & 95 & NA \\
\hline Scattering & 39.40 & 16.56 & 22.85 & $.000 *$ \\
\hline Absorption & 3.20 & 2.56 & 0.65 & .084 \\
\hline Backscatter Fraction & 0.13 & 0.17 & 0.04 & .000 \\
\hline SSA & 0.92 & 0.83 & 0.09 & .000 \\
\hline SAE & 1.97 & 2.14 & 0.17 & $.006^{*}$ \\
\hline AAE & .60 & 1.24 & 0.63 & $.000 *$ \\
\hline
\end{tabular}


Table 3.15. Differences from beginning to maturation for warm season frontal versus cool season frontal precipitation events. $P$-values (2-tailed) italicized in bold indicate significance at the $95 \%$ confidence interval or greater. Asterisks $(*)$ indicate values obtained using a parametric test.

Meteorological Values

Beech $\mathrm{T}\left({ }^{\circ} \mathrm{C}\right)$

Beech RH (\%)

Beech WS (m/s)

Beech WD (degrees)

Aerosol Values

Scattering

Absorption

Backscatter Fraction

SSA

SAE

AAE
Warm Frontal Cool Frontal

\begin{tabular}{ccc} 
p-value & & p-value \\
\hline$-0.204^{*}$ & & -0.774 \\
+0.193 & & +0.639 \\
+0.350 & & $+0.252^{*}$ \\
NA & NA \\
& \\
$-0.290^{*}$ & $\mathbf{- 0 . 0 0 2}$ \\
-0.212 & & $\mathbf{- 0 . 0 0 1}$ \\
+0.566 & & +0.057 \\
0.545 & & -0.218 \\
$-0.943^{*}$ & & $+0.061^{*}$ \\
$+0.083^{*}$ & & $+\mathbf{0 . 0 0 0} *$
\end{tabular}


Table 3.16. Mean meteorological and aerosol values and differences at beginning and maturation between light versus heavy warm season frontal precipitation events. $P$-values (2-tailed) italicized in bold indicate significance at the $95 \%$ confidence interval or greater. An asterisk $(*)$ indicates values obtained using a parametric test.

\section{BEGINNING}

Meteorological Values

Avg. Total Precip (mm)

Beech $\mathrm{T}\left({ }^{\circ} \mathrm{C}\right)$

Beech RH (\%)

Beech WS (m/s)

Beech WD (degrees)

Aerosol Values

\section{Scattering}

Absorption

Backscatter Fraction

SSA

SAE

AAE

$\frac{\text { MATURATION }}{\text { Meteorological Values }}$

Beech $\mathbf{T}\left({ }^{\circ} \mathrm{C}\right)$

Beech RH (\%)

Beech WS (m/s)

Beech WD (degrees)

Aerosol Values

\section{Scattering}

Absorption

Backscatter Fraction

SSA

SAE

AAE

Warm Frontal Warm Frontal

$\underline{\text { Light }} \quad \underline{\text { Heavy }}$

$\underline{\text { AbsDiff }} \underline{p \text {-value }}$

2.2

23.5

$21.3 \quad \mathbf{0 . 0 0 0}$

13.3

16.4

92.1

$3.1 \quad 0.011$

99.1

3.0

7.0

0.079

4.7

$181(\mathrm{~S})$

$1.7 \quad \mathbf{0 . 0 1 6}^{*}$

294 (WNW)

108

NA

$\begin{array}{cccc}41.76 & 52.32 & 10.56 & 0.517 \\ 3.28 & 3.75 & 0.47 & 0.134 \\ 0.13 & 0.12 & 0.01 & 0.586 \\ 0.92 & 0.90 & 0.02 & 0.392 \\ 1.97 & 1.93 & 0.04 & 0.641^{*} \\ 0.52 & 0.48 & 0.04 & 0.749^{*}\end{array}$

Warm Frontal Warm Frontal

$\underline{\underline{\text { Light }}} \quad \underline{\underline{\text { Heavy }}} \quad \underline{\text { AbsDiff }} \quad \underline{p \text {-value }}$

13.3

99.1

14.8

$1.5 \quad 0.147 *$

2.50 .888

4.7

4.1

0.6

$0.369^{*}$

289 (WNW)

$185(\mathrm{~S})$

109

NA

$\begin{array}{cccc}42.72 & 39.16 & 3.56 & 0.791^{*} \\ 3.42 & 3.26 & 0.16 & 0.437 \\ 0.13 & 0.14 & 0.01 & 0.527^{*} \\ 0.92 & 0.91 & 0.01 & 0.736 \\ 1.97 & 1.93 & 0.04 & 0.665^{*} \\ 0.61 & 0.66 & 0.05 & 0.707^{*}\end{array}$


Table 3.17. Differences from beginning and maturation in light versus heavy warm season frontal precipitation events. $P$-values (2-tailed) italicized in bold indicate significance at the $95 \%$ confidence interval or greater.

Asterisks $(*)$ indicate values obtained using parametric test.

\begin{tabular}{|c|c|}
\hline Warm Frontal & Warm Frontal \\
\hline$\underline{\text { Light }}$ & Heavy \\
\hline$p$-value & $p$-value \\
\hline $0.946^{*}$ & $-0.576^{*}$ \\
\hline 1.000 & +0.136 \\
\hline $0.974 *$ & $+0.268^{*}$ \\
\hline NA & NA \\
\hline+0.803 & $-0.922 *$ \\
\hline+0.852 & $-0.114^{*}$ \\
\hline 0.901 & $+0.144 *$ \\
\hline $0.938^{*}$ & +0.793 \\
\hline $0.968^{*}$ & $0.335^{*}$ \\
\hline$+0.436^{*}$ & $+0.923 *$ \\
\hline
\end{tabular}


Table 3.18. Mean meteorological and aerosol values and differences at beginning and maturation between light versus heavy cool season frontal precipitation events. $P$-values (2-tailed) italicized in bold indicate significance at the $95 \%$ confidence interval or greater. An asterisk $(*)$ indicates values obtained using a parametric test.

$\frac{\text { BEGINNING }}{\text { Meteorological Values }}$

Avg. Total Precip (mm)

Beech $\mathbf{T}\left({ }^{\circ} \mathrm{C}\right)$

Beech RH (\%)

Beech WS (m/s)

Beech WD (degrees)

Aerosol Values

\section{Scattering}

Absorption

Backscatter Fraction

SSA

SAE

AAE

$\frac{\text { MATURATION }}{\text { Meteorological Values }}$

Beech T $\left({ }^{\circ} \mathrm{C}\right)$

Beech RH (\%)

Beech WS (m/s)

Beech WD (degrees)

$$
\text { Aerosol Values }
$$

\section{Scattering}

Absorption

Backscatter Fraction

SSA

SAE

AAE
Cool Frontal Cool Frontal

\begin{tabular}{|c|c|c|c|}
\hline$\underline{\text { Light }}$ & Heavy & $\underline{\text { Abs Diff }}$ & $p$-value \\
\hline$n=12$ & $n=12$ & & \\
\hline 1.6 & 44.3 & 42.7 & 0.000 \\
\hline-2.8 & 2.3 & 5.1 & $0.015 *$ \\
\hline 99.0 & 99.8 & 0.8 & 0.196 \\
\hline 4.2 & 7.0 & 2.8 & $0.118^{*}$ \\
\hline 225 (SW) & $134(\mathrm{SE})$ & 109 & NA \\
\hline 21.49 & 35.76 & 14.27 & $0.098 *$ \\
\hline 3.39 & 5.61 & 2.22 & $0.133^{*}$ \\
\hline 0.16 & 0.15 & 0.01 & $0.248 *$ \\
\hline 0.86 & 0.84 & 0.02 & 0.564 \\
\hline 2.10 & 2.04 & 0.06 & $0.491 *$ \\
\hline 1.00 & 1.03 & 0.03 & $0.626^{*}$ \\
\hline
\end{tabular}

$\underline{\text { Cool Frontal Cool Frontal }}$

Light

$n=12$

Heavy

$n=12$

$-4.0$

98.9

2.0

99.9

8.6

243 (WSW)

152 (SSE)

$\underline{\text { Abs Diff }}$

p-value

23.02

3.20

7.11

15.91

$6.0 \quad 0.038$

$1.0 \quad 0.122$

$4.9 \quad 0.032$

0.17

1.55

1.65

0.17

0.00

0.968 *

0.85

0.82

0.03

0.065

1.96

0.23

0.570

1.26

0.07

0.177 
Table 3.19. Differences from beginning and maturation in light versus heavy cool season frontal precipitation events. $P$-values (2-tailed) italicized in bold indicate significance at the $95 \%$ confidence interval or greater. An asterisk (*) indicates values obtained using a parametric test.

\begin{tabular}{|c|c|c|}
\hline & $\frac{\text { Cool Frontal }}{\underline{\text { Light }}}$ & $\frac{\text { Cool Frontal }}{\underline{\text { Heavy }}}$ \\
\hline Meteorological Values & $p$-value & $p$-value \\
\hline Beech $\mathbf{T}\left({ }^{\circ} \mathrm{C}\right)$ & $-0.656^{*}$ & $-0.858^{*}$ \\
\hline Beech RH (\%) & -0.765 & +0.547 \\
\hline Beech WS (m/s) & $-0.764 *$ & $+0.469^{*}$ \\
\hline Beech WD (degrees) & NA & NA \\
\hline \multicolumn{3}{|l|}{ Aerosol Values } \\
\hline Scattering & +0.954 & $-0.002 *$ \\
\hline Absorption & -0.544 & $-0.005^{*}$ \\
\hline Backscatter Fraction & +0.954 & $+0.258^{*}$ \\
\hline SSA & $-0.965^{*}$ & -0.065 \\
\hline SAE & $+0.372 *$ & $-0.664 *$ \\
\hline AAE & $+0.002 *$ & $+0.003^{*}$ \\
\hline
\end{tabular}

Warm Season versus Cool Season: Non-frontal Precipitation Events

Cluster analysis of air masses associated with warm season non-frontal precipitation events (Fig. 3.13) and cool season non-frontal precipitation events (Fig. 3.17) revealed large differences in source regions influencing these events in each season. Warm season nonfrontal precipitation was strongly influenced by air masses originating in coastal areas, including the Gulf of Mexico and off the Atlantic coast to the northeast and southeast (Fig. 3.13). There was also a strong influence from air masses originating to the northwest. Aerosol values suggested a strong influence from coal-burning power plants in the Tennessee Valley associated with Cluster 1 (Table 3.20). High scattering and relatively low backscatter fraction values indicated the presence of aged sulfate, while low AAE values showed a lack of organics. Precipitation associated with events represented by Cluster 1 air masses was very low compared to the other warm season non-frontal clusters (Table 3.20). It is possible that 
aerosol loading may have contributed to precipitation suppression, but it is also possible that air masses in Cluster 1 contributed much less moisture to precipitation events compared to the other three clusters originating in more coastal regions including the Atlantic and the Gulf of Mexico (Fig. 3.13)

Approximately $75 \%$ of cool season non-frontal events were northwest flow snowfall events (e.g., Perry et al. 2007). Almost all air masses associated with these events originated in the northwest (Fig. 3.17). Orographic processes can largely influence the precipitation processes and patterns associated with northwest flow snowfall (Perry and Konrad 2006). Cool season non-frontal precipitation events produced only $3.6 \mathrm{~mm}$ of precipitation on average and were associated with low absorption and scattering values (Table 3.21). High backscatter fraction and SAE values, coupled with relatively low SSA and AAE values indicated the presence of small, highly absorbing particles from fossil fuel combustion.

Statistical analysis of aerosol properties associated with non-frontal precipitation events in both seasons revealed strongly significant differences between warm season and cool season non-frontal precipitation (Table 3.22). Warm season non-frontal precipitation events produced significantly higher precipitation than cool season non-frontal events. Warm season non-frontal precipitation events exhibited significantly higher scattering and absorption values, significantly lower backscatter fraction, SAE values, and higher SSA values, indicating larger, more scattering particles; and significantly lower AAE values indicating a relatively stronger black carbon signal. Additionally, AAE values displayed a significant positive difference from beginning to maturation during non-frontal precipitation events in both seasons (Table 3.23). 
Analysis of light and heavy warm season non-frontal precipitation revealed significant differences in aerosol properties only during maturation (Table 3.24). At maturation, scattering and SSA values were significantly higher during light events versus heavy events. Also, SAE values were significantly higher and AAE values were significantly lower during light events, which indicated the presence of smaller more soot-like particles. During warm non-frontal heavy precipitation events, there was also a significant increase in AAE values from beginning to maturation (Table 3.25). Again, these values all suggested that hygroscopic secondary organic aerosols were acting as effective $\mathrm{CCN}$ and possibly increased precipitation intensity. There was not enough data for statistically significant analysis of light versus heavy cool season non-frontal precipitation events. 

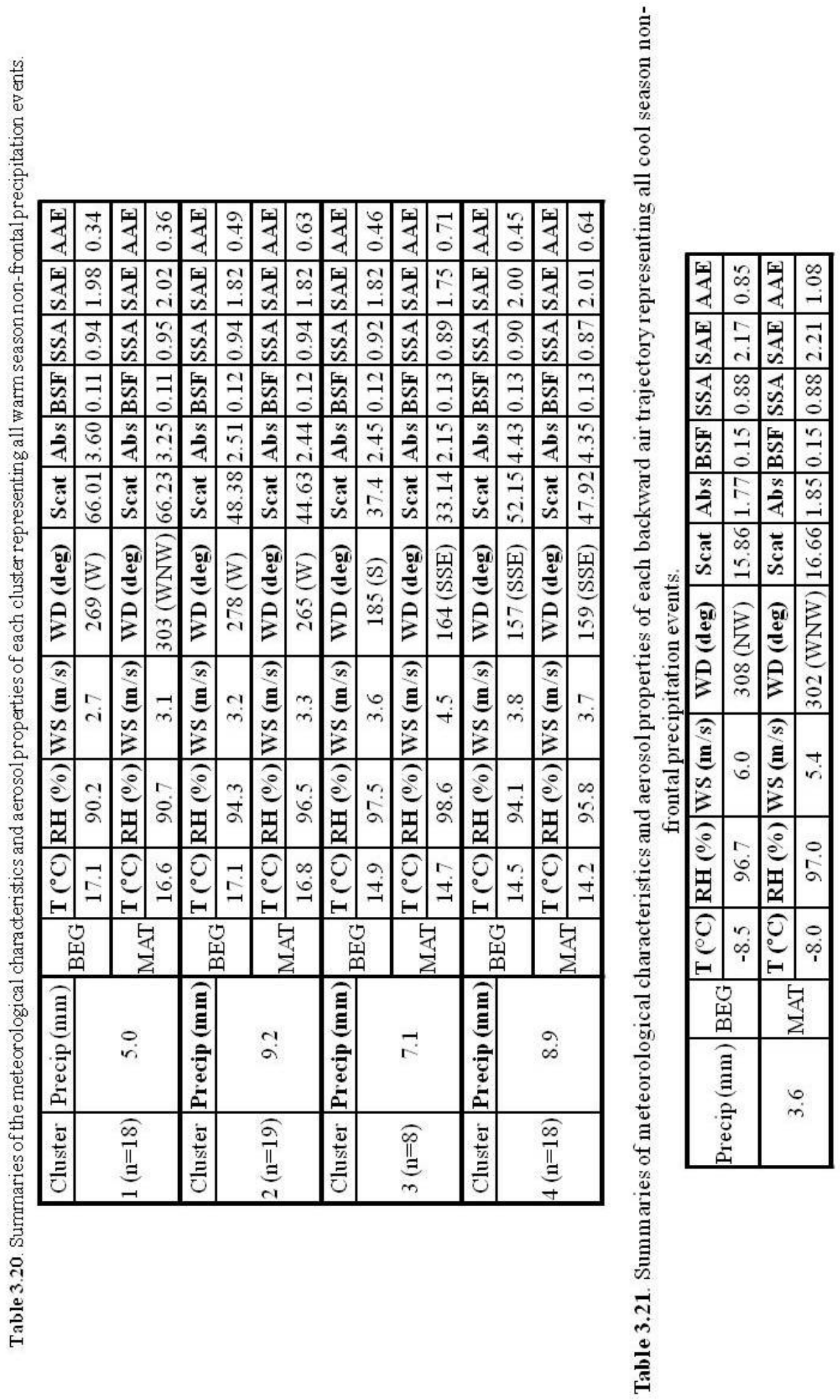
Table 3.22. Mean meteorological and aerosol values and differences at beginning and maturation for warm season versus cool season non-frontal events. $P$-values (2-tailed) italicized in bold indicate significance at the $95 \%$ confidence interval or greater. Asterisks $(*)$ indicate values obtained using parametric test.

$\frac{\text { BEGINNING }}{\text { Meteorological Values }}$

Avg. Total Precip (mm)

Beech T $\left({ }^{\circ} \mathrm{C}\right)$

Beech RH (\%)

Beech WS (m/s)

Beech WD (degrees)

Aerosol Values

Scattering

Absorption

Backscatter Fraction

SSA

SAE

AAE

MATURATION

Meteorological Values

Beech T $\left({ }^{\circ} \mathrm{C}\right)$

Beech RH (\%)

Beech WS (m/s)

Beech WD (degrees)

Aerosol Values

Scattering

Absorption

Backscatter Fraction

SSA

SAE

AAE
Warm Non-Frontal

$n=63$
7.64
16.1
93.5
3.3
207 (SSW)

53.10

3.36

0.12

0.93

1.92

0.43

Warm Non-Frontal

$$
n=63
$$

15.7

94.9

3.5

220 (SW)

50.11

3.19

0.12

0.92

1.92

0.57
Cool Non-Frontal

$n=12$
3.60
-8.5
96.7
4.0
$308(\mathrm{NW})$

$\underline{\text { Abs Diff }}$

$\begin{array}{cc}4.04 & .010 \\ 24.50 & .000^{*} \\ 3.2 & .834 \\ 0.7 & .488^{*} \\ 88 & \text { NA }\end{array}$

15.86

1.77

0.15

0.88

2.17

0.85

Cool Non-Frontal

$$
n=12
$$

$-8.0$

97.0

3.6

302 (WNW)

16.66

1.85

0.15

0.88

2.21

1.08
37.25

$1.59 \quad .002$

$0.04 \quad .000$

$0.05 \quad .000$

$0.25 \quad .005^{*}$

$0.42 \quad .000 *$

$\underline{\text { Abs Diff } p \text {-value }}$

$\begin{array}{cc}23.76 & .00 *^{*} \\ 2.1 & .773 \\ 0.1 & .917^{*} \\ 95 & \text { NA }\end{array}$

$33.45 \quad .000$

$1.34 \quad \mathbf{0 1 0}$

$0.02 \quad .000$

$0.03 \quad .001$

$0.28 \quad .001$

$0.52 \quad .000^{*}$ 
Table 3.23. Differences from beginning to maturation for warm season non-frontal versus cool season nonfrontal precipitation events. $P$-values (2-tailed) italicized in bold indicate significance at the $95 \%$ confidence interval or greater. Asterisks $(*)$ indicate values obtained using a parametric test.

$$
\text { Warm } \quad \underline{\text { Cool }}
$$

Non-Frontal Non-Frontal

Meteorological Values

$p$-value

$p$-value

Beech $\mathrm{T}\left({ }^{\circ} \mathrm{C}\right)$

Beech RH (\%)

$-0.521$

$+0.297$

+0.887 *

Beech WS (m/s)

$+0.463 *$

$+0.653$

Beech WD (degrees)

NA

$-0.762 *$

Aerosol Values

Scattering
Absorption
Backscatter Fraction

$-0.593$

+0.857 *

$-0.444$

$+0.707$

0.653

0.312

SSA

$-0.897$

0.583

SAE

$0.934 *$

$-0.840$

AAE

$+0.024 *$

$+0.057^{*}$ 
Table 3.24. Mean meteorological and aerosol values and differences at beginning and maturation between light versus heavy warm season non-frontal precipitation events. $P$-values (2-tailed) italicized in bold indicate significance at the $95 \%$ confidence interval or greater. Asterisks $(*)$ indicate values obtained using parametric test.

\section{$\underline{\text { BEGINNING }}$}

Meteorological Values

Avg. Total Precip (mm)

Beech T $\left({ }^{\circ} \mathrm{C}\right)$

Beech RH (\%)

Beech WS (m/s)

Beech WD (degrees)

Aerosol Values

Scattering

Absorption

Backscatter Fraction

SSA

SAE

AAE

MATURATION

Meteorological Values

Beech T $\left({ }^{\circ} \mathrm{C}\right)$

Beech RH (\%)

Beech WS (m/s)

Beech WD (degrees)

Aerosol Values

Scattering

Absorption

Backscatter Fraction

SSA

SAE

AAE

\begin{tabular}{|c|c|c|c|}
\hline$\underline{\text { Warm }}$ & $\underline{\text { Warm }}$ & & \\
\hline Non-Frontal & Non-Frontal & & \\
\hline$\underline{\text { Light }}$ & Heavy & $\underline{\text { Abs Diff }}$ & $p$-value \\
\hline$n=16$ & $n=16$ & & \\
\hline 2.1 & 16.4 & 14.3 & 0.000 \\
\hline 15.4 & 16.0 & 0.6 & $0.630 *$ \\
\hline 93.6 & 93.9 & 0.3 & 0.626 \\
\hline 3.6 & 3.7 & 0.1 & $0.916^{*}$ \\
\hline $177(\mathrm{~S})$ & 198 (SSW) & 21 & NA \\
\hline 59.52 & 45.54 & 13.98 & 0.132 \\
\hline 3.59 & 2.99 & 0.60 & 0.451 \\
\hline 0.12 & 0.12 & 0.00 & 0.451 \\
\hline 0.94 & 0.91 & 0.03 & 0.258 \\
\hline 2.10 & 1.91 & 0.19 & $0.215^{*}$ \\
\hline 0.28 & 0.51 & 0.23 & $0.343^{*}$ \\
\hline$\underline{\text { Warm }}$ & $\underline{\text { Warm }}$ & & \\
\hline Non-Frontal & Non-Frontal & & \\
\hline$\underline{\text { Light }}$ & Heavy & $\underline{\text { Abs Diff }}$ & $p$-value \\
\hline$n=16$ & $n=16$ & & \\
\hline 15.4 & 15.3 & 0.1 & $0.921 *$ \\
\hline 93.1 & 96.9 & 3.8 & 0.601 \\
\hline 3.7 & 4.1 & 0.4 & $0.499 *$ \\
\hline $182(\mathrm{~S})$ & $170(\mathrm{~S})$ & 12 & NA \\
\hline 58.67 & 30.43 & 28.24 & $0.006^{*}$ \\
\hline 3.46 & 2.33 & 1.13 & 0.082 \\
\hline 0.12 & 0.13 & 0.01 & $0.347^{*}$ \\
\hline 0.94 & 0.85 & 0.09 & 0.058 \\
\hline 2.11 & 1.87 & 0.24 & $0.001 *$ \\
\hline 0.35 & 0.79 & 0.44 & $0.001 *$ \\
\hline
\end{tabular}


Table 3.25. Differences from beginning and maturation in light versus heavy warm season non-frontal precipitation events. $P$-values (2-tailed) italicized in bold indicate significance at the $95 \%$ confidence interval or greater. An asterisk $(*)$ indicates values obtained using a parametric test.

\begin{tabular}{|c|c|c|}
\hline & $\frac{\frac{\text { Warm }}{\text { Non-Frontal }}}{\underline{\text { Light }}}$ & $\frac{\begin{array}{l}\text { Warm } \\
\text { Non-Frontal }\end{array}}{\underline{\text { Heavy }}}$ \\
\hline Meteorological Values & $p$-value & $p$-value \\
\hline Beech $\mathbf{T}\left({ }^{\circ} \mathrm{C}\right)$ & $0.972^{*}$ & $-0.612 *$ \\
\hline Beech RH (\%) & -0.982 & +0.153 \\
\hline Beech WS (m/s) & $+0.945^{*}$ & $+0.551 *$ \\
\hline Beech WD (degrees) & NA & NA \\
\hline \multicolumn{3}{|l|}{ Aerosol Values } \\
\hline Scattering & -0.970 & $-0.199 *$ \\
\hline Absorption & -0.850 & $-0.206^{*}$ \\
\hline Backscatter Fraction & 0.850 & $+0.206^{*}$ \\
\hline SSA & $0.815^{*}$ & -0.418 \\
\hline SAE & $+0.984 *$ & $-0.612 *$ \\
\hline AAE & $+0.495^{*}$ & $+0.020 *$ \\
\hline
\end{tabular}




\section{Synoptic Variation}

Warm Season: Frontal vs. Non-frontal

Warm season frontal (Fig. 3.18) and non-frontal (Fig. 3.13) precipitation events displayed very different air mass source regions during the time period of this thesis. Statistical analysis of warm season frontal versus non-frontal precipitation events revealed no significant differences in the meteorological characteristics or aerosol values associated with these events (Table 3.26). There was, however, a significant increase in AAE values from beginning to maturation during non-frontal events, which was consistently seen throughout this thesis (Table 3.27).

There were no significant differences in precipitation between lower and upper quartile aerosol values for warm season frontal events (Table 3.28). This may be a result of the snowplow effect of frontal events causing light and heavy events associated with fronts to accumulate similar aerosol loading while approaching the SAM. Precipitation totals associated with upper and lower quartile aerosol values did exhibit significant differences during warm season non-frontal precipitation events (Table 3.29). During beginning and maturation, events exhibited significantly lower precipitation in association with higher SAE values. Smaller particles serve as poor CCN (Andreae and Rosenfeld 2008), and therefore may have suppressed precipitation in these cases. A significant difference occurred in precipitation values associated with lower and higher AAE values, as well. However, this difference was opposite between beginning and maturation times (Table 3.29). During event beginning, precipitation was significantly higher in association with higher AAE values; during event maturation, precipitation was significantly lower in association with higher AAE values. The effect which took place during event beginning indicated organic particles 
serving as $\mathrm{CCN}$. However, the effect that took place during event maturation indicated some level of precipitation suppression related to higher aerosol loading (Albrecht 1989) or that the organics were rained out.

Table 3.26. Mean meteorological and aerosol values and differences at beginning and maturation for all warm season frontal and non-frontal precipitation events. $P$-values (2-tailed) italicized in bold indicate significance at the $95 \%$ confidence interval or greater. Asterisks $(*)$ indicate values obtained using parametric test.

\begin{tabular}{|c|c|c|c|c|}
\hline$\underline{\text { BEGINNING }}$ & $\underline{\text { Warm Frontal }}$ & $\underline{\text { Warm Non-Frontal }}$ & $\underline{\text { Abs Diff }}$ & $p$-value \\
\hline Meteorological Values & $n=60$ & $n=63$ & & \\
\hline Avg. Total Precip (mm) & 10.2 & 7.6 & 2.53 & .231 \\
\hline Beech T $\left({ }^{\circ} \mathbf{C}\right)$ & 15.6 & 16.1 & 0.49 & $.336^{*}$ \\
\hline Beech RH (\%) & 95.8 & 93.5 & 2.4 & .110 \\
\hline Beech WS (m/s) & 3.5 & 3.3 & 0.3 & .576 \\
\hline Beech WD (degrees) & $262(\mathrm{~W})$ & $220(\mathrm{SW})$ & 42 & NA \\
\hline \multicolumn{5}{|l|}{ Aerosol Values } \\
\hline Scattering & 44.93 & 53.10 & 8.17 & .160 \\
\hline Absorption & 3.21 & 3.36 & 0.15 & .533 \\
\hline Backscatter Fraction & 0.12 & 0.12 & 0.00 & .180 \\
\hline SSA & 0.92 & 0.93 & 0.00 & .698 \\
\hline SAE & 1.98 & 1.92 & 0.06 & $.240^{*}$ \\
\hline AAE & 0.50 & 0.43 & 0.07 & $.180^{*}$ \\
\hline MATURATION & $\underline{\text { Warm Frontal }}$ & Warm Non-Frontal & $\underline{\text { Abs Diff }}$ & $p$-value \\
\hline Meteorological Values & $n=60$ & $n=63$ & & \\
\hline Beech T $\left({ }^{\circ} \mathrm{C}\right)$ & 14.9 & 15.7 & 0.80 & $.110^{*}$ \\
\hline Beech RH (\%) & 97.6 & 94.9 & 2.7 & .071 \\
\hline Beech WS (m/s) & 3.8 & 3.5 & 0.4 & $.256^{*}$ \\
\hline Beech WD (degrees) & $271(\mathrm{~W})$ & 207 (SSW) & 64 & NA \\
\hline \multicolumn{5}{|l|}{ Aerosol Values } \\
\hline Scattering & 39.40 & 50.11 & 10.71 & .072 \\
\hline Absorption & 3.20 & 3.19 & 0.01 & .255 \\
\hline Backscatter Fraction & 0.13 & 0.12 & 0.01 & .165 \\
\hline SSA & 0.92 & 0.92 & 0.00 & .352 \\
\hline SAE & 1.97 & 1.92 & 0.05 & $.284^{*}$ \\
\hline AAE & 0.60 & 0.57 & 0.04 & $.563 *$ \\
\hline
\end{tabular}


Table 3.27. Differences from beginning and maturation in warm season frontal versus non-frontal precipitation events. P-values (2-tailed) italicized in bold indicate significance at the $95 \%$ confidence interval or greater. An asterisk $(*)$ indicates values obtained using a parametric test.

\begin{tabular}{lccc} 
& Warm Frontal & & Warm Non-Frontal \\
\cline { 2 - 3 } Meteorological Values & $p$-value & & $p$-value \\
Beech T $\left({ }^{\circ} \mathrm{C}\right)$ & $-0.204^{*}$ & & $-0.521^{*}$ \\
Beech RH (\%) & +0.193 & & +0.297 \\
Beech WS (m/s) & +0.350 & $+0.463^{*}$ \\
Beech WD (degrees) & NA & NA \\
$\quad$ Aerosol Values & & \\
Scattering & $-0.290^{*}$ & -0.593 \\
Absorption & +0.212 & -0.444 \\
Backscatter Fraction & +0.566 & 0.653 \\
SSA & 0.545 & -0.897 \\
SAE & $-0.943^{*}$ & $0.934^{*}$ \\
AAE & $+0.083^{*}$ & $+\mathbf{0 . 0 2 4}$
\end{tabular}

Table 3.28. Mean precipitation $(\mathrm{mm})$ values associated with lower and upper quartile aerosol values during warm season frontal precipitation events.

\begin{tabular}{lcccc}
\multicolumn{5}{c}{ BEGINNING } \\
\multicolumn{1}{c}{ Lower $(\mathrm{n}=15)$} & Upper $(\mathrm{n}=15)$ & & \\
\multicolumn{1}{c}{ Aerosol Value } & Precip & Precip & Abs Diff & $p$-value \\
Scattering & 6.2 & 8.5 & 2.3 & 0.329 \\
Absorption & 5.8 & 11.2 & 5.4 & 0.287 \\
Backscatter Fraction & 11.2 & 7.3 & 3.9 & 0.635 \\
SSA & 8.3 & 9.6 & 1.3 & 0.265 \\
SAE & 6.1 & 7.7 & 1.6 & 0.629 \\
AAE & 8.4 & 7.6 & 0.8 & 0.689 \\
& \multicolumn{2}{c}{ MATURATION } & & \\
\multicolumn{1}{c}{ Aerosol Value } & Lower (n=15) & Upper (n=15) & & \\
Scattering & Precip & Precip & Abs Diff & $p$-value \\
Absorption & 13.0 & 7.6 & 5.4 & 0.232 \\
Backscatter Fraction & 11.8 & 8.3 & 3.5 & 0.801 \\
SSA & 9.2 & 10.6 & 1.4 & 0.783 \\
SAE & 11.8 & 9.0 & 2.8 & 0.804 \\
AAE & 10.1 & 9.3 & 0.8 & 0.646 \\
& 10.5 & 10.5 & 0.0 & 0.762
\end{tabular}


Table 3.29. Mean precipitation $(\mathrm{mm})$ values associated with lower and upper quartile aerosol values during warm season non-frontal precipitation events. P-values italicized in bold indicate significance at the $95 \%$ confidence interval or greater.

\begin{tabular}{|c|c|c|c|c|}
\hline \multicolumn{5}{|c|}{$\underline{\text { BEGINNING }}$} \\
\hline & Lower $(\mathrm{n}=16)$ & Upper $(n=16)$ & & \\
\hline Aerosol Value & Precip & Precip & Abs Diff & $p$-value \\
\hline Scattering & 9.1 & 6.8 & 2.3 & 0.128 \\
\hline Absorption & 8.1 & 7.7 & 0.4 & 0.590 \\
\hline Backscatter Fraction & 8.6 & 6.8 & 1.8 & 0.381 \\
\hline SSA & 9.1 & 7.0 & 2.1 & 0.491 \\
\hline SAE & 8.3 & 4.4 & 3.9 & 0.012 \\
\hline AAE & 6.3 & 9.3 & 3.0 & 0.051 \\
\hline \multicolumn{5}{|c|}{ MATURATION } \\
\hline & Lower $(\mathrm{n}=16)$ & Upper $(\mathrm{n}=16)$ & & \\
\hline Aerosol Value & Precip & Precip & Abs Diff & $p$-value \\
\hline Scattering & 1.2 & 5.5 & 4.3 & 0.017 \\
\hline Absorption & 8.2 & 5.2 & 3.0 & 0.224 \\
\hline Backscatter Fraction & 6.2 & 7.7 & 1.5 & 0.838 \\
\hline SSA & 1.0 & 5.8 & 4.8 & 0.160 \\
\hline SAE & 8.7 & 3.7 & 5.0 & 0.001 \\
\hline AAE & 6.1 & 1.3 & 4.8 & 0.001 \\
\hline
\end{tabular}

\section{Cool Season: Frontal vs. Non-frontal}

Cool season frontal (Fig. 3.18) and non-frontal (Fig. 3.17) precipitation events displayed quite different air mass source regions. Statistical analysis of cool season frontal versus nonfrontal precipitation events revealed significant differences in the meteorological characteristics and aerosol values associated with these events (Table 3.30). Frontal events were wetter and warmer than non-frontal events. Higher scattering, absorption, and AAE values were associated with cool season frontal precipitation events. This was due to large frontal air masses exhibiting the snowplow effect of accumulating aerosols while approaching the study area. Additionally, there are significant differences in aerosol properties from beginning to maturation during cool season frontal events (Table 3.31). Scattering and absorption values were significantly lower during maturation, while 
backscatter fraction values were significantly higher during maturation, indicating that these aerosols were serving as more effective $\mathrm{CCN}$. As was consistently seen throughout this thesis, values in AAE were significantly higher during maturation for both cool season frontal and non-frontal events, providing evidence for the coalescence of water soluble organic carbon compounds with increasing relative humidity (Table 3.31).

During cool season frontal events, precipitation was significantly higher in association with upper quartile absorption values during event beginning (Table 3.32). This reflected a combination of both the snowplow effect of frontal systems collecting aerosols, coupled with strong precipitation associated with frontal events. Additionally, precipitation was significantly lower in association with upper quartile scattering and SSA values during event maturation. This effect is consistent with the idea that scattering particles can often serve as efficient CCN, promoting precipitation. During cool season non-frontal events, there were no significant differences in precipitation between lower and upper quartile aerosol values for any of the aerosol properties (Table 3.33). This suggested that while aerosol values play an important role in precipitation processes, they were not significant in differentiating between heavy and light events during cool season non-frontal precipitation. 
Table 3.30. Mean meteorological and aerosol values and differences at beginning and maturation for all cool season frontal and non-frontal precipitation events. $P$-values (2-tailed) italicized in bold indicate significance at the $95 \%$ confidence interval or greater. Asterisks $(*)$ indicate values obtained using parametric test.

\begin{tabular}{|c|c|c|c|c|}
\hline$\underline{\text { BEGINNING }}$ & $\underline{\text { Cool Frontal }}$ & $\underline{\text { Cool Non-Frontal }}$ & $\underline{\text { Abs Diff }}$ & $\underline{p \text {-value }}$ \\
\hline Meteorological Values & $n=49$ & $n=12$ & & \\
\hline Avg. Total Precip (mm) & 15.8 & 3.6 & 12.2 & .007 \\
\hline Beech T $\left({ }^{\circ} \mathrm{C}\right)$ & 0.1 & -8.5 & 8.6 & $.002 *$ \\
\hline Beech RH (\%) & 98.3 & 96.7 & 1.6 & .002 \\
\hline Beech WS (m/s) & 5.2 & 4.0 & 1.2 & $.349 *$ \\
\hline Beech WD (degrees) & $172(S)$ & $262(\mathrm{~W})$ & 90 & NA \\
\hline \multicolumn{5}{|l|}{ Aerosol Values } \\
\hline Scattering & 27.15 & 15.86 & 11.30 & .041 \\
\hline Absorption & 4.14 & 1.77 & 2.37 & .001 \\
\hline Backscatter Fraction & 0.15 & 0.15 & 0.00 & $.550^{*}$ \\
\hline SSA & 0.85 & 0.88 & 0.03 & .185 \\
\hline SAE & 2.11 & 2.17 & 0.06 & $.306^{*}$ \\
\hline AAE & 0.99 & 0.85 & 0.13 & $.033^{*}$ \\
\hline$\underline{\text { MATURATION }}$ & $\underline{\text { Cool Frontal }}$ & $\underline{\text { Cool Non-Frontal }}$ & $\underline{\text { Abs Diff }}$ & $\underline{p \text {-value }}$ \\
\hline Meteorological Values & $n=49$ & $n=12$ & & \\
\hline Beech $\mathrm{T}\left({ }^{\circ} \mathrm{C}\right)$ & -0.7 & -8.0 & 7.3 & .003 \\
\hline Beech RH (\%) & 99.3 & 97.0 & 2.3 & .013 \\
\hline Beech WS (m/s) & 6.2 & 3.6 & 2.6 & $.076^{*}$ \\
\hline Beech WD (degrees) & $176(\mathrm{~S})$ & $271(\mathrm{~W})$ & 95 & NA \\
\hline \multicolumn{5}{|l|}{ Aerosol Values } \\
\hline Scattering & 16.56 & 16.66 & 0.11 & $.981 *$ \\
\hline Absorption & 2.56 & 1.85 & 0.71 & .693 \\
\hline Backscatter Fraction & 0.17 & 0.15 & 0.02 & .083 \\
\hline SSA & 0.83 & 0.88 & 0.05 & $.009 *$ \\
\hline SAE & 2.14 & 2.21 & 0.06 & .699 \\
\hline AAE & 1.24 & 1.08 & 0.15 & $.046^{*}$ \\
\hline
\end{tabular}


Table 3.31. Differences from beginning and maturation in cool season frontal versus non-frontal precipitation events. $P$-values (2-tailed) italicized in bold indicate significance at the $95 \%$ confidence interval or greater. An asterisk $(*)$ indicates values obtained using a parametric test.

\begin{tabular}{lccc} 
& Cool Frontal & & Cool Non-Frontal \\
\cline { 2 - 3 } Meteorological Values & $p$-value & & $p$-value \\
Beech T $\left({ }^{\circ} \mathrm{C}\right)$ & -0.774 & & $+0.887^{*}$ \\
Beech RH (\%) & +0.639 & & +0.653 \\
Beech WS (m/s) & $+0.252^{*}$ & $-0.762^{*}$ \\
Beech WD (degrees) & $\mathrm{NA}$ & $\mathrm{NA}$ \\
$\quad$ Aerosol values & & \\
Scattering & $\mathbf{- 0 . 0 0 2}$ & $+0.857^{*}$ \\
Absorption & $\mathbf{- 0 . 0 0 1}$ & +0.707 \\
Backscatter Fraction & $+\mathbf{0 . 0 5 7}$ & 0.312 \\
SSA & -0.218 & 0.583 \\
SAE & $+0.061^{*}$ & +0.840 \\
AAE & $+\mathbf{0 . 0 0 0}^{*}$ & $+\mathbf{0 . 0 5 7 *}$
\end{tabular}

Table 3.32. Mean precipitation $(\mathrm{mm})$ values associated with lower and upper quartile aerosol values during cool season frontal precipitation events.

\begin{tabular}{|c|c|c|c|c|}
\hline \multicolumn{5}{|c|}{$\underline{\text { BEGINNING }}$} \\
\hline & Lower $(n=12)$ & Upper $(n=12)$ & & \\
\hline Aerosol Value & Precip & Precip & Abs Diff & $p$-value \\
\hline Scattering & 11.4 & 20.8 & 9.4 & 0.198 \\
\hline Absorption & 9.1 & 20.3 & 11.2 & 0.060 \\
\hline Backscatter Fraction & 19.0 & 14.3 & 4.7 & 0.347 \\
\hline SSA & 12.4 & 11.5 & 0.9 & 0.544 \\
\hline SAE & 17.6 & 13.6 & 4.0 & 0.630 \\
\hline AAE & 13.2 & 20.8 & 7.6 & 0.470 \\
\hline \multicolumn{5}{|c|}{$\underline{\text { MATURATION }}$} \\
\hline & Lower $(n=12)$ & Upper $(n=12)$ & & \\
\hline Aerosol Value & Precip & Precip & Abs Diff & $p$-value \\
\hline Scattering & 20.5 & 5.4 & 15.1 & 0.026 \\
\hline Absorption & 17.5 & 10.1 & 7.4 & 0.511 \\
\hline Backscatter Fraction & 15.7 & 15.5 & 0.2 & 0.693 \\
\hline SSA & 10.2 & 3.7 & 6.5 & 0.067 \\
\hline SAE & 19.3 & 11.4 & 7.9 & 0.324 \\
\hline AAE & 11.8 & 27.1 & 15.3 & 0.412 \\
\hline
\end{tabular}


Table 3.33. Mean precipitation $(\mathrm{mm})$ values associated with lower and upper quartile aerosol values during cool season non-frontal precipitation events.

\begin{tabular}{lcccc}
\multicolumn{5}{c}{ BEGINNING } \\
\multicolumn{1}{c}{ Aerosol Value } & Lower $(\mathrm{n}=3)$ & Upper (n=3) & & \\
Scattering & Precip & Precip & Abs Diff & $p$-value \\
Absorption & 1.7 & 3.4 & 1.7 & 0.127 \\
Backscatter Fraction & 1.7 & 1.8 & 0.1 & 0.827 \\
SSA & 1.9 & 6.9 & 5.0 & 0.127 \\
SAE & 1.7 & 3.3 & 1.6 & 0.127 \\
AAE & 3.4 & 4.8 & 1.4 & 0.513 \\
& 2.0 & 2.8 & 0.8 & 0.827 \\
\multicolumn{1}{c}{ Aerosol Value } & MATURATION & & \\
Scattering & Precip & Precip & Abs Diff & $p$-value \\
Absorption & 1.7 & 4.4 & 2.7 & 0.127 \\
Backscatter Fraction & 1.7 & 2.9 & 1.2 & 0.513 \\
SSA & 5.0 & 6.2 & 1.2 & 0.827 \\
SAE & 1.7 & 3.0 & 1.3 & 0.513 \\
AAE & 3.0 & 4.8 & 1.8 & 0.827 \\
& 6.6 & 2.9 & 3.7 & 0.513
\end{tabular}

\section{Summer 2009 versus Summer 2010}

Composite surface analysis charts of precipitation events taking place during the summer of 2009 and 2010 revealed widespread regional low pressure and the presence of the NASH offshore to the east-southeast (Fig. 3.19). There were differences in $500 \mathrm{hPa}$ heights between the two summers, in which JJA 2010 exhibited a warmer lower troposphere than JJA 2009 (Fig. 3.20). Precipitation events during both summers were associated primarily with nonfrontal mechanisms, but also with cold, warm, and stationary fronts. The Boone COOP monitoring station reported a total of $487.6 \mathrm{~mm}$ of precipitation during JJA 2009 and 292.2 mm of precipitation during JJA 2010. 
Sixty-nine precipitation events occurred during the summer of 2009 and produced an average of $8.2 \mathrm{~mm}$ of precipitation per event across the study area (Table 3.34). Most events exhibited widespread coverage and lasted an average of 6 hours, ranging in duration from 1 to 29 hours. Air masses associated with JJA 2009 precipitation events primarily originated to the northwest and southwest of the study area, with the majority of events originating in coastal areas including the Atlantic or the Gulf of Mexico (Fig. 3.21). Cluster 3 air masses originated in the Gulf of Mexico and were associated with events that produced the greatest precipitation. Events associated with this cluster were also characterized by lower backscatter fraction and SSA values and higher AAE values, indicating the presence of larger organic particles (Table 3.35). Cluster 2 air masses originated near the Atlantic with a much shorter trajectory path and were primarily associated with non-frontal precipitation. This cluster also exhibited the lowest AAE values, indicating a higher relative black carbon signal possibly tied to local fossil fuel combustion.

Fifty-four precipitation events occurred during the summer of 2010 and produced an average of $8.4 \mathrm{~mm}$ of precipitation per event across the study area (Table 3.34). Most JJA 2010 precipitation events exhibited widespread coverage and were shorter events, lasting an average of 5 hours, ranging from 1 to 19 hours. Air masses associated with JJA 2010 precipitation events also exhibited a strong influence from the Gulf of Mexico, but also to the west and north of the study area (Fig. 3.21). Cluster 2 air masses originated approximately due west of the study area and were associated with events producing the greatest precipitation (Table 3.36). These events were the warmest and calmest events, with an average temperature of approximately $18.2^{\circ} \mathrm{C}$ and average winds of $2.9 \mathrm{~m} / \mathrm{s}$ at maturation. Cluster 1 air masses originated in the Gulf of Mexico and were associated with events which 
exhibited the lowest scattering and absorption values (Table 3.36). Air masses represented by Cluster 3 originated north of the study area but approached from the southeast (Fig. 3.21). This cluster represented events with the highest scattering and absorption values, and were mostly non-frontal precipitation events (Table 3.36).

Statistical analyses of aerosol values at event beginning and maturation displayed significant differences between JJA 2009 and JJA 2010 precipitation events (Table 3.37). JJA 2010 was significantly warmer and drier than JJA 2009, and exhibited significantly lower AAE values during event beginning, and lower backscatter fraction values during maturation. These differences indicated a lower organic carbon signal during event beginning and overall larger particles during maturation. The only significantly different aerosol value between beginning and maturation for JJA 2009 and JJA 2010 was higher AAE values during maturation of JJA 2010 events (Table 3.38). This pattern was somewhat consistent throughout this study, and suggests again that water soluble organic carbon compounds are being taken up into particles as relative humidity increases.

Analysis of light versus heavy JJA 2009 precipitation events revealed significantly lower SAE values associated with heavy events, which suggested that smaller particles are associated with light events and larger particles are associated with heavy events (Table 3.39). There were no significant differences in aerosol values between light and heavy JJA 2009 precipitation events from beginning to maturation (Table 3.40). Analysis of light versus heavy JJA 2010 precipitation events revealed no significant differences in aerosol values (Table 3.41). However, from beginning to maturation of heavy events, AAE values were significantly higher during maturation (Table 3.42). 
In order to determine any differences in precipitation associated with aerosol properties, precipitation totals were analyzed with lower and upper quartile aerosol values during JJA 2009 (Table 3.43) and JJA 2010 events (Table 3.44). During JJA 2009 precipitation events, precipitation was significantly lower in association with upper quartile SAE values during event beginning and upper quartile scattering values at maturation. Additionally, precipitation was significantly higher in association with upper quartile AAE values (Table 3.43). There were no significant differences in precipitation totals associated with upper and lower quartile aerosol values during JJA 2010 precipitation events (Table 3.44). 
Table 3.34. Summary of JJA 2009 and JJA 2010 precipitation events. Average total precipitation values from COOP and CoCoRaHS stations in study area. Temperature, relative humidity, wind speed, and wind direction are from the BEECHTOP meteorological station.

\begin{tabular}{|c|c|c|c|c|c|c|c|}
\hline & $\mathbf{n}$ & $\begin{array}{c}\text { Coverage } \\
(\mathbf{\%})\end{array}$ & $\begin{array}{c}\text { Avg. Total } \\
\text { Precip (mm) }\end{array}$ & $\begin{array}{c}\text { Temperature } \\
\left(\mathbf{} \mathbf{}^{\mathbf{C}}\right)\end{array}$ & $\begin{array}{c}\text { Relative } \\
\text { Humidity (\%) }\end{array}$ & $\begin{array}{c}\text { Wind Speed } \\
(\mathbf{m} / \mathbf{s})\end{array}$ & $\begin{array}{c}\text { Wind Direction } \\
(\mathbf{d e g r e e s})\end{array}$ \\
\hline JJA 2009 & 53 & 78 & 8.2 & 14.9 & 95.7 & 3.8 & $236(\mathrm{SW})$ \\
\hline JJA 2010 & 46 & 81 & 8.4 & 17.4 & 95.9 & 3.0 & $277(\mathrm{~W})$ \\
\hline
\end{tabular}

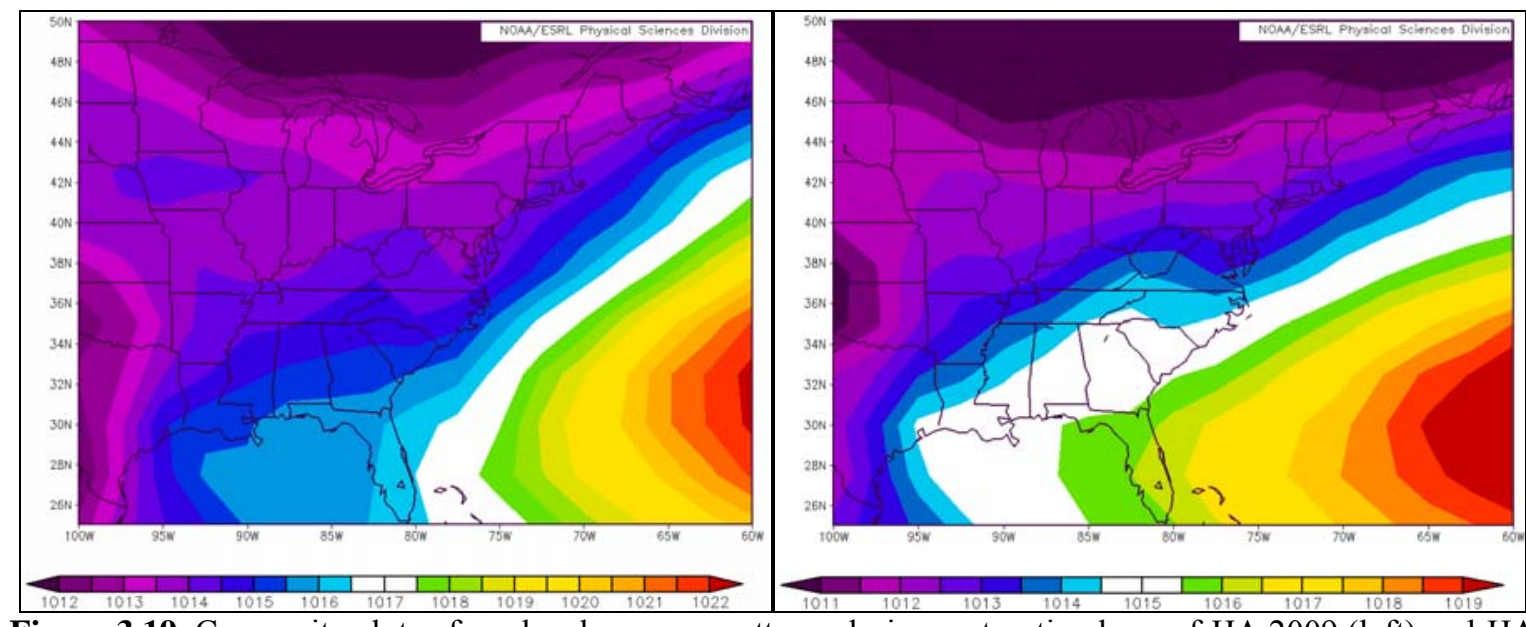

Figure 3.19. Composite plots of sea level pressure patterns during maturation hour of JJA 2009 (left) and JJA 2010 (right) precipitation events. (Images provided by the NOAA/ESRL Physical Sciences Division, Boulder Colorado, USA, from their Web site at http://www.esrl.noaa.gov/psd/).

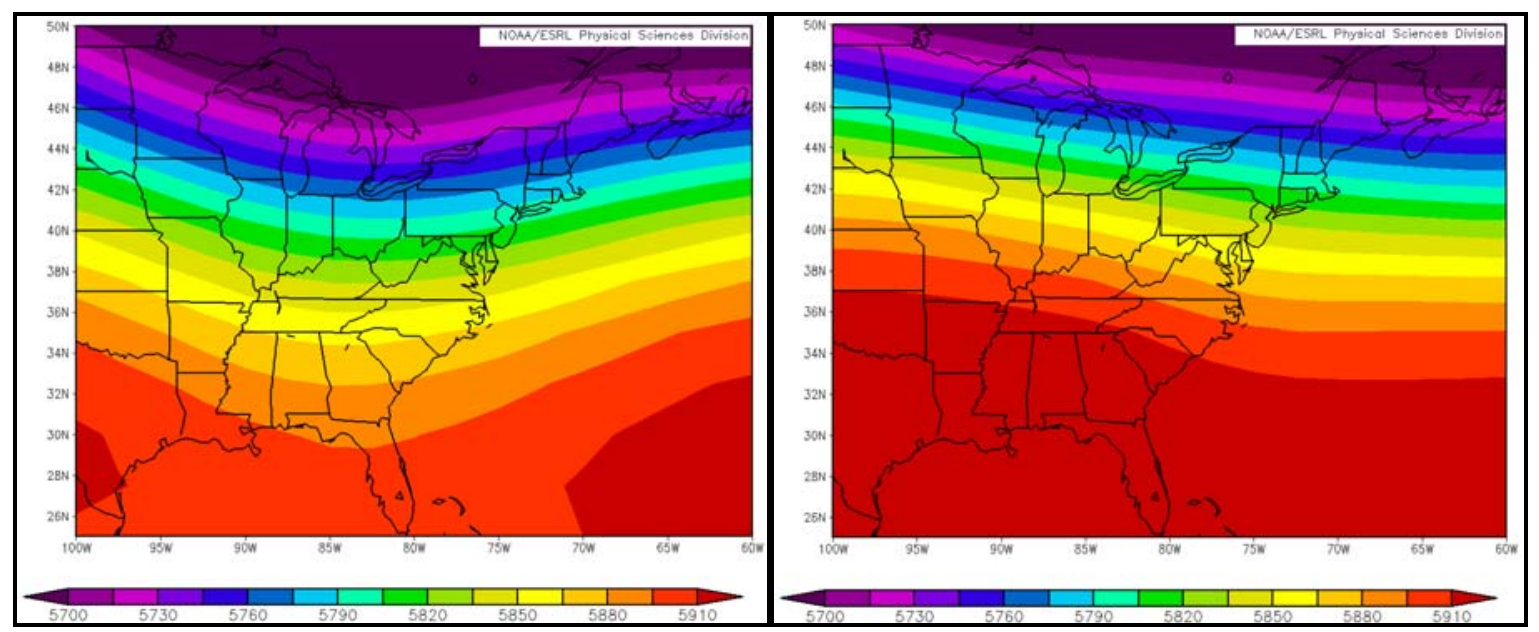

Figure 3.20. Composite plots of $500 \mathrm{hPa}$ geopotential heights during maturation hour of JJA 2009 (left) and JJA 2010 (right) precipitation events. (Images provided by the NOAA/ESRL Physical Sciences Division, Boulder Colorado, USA, from their Web site at http://www.esrl.noaa.gov/psd/). 


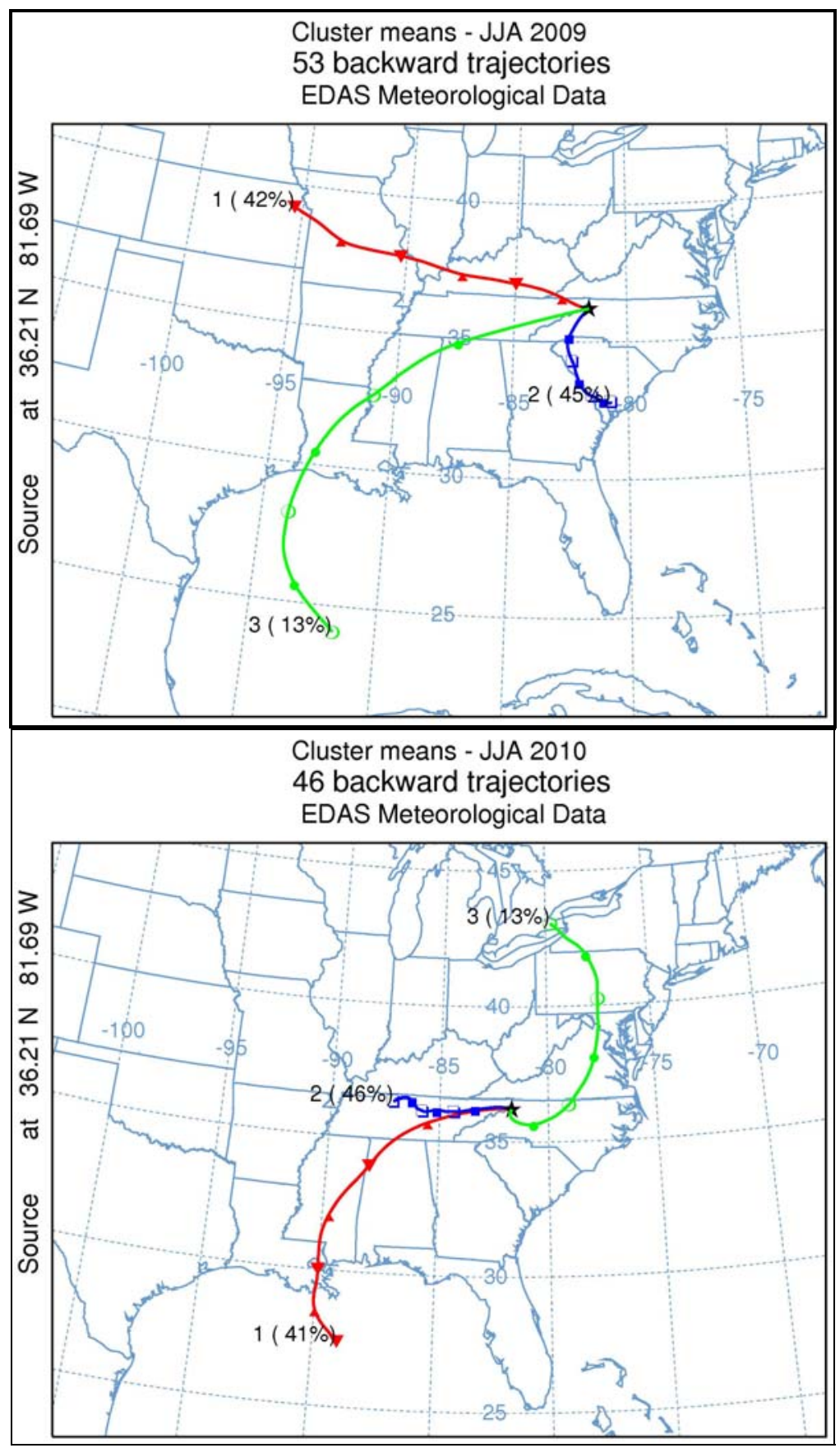

Figure 3.21. HYSPLIT cluster analysis of backward air trajectories representing maturation hour of each precipitation event during JJA 2009 (top) and JJA 2010 (bottom) precipitation events. Clusters are numbered and values in parentheses represent the percentage of backward air trajectories included in each cluster. 

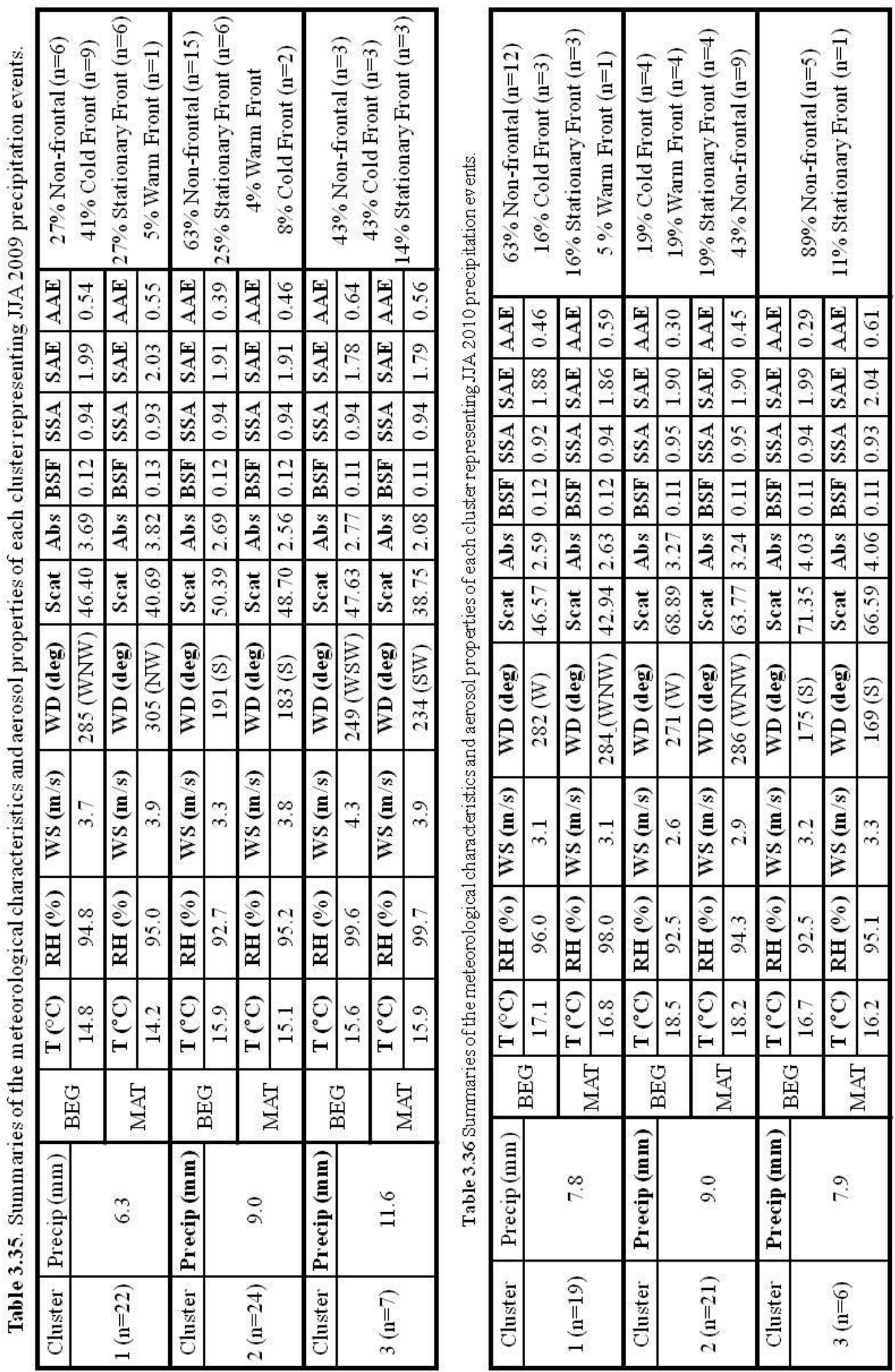
Table 3.37. Mean meteorological and aerosol values and differences at beginning and maturation for JJA 2009 vs. JJA 2010. $P$-values (2-tailed) italicized in bold indicate significance at the $95 \%$ confidence interval or greater. Asterisks $(*)$ indicate values obtained using parametric test.

BEGINNING
Meteorological Values
Avg. Total Precip (mm)
Beech T $\left({ }^{\circ} \mathbf{C}\right)$
Beech RH $(\%)$
Beech WS (m/s)
Beech WD (degrees)

Aerosol Values

\section{Scattering}

Absorption

Backscatter Fraction

SSA

SAE

AAE

MATURATION

Meteorological Values

Beech $\mathbf{T}\left({ }^{\circ} \mathrm{C}\right)$

Beech RH (\%)

Beech WS (m/s)

Beech WD (degrees)

Aerosol Values

Scattering

Absorption

Backscatter Fraction

SSA

SAE

AAE

\begin{tabular}{c} 
JJA 2009 \\
\hline$n=53$ \\
8.2 \\
15.4 \\
94.5 \\
3.6 \\
$235(\mathrm{SW})$
\end{tabular}

48.25

3.10

0.12

0.94

1.92

0.49

JJA 2009

$n=53$

14.8

95.7

3.8

236 (SW)

43.85

3.01

0.12

0.94

1.94

0.51

JJA 2010
$n=46$
8.4
17.7
94.0
2.9
$269(\mathrm{~W})$

59.79

3.09

0.11

0.94

1.90

0.36

JJA 2010

$n=46$

17.3

95.9

3.0

277 (W)

55.54

3.09

0.11

0.94

1.90

0.53

$\begin{array}{ccc}\text { Abs DIff } & & p \text {-value } \\ & & \\ 0.2 & & 0.489 \\ 2.3 & & \mathbf{0 . 0 0 0} \\ 0.5 & & \mathbf{0 . 0 3 0} \\ 0.7 & & 0.782^{*} \\ 34 & & \text { NA }\end{array}$

$11.54 \quad 0.067^{*}$

$0.01 \quad 0.666$

$0.01 \quad 0.065$

$0.00 \quad 0.667$

$0.02 \quad 0.159$

$0.13 \quad \mathbf{0 . 0 5 0}$ *

$\underline{\text { Abs DIff } p \text {-value }}$

$2.5 \quad \mathbf{0 . 0 0 0}^{*}$

$0.2 \quad 0.937$

$0.8 \quad 0.905^{*}$

$41 \quad$ NA

$11.69 \quad 0.061^{*}$

$\begin{array}{ll}0.08 & 0.569\end{array}$

$0.01 \quad \mathbf{0 . 0 0 6}$

$0.00 \quad 0.650$ *

$0.96 \quad 0.649$

$0.02 \quad 0.788^{*}$ 
Table 3.38. Differences from event beginning and maturation during JJA 2009 and JJA 2010 events. $P$-values (2-tailed) italicized in bold indicate significance at the $95 \%$ confidence interval or greater. An asterisk $(*)$ indicates values obtained using a parametric test.

\begin{tabular}{|c|c|c|}
\hline & JJA 2009 & JJA 2010 \\
\hline Meteorological Values & $p$-value & $p$-value \\
\hline Beech T $\left({ }^{\circ} \mathrm{C}\right)$ & -0.196 & $-0.478^{*}$ \\
\hline Beech RH (\%) & +0.329 & +0.319 \\
\hline Beech WS (m/s) & $+0.479 *$ & $+0.613^{*}$ \\
\hline Beech WD (degrees) & NA & NA \\
\hline \multicolumn{3}{|l|}{ Aerosol values } \\
\hline Scattering & $-0.351^{*}$ & $-0.572 *$ \\
\hline Absorption & -0.367 & 0.665 \\
\hline Backscatter Fraction & 0.380 & $0.895^{*}$ \\
\hline SSA & $0.761^{*}$ & 0.611 \\
\hline SAE & -0.587 & $0.969^{*}$ \\
\hline AAE & $+0.723^{*}$ & $+0.003^{*}$ \\
\hline
\end{tabular}


Table 3.39. Mean meteorological and aerosol values and differences at beginning and maturation for light versus heavy precipitation events during JJA 2009. $P$-values (2-tailed) italicized in bold indicate significance at the $95 \%$ confidence interval or greater. Asterisks $(*)$ indicate values obtained using parametric test.

BEGINNING

Meteorological Values

Avg. Total Precip (mm)

Beech $\mathrm{T}\left({ }^{\circ} \mathrm{C}\right)$

Beech RH (\%)

Beech WS (m/s)

Beech WD (degrees)

Aerosol Values

Scattering

Absorption

Backscatter Fraction

SSA

SAE

AAE

MATURATION

Meteorological Values

Beech $\mathrm{T}\left({ }^{\circ} \mathrm{C}\right)$

Beech RH (\%)

Beech WS (m/s)

Beech WD (degrees)

Aerosol Values

Scattering

Absorption

Backscatter Fraction

SSA

SAE

AAE
JJA 2009

Light

$n=13$

2.2

14.1

95.8

4.3

207 (SSW)

49.79

3.23

0.12

0.93

2.08

0.32

JJA 2009

Light

$n=13$

14.0

95.2

4.3

204 (SSW)

51.57

3.36

0.12

0.93

2.09

0.35
JJA 2009

Heavy

$n=13$

18.0

16.2

93.2

3.5

248 (WSW)

44.55

2.81

0.12

0.95

1.88

0.53

JJA 2009

Heavy

$n=13$

15.2

94.9

3.9

245 (WSW)

$\underline{\text { Abs DIff } \underline{p \text {-value }}}$

15.8

2.1

0.000 *

2.6

0.8

0.152

41

$0.214^{*}$

NA

$5.24 \quad 0.622 *$

$0.42 \quad 0.385$

$0.00 \quad 0.704 *$

$0.02 \quad 0.201$ *

$0.20 \quad 0.005$

$0.21 \quad 0.163^{*}$

Abs DIff $p$-value

$\begin{array}{cc}1.2 & 0.188^{*} \\ 0.3 & 0.718 \\ 0.4 & 0.420^{*} \\ 40 & \text { NA }\end{array}$

30.93

20.64

$0.069 *$

2.14

1.22

0.385

0.13

0.01

$0.632 *$

0.94

0.01

0.677 *

1.94

0.15

0.043*

0.56

0.21

$0.211^{*}$ 
Table 3.40. Differences from event beginning to maturation during JJA 2009 light and heavy precipitation events. $P$-values (2-tailed) italicized in bold indicate significance at the $95 \%$ confidence interval or greater. An asterisk $(*)$ indicates values obtained using a parametric test.

\begin{tabular}{lcc} 
& $\frac{\text { JJA 2009 }}{\underline{\text { Light }}}$ & $\underline{\underline{\text { JJA } 2009}}$ \\
\multicolumn{1}{c}{ Meteorological Values } & $p$-value & $\underline{\underline{\text { Heavy }}}$ \\
Beech T $\left({ }^{\circ} \mathrm{C}\right)$ & $-0.859^{*}$ & -0.383 \\
Beech RH (\%) & -0.972 & +0.291 \\
Beech WS (m/s) & $0.987^{*}$ & +0.505 \\
Beech WD (degrees) & $\mathrm{NA}$ & $\mathrm{NA}$ \\
$\quad$ Aerosol values & & \\
Scattering & $+0.876^{*}$ & $-0.106^{*}$ \\
Absorption & +0.939 & $-0.120^{*}$ \\
Backscatter Fraction & 0.837 & $+0.485^{*}$ \\
SSA & 0.918 & -0.513 \\
SAE & +0.837 & +0.653 \\
AAE & $+0.863^{*}$ & $+0.788^{*}$
\end{tabular}


Table 3.41. Mean meteorological and aerosol values and differences at beginning and maturation for light versus heavy precipitation events during JJA 2010. $P$-values (2-tailed) italicized in bold indicate significance at the $95 \%$ confidence interval or greater. Asterisks $\left(^{*}\right)$ indicate values obtained using parametric test.

BEGINNING

Meteorological Values

Avg. Total Precip (mm)

Beech $\mathrm{T}\left({ }^{\circ} \mathrm{C}\right)$

Beech RH (\%)

Beech WS (m/s)

Beech WD (degrees)

Aerosol Values

Scattering

Absorption

Backscatter Fraction

SSA

SAE

AAE

MATURATION

Meteorological Values

Beech $\mathrm{T}\left({ }^{\circ} \mathrm{C}\right)$

Beech RH (\%)

Beech WS (m/s)

Beech WD (degrees)

Aerosol Values

Scattering

Absorption

Backscatter Fraction

SSA

SAE

AAE

$$
\text { JJA } 2010
$$

Light

$n=11$

2.6

17.6

96.0

2.9

$290(\mathrm{WNW})$

76.97

3.93

0.11

0.95

1.97

0.35

JJA 2010

Light

$n=11$

17.7

96.1

2.9

291 (WNW)

73.90

3.81

0.11

0.95

1.97

0.46

JJA 2010

Heavy

$n=11$

16.9

18.9

91.0

2.8

194 (SSW)

70.65

3.47

0.11

0.91

1.94

0.24

JJA 2010

Heavy

$n=11$

17.9

94.0

3.3

225 (SW)

52.47

3.03

0.11

0.94

1.89

0.59 $\underline{\text { Abs DIff } \quad \underline{p \text {-value }}}$

$\begin{array}{cc}14.3 & \mathbf{0 . 0 0 0 *} \\ 1.3 & 0.227 * \\ 5.0 & 0.648 \\ 0.1 & 0.768 \\ 96 & \text { NA }\end{array}$

6.32

$0.706^{*}$

$0.46 \quad 0.435^{*}$

$0.00 \quad 0.833$

$0.04 \quad 0.324$

$0.03 \quad 0.757^{*}$

$0.11 \quad 0.264^{*}$

Abs DIff $p$-value

$\begin{array}{ll}0.02 & 0.511\end{array}$

$2.1 \quad 0.905$

$0.4 \quad 0.453^{*}$

66

NA

21.43

$0.126^{*}$

$0.78 \quad 0.252 *$

$0.00 \quad 0.974$

$0.01 \quad 0.405^{*}$

$0.08 \quad 0.357^{*}$

$0.13 \quad 0.227^{*}$ 
Table 3.42. Differences from event beginning to maturation during JJA 2010 light and heavy precipitation events. $P$-values (2-tailed) italicized in bold indicate significance at the $95 \%$ confidence interval or greater. An asterisk $(*)$ indicates values obtained using a parametric test.

$\begin{array}{lcc} & \frac{\text { JJA 2010 }}{\underline{\text { Light }}} & \frac{\underline{\text { JJ } 2010}}{\underline{\text { Heavy }}} \\ \text { Meteorological Values } & p \text {-value } & p \text {-value } \\ \text { Beech T }\left({ }^{\circ} \mathrm{C}\right) & +0.932^{*} & -0.358 \\ \text { Beech RH (\%) } & +0.970 & +0.634 \\ \text { Beech WS (m/s) } & 0.818 & +0.293 \\ \text { Beech WD (degrees) } & \text { NA } & \text { NA } \\ \quad \text { Aerosol values } & & \\ \text { Scattering } & -0.787^{*} & -0.332^{*} \\ \text { Absorption } & -0.818 & -0.576^{*} \\ \text { Backscatter Fraction } & 0.921 & 0.955^{*} \\ \text { SSA } & 0.921 & +0.379 \\ \text { SAE } & 0.981^{*} & -0.460 \\ \text { AAE } & +0.179^{*} & +0.038^{*}\end{array}$


Table 3.43. Mean precipitation $(\mathrm{mm})$ values associated with lower and upper quartile aerosol values during JJA 2009 precipitation events. $P$-values (2-tailed) italicized in bold indicate significance at the 95\% confidence interval or greater.

\begin{tabular}{lcccc}
\multicolumn{5}{c}{ BEGINNING } \\
\multicolumn{1}{c}{ Aerosol Value } & Lower $(\mathrm{n}=13)$ & Upper $(\mathrm{n}=13)$ & & \\
Scattering & Precip & Precip & Abs Diff & $p$-value \\
Absorption & 6.7 & 5.6 & 1.1 & 0.538 \\
Backscatter Fraction & 5.8 & 7.1 & 1.3 & 0.269 \\
SSA & 6.5 & 7.0 & 0.5 & 0.857 \\
SAE & 5.7 & 5.6 & 0.1 & 0.980 \\
AAE & 7.9 & 3.7 & 4.2 & $\mathbf{0 . 0 0 9}$ \\
& 4.1 & 7.5 & 3.4 & 0.090 \\
\multicolumn{1}{c}{ Aerosol Value } & MATURATION & & \\
Scattering & Precip & Precip & Abs Diff & $p$-value \\
Absorption & 10.1 & 3.8 & 6.3 & $\mathbf{0 . 0 0 8}$ \\
Backscatter Fraction & 9.2 & 6.2 & 3.0 & 0.521 \\
SSA & 5.0 & 7.1 & 2.1 & 0.412 \\
SAE & 8.2 & 5.8 & 2.4 & 0.369 \\
AAE & 8.7 & 5.0 & 3.7 & 0.061 \\
& 4.8 & 8.8 & 4.0 & $\mathbf{0 . 0 5 7}$
\end{tabular}

Table 3.44. Mean precipitation $(\mathrm{mm})$ values associated with lower and upper quartile aerosol values during JJA 2010 precipitation events.

\begin{tabular}{|c|c|c|c|c|}
\hline \multicolumn{5}{|c|}{$\underline{\text { BEGINNING }}$} \\
\hline & Lower $(n=11)$ & Upper $(n=11)$ & & \\
\hline Aerosol Value & Precip & Precip & Abs Diff & $p$-value \\
\hline Scattering & 9.8 & 9.9 & 0.1 & 0.622 \\
\hline Absorption & 7.1 & 9.5 & 2.4 & 0.974 \\
\hline Backscatter Fraction & 9.1 & 6.7 & 2.4 & 0.278 \\
\hline SSA & 8.5 & 11.2 & 2.7 & 0.200 \\
\hline SAE & 6.4 & 4.6 & 1.8 & 0.074 \\
\hline AAE & 12.1 & 9.6 & 2.5 & 0.212 \\
\hline \multicolumn{5}{|c|}{$\underline{\text { MATURATION }}$} \\
\hline & Lower $(\mathrm{n}=11)$ & Upper $(n=11)$ & & \\
\hline Aerosol Value & Precip & Precip & Abs Diff & $p$-value \\
\hline Scattering & 10.9 & 8.1 & 2.8 & 0.293 \\
\hline Absorption & 9.9 & 8.1 & 1.8 & 0.599 \\
\hline Backscatter Fraction & 10.9 & 7.8 & 3.1 & 0.411 \\
\hline SSA & 10.5 & 10.0 & 0.5 & 0.974 \\
\hline SAE & 9.5 & 5.3 & 4.2 & 0.114 \\
\hline AAE & 12.3 & 9.9 & 2.4 & 0.718 \\
\hline
\end{tabular}




\section{Chapter IV}

\section{SUMMARY AND CONCLUSION}

This thesis investigated the interactions of aerosols and precipitation in the SAM by examining 1) variations in aerosol properties by season and by synoptic event type, 2) differences in aerosol properties between the 2009 and 2010 warm seasons, and 3) the effects of air mass source region on aerosol properties. Hourly aerosol data and daily precipitation totals were analyzed from 01 June 2009 through 30 September 2010. A synoptic classification scheme was created for this project, based on Keim (1996) and emphasizing frontal and non-frontal precipitation events during the warm and cool season. Meteorological and aerosol profiles were compared among event types based on season and synoptic event type, as well as source region. Aerosol properties were compared between light versus heavy events, and precipitation totals were examined in association with lower and upper quartile aerosol values to determine any significant effects. A special comparison was made among aerosol values associated with precipitation events during summer 2009 versus summer 2010, inspired by major differences in atmospheric circulation impacting the SAM in each season. 


\section{$\underline{\text { Precipitation Event Classifications }}$}

The synoptic classification created for this thesis (Fig. 2.5) revealed that frontal precipitation events produced the greatest precipitation amounts in both seasons. Cool season precipitation events were overall wetter, longer events than warm season precipitation events, and more dynamic weather systems during the cool season resulted in a variety of frontal activity. Precipitation associated with occluded fronts produced the highest average precipitation per event during the cool season. Warm season precipitation events were characterized by short periods of heavy precipitation associated with weaker, convective systems. Precipitation associated with stationary fronts resulted in the greatest average precipitation per event during the warm season.

\section{$\underline{\text { Seasonal and Synoptic Variation in Aerosols }}$}

One of the most interesting aerosol patterns to emerge from this thesis was the consistent and statistically significant increase in AAE from beginning to maturation hour during precipitation events. Additionally, the same trend in AAE values was detected from light to heavy events, in which AAE values were lower during light precipitation events and higher during heavy precipitation events. Theoretically, one would expect to see a decrease in AAE, which would suggest a raining out effect of more hygroscopic organic particles, leaving behind hydrophobic black carbon particles (Seinfeld and Pandis 2006). Instead, during the warm season, this increase in AAE was likely related to a relatively higher fraction of water soluble organic carbon compounds coalescing and serving as effective $\mathrm{CCN}$, which ultimately enhanced precipitation. 
Alternatively, this trend in AAE values in both seasons may have indicated the aging and/or mixing state of aerosols impacting AppalAIR (Sheridan, 2010). Conventionally, freshly emitted soot particles are more hydrophobic than organic particles. However, if organic particles are being emitted from a nearby source and soot particles are being advected from some distance away, the soot particles may experience atmospheric aging and mixing with scattering sulfate. This may cause the soot particle to end up being not only more hygroscopic than the freshly emitted organics, but also to scatter light more effectively due to the collection of more scattering material and a change in fractal shape. Therefore, the trend in AAE values may have indicated the raining out of coated soot particles, although this could not be proven without the use of an electron microscope. As a result, an increase in AAE from beginning to maturation (or from light to heavy precipitation) may have indicated that AppalAIR was not primarily subject to local pollution sources, but rather more strongly impacted by secondary organic aerosols from local biogenic emissions

\section{Warm Season}

During the time period of this study, warm season precipitation events were associated with cold, warm, and stationary fronts, as well as non-frontal mechanisms involving upslope flow and orographic enhancement. Overall, the average precipitation of each during the warm season was lower than during the cool season. Warm season precipitation events exhibited a wide range of source regions, possibly related to the opposite phases of ENSO affecting each season. A large portion of the low-level moisture associated with warm season precipitation originated in coastal areas. Events were associated with larger and more scattering aerosols, and including a relatively high black carbon signal. These aerosol 
properties were tied to a seasonal increase in emissions related to phenological processes and tourist traffic.

Warm season frontal precipitation was strongly influenced by low-level air trajectories originating in the Gulf of Mexico and to the northwest of the study area. Warm season nonfrontal precipitation was strongly influenced by air masses that originated in coastal areas including the Gulf of Mexico and the Atlantic. There were no significant differences in the aerosol profiles of warm season frontal and non-frontal precipitation events during this study.

\section{JJA 2009 versus JJA 2010}

Precipitation events associated with JJA 2009 and JJA 2010 exhibited a different assortment of source regions, and the aerosol profiles of both seasons served to illustrate the reciprocal relationship between aerosols and climate patterns (Power et al. 2006). Both seasons were characterized by the presence of the NASH offshore to the east of the study area, causing the advection of moist air from the Atlantic and the Gulf of Mexico. JJA 2009, however, exhibited a cooler lower troposphere and wetter conditions. This season was strongly influenced by air masses originating south-southwest of the study area in the Gulf of Mexico. Overall, aerosol optical property values were lower during JJA 2009. If weather patterns dictated aerosol properties, then persistently wetter conditions may have increased the removal of atmospheric aerosols by wet deposition (i.e., precipitation). If aerosols dictated the weather patterns during JJA 2009, then relatively lower aerosol optical properties decreased precipitation suppression during JJA 2009, a hypothesis supported by relatively longer events and a higher total precipitation reported at the Boone COOP station. 
JJA 2010 exhibited a warmer lower troposphere and drier conditions, under the influenced of a cool-phase ENSO. Air masses affecting the SAM during this season exhibited a more northeasterly origin, and precipitation events were associated with higher overall aerosol optical properties and higher AAE values in particular. Precipitation events were relatively short in duration compared to those that took place during JJA 2009. If weather patterns dictated the aerosol loading, then northeasterly flow caused an influx of anthropogenic particles from areas northeast of the study area including the I-81 corridor. Conversely, if aerosols dictated weather patterns during JJA 2010, then higher aerosol loading led to precipitation suppression in the SAM, supported by overall shorter events and lower total precipitation reported at the Boone COOP station.

\section{Cool Season}

Cool season precipitation events were associated with a wide variety of synoptic event types, including cold, warm, and occluded fronts, Gulf lows, Nor'easters, and non-frontal mechanisms of precipitation formation. During the time period of this study, the cool season was much wetter than the warm season. Cool season precipitation primarily originated in inland areas north-northwest of the study area, with a component originating near the Gulf of Mexico. In the absence of seasonal biogenic emissions, these events exhibited overall lower aerosol optical properties and showed high organic emissions from biomass burning.

Cool season frontal precipitation was strongly influenced by air masses originating to the northwest of the study area, and also from coastal areas near the Gulf of Mexico and the Atlantic, while cool season non-frontal events were largely characterized by northwest flow snowfall. Cool season frontal precipitation events were associated with higher aerosol 
loading than non-frontal events. This indicates that large frontal air masses exhibited the snowplow effect of accumulating aerosols while approaching AppalAIR. Also, precipitation associated with cool season frontal events was significantly lower in association with upper quartile aerosol values at maturation, which may have indicated some level of precipitation suppression.

\section{$\underline{\text { Implications }}$}

This thesis reported on 16 months of continuous surface-based aerosol measurements in association with precipitation events in order to characterize the interactions between aerosols and precipitation in the SAM. This work constitutes a small piece of the research required to better understand aerosol and precipitation patterns in the SAM and to help model and forecast future climate scenarios. It is possible that modifications in emissions standards may have led to changes in the composition, loading, and distribution of aerosols across the region, resulting in less sulfate aerosols and a higher relative concentration of organic carbon. The reciprocal relationship that exists between aerosols and climate dictates that as changes in climate affect aerosol properties, so do changes in aerosol properties affect climate patterns. It is yet to be fully understood how changes in aerosol properties affecting the SAM may influence the surface energy balance across the region and impact weather and climate patterns as a result.

Additionally, changes in atmospheric circulation patterns may lead to synoptic-scale conditions that enhance aerosol loading in the SAM. JJA 2010 was one of the hottest periods on record for many regions in the SEUS, and it has been predicted that the region may become drier and warmer in the coming decades (Karl et al. 2009, Li et al. 2010). Currently, 
global circulation models (GCM) are not equipped to sufficiently parameterize aerosols in order to account for the direct and indirect effects of aerosols on weather and climate patterns (Power et al. 2006). Current circulation models forecast increased variability in precipitation patterns in the southeast US, indicating more intense periods of deluge and drought, particularly as a result of anthropogenic-induced warming (Li et al. 2010). However, these models have been shown to under-predict future warming by over-predicting precipitation (Science Daily 2010), possibly in part as a result of not accurately accounting for the indirect effects of aerosols While this research provides a short-term preliminary assessment of the patterns and properties of aerosols associated with precipitation patterns in the SAM, much more research is required to gain a more thorough and conclusive understanding of this relationship.

\section{$\underline{\text { Limitations }}$}

Several limitations impacted the results of thesis. The short time period of this study resulted in a small sample size for some of the precipitation events (e.g., cool season nonfrontal precipitation events, $\mathrm{n}=12$ ). Aerosol data from AppalAIR only go back as far as June 2009 , so a longer term study using those data is not possible at this time. Additionally, due to technical and mechanical problems, aerosol particle concentrations were not available. These data would indicate levels of aerosol loading in association with seasonal precipitation events. It is possible that AAE values used in this thesis may have represented artifacts of multiple stages of particle heating before passing through the PSAP, thereby playing a potential role in the curious change in AAE from beginning to maturation during each event. AAE values can also be calculated using 7-wavelength aetholometer data, which were 
considered poor quality during the period of study and were therefore not used in this thesis. It is possible that values calculated using aetholometer data would lack an artifact of particle heating and would thus be a more accurate measure of AAE from beginning to maturation during each event. This possibility will be assessed in future work. Also, it would have been beneficial to have access to hourly precipitation data from a larger number of stations within the study region. This thesis used hourly weather-type data, but only had access to daily precipitation totals. Analyzing hourly precipitation and hourly aerosol data would allow for a clearer picture of what sort of patterns and possible interactions are taking place hour-byhour during each precipitation event.

The addition of more state-of-the-art atmospheric research instrumentation at AppalAIR would greatly benefit this work and future work regarding aerosol-precipitation interactions. In order to determine the exact type of aerosols present, a high-resolution mass spectrometer would provide real-time quantitative aerosol chemical composition analysis and a cloud condensation nuclei counter would indicate abilities of sampled aerosols to serve as cloud condensation nuclei. Additionally, on-site information about the characteristics of the atmospheric column above AppalAIR would give a much better idea of what is happening locally where aerosols are being sampled. This could be achieved using micro-pulsed Light Detection and Ranging (LIDAR) technology providing high-resolution profiles of aerosols and clouds and a microwave radiometer to capture on-site vertical profiles of temperature, humidity, and liquid water. A vertically-pointing radar is another critical instrument for investigating the vertical structure of precipitation. AppalAIR currently has an automated sun/sky radiometer capable of detecting atmospheric column-averaged aerosol properties, but these data were not available for this thesis. 
Additionally, it would be ideal to have one or more AppalAIR companion sites within the region for comparison of data. These companion sites could be stationed at higher elevations in the SAM, such as at Grandfather Mountain or Beech Mountain, as well as at lower elevation. Multiple sources of meteorological and aerosol data would create a more robust picture of the synoptic influences on the atmospheric properties and processes in the SAM.

\section{$\underline{\text { Future Work }}$}

This thesis sets the stage for many future research endeavors. A more comprehensive long-term analysis of the aerosol-synoptic climatology in the SAM could be performed by characterizing the aerosol properties affecting AppalAIR without discriminating against periods of no precipitation. This would allow for a much more robust picture of the seasonal and synoptic variation of aerosols while providing a background signal of aerosol properties associated with fair weather conditions. A longer-term study would incorporate both normal and anomalous conditions and may provide more reliable information regarding the indirect effects of aerosol to be incorporated in weather forecasting and climate models.

The curious behavior of AAE values reported by AppalAIR may be investigated by partnering with another aerosol monitoring station in a more urbanized area preferably upwind of AppalAIR. This would allow for direct collection of anthropogenically produced particles, likely with a high black carbon signal, before transport and atmospheric aging affect the hygroscopic properties of the particles. This partnership may allow for the detection of any changes in AAE values from the remote site to AppalAIR, and may enhance the understanding of exactly what types of aerosols affect AppalAIR and the SAM. 
The identification of the indirect effects of aerosols may be more thoroughly investigated by incorporating remotely sensed cloud microphysical data (e.g., Rosenfeld and Givati 2006) including moisture content and particle concentration coupled with long-term in-situ precipitation measurements. It would be ideal to set up transects of precipitation gauges traversing high elevation mountains in the SAM, including leeward and windward locations, in order to collect long-term records of orographic precipitation patterns. Combined with aerosol data from AppalAIR and multiple companion sites in the SAM, these transects may illuminate any possible suppressed or delayed orographic precipitation as a result of aerosols (e.g., Rosenfeld and Givati 2006; Bell et al. 2008). 


\section{LIST OF ABBREVIATIONS AND ACRONYMS}

AAE - Absorption Angström Exponent

AEROCE - Atmosphere/Ocean Chemistry Experiment

$\mathrm{AO}-$ Arctic Oscillation

AOD - Aerosol Optical Depth

AppalAIR - Appalachian Atmospheric Interdisciplinary Research

AR4 - Fourth Assessment Report

ASL - Above sea level

ASU - Appalachian State University

AWOS - Automated Weather Observing System

BEECHTOP - Beech Mountain meteorological station

CCN - Cloud Condensation Nuclei

CoCoRaHS - Community Collaborative Rain, Hail, and Snow

COOP - National Weather Service Cooperative Observer System

CRONOS - Climate Retrieval and Observations Network of the Southeast

DJF - December, January, February; Northern Hemisphere climatological winter

ECONet - Environmental and Climate Observing Network

EDAS - Eta Data Assimilation System

ENSO - El Niño-Southern Oscillation

ESRL - Earth System Research Laboratory

GCCN - Giant Cloud Condensation Nuclei

GCM - Global Circulation Model

HYSPLIT - Hybrid Single Particle Lagrangian Integrated Trajectory 
IN - Ice Nuclei

IPCC - Intergovernmental Panel on Climate Change

IR - Infrared

JJA - June, July, August; Northern Hemisphere climatological summer

LIDAR - Light Detection and Ranging

NAM - North American Mesoscale

NASH - North Atlantic Subtropical High

NCAR - National Center for Atmospheric Research

NCEP - National Centers for Environmental Protection

NOAA - National Oceanic and Atmospheric Administration

NWFS - Northwest flow snowfall

NWS - National Weather Service

PSAP - Particle Soot Absorption Photometer

$\mathrm{RF}$ - Radiative forcing

SAE - Scattering Angström Exponent

SAM - Southern Appalachian Mountains

SEUS - Southeastern United States

SRRS - Service Records Retention System

SSA - Single Scattering Albedo

SSC - Spatial Synoptic Classification

SST - Sea Surface Temperature

TSV - Total Spatial Variance

VOC - Volatile Organic Compound 


\section{BIBLIOGRAPHY}

Abbatt, J. P. D., K. Broekhuizen, and P. Pradeep Kumar. 2005. Cloud condensation nucleus activity of internally mixed ammonium sulfate/organic acid aerosol particles. Atmospheric Environment 39:4767-4778.

Adam, J. R., N. R. Lindblad, C. D. Hendricks. 1968. The Collision, Coalescence, and Disruption of Water Droplets. Journal of Applied Physics 39(11):5173-5180.

Ahrens, C. D. 2000. Meteorology Today: An Introduction to Weather, Climate, and Environment ( $6^{\text {th }}$ Edition). New York, NY: Brooks Cole.

Albrecht, B. A. 1989. Aerosols, Cloud Microphysics, and Fractional Cloudiness. Science 245(4923):1227-1230.

Andreae, M. O., C. D. Jones, and P. M. Cox. 2005. Strong present-day aerosol cooling implies a hot future. Nature 435:1187-1190.

Andreae, M. O. and D. Rosenfeld. 2008. Aerosol-cloud-precipitation interactions. Part 1. The nature and sources of cloud-active aerosols. Earth-Science Reviews 89: 13-41.

Andreae, M. O., D. Rosenfeld, P. Artaxo, A. A. Costa, G. P. Frank, K. M. Longo, and M. A. F. Silva-Dias. 2004. Smoking Rain Clouds over the Amazon. Science 303:1337-1342.

Barcelo, A., R. Robert, and J. Coudray. 1997. A Major Rainfall Event: The 27 February - 5 March 1993 rains on the southeastern slope of Piton de la Fournaise Massif (Reunion Island, Southwest Indian Ocean). Monthly Weather Review 125(12):3341 - 3346.

Barr, J. G., J. D. Fuentes, and J. W. Bottenheim. 2003. Radiative forcing of phytogenic aerosols. Journal of Geophysical Research, 108(D15): doi:10.1029/2002JD002978.

Barros, A. P. and R. J. Kuligowski. 1998. Orographic effects during a severe wintertime rainstorm in the Appalachian Mountains. Monthly Weather Review 126:2648-2672.

Barros, A. P. and D. P. Lettenmaier. 1994. Dynamic modeling of orographically induced precipitation. Reviews of Geophysics 32(3):265-284.

Barry, G. B. 1992. Mountain Weather and Climate (2 ${ }^{\text {nd }}$ Edition). New York, NY: Routledge, Chapman, and Hall, Inc.

Bell, T. L., D. Rosenfeld, K. M. Kim, J. M. Yoo, M. I. Lee, and M. Hahnenberger, M. 2008. Midweek increase in U.S. summer rain and storm heights suggests air pollution invigorates rainstorms. Journal of Geophysical Research, 113:D02209. 
Bergeron, T. 1935. On the physics of cloud and precipitation. Procés-Verb. Assoc. Mét. U.G.G.I, Part 2:156-178.

-----. 1965. On the low-level redistribution of atmospheric water caused by orography. Proceedings of the International Conference on Cloud Physics, Tokyo and Sapporo, May 24 - June 1, 96-100.

Bollasina, M., S. Nigam, and K. M. Lau.2007. Absorbing Aerosols and Summer Monsoon Evolution over South Asia: An Observational Portrayal. Journal of Climate 21 (13):32213239.

Borys, R. D., D. H. Lowenthal, S. A. Cohn, and W. O. J. Brown. 2003. Mountaintop and radar measurements of anthropogenic aerosol effects on snow growth and snowfall rate. Geophysical Research Letters 30(10):1538.

Brankov, E., S. T. Rao, and P. S. Porter. 1998. A trajectory-clustering-correlation methodology for examining the long-range transport of air pollutants. Atmospheric Environment 32 (9):1525-1534.

Brenguier, J. L., H. Pawlowska, L. Schüller, R. Preusker, J. Fischer, and Y. Fouquart. 2000. Radiative Properties of Boundary Layer Clouds: Droplet Effective Radius versus Number Concentration. Journal of Atmospheric Sciences 57(6):803-821.

Bruintjes, R. T. 1999. A review of cloud seeding experiments to enhance precipitation and some new prospects. Bulletin of the American Meteorological Society 80(5):805-820.

Cakmur, R. V., R. L. Miller, I. Tegen. 2001. A comparison of seasonal and interannual variability of soil dust aerosols over the Atlantic Ocean as inferred by the TOMS AI and AVHRR AOT retrievals. Journal of Geophysical Research 106(D16):18,287-18,303.

Choularton, T. W. and S. J. Perry. 1986. A Model of Orographic Enhancement of Snowfall by the Seeder-feeder Mechanism. Quarterly Journal of the Royal Meteorological Society 112:335-345.

Cifelli, R., N. Doesken, P. Kennedy, L. D. Carey, S. A. Rutledge, C. Gimmestad, and T. Depue. 2005. The Community Collaborative Rain, Hail, and Snow Network. Bulletin of the American Meteorological Society 86:1069-1077.

Cohen, J., J. Foster, M. Barlow, K. Saito, and J. Jones. 2010. Winter 2009-2010: A case study of an extreme Arctic Oscillation event. Geophysical Research Letters 37 (L17707). Dai, A., and K.E. Trenberth, 2004: The diurnal cycle and its depiction in the Community Climate System Model. Journal of Climatology 17:930-995. 
Dai, A., M. Simmel, and S. Wurzler. 2004. A Global Dataset of Palmer Drought Severity Index for 1870-2002: Relationship with Soil Moisture and Effects of Surface Warming. Journal of Hydrometeorology 5:1117-1130.

Diehl, K., M. Simmel, and S. Wurzler. 2007. Effects of drop freezing on microphysics of an ascending cloud parcel under biomass burning conditions. Atmospheric Environment 41:303-314.

Diem, J. E. 2006. Synoptic-scale controls of summer precipitation in the southeastern United States. Journal of Climate 19:613-621.

Dore, A. J., T. W. Choularton, D. Fowler, and A. Crossley. 1992. Orographic enhancement of snowfall. Environmental Pollution 75:175-179.

Dorling, S. R., T. D. Davies, and C. E. Pierce. 1992. Cluster analysis: a technique for estimating the synoptic meteorological controls on air and precipitation chemistryResults from Eskdalemuir, South Scotland. Atmospheric Environment 26A (14):25832602.

Draxler, R. R. 1999. HYSPLIT4 user's guide. NOAA Tech. Memo. ERL ARL-230, NOAA Air Resources Laboratory, Silver Spring, MD.

Draxler, R. R., and G. D. Hess. 1997. Description of the HYSPLIT_4 modeling system. NOAA Tech. Memo. ERL ARL-224, NOAA Air Resources Laboratory, Silver Spring, MD.

-----. 1998. An overview of the HYSPLIT_4 modeling system of trajectories, dispersion, and deposition. Australian Meteorological Magazine 47: 295-308.

Forster, P, V., Ramaswamy, P Artaxo, T. Berntsen, R. Betts, D. W. Fahey, J. Haywood, J. Lean, D. C. Lowe, G. Myhre, J. Nganga, R. Prinn, G. Raga, M. Schulz, and R. Van Dorland. 2007. Changes in Atmospheric Constituents and Radiative Forcing. In Climate Change 2007: The Physical Science Basis. Contribution of Working Group I to the Fourth Assessment Report of the Intergovernmental Panel on Climate Change [Solomon, S., D. Qin, M. Manning, Z. Chen, M. Marquis, K. B. Averyt, M. Tignor, and H. L. Miller (eds.)]. Cambridge: Cambridge University Press, 2007.

Gershunov, A. and T. P. Barnett. 1998. ENSO Influence on Intraseasonal Extreme Rainfall and Temperature Frequencies in the Contiguous United States: Observations and Model Results. Journal of Climate 1:1575-1586.

Givati, A. and D. Rosenfeld. 2004. Quantifying Precipitation Suppression Due to Air Pollution. Journal of Applied Meteorology 43:1038-1056.

------. 2005. Separation between cloud-seeding and air-pollution effects. Journal of Applied Meteorology 44:1298-1314. 
Goldstein, A H., C. D. Koven, C. L. Heald, and I. Y. Fung. 2009. Biogenic carbon and anthropogenic pollutants combine to form a cooling haze over the southeastern United States. Proceedings of the National Academy of Science 106:8835-8840.

Harnack, R., K. Apffel, M. Georgescu, and S. Baines. 2001. The determination of observed atmospheric differences between heavy and light precipitation events in New Jersey, USA. International Journal of Climatology 21:1529-1560.

Haywood, J. and O. Boucher. 2000. Estimates of the direct and indirect radiative forcing due to tropospheric aerosols: A review. Reviews of Geophysics 38(4):513-543.

Holben, B. N., D. Tanré, A. Smirnov, T. F. Eck, I. Slutsker, N. Abuhassan, W. W. Newcomb, J. S. Schafer, B. Chatenet, F. Lavenu, Y. J. Kaufman, J. Vande Castle, A. Setzer, B. Markham, D. Clark, R. Frouin, R. Halthore, A. Karneli, N. T. O’Neill, C. Pietras, R. T. Pinker, K. Voss, and G. Zibordi. 2001. An emerging ground-based aerosol climatology: aerosol optical depth from AERONET. Journal of Geophysical Research 106 (D11):12.067-12.097.

Houghton, H. G. 1950. A preliminary quantitative analysis of precipitation mechanisms. Journal of Meteorology 7:363-369.

Jirak, I. L. and W. R. Cotton. 2005. Effect of air pollution on precipitation along the Front Range of the Rocky Mountains. Journal of Applied Meteorology and Climatology 45:236-245.

Johnstone, T. P. and S. A. Burrus. 1998. An Analysis of the 4 September 1996 Hickory Nut Gorge Flash Flood in Western North Carolina. Conference on Weather Analysis and Forecasting 16: 275-277.

Kalnay, E. and Coauthors. 1996. The NCEP/NCAR Reanalysis 40-year Project. Bulletin of the American Meteorological Society 77:437-471.

Karl, T.R., Melillo, J.M., and Peterson, T.C. 2009. Global Climate Change Impacts in the United States. New York, NY:Cambridge University Press.

Karoly, D.J. and Q. Wu. 2005. Detection of regional surface temperature trends. Journal of Climatology 18:4337-4343.

Keim, B. D. 1996. Spatial, synoptic, and seasonal patterns of heavy rainfall in the southeastern United States. Physical Geography 17(4):313-328.

Khain, A., A. Pokrovsky, and M. Pinsky. 2004. Simulation of Effects of Atmospheric Aerosols on Deep Turbulent Convective Clouds Using a Spectral Microphysics MixedPhase Cumulus Cloud Model. Part I: Model Description and Possible Applications. Journal of the Atmospheric Sciences 61:2963-2982. 
Khain, A., D. Rosenfeld, and A. Pokrovsky. 2005. Aerosol impact on the dynamics and microphysics of deep convective clouds. Quarterly Journal of the Royal Meteorological Society 131:2639-2663.

Konrad, C. E. 1997. Synoptic-scale features associated with warm season heavy rainfall over the interior southeastern United States. Weather and Forecasting 12:557-571.

Konrad, C. E. and V. Meentemeyer. 1994. Lower tropospheric warm air advection patterns associated with heavy rainfall over the Appalachian region. Professional Geographer 46(2):143-155.

Lee, L. G. and G. W. Goodge. 1984. Meteorological analysis of an intense 'east slope' rainstorm in the southern Appalachians. Tenth Conference on Weather Forecasting and Analysis. American Meteorological Society, Boston.

Le Treut, H., R. Somerville, U. Cubasch, Y. Ding, C. Mauritzen, A. Mokssit, T. Peterson, and M. Prather. 2007. Historical Overview of Climate Change. In Climate Change 2007: The Physical Science Basis. Contribution of Working Group I to the Fourth Assessment Report of the Intergovernmental Panel on Climate Change [Solomon, S., D. Qin, M. Manning, Z. Chen, M. Marquis, K. B. Averyt, M. Tignor, and H. L. Miller (eds.)]. Cambridge: Cambridge University Press, 2007.

Li, W., L. Li, R. Fu, Y. Deng, and H. Wang. 2010. Changes to the North Atlantic Subtropical High and its role in the intensification of summer rainfall variability in the southeastern United States. Journal of Climate 24(5):1499-1506.

Lin, Y., S. Chiao, T. Wang, M. L. Kaplan, and R. P. Weglarz. 2001. Some common ingredients for heavy orographic rainfall. Weather and Forecasting 16:633-660.

Lohmann, U., and J. Feichter. 2005. Global indirect aerosol effects: a review. Atmospheric Chemistry and Physics 5:715-737.

Lohmann, U. and C. Hoose. 2009. Sensitivity studies of different aerosol indirect effects in mixed-phase clouds. Atmospheric Chemistry and Physics 9:15049-15081.

Lutgens, F. K. and E. J. Tarbuck. 2010. The Atmosphere: An Introduction to Meteorology ( $11^{\text {th }}$ Edition). Upper Saddle River, NJ: Pearson Prentice Hall.

Maddox, R. A., C. F. Chappell, and L. R. Hoxit. 1979. Synoptic and meso- $\alpha$ scale aspects of flash flood events. Bulletin of the American Meteorological Society 60 (2):115-123.

Miller, J. E. 1946. Cyclogenesis in the Atlantic coastal region of the United States. Journal of Meteorology 3:31-44. 
Muhlbauer, A. and U. Lohmann. 2006. Aerosol-cloud interactions and the effects on orographic precipitation. $12^{\text {th }}$ Conference on Atmospheric Radiation and Cloud Physics.

Muller, R. A. 1977. A synoptic climatology for environmental baseline analysis: New Orleans. Journal of Applied Meteorology 16:20-33.

NCEP 2010a. National Climatic Data Center Service Records Retention System Analysis and Forecast Charts. http://nomads.ncdc.noaa.gov/ncep/NCEP (accessed January 12, 2011).

NCEP 2010b. National Centers for Environmental Prediction Daily Weather Maps. http://www.hpc.ncep.noaa.gov/dailywxmap/index.html (accessed January 12, 2011).

NCEP 2010c. National Oceanic and Atmospheric Administration Earth System Research Laboratory Daily Mean Composites. http://www.esrl.noaa.gov/psd/data/composites/day/ (accessed January 12, 2011).

NCEP 2010d. Air Resources Laboratory Eta Data Assimilation System (EDAS40) Archive Information. http://www.arl.noaa.gov/edas40.php (accessed January 12, 2011).

Perry, L. B. and C. E. Konrad. 2006. Relationships between NW flow snowfall and topography in the Southern Appalachians, USA. Climate Research 32:35-47.

Perry, L. B., C. E. Konrad, and T. W. Schmidlin. 2007. Antecedent Upstream Air Trajectories Associated with Northwest Flow Snowfall in the Southern Appalachians. Weather and Forecasting 22:334-352.

Perry, L. B., C. E. Konrad, D. G. Hotz, and L. G. Lee. 2010. Synoptic Classification of Snowfall Events in the Great Smoky Mountains, USA. Physical Geography 31(2):156171.

Petzold, A., M. Gysel X. Vancassel, R. Hitzenberger, H. Puxbaum, S. Vrochticky, E. Weingartner, U. Baltensperger, and P. Mirabel. 2005. On the effects of organic matter and sulphur-containing compounds on the $\mathrm{CCN}$ activation of combustion particles. Atmospheric Chemistry and Physics 5:3187-3203.

Power, H. C., S. C. Sheridan, J. C. Senkbeil. 2006. Synoptic climatological influences on the spatial and temporal variability of aerosols over North America. International Journal of Climatology 26:732-741.

Prados, A. I., R. R. Dickerson, B. G. Doddridge, P. A. Milne, J. L. Moody, and J. T. Merrill. 1999. Transport of ozone and pollutants from North America to the North Atlantic Ocean during the 1996 Atmosphere/Ocean Chemistry Experiment (AEROCE) intensive. Journal of Geophysical Research 104:26,219-26,233. 
Quetelard, H., P. Bessemoulin, R. S. Cerveny, T. C. Peterson, A. Burson, and Y. Boodhoo. 1999. World-Record Rainfalls during Tropical Cyclone Gamede. Bulletin of the American Meteorological Society 90(5):603-608.

Ramanathan, V., P. J. Crutzen, J. T. Kiehl, and D. Rosenfeld. 2001. Aerosols, climate, and the hydrological cycle. Science 294:2119-2124.

Reinhardt, K. and W. K. Smith. 2008. Leaf gas exchange of understory spruce-fir saplings in relict cloud forests, southern Appalachian Mountains, USA. Tree Physiology 28:113-122.

Reinking, R. F., J. B. Snider, and J. L. Coen. 2000. Influences of storm-embedded orographic gravity waves on cloud liquid water and precipitation. Journal of Applied Meteorology, 39:733-759.

Rosenfeld, D. 1999. TRMM observed first direct evidence of smoke from forest fires inhibiting rainfall. Geophysical Research Letters, 26(20):3105-3108.

-----. 2000. Suppression of rain and snow by urban and industrial air pollution. Science 287:1793.

Rosenfeld, D., J. Dai, X. Yu, Z. Yao, X. Xu, X. Yang, and C. Du. 2007. Inverse Relations Between Amounts of Air Pollution and Orographic Precipitation. Science 315:13961398.

Rosenfeld, D. and A. Givati. 2006. Evidence of orographic precipitation suppression by air pollution induced aerosols in the western United States. 2005. Journal of Applied Meteorology and Climatology 45:893-911.

Rosenfeld, D., R. Lahav, A. Khain, and M. Pinsky. 2002. The role of sea spray in cleansing air pollution over ocean via cloud processes. Science 297:1667-1670.

Rudich, Y. and O. Khersonsky. 2002. Treating clouds with a grain of salt. Geophysical Research Letters 29(22):2060.

Science Daily 2010. Science News. http:/www.sciencedaily.com/releases/2007/05/ 070509210100.htm (accessed March 6, 2011).

Seinfeld, J. H., and S. N. Pandis. 2006. Atmospheric Chemistry and Physics (2 ${ }^{\text {nd }}$ Edition). Hoboken, NJ: John Wiley \& Sons, Inc.

Sheridan, Patrick. Personal communication, February 15, 2010.

Singh, R. P., S. Dey, S. N. Tripathi, V. Tare, and B. Holben. 2004. Variability of aerosol parameters over Kanpur, northern India. Journal of Geophysical Research, 19:D23206. 
Solomon, S., D. Qin, M. Manning, R. B. Alley, T. Berntsen, N. L. Bindoff, Z. Chen, A. Chidthaisong, J. M. Gregory, G. C. Hegerl, M. Heimann, B. Hewitson, B. J. Hoskins, F. Joos, J. Jouzel, V. Kattsov, U. Lohmann, T. Matsuno, M. Molina, N. Nicholls, J. Overpeck, G. Raga, V. Ramaswamy, J. Ren, M. Rusticucci, R. Somerville, T. F. Stocker, P. Whetton, R. A. Wood, and D. Wratt. 2007: Technical Summary. In Climate Change 2007: The Physical Science Basis. Contribution of Working Group I to the Fourth Assessment Report of the Intergovernmental Panel on Climate Change [Solomon, S., D. Qin, M. Manning, Z. Chen, M. Marquis, K. B. Averyt, M. Tignor, and H. L. Miller (eds.)]. Cambridge: Cambridge University Press, 2007.

Soulé, P. T. 2011. Changing Climate, Atmospheric Composition, and Radial Tree Growth in a Spruce-Fir Ecosystem on Grandfather Mountain, North Carolina. Natural Areas Journal, 31(1):65-74.

Swap, R. M. Garstang, S. Greco, R. Talbot, and P. Kållberg. 1992. Saharan dust in the Amazon Basin. Tellus 44B: 133-149.

Taubman, B. F., J. C. Hains, A. M. Thompson, L. T. Marufu, B. G. Doddridge, J. W. Stehr, C. A. Piety, and R. R. Dickerson. 2006. Aircraft vertical profiles of trace gas and aerosol pollution over the mid-Atlantic Unites States: Statistics and meteorological cluster analysis. Journal of Geophysical Research 111:D10S07.

Tegen, I. and I. Fung. 1995. Contribution to the atmospheric mineral aerosol load from land surface modification. Journal of Geophysical Research 100(D9):18,707-18,726.

Thompson, D. W. J. and J. M. Wallace. 2000. Annular Modes in the Extratropical Circulation. Part I: Month-to-Month Variability. Journal of Climate 13:1000-1016.

Trenberth, K.E., P.D. Jones, P. Ambenje, R. Bojariu, D. Easterling, A. Klein Tank, D. Parker, F. Rahimzadeh, J.A. Renwick, M. Rusticucci, B. Soden, and P. Zhai. 2007. Observations: Surface and Atmospheric Climate Change. In: Climate Change 2007: The Physical Science Basis. Contribution of Working Group I to the Fourth Assessment Report of the Intergovernmental Panel on Climate Change [Solomon, S., D. Qin, M. Manning, Z. Chen, M. Marquis, K.B. Averyt, M. Tignor and H.L. Miller (eds.)]. Cambridge, United Kingdom and New York, NY, USA: Cambridge University Press.

Tunved, P, H. C. Hansson, V. M. Kerminen, J. Ström, M. Dal Maso, H. Lihavainen, Y. Viisanen, P. P. Aalto, M. Komppula, and M. Kulmala. 2006. High Natural Aerosol Loading over Boreal Forests. Science, 312:261-263.

Twomey, S. 1974. Pollution and the Planetary Albedo. Atmospheric Environment 8:12511256.

-----. 1984. An assessment of the impact of pollution on global cloud albedo. Tellus 36B:356-366. 
Wallace, J. M. and P. V. Hobbs. 2006. Atmospheric Science: An Introductory Survey $\left(2^{\text {nd }}\right.$ Edition). Burlington, MA: Elsevier.

Wang, H., R. Fu, A. Kumar, and W. H. Li. 2010. Intensification of summer rainfall variability in the southeastern United States during recent decades. Journal of Hydrometeorology 11:1007-1018.

Whiteman, C. D. 2000. Mountain Meteorology: Fundamantals and Applications. New York, NY: Oxford University Press.

Zhang, J, U. Lohmann, and P. Stier. 2005. A microphysical parameterization for convective clouds in the ECHAM5 climate model: 1. Single column results evaluated at the Oklahoma ARM site. Journal of Geophysical Research 110:D15S07. 


\section{BIOGRAPHICAL INFORMATION}

Ginger Marie Kelly was born in Morehead City, NC, on December 11, 1982. She attended Camp Glenn Elementary, Morehead Elementary, and Morehead City Middle

School, and graduated from West Carteret High School in May 2001. The following August, she entered the University of North Carolina at Chapel Hill and received a Bachelor of Science degree in Geological Sciences in December 2005.

In August 2009, she began work toward a Master of Arts in Geography at Appalachian State University, and will be awarded the degree in May 2011. Ms. Kelly is a member of the Phi Kappa Phi honors society. Her permanent address is 1744 River Drive, Morehead City, NC 28557. Her parents are Lois Mitchell Kelly and Steven Coleman Kelly. 